


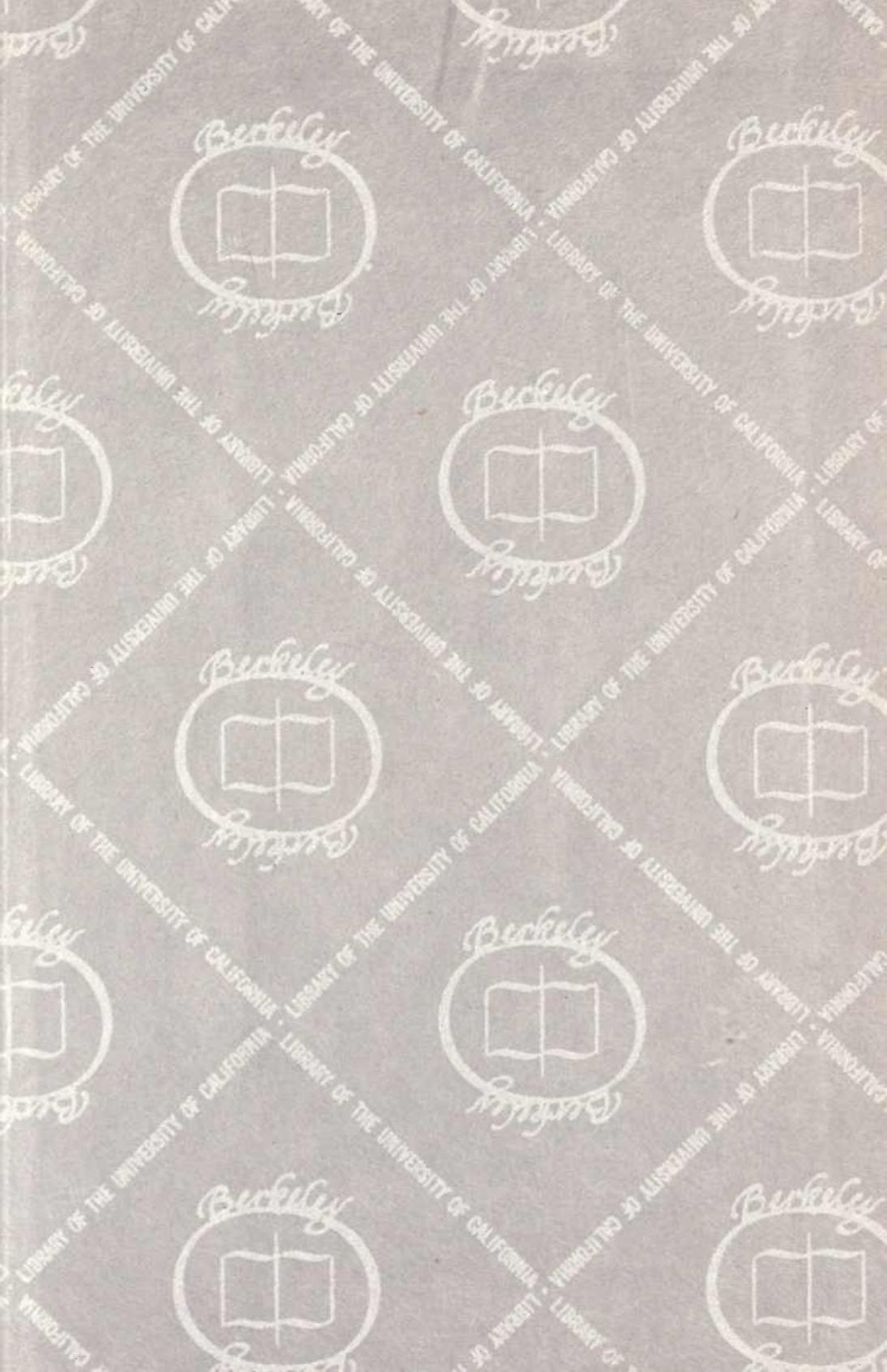





THE RUBBER INDUSTRY IN BRAZIL AND THE ORIENT 




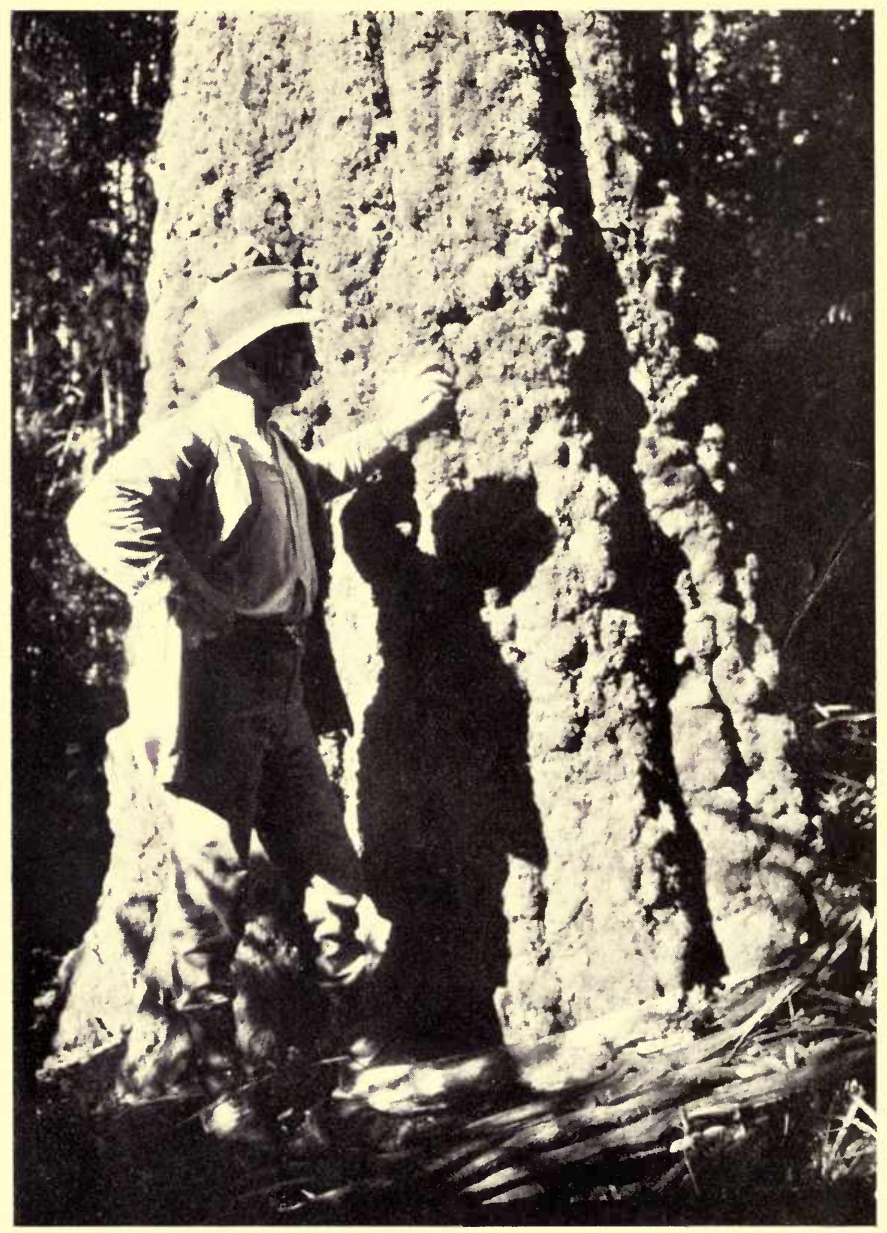

A GIANT SPECINEN OF Her'e Brasiliensis, MHRARY, RIVEK MADEJRA. (IKTH AT 3 FEET FROM THE GROUND 266 1NCHES 


\title{
THE RUBBER INDUSTRY
}

IN BRAZIL AND THE ORIENT

\author{
BY \\ C. E. AKERS
}

WITH TWENTY-SIX ILLUSTRATIONS AND TWO MAPS

METHUEN \& CO. LTD.

36 ESSEX STREET W.C.

LONDON 


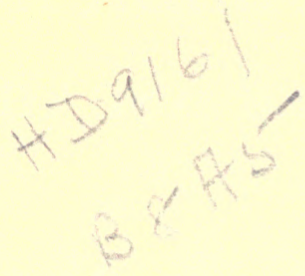

First Published in 1914 


\section{CONTENTS}

\section{PART I}

THE RUBBER INDUSTRY IN THE AMAZON VALLEY CHAPTER

I. HISTORY AND GENERAL CONDITIONS - $\quad$ - I

II. LOCAL CHARACTERISTICS - $\quad$ - $\quad$ - $\quad$ -

III. THE PRINCIPAL RUBBER DISTRICTS - - 26

IV. DISEASES AND PESTS COMMON TO RUBBER-TREES

IN BRAZIL $\quad$ - $\quad$ - $\quad$ - $\quad$ - $\quad$ - $\quad$ - 40

V. THE LABOUR-SUPPLY - $\quad$ - $\quad$ - $\quad$ - 5 I

VI. TAPPING

VII. YIELD AND DENSITY OF LATEX - $\quad$ - 77

VIII. CURING AND PREPARATION OF RUBBER - - $9 I$

IX. COST OF PRODUCTION $\quad$ - $\quad$ - $\quad$ - $\quad$ - $\quad$ IO5

X. A COMPARISON OF THE BRAZILIAN AND ORIENTAL RUBBER INDUSTRIES - $\quad$ - $\quad$ - $\quad$ - $\quad$ II8

\section{PART II}

THE RUBBER INDUSTRY IN THE ORIENT

XI. CEYLON

XII. CEYLON-continued

-XIII. THE MALAY PENINSULA -

XIV. THE MALAY PENINSULA-continued
- $\quad 29$

- I45

- 166

- $\mathbf{1} 86$ 
CHAPTER

PAGE

- XV. THE MALAY PENINSULA-continued - - 2 II

XVI. THE NETHERLANDS EAST INDIES: SUMATRA - 228

XVII. THE NETHERLANDS EAST INDIES: SUMATRA-

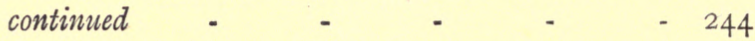

XVIII. THE NETHERLANDS EAST INDIES: JAVA - 260 XIX. THE NETHERLANDS EAST INDIES: JAVA-COn-

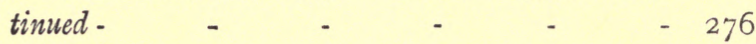

XX. A BRIEF REVIEW OF THE ORIENTAL SITUATION 29 I

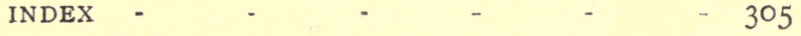




\section{LIST OF ILLUSTRATIONS}

MAP OF BRAZIL

- Front end-paper

A GIANT SPECIMEN OF " HEVEA BRASIliensis," MiRARY, RIVER MADEIRA

Frontispiece

FACING PAGE

PORTO VELHO, RIVER MADEIRA, BRAZIL

IO

HAULING A BOAT OVER CATARACT AT LOW RIVER, ABOVE SAN ANTONIO, RIVER MADEIRA - $\quad 22$ KARIPUN INDIANS, RIVER MADEIRA, BRAZIL - $\quad 22$

A RUBBER PROPERTY, RIVER MADEIRA - - $\quad 28$ THE MADEIRA FALLS, BRAZIL - $\quad$ - $\quad$ - $\quad$ - 28

From " The Upper Reaches of the Amazon," by J. F. Woodroffe MUTUM PARANÁ, MATTO GROSSO, BRAZIL - $\quad 34$ RIO BENI, CACHUEla ESPERANZA, BOLIVIA - $\quad 34$ KARIPUN INDIANS, RIVER MADEIRA, BRAZIL - - 38 MATTO GROSSO, BRAZIL $\quad$ - $\quad$ - $\quad$ - $\quad$ - 38 BOM FUTURO, RIVER MADEIRA, BRAZIL - - 54 COLleCtiNG LATEX, RIVER MADEIRA - - - 66 TAPPING RUBBER-TREE WITH THE MACHADINHA, RIVER

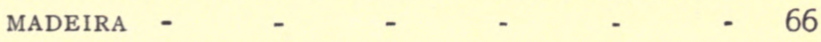

INDIAN COOLIES TAPPING TREES IN THE PUBLIC GARDENS AT PARÁ- 


\section{THE RUBBER INDUSTRY}

FACING PAGE

FINISHING WATER-PROOF COVERINGS, RIVER GUAPORÉ,

$\begin{array}{rllll}\text { MATTO GROSSO - } & - & - & - & -92 \\ \text { BALLS OF RUBBER (PELlES) } & - & - & - & -92\end{array}$

A RUBBER PROPERTY, MATTO GROSSO - - - $\quad 96$

SMOKING LATEX, RIVER MADEIRA - - - $\quad$ - 96

PLATFORM FOR DRYING CACAO, CACAUAL IMPERIAL - I 24

CACAUAL GRANDE, RIVER AMAZON - - - - $\quad$ - I 24

INTERIOR OF A RUBBER FACTORY IN CEYLON - I36

A RUBBER FACTORY IN CEYLON, SHOWING A PASSBERG

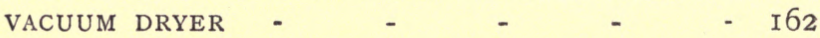

A RUBBER FACTORY IN CEYLON, SHOWING RUBBER

HANGING IN DRYING-SHED - - - - I62

AVENUE OF SEVEN-YEAR-OLD HEVEA TREES (CALEDONIA

ESTATE, PROVINCE WEllesley) - - - I7O

From “ Rubber," by Philip Schidrowitz, Ph.D., F.C.S.

A VIEW OVER PART OF BUKIT RAJAH - - $\quad-194$ From “"Rubber," by Philip Schidrowitz, Ph.D., F.C.S.

MAP OF MALAY, JAVA, AND SUMATRA - - End end-paper 


\section{INTRODUGTION}

A GREAT deal has been written concerning the - 1 rubber plantations of the Orient and the phenomenal expansion that has taken place during the past five years; of the Amazon Valley industry, however, very little information has been published, in spite of the fact that it was the dominant feature in the rubber situation of the world until the end of rgr2. While it is clear that Oriental developments have altered completely the conditions of production, the annual output of the Amazon Valley is still a very important factor in the market, and it will continue to be so for some time to come, on account of the high quality of the latex extracted from the thoroughly matured trees of Brazilian forests. During my investigations as chief of the Commission working in the Orient in IgII-I2 in connection with the conditions of the rubber industry, I was con. fronted frequently by the erroneous impressions prevailing amongst Eastern planters in regard to Brazilian methods and resources; I propose now to describe the essential conditions so as to enable accurate deductions to be drawn, and a correct comparison made between the plantation industry of the East and the production of wild rubber in the Amazon Valley. That the Orient has still something to learn from Brazil is evidenced by 
the efforts now afoot in both Ceylon and the Malay Peninsula to manufacture fine hard smoke-cured rubber to compete with the Pará product. For the Brazilians it is absolutely necessary to reach an intelligent appreciation of the complete revolution in the rubber situation created by the development of the Eastern industry with the very important factors of cheap labour and efficient and enterprising direction.

The amazing incidents connected with the rapid progress of the rubber industry in Ceylon and Malaya since I908 partake more of the character of a fairy tale than the plain facts of a nineteenth-century ordinary commercial undertaking. From the position of a constant struggle for a bare existence, owners of plantations advanced suddenly to an era of most unprecedented prosperity. Poverty gave place to wealth, and in all directions the conditions of life were transformed with an almost incredible swiftness.

The period of fabulous dividends has passed; the large increased production has brought into play the natural result of a regulation of prices on the basis of demand and supply. Lower values do not necessarily imply any serious injury to properly-managed plantations as industrial undertakings, but rather an adjustment of the administration and costs of production to a standard allowing a fair profit on the invested capital. The wildcat flotations brought out during the period of inflation between Igog and I9I I will be reorganized or disappear, and the rubber industry of the Orient will settle down into a sound, vigorous enterprise with every prospect of re- 
munerative and steady returns in regard to all properties where the initial expenditure has been restrained within conservative limits.

The Brazilian situation differs widely from that of the Eastern plantations. The problems to be faced in the Amazon Valley are a cheaper labour-supply, reduced taxation, and better administration. On those three factors depend the future existence of the Brazilian rubber industry; and unless some satisfactory solution of these difficulties be found, the production will diminish rapidly in the near future, and soon cease to influence the world's market.

Looking back over the past five years, there can be no doubt that the paramount difference between the producers in the Orient and those of the Amazon Valley has been that the former anticipated and made ready for a fall in values, while the latter persistently believed in higher prices. This attitude of the Brazilians has left them unprepared to meet the serious effects of Eastern competition, and the consequent shrinkage in the money value of the output that was so marked a feature during the year I9I3. Trade prospects at the great manufacturing centres of Europe and America show signs of improvement, but they do not justify the hope that any sudden increased demand for the raw material will lead to a reversion of prices to the level of I912; the available supplies from the Orient will more than suffice to meet the void occasioned by the probable diminution in the production of wild rubber from Africa and other countries, and in the circumstances the most 
the Orient; therefore the price must eventually adjust itself, no matter how great may be the fluctuations in the immediate future.

Three factors will exercise an important influence over the future of the rubber market. The first is the advent of the steel wire wound or webbed tyre for motor-cars; after long research, a system has been found for the manufacture of these tyres with the required resiliency at one-third the cost of the rubber tyre. The second is that synthetic rubber will become a commercial possibility at no distant date. The third is the amount of reformed rubber that will result from the largely increased production of the crude material.

C. E. AKERS.

February, I9I4. 


\section{NOTE}

IN all considerations of the rubber industry in the Orient, the value of the currency unit is a most important factor; on it depends to a great extent the cost in sterling of every pound of rubber produced. The number of cents for the daily wage rate varies very slightly in the different centres of production, no matter if the unit be rupees, dollars, or guilders ; but the influence of the monetary unit on the aggregate annual expenditure is one of the most prominent features in the situation.

In regard to the countries dealt with in this volume, the following standard of values should be kept in mind for all purposes of comparison :

\begin{tabular}{|lll|l|l|}
\hline \multicolumn{2}{|c|}{ Country. } & \multicolumn{1}{c|}{ Unit. } & Sterling Value. \\
\hline I. Ceylon and India & $\ldots$ & Rupee & \multicolumn{2}{c|}{ I6 pence } \\
2. Malay Peninsula & $\ldots$ & Dollar & $28, "$, \\
3. Sumatra $\ldots$ & $\ldots$ & $\ldots$ & Guilder or florin & $20 \quad$, \\
4. Java $\quad \ldots$ & $\ldots$ & $\ldots$ & Guilder or florin & $20 \quad$, \\
\hline
\end{tabular}





\section{PART I \\ THE RUBBER INDUSTRY OF THE AMAZON VALLEY}

\section{CHAPTER I}

\section{HISTORY AND GENERAL CONDITIONS}

Origin of the Brazilian rubber industry-First steps in manufacture of rubber articles-Discovery of vulcanization-Varieties of Hevea-Castilloa or caucho-Hevea Brasiliensis the mainstay of the Amazon industry-Superiority of the black Hevea-The white Hevea - Itapirú and Bariguda-Different qualities of rubber-Output and classification for season ending June 30 , 1913-Rubber from Ceará-Total Brazilian shipments-Area of rubber-producing lands in the Amazon Valley-Principal affluents of the Amazon - Rubber the only important industry in the Amazon Valley-Forest vegetation-Varieties of timber-Slight fall in gradient of rivers-Strong currents-Rivers fed by melting snows from the Andes-Annual rise in the water-level-Inundations and agricultural enterprise-Lands above flood-level-Variations of temperature-Dry and wet seasons-Rainfall-Climatic diseases -Malaria-Beri-beri-Yellow fever-Difficulty of enforcing sanitation measures-Anæmic condition of inhabitants-Classification of population.

THE origin of the Brazilian rubber industry can be I traced back for several centuries, to a period when the Indian population of the Amazon Valley made use of the gum for various domestic purposes. As far back as 1536 mention is made by Orviedo y Valle, in his "Historia Universal de las Indias," published at 
Madrid in that year, of different articles manufactured from the coagulated latex of the rubber-tree by the Amazonian Indians. In I734 La Condamine was sent by the Paris Academy in charge of a scientific expedition to the Equator, and in 1736 he forwarded to Paris a small quantity of rubber under the designation of "caoutchouc," giving a description of the uses to which it was put. To the species of tree from which this rubber was obtained La Condamine gave the name of heve, a word of Indian derivation, and this later was transformed into hevea, a term covering the many varieties providing the principal source of production in Brazil and the Orient at the present time. In I770 Priestly discovered that caoutchouc would erase pencilmarks from paper, and hence arose its common name of indiarubber.

In I823 the first important step was made towards the application of rubber for practical purposes in Europe. In that year Charles McIntosh discovered that it was soluble in benzine, and he applied this knowledge to the manufacture of waterproof coats and other rain-resisting articles. A few years later, in I832, the firm of Chaffee and Haskins founded the Roxbury Indiarubber Company in the United States for making waterproof materials. It was in connection with this latter enterprise that a chemist named Charles Goodyear, after many experiments, proved that a mixture of sulphur with rubber rendered the latter capable of resisting great extremes of cold and heat, and this process, subsequently known as "vulcanization," was adopted generally in the manufacture of all classes of rubber goods. 


\section{HISTORY AND GENERAL CONDITIONS}

It is from the various species of the Hevea that the greater part of the rubber of the Amazon Valley is obtained. Of these, some seventeen varieties are known to exist, the most common being the Hevea Brasiliensis, the Hevea Guayanensis, and the Hevea spruceana. The Castilloa elastica, yielding the product known locally as caucho, as distinct from goma, or rubber, is found principally on the higher reaches of the Amazon tributaries, and of recent years has provided one-fifth of the total rubber exports from Brazil.

The mainstay of the Amazon Valley industry is the Hevea Brasiliensis, the three varieties most in evidence being the black (preta), the white (branca), and the red (vermelho). Broadly speaking, it may be said that the white and red species belong more particularly to the districts of the Lower Amazon and its feeders; the black to the upper rivers and the territories adjoining the frontier of Bolivia, and also in certain sections of that country. In this latter area are found also trees of the white and red variety, the former in greater abundance than the latter.

It is from the latex of the black Hevea that the finest rubber is prepared, and when free from impurities, and without any addition of latex from other varieties, it is undoubtedly of exceptional value on account of its high standard of resiliency. The best quality of this rubber is classified as "fine hard Pará," the lower grade being placed on the market as entre fina. The tree grows to a great size in girth and height, and yields freely, the latex being of high density, and easily, although slowly, coagulated by the smoke of the Urucury nuts employed for this purpose. 


\section{THE RUBBER INDUSTRY}

Tests made with acetic acid show that fifteen to twenty minutes are required before coagulation takes place.

From the white Hevea the rubber obtained is designated locally as fraca (weak). It is, however, of good quality, and the fraca fina and fine island grades sell readily at only 20 per cent. less value than fine hard Pará. It has less resiliency than the product of the black Hevea, and, as a general rule, less care is taken in its manufacture, with the result that the percentage of impurities is greater than is the case with the rubber from the upper rivers. The latex from the Itapiru (Hevea Guayanensis) and the Bariguda (Hevea spruceana) is mixed frequently with that from the white Hevea whenever those varieties are plentiful in the neighbourhood.

The latex of the red Hevea reaches the market in a condition locally qualified as "soft." It does not coagulate as freely as the black and white species, and contains a greater percentage of moisture than the other two varieties when forwarded for shipment, the consequence being a lower selling value.

Scrap, or sernamby, is an unavoidable by-product, in more or less degree, of all classes of rubber, and it forms a considerable proportion of the total export from the Amazon Valley, often representing I5 per cent. of the annual shipments. In the upper rivers the scrap comprises only the unavoidable cup coagulations and the lump formed when the latex is being brought in to the smoking-house; but in many districts of the Lower Amazon the latex is allowed to remain purposely in the cups until coagulation has 


\section{HISTORY AND GENERAL CONDITIONS}

taken place, and is then collected and shipped without undergoing any curative process.

The gum of the Castilloa elastica is dealt with in the markets of Manáos and Pará under the designation of caucho, but appears in the export returns as part of the rubber shipments. It is obtained from the upper river districts in Brazilian territory, and from Peru and Bolivia. It formed in Igr 3 more than 23 per cent. of the total rubber exports from the Amazon Valley; but it is unlikely that this proportion will be maintained in future, for, apart from the deterrent effect of a very low market price, the method of collection entails cutting down the trees to obtain the latex, and the consequent destruction of the source of supply.

The total output of all grades of rubber from the Amazon Valley for the twelve months ending June 30 , I9I3, was 43,362 tons. Of this amount, 31,362 tons was produced on the upper rivers, including Bolivia and Peru, and I2,000 tons in the districts of the Lower Amazon and its tributaries. The percentages and quantities of all classes for this period were-

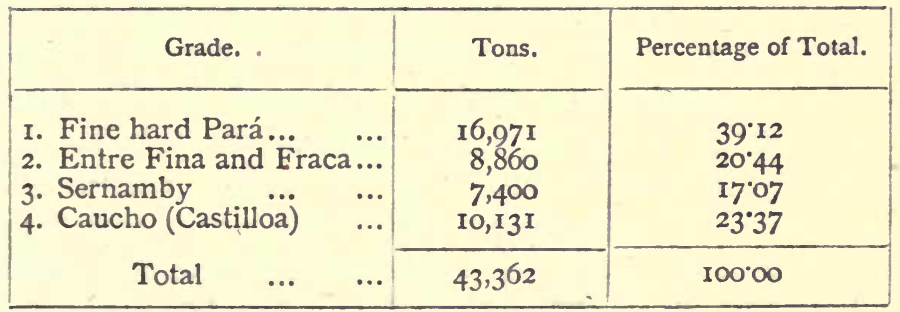

Outside the Amazon Valley the Brazilian shipments were 4,000 tons, in round figures, chiefly of the manihot varieties, produced in Ceará and the adjacent States. 
Therefore the total Brazilian crop for the year ending June 30 , I9I3, was 47,000 tons, equal to 40 per cent. of the world's production.

In order to understand the general conditions connected with the rubber industry of the Amazon Valley, it is necessary to realize and appreciate the vast area covered by the rubber-producing districts. It extends from the Atlantic seaboard on the east, and on the west to the southern boundary of Colombia, at a point not more than 150 miles in a direct line from the Pacific Ocean, a total distance of some 3,000 miles. As far as Iquitos in Peru, 2,400 miles from the Atlantic coast, a regular service of steamers is maintained from Liverpool by the Booth Steamship Company, and beyond that place the waterways are navigable for small craft for some hundreds of miles. The valley formed by the Amazon and its numerous tributaries is fan-shaped, with the apex situated roo miles to the east of Pará, where the river discharges into the Atlantic. At the delta of the river the valley is some 200 miles wide, and then it broadens out rapidly until reaching the foot-hills of the Andes, where the extreme width exceeds I,500 miles. This great area covers $2,400,000$ square miles approximately, and, in addition to Brazilian territory, it embraces large sections of Bolivia, Colombia, Ecuador, and Peru. A rough calculation computes the waterways of the main rivers and their tributaries navigable for ocean steamers and river craft at 30,000 miles. These waterways, in addition to the Amazon, include to the south the Rivers Tocantins, Xingu, Tapajoz, Madeira, Madre de Dios, Beni, Guaporé, Marmoré, Araguaya, Purús, Aquiry, Juruá, 
Javary, Ucayali, Marañon, and many others; to the north the principal rivers are the Jary, Pary, Trompetas, Rio Negro, Rio Branco, Yapurá, Napo, and many less important streams too numerous to chronicle. It is on the banks of these rivers that the chief development of the rubber industry has taken place during the last quarter of a century, the annual output during that period having increased from ro, 000 to 43,000 tons. Throughout this enormous territory the only established industry of real importance since I880 has been the collection and shipment of rubber. Minor enterprises, such as the cultivation of cacao and the collection of cinchona bark, were carried on to some extent in certain districts, but of recent years these declined to such small proportions that they ceased to be a factor calling for any serious attention.

Heavy forest growth is the characteristic feature of the vegetation of the whole Amazon Valley. In a few districts a comparatively limited area of savanas, or open grasslands, are found; but these are confined principally to the country adjacent to the Rio Branco on the north and the Rio Beni to the south-west, the latter lying within the boundaries of Bolivia. These great forests contain quantities of fine timber trees, some of the most valuable being red cedar, sandalwood, lancewood, and many varieties of fine hard woods. In spite of the abundance of the supply, no systematic effort has been made as yet to tap this source of natural wealth. Climatic conditions, difficulties and cost of transport, and lack of energy on the part of the population, have prevented these virgin forests being exploited hitherto, but in future years they will become 
an important factor in the lumber industry of the world. It is in these forests that the many varieties of rubber-yielding trees are found, but no accurate information as to the number is available. There is not the smallest doubt that the total runs into hundreds of millions, and for practical purposes may be considered inexhaustible; but the supply of latex for the manufacture of rubber for export is controlled by the lack of any large labouring population, and by the cost of collection and carriage to the river-banks for transport to any commercial market.

One most remarkable fact in connection with the waterways of the Amazon Valley is the very insignificant gradient of the rivers. The fall seldom exceeds ro feet in roo miles. The difference between sea-level on the Atlantic coast and Iquitos, 2,400 miles inland, is less than 200 feet, or approximately $0^{\circ} 0000015$ per cent. In spite of this very slight difference in levels, the average current in the main river and its tributaries in normal seasons is at the rate of four miles an hour, increasing to a noticeable degree in times of flood. This strong current is accounted for by the discharge of water from the melting of the snow in the Andine ranges, and the enormous accumulations of rain-water in the basin through which the upper rivers take their course.

The melting of the snow in the Cordillera of the Andes and the heaviest rainfall take place concurrently during a period extending from the middle of November to the end of March in each twelve months, and it is then that the volume of water in the river channels attains its maximum height. The 
absence of any adequate gradient between the districts of the interior and the seaboard impedes the rapid discharge of these additional waters, and consequently the rise in the water-level is phenomenal throughout all sections of the Amazon Valley. In the season Igr2-I3, at Porto Velho, I,600 miles inland, the River Madeira rose nearly 50 feet from the lowest point; at Manáos, distant I,000 miles from the sea-coast, the rise was 45 feet. Even in the main body of the Amazon, between Manáos and Pará, the differences of the waterlevel were from I 2 to 20 feet. In these periods of flood the country is inundated for many miles from the river-banks, and frequently is under water until the begirning of May. The impossibility of controlling these annual floods is one of the greatest difficulties in the way of any successful colonization and the establishment of permanent agricultural and industrial enterprises. Owing to these conditions, agricultural operations can be attempted only during some five months of the year, and therefore all efforts at cultivation must be confined to crops coming quickly to maturity, or such trees and plants as can resist the effects of being constantly in water for months at a time. In nearly all districts of the Amazon Valley there exist certain lands above the annual flood-level; but as a rule the soil on these higher sections is of poorer quality than on the flat, and they lie some miles from the river, thus necessitating the construction of costly roadways to maintain communication and transport produce during the period of the inundations. Indeed, the cost of any such work would be prohibitive; for, to be effective, a causeway above the 
flood-level would be required, and to build anything of the kind in a country where stone is rarely found would entail an expenditure out of all proportion to any possible results to be obtained from a colonization or agricultural standpoint.

In such a vast extension of territory as that comprised within the area embraced by the Amazon Valley, considerable difference of climate must necessarily exist; but throughout a very large section, more especially in those districts where rubber-yielding trees are most abundant, the variations of temperature are not so great as might be expected. In the portion of the Amazon Valley situated between the Atlantic coast and Porto Velho, a distance of 1,600 miles, the following results were obtained as the average maximum and minimum records, extending over a period of the five years from 1907 to I9I2:

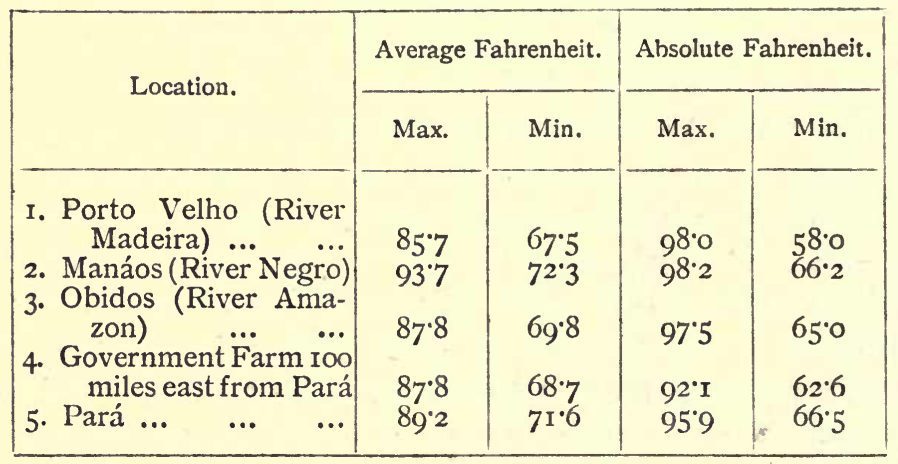

No accurate statistics are available to determine any variations at other points; but the deductions to be drawn from occasional reports and observations are 


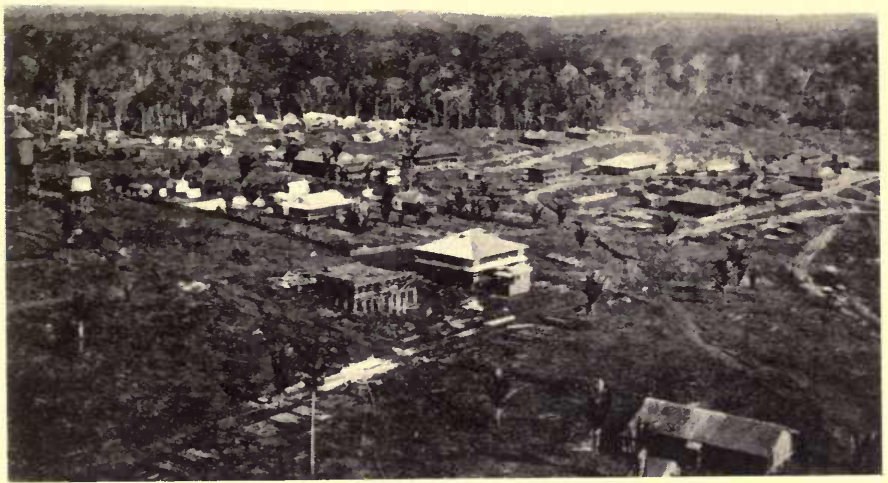

P()RT( VEI.H(), RIVER MADEIRA, BRAZII,

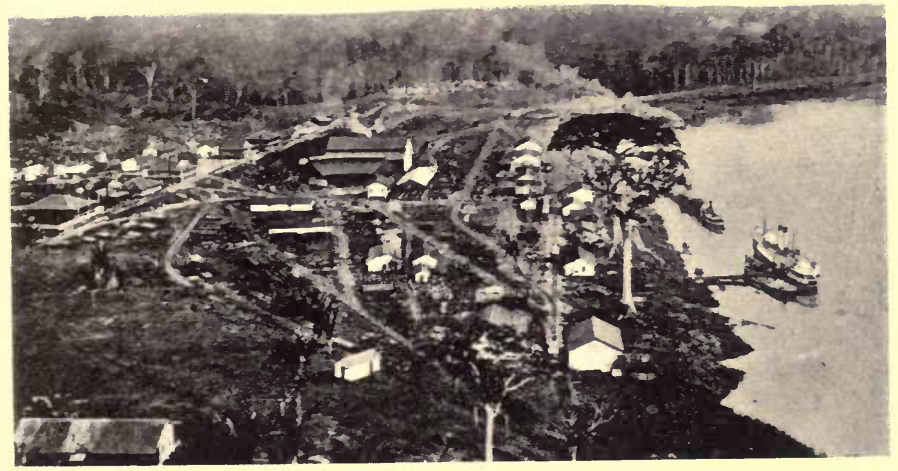

PORTO VIEHO, RIVER MADEIRA, ISRAZII. 



\section{HISTORY AND GENERAL CONDITIONS II}

that the differences are unimportant, except in the vicinity of the foot-hills of the Andes, where at the higher elevation above sea-level lower temperatures occur, especially at night-time.

For practical purposes the year in the Amazon Valley may be divided into the dry and the wet seasons. The former covers the months of May to October; the latter extends from November to April. The rainfall varies to a marked degree in different sections, owing to the existence of the Tumuc Humac and other mountain ranges on the southern borders of the Guianas. These mountains precipitate the rainfall before it reaches the north-eastern part of the Amazon Valley, the effect being particularly noticeable throughout a section of some 500 miles from east to west, of which Manáos and Obidos are the two principal points. Outside the influence of these northern mountain ranges the rainfall is comparatively equable. Reliable records of the meteorological conditions are available at five points only. In IgII these observations showed the following precipitations:

\begin{tabular}{|c|c|}
\hline Location. & Rainfall in Inches. \\
\hline I. Pará & 98 \\
\hline 2. Government Farm at Igarape-Assu & 94 \\
\hline 3. Manáos $\ldots$ … $\ldots$ & 53 \\
\hline $\begin{array}{l}\text { 4. Madeira-Marmoré Railway, Porto Velho } \\
\text { 5. Obidos } \ldots\end{array}$ & $\begin{array}{r}106 \\
63\end{array}$ \\
\hline
\end{tabular}

These figures give an annual average of 58 inches for the dry sections affected by the Guiana Mountains, and $99^{\circ} 33$ inches for the districts free from that influence. From notes taken in connection with the 
Rivers Beni, Purús, and Juruá, and the Acre division of Brazilian territory, there is little doubt that the average of 99 inches is applicable equally to those sections of Bolivia and Brazil, and may be taken approximately as the basis generally in the Amazon Valley. The maximum rainfall recorded in IgII was 4.70 inches in twenty-four hours, at Porto Velho. At the same place the average for five years, from July $I$, I907, to June 30 , I9I2, was $103^{\circ} 96$ inches.

The moist heat prevalent throughout the Amazon Valley is conducive to the many climatic diseases common to tropical zones. Mosquitoes, flies, and many other insects, constitute a pest and cause of infection difficult to resist. Malaria, blackwater fever, and similar forms of illness, are constantly in evidence. Beri-beri and dysentery are common evils. Yellow fever has been stamped out of Pará, and the necessary sanitary measures have been taken to eradicate this plague from Manáos, where it has been endemic for many years past. Except in the more populous centres, such as Pará, Manáos, Iquitos, and a few other places, it is a practical impossibility to grapple with the question of sanitation in the Amazon Valley. With a scanty population scattered over an enormous area, there is probably less than one inhabitant to the square mile; and to establish any effective system of medical assistance, dispensaries or hospitals, is out of the question under existing conditions. Something can be done to improve the welfare of the dwellers in the various small towns and villages, but this can be carried out only at a very heavy cost, and will require years of steady effort to achieve. To go farther, and attempt 
to enforce public hygiene and adequate medical supervision throughout the districts of the Amazon and its tributaries, is only to court disaster and waste immense sums of money for no useful purpose. A large proportion of the population suffers from anæmia, induced partly by climatic causes, and partly by the poor quality and little variety of the fnod. The result of this widespread anæmic condition of the people is a lack of energy in regard to all work, especially amongst the European inhabitants, and a general apathy in regard to all present or future development of the great natural resources of the country.

As an indication of the effect of climatic diseases on the working population, the case of the MadeiraMarmoré Railway may be cited. From June, I907, to December, I9I2, the pay-rolls show I3,I86 men employed, and I,238 deaths, principally due to malaria.

No proper census of the pepulation of the Amazon Valley has ever been taken, and the figures quoted in official returns from time to time are guesswork made by irresponsible persons at different points on the principal rivers. Probably the total number of inhabitants is about 900,000 approximately, comprising some 250,000 whites or their descendants, with a certain mixture of Indian blood; 450,000 negroes and mulattoes; and 200,000 domesticated and wild Indians. The white population comprises the descendants of Portuguese and Spanish settlers, and the results of inters marriage with native Indian women; Brazilians, Bolivians, Colombians, Ecuadorians, and Peruvians, who have drifted to the Amazon Valley from other sections of South America; and European immigrants 
from Portugal and Spain, and a few from Italy. Except in the cities of Manáos, Pará, and Iquitos, or in connection with railway enterprises at Porto Velho or elsewhere, persons of British, American, French, or German nationality are met with only on rare occasions. The negro and mulatto part of the population owes its origin to the former slaves, and to the immigrants from the States of Ceará, Rio Grande del Norte, Parahyba, and Maranhao, who have been brought to the Amazon Valley as labourers, or come there on their own account owing to the attraction of high wages in connection with the rubber industry. A small number of negroes from Barbadoes and other West Indian islands are found also in various districts. The number of native domesticated Indians is not large, and they are established principally in Bolivian and Peruvian territory. The wild Indians are an unknown factor. They are nomads, and they live in the interior of the forests for the most part, only coming temporarily to the principal rivers on fishing expeditions or for trading purposes. As far as possible, they avoid all contact with the civilized portion of the community. 


\section{CHAPTER II \\ LOCAL CHARACTERISTICS}

Land tenure-Origin of Brazilian titles to real estate-Absence of any survey of properties-Small value of real estates as security for loans-Characteristic features of the soil-Possible future development-Tax on land transfer-Export and import duties -Federal and State contributions-Political relations of Federal and State Governments-The waterways of the Amazon ValleyImpediments to navigation-Means of communication and social life-Exchange and industrial enterprise.

THE tenure of land in the Amazon Valley is on a 1 very unsatisfactory basis; in the great majority of properties the title is defective, and practically always open to dispute in regard to boundaries whenever a transfer of ownership takes place. The titles of rural real estate so far as Brazil is concerned may be classified under six separate headings. These are-(I) Old grants issued by the Portuguese Crown during the colonial period; (2) grants given under the Empire; (3) concessions sanctioned after the establishment of the Republic in 1889 ; (4) lands sold or conceded for a nominal consideration by the authorities of the States of Pará, Amazonas, and Matto Grosso; (5) lands purchased outright from the National or State Government; and (6) lands acquired by occupation under the conditions of settlers' rights.

With the exception of a very few properties owned by foreigners or in the hands of foreign syndicates, no 
attempt has been made to survey the lands held under the various classes of title by which ownership is claimed. Boundaries are defined by a certain length of frontage to a river, with imaginary lines running inland for so many leagues or kilometres, or occasionally from a point on the river to a hill in the background, thence to some other prominent physical feature and back to the river-bank. This condition of affairs naturally leads to frequent disputes, especially in districts rich in rubber-yielding trees; but the area of land is so vast and the population of such scanty proportions that resource to litigation is almost unknown. Might is right in most cases where these boundary disputes arise, and the privileges of possession must be maintained by force or abandoned to the successful intruder. Many of these properties nominally comprise areas of several hundreds of square miles, and it happens frequently that large sections have been left unexplored by the owners.

In such circumstances, titles to real estate possess small value as neggotiable securities for commercial purposes. They are not assets against which bankers or merchants are justified in making advances of money, and are only accepted as additional security in cases where loans are contracted to enable the crop of rubber to be harvested under conditions entailing the shipment of the year's produce to the creditor for sale in Manáos or Pará, or for export to Europe or the United States. This uncertainty in regard to the tenure of land has been one of the principal drawbacks in the past to the acquisition to any great extent of real estate by foreign syndicates, and has proved a serious obstacle to the 
rapid development of the Amazon Valley, especially in connection with properties held under the three first headings enumerated. In the case of lands conceded for a nominal consideration by the Brazilian State Governments, the accompanying conditions, as a rule, are not easy to fulfil in the exact terms of the wording of the grant; hence the title is open to dispute in nearly all such concessions whenever political considerations are strong enough to provoke a hostile attitude on the part of the authorities.

The soil in the Amazon Valley varies to some extent in the different districts, but speaking broadly it may be described as a red or yellow clay subsoil covered with a considerable depth of vegetable mould, this layer of humus being particularly rich in organic matter. On the foreshore of all the principal rivers, after the subsidence of the annual inundations, a deposit of silt from two to three feet in depth is left by the falling waters, and this is of surprising fertility. If a comparison be made of the river-banks of the waterways of the Amazon Valley and those of the Nile, the conditions for cultivation are distinctly in favour of the former. The lack of population is the only reason why advantage is not taken of the extraordinarily productive qualities of these deposits to cultivate many classes of tropical cereals and other suitable crops. If at some future period adequate methods are established for controlling the waters of these rivers for irrigation purposes, and securing the riparian lands from inundation, the Amazon Valley may develop into one of the greatest centres of tropical agriculture throughout the world, and it may become the outlet for the surplus 
millions in China and other densely-populated countries in Asia and elsewhere.

On land sales a tax of 6 per cent. is levied, but other direct contributions are not onerous, the principal impost being a small charge in proportion to the number of rubber-trees tapped by the collectors employed on each of the various properties. Indirect taxation, on the other hand, is exceptionally heavy, and takes the form of duties on all rubber exported and on merchandise brought into the country. This export duty up to the end of Igr3 was at the rate of 20 per cent. of the value on rubber produced in the States of Pará and in the national territories, and I8 per cent. for that from Amazonas; but in January, I9I4, the duty was reduced to 18 per cent. in the case of Pará and the national territory, and a further diminution is promised.* A duty of 8 per cent. is levied by Bolivia at present, but a reduction in the immediate future is proposed.

The whole question of taxation is on a most unsatisfactory basis as regards both the State and Federal Governments. In the case of the former, the export duties on rubber have yielded a large revenue of recent years, and a costly and cumbrous administration has been created as a result of the period of high prices from Igog to I9I2. Heavy public indebtedness has been contracted without any compensating benefit to the State, and the rubber industry is now called upon to bear the burden of the extravagant expenditure incurred during the last few years of unusual prosperity. In the present situation of the rubber market, it is inevitable that the State revenues must show a most serious falling off in

* Although the State of Pará formally agreed to this reduction, the lower rate had not come into force in April, I9I4. 
the near future; and in the existing condition of severe competition with Oriental production, it is doubtful if it will be possible to levy any export duty at all on rubber shipments in the near future if the industry is to survive the crisis that has now overtaken it. Unless the producers obtain certain measures of relief, they will be ruined, and the whole fabric of the trade of the Amazon Valley will be broken down; but to give any appreciable assistance the most drastic economies must be practised by the local administrations, and these are extremely difficult to effect at the present time.

All duties on merchandise imported into the Brazilian section of the Amazon Valley are collected on account of the Federal Government, and the high rates charged under the existing tariff are a constant cause of complaint on the part of every class of the community. Industrial enterprise is hampered severely by these duties, on account of the increased cost thereby entailed for most of the necessities of life causing an abnormally high wage rate. The average charges exceed roo per cent. on the value of all imported materials; and as this applies to the canned goods and provisions required for the maintenance of the labourers in the interior districts, the price of living is unduly enhanced and the cost of the production of rubber relatively increased. The refusal of the Federal authorities to afford any relief in this direction is based on constitutional law, the argument being that if any reduction of duties was made for the Amazon Valley to aid the rubber industry, a similar concession would be necessary for the remainder of the States forming the Brazilian Republic. This may be the correct interpretation of the letter of the law, but the exceptional difficulties confronting the 
northern States at the present juncture call for extraordinary measures to save the situation; and unless action is taken in the immediate future to meet the conditions now prevailing, a collapse in the industrial position must occur very shortly.

The question of the high duties on imported merchandise has been the cause of no little friction between the States situated in the Amazon Valley and the Federal Government, and it is within the scope of practical politics that it may lead to a complete readjustment of the relations of the northern section of Brazil with the administration at Rio de Janeiro. As matters are today, the fact that the dominant partner is separated from Pará and Amazonas by a two weeks' journey is a factor of too great importance to be ignored. It means that all disputes with the Federal authorities must be taken at great loss of time and money to the Federal capital, and months may elapse before any decision be obtained. A natural corollary to the present state of affairs would be an arrangement by which the States in the north are allowed exemption from the general tariff, or, failing this concession, the declaration of their separation from the remainder of Brazil.

As an example of the relations existing between the Federal authority and the State Governments in the north of Brazil, the conditions prevailing in Amazonas may be quoted. When the newly-elected Governor took office in I9I3, he found the Legislature in opposition to his policy; he dissolved the Chambers at once, disregarding all the tenets of Brazilian constitutional law. At the fresh elections the Governor secured a favourable majority; thereupon the members of the 
former Legislature appealed to the Supreme Court at Rio de Janeiro, and obtained a decision declaring the new elections to be invalid. The Governor accepted the situation, and stated that the former Chambers could meet without interference, but that he intended to carry on all legislation with the recently-elected majority favourable to himself. And so the matter remained, both sets of legislators meeting at intervals to discuss public affairs, and no effort being made by the Federal Administration to enforce the ruling pronounced in the Supreme Court at Rio de Janeiro.

It is necessary to refer to the political conditions in the Amazon Valley, as they exercise a most powerful influence in connection with all industrial enterprise. The question of Federal and State taxation is one of the most important factors for the Brazilian rubber industry, and unless joint action be taken in the immediate future by the Federal and State authorities, the position of the rubber producers will become most precarious and arouse a spirit of dangerous discontent, leading to serious political disturbances.

It has been the custom to regard the network of rivers in the Amazon Valley as providing easy means of transport throughout the greater part of these vast territories. To a certain extent this popular view is not without justification, but there are many circumstances minimizing the usefulness of this system of natural waterways. In the first place, the rivers are not properly charted, buoyed, or lighted for navigation purposes, and the blame for this state of affairs can only be attributed to the apathy of the Federal authorities. Then the cost of fuel is abnormally dear, due in great 
part to the high wage for labourers handling the coal at Pará, Manáos, and elsewhere, or cutting firewood on the river-banks for the supplies required by passing steamers. The crews of vessels engaged in the river traffic are paid out of all proportion to the services rendered, and the National Coasting Trade Law obliges the owners of such craft to employ many more men than are actually required for efficient navigation. The port authorities are dilatory in despatching and receiving shipping, and serious delay, entailing loss of time and money, thereby results. Representations to the Federal Government in connection with these unsatisfactory conditions have availed nothing hitherto, and there is small immediate prospect of any practical reforms being adopted to meet the urgent necessities of the situation. The consequence of the difficulties referred to is that the transport charges for freight and passengers are abnormally high, in view of the heavy fall in the value of rubber during the last two years, and they have become a factor of very great importance at the present critical stage of the industry.

Apart from unnecessary obstacles, due for the most part to incompetent administration, many natural physical impediments to navigation exist in a large number of the rivers. These consist principally of cataracts and rapids obstructing the passage of all craft except flat-bottomed boats or native canoes, and they occur notably on the rivers Juruá, Purús, Madeira, Tapajoz, Xingu, Tocantins, and Rio Branco. In one case only has this difficulty been overcome by establishing a railway to connect the upper and lower reaches of the river, the line of the Madeira-Marmoré Company starting from below the cataract of San Antonio and giving 


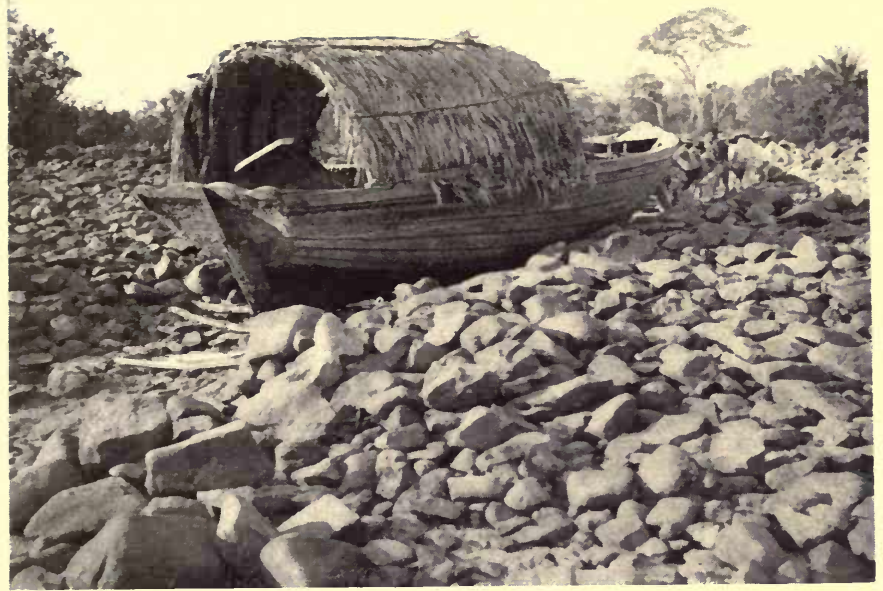

HALIIVG A WUAT OVER CATARACT AT LOW RIVER ABUN SAN ANTUNIU,

RIVER MADEIR.A

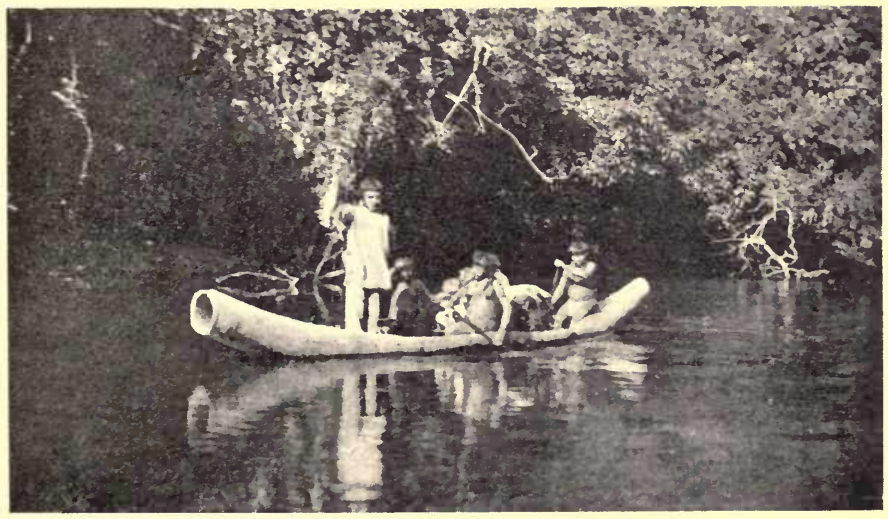

KARIPLN INDIANS, RIVER MADEIRA, BRAZII. 

access to the navigable waters of the Beni, Marmoré, and Guaporé. An attempt was made also to build a railway to open traffic from the Tocantins to the Araguaya, but after some thirty miles of track had been constructed the effort was abandoned. In some cases channels could be cut through the rapids to allow the passage of vessels, but broadly speaking the only practical means of overcoming these natural mbstacles is by the prorision of railway communication to connect the navigable sections of the rivers. It is a public work of such great magnitude that its accomplishment is unlikely in the present condition of the Brazilian finances. In another direction much beneficial work could be achieved without any very heavy expenditure by systematically clearing the principal waterways of the dangerous snags and drift logs brought down by the annual inundations. These form a constant menace to the steamer traffic, and are the cause of much delay in transit, owing to the fact that they render night travelling on many of the rivers practically impossible with any degree of comfort or safety.

Telegraphic communication between the Amazon Valley and the outside world is maintained by cable connection between Pará and Manáos, land lines linking up Pará and Rio de Janeiro by way of Matto Grosso, and by wireless stations at Pará, Manáos, Rio Branco, Porto Velho, Senna Madureira, and Iquitos. The cable is the property of a public company; the wireless installations and the land lines belong to the Federal Government, and are controlled and operated by Federal employés. By the cable an efficient service is available, but over the wireless system and the land lines com. 
munication is dilatory and the subject of constant complaints. The postal arrangements are sadly deficient, and outside the principal towns the delivery of letters is always uncertain, and frequently results in a delay of months before they are received.

Outside the more important towns social life can hardly be said to exist. The distances between the various homesteads on the rubber-producing properties are too great to admit of any constant interchange of friendly courtesies, and as a consequence the life on the rivers is dull and monotonous to an extreme degree. During the annual floods from March to May, in the great majority of localities, the only means of moving about when leaving the dwelling-house is by canoe or flat-bottomed boat, and the effect is that for all intents and purposes the inhabitants are marooned for several months in the year. The isolation under such conditions is one of the most trying features of the situation for all concerned, while for educated Brazilians or foreigners it is a hardship of the most severe description. Work is impossible during this epoch of the inundations, and, to add to the general misery, swarms of insects are a continuous source of irritation by day and night. In view of these circumstances it is not surprising that a large proportion of the owners of rubber-producing properties abandon their estates for six months in the year, and migrate to Manáos or Pará, leaving the administration of their affairs in charge of managers who, for the most part, are lacking in any high standard of intelligence or sense of responsibility.

No adequate appreciation of the industrial situation in Brazil is possible without due consideration of the effect of the variation in the exchange value of the local 
currency in its relation to gold. This factor is of special importance in connection with rubber production, for not less than 75 per cent. of the total cost is due to payments to collectors working on a profitsharing system. These payments are made in currency, whereas the value of all rubber is regulated by the gold prices quoted in Europe or the United States. How far-reaching is this question of exchange may be gathered from the fact that during the last twenty years the sterling value of the milveis has varied from sixpence to eighteenpence. A sudden drop or rise in exchange does not meet with any corresponding difference in the rate paid for the necessities of life, and it is only after a comparatively prolonged period that the prices of local commodities respond to the higher or lower sterling value of the currency. At present the established rate for nearly all calculations is sixteen pence to the milveis. If gold should be drained away from Brazil, and the rate fall to twelve pence, a substantial gain would accrue to the producer, for he would receive a greater number of milveis for every pound of rubber delivered. Where daily wages are the rule the amount paid in currency fluctuates very slightly, even when substantial variation in exchange takes place. Hence it is that when the currency depreciates and the national credit is adversely affected the situation becomes distinctly more favourable for all industrial undertakings where the value of the production is regulated by the prices ruling in foreign markets. However incongruous the statement may appear to be, there is no doubt that national bankruptcy might infer an immediate revival of prosperity for the rubber industry in the Amazon Valley, and prove to be a temporary solution of the present crisis. 


\section{CHAPTER III}

\section{THE PRINCIPAL RUBBER DISTRICTS}

General definition of the Amazon industry-Collection of castilloa-Rubber-producing area divided into three sectionsThe Lower Amazon-Highlands of the Lower Amazon-The central districts-Rivers Madeira, Purús, and Juruá-Population on the River Madeira-Rubber-planting on the Madeira, Purús, and Juruá-Western section of the Amazon Valley-Bolivian rubber districts-Buildings on rubber properties-Access difficult to upper rivers-Expeditions from Peru-Acre territory-Iquitos.

$7 \mathrm{HE}$ characteristic features of the Amazon Valley the different sections of the country, and some explanation is necessary to emphasize the salient points in the principal districts. As a general rule the industry is understood to consist of the collection of rubber from trees scattered throughout the forests, as opposed to the systematic plan of cultivation in plantations prevailing throughout the Orient. Broadly speaking this popular idea of the Amazon Valley situation is correct, although it is qualified to some extent by the fact that some hundreds of thousands of rubber-trees have been planted from time to time in various localities. An erroneous impression, however, has been conceived in many quarters, that because the rubber is obtained from forest-grown trees it necessitates the annual despatch of numbers of expeditions to the interior regions for the purpose of collecting the product. In former years 


\section{THE PRINCIPAL RUBBER DISTRICTS}

such expeditions were sent from the Pacific slope for that purpose; but that system has long disappeared, and to-day practically all the rubber is obtained by the employés of permanent establishments working regularly within the circumscribed areas of their respective concessions. The only variation from this rule is in the case of certain districts where small gangs of men obtain permission to collect caucho or castilloa, and even when this occurs stringent conditions are exacted as to the terms under which the work shall be done, and the subsequent delivery of the product to the owners of the property exploited.

For descriptive purposes, the rubber-producing districts of the Amazon Valley may be divided into three sections, and in each of these the methods employed differ in many practices. The first section comprises the delta of the Amazon, the numerous islands situated in the river, and the tributaries discharging into the main stream for a distance of some 500 miles from its junction with the Atlantic; the second area is the territory stretching eastwards from the vicinity of Santarem, and including the neighbourhood of Manáos, the Madeira, the lower portions of the Rivers Purús and Juruá, a part of the Rio Negro, and many other waterways; the third section takes in the rubber districts of Bolivia, the upper rivers, and the country included within the boundaries of Peru, Ecuador, and as far north as Colombia.

On the islands in the Amazon delta the land is lowlying and subject to the effect of ocean tides. At highwater the ground is inundated over a very large proportion of the area where rubber-trees are found within 
fairly close proximity to the foreshore. This condition applies also to the riparian lands of many of the tributaries, and to large sections of the main river, the tidal influence being felt as far inland as Santarem, a distance of some 530 miles from the seaboard. The number of trees in these very low-lying districts is abundant, but they have neither the development nor the healthy appearance of those found in drier localities, and they are nearly all of the white variety of Hevea Brasiliensis, yielding rubber classed as weak (fraca) in the Manáos and Pará markets. In this section of the Amazon Valley, the population generally, and the rubber collectors especially, live for the most part in a state of the utmost poverty. They dwell in temporary wooden or reed huts built on piles to raise them above the tidal level, and they exist on fish caught in the river, together with the absolute necessities of life purchased with the proceeds of the rubber they take to the nearest store for sale. Year after year this desolate and wretched existence is dragged out, with small profit to the people individually and no substantial benefit whatever to the community as a whole.

On the higher lands of these districts of the Lower Amazon some attempts have been made to establish plantations of rubber-trees, but seldom with any satisfactory results. In many cases the young plants have been set out in clearings opened for growing crops of mandioca, maize, and other foodstuffs, but it is rarely that any effort is made to keep the young trees free from undergrowth and weeds, and where they survive at all they are stunted and of such slow development as to be of little value. Occasionally the forest is cleaned 

of scrub, and rubber seedlings planted under the thick shade of the bigger trees; but the growth is abnormally backward owing to lack of air and light, and the development in twenty years under such conditions no more than equals that attained in one quarter of the time by systematic cultivation on plantations in Ceylon or Malaya.

The rubber-trees in this section of the Amazon Valley are worked on the estrada system, but in much more irregular fashion than prevails elsewhere in Brazil. Where the land is comparatively dry, paths are cut through the jungle from tree to tree to enable the collectors to carry out tapping operations and gather the latex; but it happens frequently that in districts subject to tidal influence passage on foot is impossible, and recourse to canoes is necessary to enable the daily round to be made. In these circumstances the total number of trees alloted to each estrada is dependent on the existing facilities of access, and it varies according to local conditions-so much so, indeed, is this the case that the term estrada may apply to any number from fifty to two hundred. Practically no supervision over the collectors is attempted in regard to methods of tapping or preparation of the rubber, and consequently the product is of poorer and more uneven quality than that from the other rubber-producing districts in the Amazon territory. This section, comprising the islands of the delta and the lands of the adjacent waterways, has been exploited for a much longer period than the districts of the upper rivers, and the output now shows signs of a steady diminution in the immediate future, although it is provided with a fairly abundant local resident popula- 
lation, and is not dependent on an imported, and therefore costly, labour-supply. The trees have been so badly treated in the past that the yield is seriously affected at the present time.

The second section, from Santarem eastwards for about a thousand miles, and including the Rivers Tapajoz, Madeira, and the lower portions of the Purús and Juruá, is free from any tidal influence. It is only subject to inundation between the middle of March and the end of May, as the result of the annual rains during the wet season and the increased volume of water caused by the melting of the snows in the higher Andine ranges. Throughout this area systematic efforts have been made to organize and regulate the rubber industry on methodical lines as far as the surrounding circumstances permitted, and, faulty as the outcome has been, it is a model of progress compared to the conditions existent in the Lower Amazon territory. The districts of the River Madeira afford the best example of the industrial development that has taken place during the last fifty years.

On the properties situated along the River Madeira, and to a lesser extent on the Purús and Juruá, permanent buildings erected at considerable cost indicate the profitable nature of the rubber industry in the past. These are frequently constructed of stone, brought from long distances at great expense, and roofed with tiles imported from France or Portugal. In many cases where the slightly higher elevation of the land permitted, quite extensive gardens have been laid out, and stocked with flowering plants and fruit-trees obtained from Rio de Janeiro or elsewhere. Since the rubber 
crisis has developed to an acute stage both buildings and gardens have been neglected, the former falling rapidly into a dilapidated state, and the latter becoming choked with undergrowth and rank weeds.

In these districts the rubber-trees are found in the forests at distances varying from 200 to 250 feet apart, and from I30 to I5O trees are allowed to each estrada. Pathways are cleared through the jungle from tree to tree, and these are cleaned up once a year to free them from vines and other quick-growing vegetation. To each collector is allotted one or more estradas, according to his capacity for work, and also with regard to the quality of the trees. Rules are imposed in connection with methods of tapping, but these are more often followed in the breach than in the observance. Nominally the collection of the latex is under the supervision of headmen appointed to safeguard the interests of the owner; but all discipline is slack, and regulations of any kind seldom enforced, except in the case of a very few establishments. Many of the rubber-producing properties in the Madeira districts extend back from the river for several miles, and to these inland stations access is obtained by creeks available for steam-launches or boats when the water is high, or by canoe or road in the dry season. Where roads are cut through the jungle, the brush and logs are cleared to an extent permitting the passage of pack animals, but are not sufficiently open to allow the use of wheeled vehicles of any description. In this section the lands lying a few miles back from the waterways are undulating in character, and for the most part are situated above the flood-level; but all communication 
through them is difficult when the rivers are high, as the ravines and depressions fill with water, and the majority of the pathways and roads become impassable. One rule established for many years past in the districts immediately adjoining the River Madeira, and generally adhered to by the collectors, is that the rubbertrees shall be tapped only for some ro feet from the ground. This condition is not observed elsewhere in the Amazon Valley, overhead tapping to a height of 20 to 30 feet being a common practice in the delta, on the Juruá and Purús, and in the national territories of the Acre.

A small resident population is found in the vicinity of the River Madeira, and a certain proportion of the collectors and labourers employed are drawn from this source; but in all other districts in this section the work of the rubber industry is carried on exclusively by labour imported from Ceará and the adjacent States. Foodstuffs for the maintenance of the labourers are cultivated to some extent in this district, but it is the only example of any systematic effort to raise a supply of the common necessities of life for local consumption to be found throughout these regions until the recent fall in the price of rubber forced property owners to pay some attention to this important factor in the industrial situation. The general conditions on the Madeira have been influenced by the additional traffic caused by the transport of men and material for the construction of the Madeira-Marmoré railway between I907 and I9r3. Ocean steamers frequently made the journey to Porto Velho with cargo for the railroad, and many thousands of labourers of various nationalities were imported for 
carrying out the works. During this period a steady demand existed for many different kinds of produce to provision this large labour force, and high prices were paid for all supplies of fresh food brought to Porto Velho or San Antonio. Under these conditions a limited number of settlers were induced to cultivate. land and raise crops of fruit and vegetables, subsequently planting rubber-trees on the cleared spaces. With the completion of the railway, the demand for fresh provisions has rapidly decreased, and what promised to become a profitable industry has now been abandoned for all practical purposes, and left very little permanent impression behind it.

On the properties adjoining the River Madeira, and to a less extent on those situated on the Purús and Juruá, the planting of a limited number of rubber-trees has been a general practice, extending over a period of some fifteen years past. As a rule the clearings made for growing mandioca and other food products have been utilized for this purpose, but in only very rare cases has any subsequent cultivation been attempted. The initial growth of the young trees has been retarded by rank vegetation, and those that have survived are stunted in appearance owing to all natural development having been checked by thick scrub. Trees of fifteen years of age are no bigger in girth and height than those of six years old found in the average plantation of Ceylon or the Malay Peninsula. These conditions are largely due to the high wages paid to daily labourers, and to the inefficiency of supervision when they are employed. For an approximate estimate of the planting enterprise in this section, it is safe to say that more 
than 2,000,000 young trees have been set out during the past twenty years, and that less than 20 per cent. of these have reached maturity owing to subsequent neglect in regard to cultivation.

The third section of the rubber-producing area of the Amazon Valley includes the Brazilian State of Matto Grosso; the lands adjacent to the Rivers Beni and Madre de Dios in Bolivia; those comprised in the Brazilian national territory extending over the Upper Purús and Juruá, and known as the Acre; the Putamayo and Iquitos districts of Peru; and certain portions of Ecuador and Colombia. It is from this section that the bulk of the best quality of rubber, classified as fine hard Pará, is exported; and it is from this quarter also that the largely increased production of recent years has been obtained. It is these districts, moreover, that have supplied a very great proportion of the caucho (castilloa) that has been such a prominent feature in the Amazon Valley for several years past and helped so largely towards the development and successful progress of Iquitos and the districts in its vicinity. The quantity of rubber exported from Iquitos is insignificant in comparison to the amount of caucho shipped annually from that port.

In this section the lands immediately adjoining the rivers and creeks are subject to annual inundations similar to those occurring in the central districts; but a short distance away from the waterways the ground, as a general rule, gradually rises to an elevation above the flood-level, and in many cases it attains an altitude of several hundred feet. These conditions of a dry soil are favourable to the development of the black hevea, 


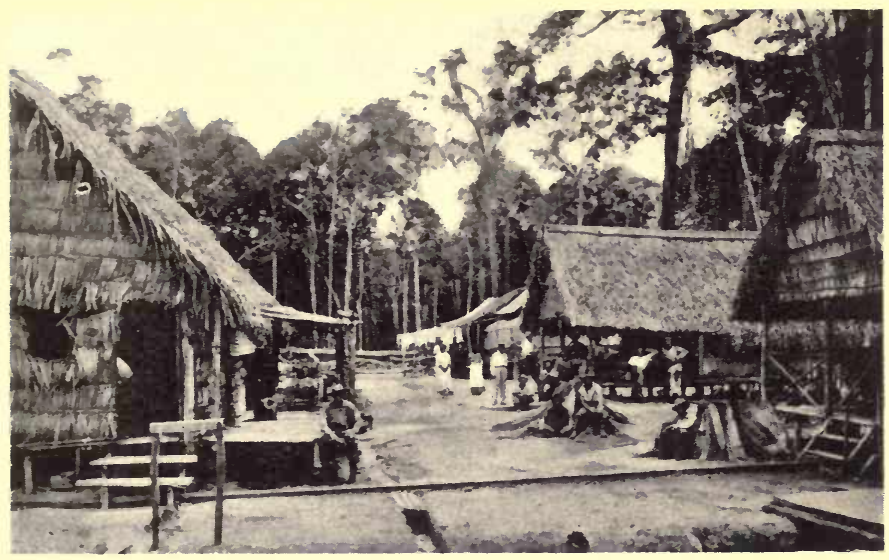

METLU PARANA. MATTU GROSSO, IRAZH.

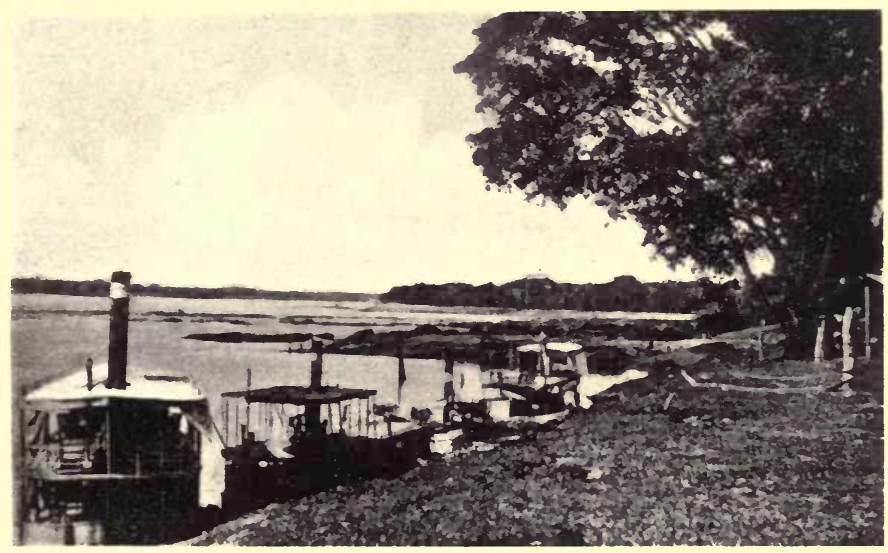

RIO ISENI. CACHLEI.A ESIEKAXZA, BOIIVI.I 



\section{THE PRINCIPAL RUBBER DISTRICTS}

and it is the predominant species of rubber-tree throughout these regions. Castilloa also flourishes at the higher elevations, but the ruthless destruction of the trees during recent years by the caucho collectors is a serious menace to its future profitable exploitation.

In the rubber-producing districts of Bolivia in the neighbourhood of the River Beni and the adjacent waterways, a considerable proportion of the collectors is recruited from the domesticated Indian population who have been settled in this part of the country since the Inca period. Nowhere else, however, in the Amazon Valley is there any regular supply of Indian labourers, all efforts to civilize the various nomad tribes having proved futile in Brazilian and Peruvian territory. In these circumstances the exploitation of the rubber-trees has been carried on almost entirely by imported workmen, and the expense of recruiting these immigrants in Ceara and elsewhere, and transporting them over the 2,000 miles intervening between this section of country and the Atlantic seaboard, has been one of the most formidable obstacles in the way of the expansion of the industry in the past, and promises to be a very serious problem in the future.

With few exceptions, the buildings erected in the third section of the Amazon Valley are of a temporary character, and constructed of timber or reeds, with floors raised on piles above the level of the annual inundations. It is a remarkable fact that, although high and dry land is very frequently available within a few hundred yards from the banks of the rivers, the general custom is to locate the homesteads as close as possible to the water, the only explanation being that this habit saves 
time and trouble in the transport of merchandise and rubber to and from passing vessels. There is, indeed, very little outstanding evidence in this section of the great wealth extracted from these regions during the past decade; and should low prices lead to the abandonment of the properties for a year or two, all proofs of civilization would disappear, and the greater part of the country revert to its pristine state of jungle and impenetrable undergrowth.

Access to the territories comprised in the third section of the Amazon Valley is made difficult by the presence of a rocky ledge which exists for some thousands of miles, outcropping to the east of the River Tocantins, and following the contour of the foot-hills of the Andes in a north-westerly direction for a distance of some 2,500 miles. This ledge is the cause of the cataracts and rapids dividing the upper and lower rivers of the southern and western areas; it passes through the State of Matto Grosso, crossing the Rivers Tocantins, Xingu, and Tapajoz, thence to the vicinity of Porto Velho on the Madeira; it continues to Cachoeira on the Purús and São Felipe on the Juruá; and finally it reaches the Ucayale, to the south-west of Iquitos. The cataracts formed by this outcrop of rocky stratification are a serious impediment to navigation; the fact that in the dry season they restrict all communication except by flat-bottomed vessels of very shallow draught, and that when the river is unusually low even these cannot pass the rapids, adds materially to the difficulties of working on the rubber properties. They increase the cost of transport for both inward and outward freight, and necessitate a heavy capital 


\section{THE PRINCIPAI, RUBBER DISTRICTS}

expenditure for the purchase of large stores of provisions to maintain the labourers for many months, until fresh supplies can be forwarded by merchants at Manáos or Pará, this obligation constituting a serious consideration at the present critical stage of the rubber industry.

In former years the difficulties of reaching this territary from the Atlantic seaboard induced the despatch of large expeditions from the Pacific slopes of Bolivia and Peru for rubber-collecting purposes. It was from this custom the idea arose that the Amazon Valley rubber was obtained by organizing such expeditions to work the great forest areas situated to the east of the Andine ranges. For the past fifteen years these methods have been abandoned as unnecessary and unprofitable, and the only semblance remaining of the practice is the occasional recruiting of gangs of labourers in Bolivia and Peru to work on the rubber-producing properties of the Acre and other similarly-situated districts.

The Acre territory has been the scene of much international intrigue during recent years. It was claimed by Brazil, Bolivia, and Peru, and only after these countries had been brought to the verge of war was the dispute concerning its ownership submitted to arbitration. In the end the greater portion of these districts was awarded to Brazil. While this international question was pending local politics became disturbed, and a movement set afoot by a Colonel Galvez ended by proclaiming the territory an independent republic. This occurred in I903, and for some two years subsequently disturbed conditions prevailed, and it was not until a military expedition was sent from Rio de Janeiro by the Federal Government that order was restored 
and Brazilian authority recognized once more. Since that period the country has been administered as national territory under the authority of Federal officials.

Throughout this eastern section of the Amazon Valley no systematic attempt has been made to create plantations of rubber-trees. Probably this is due to the great abundance of the wild rubber and to the scarcity of labour. The principal development in these districts has taken place in comparatively recent years only, and received its strongest encouragement from the high prices ruling for the raw material from Igog to IgII; and during that period all available men were employed as collectors, to the complete neglect of any form of agricultural enterprise. The result of this condition of affairs was that the wage rate reached an abnormally high figure, and it has not fallen to any extent since the profits of the rubber industry have been reduced to a minimum. It is unlikely now that any serious attention will be paid to the opening up of any plantation industry on a substantial scale in the immediate future, the fear of lower prices due to Eastern competition acting as a strong deterrent to any such innovation. Moreover, the lands comprised in this area are still enormously wealthy in virgin trees available for tapping whenever the financial situation shows any marked improvement, or when different methods permit of a decided reduction in the cost of production.

With the exception of Iquitos, this region contains no centres of any particular political or commercial importance. Such towns as exist are nothing more than distributing posts to supply the necessities of the 


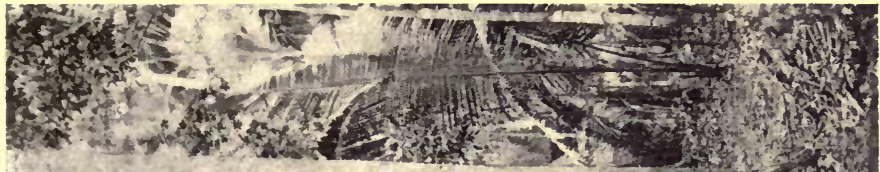

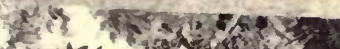

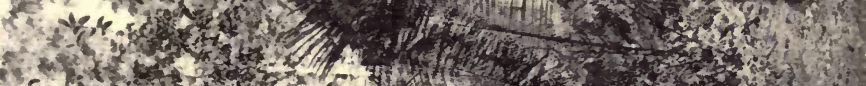

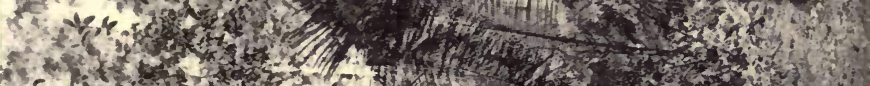

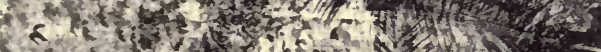

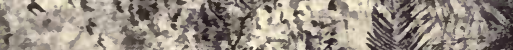

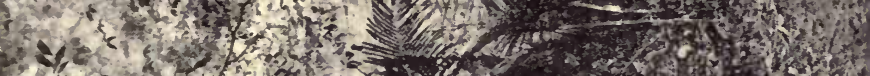

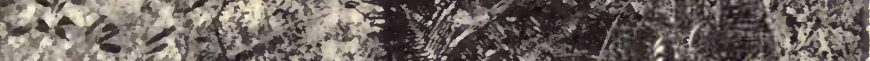

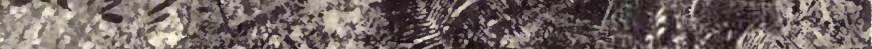

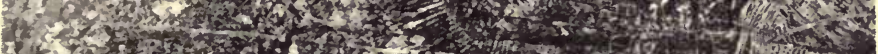

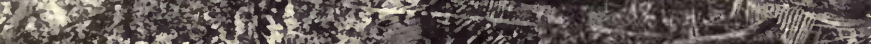

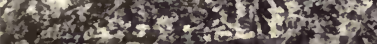

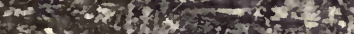

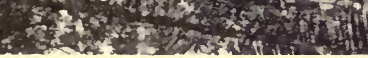

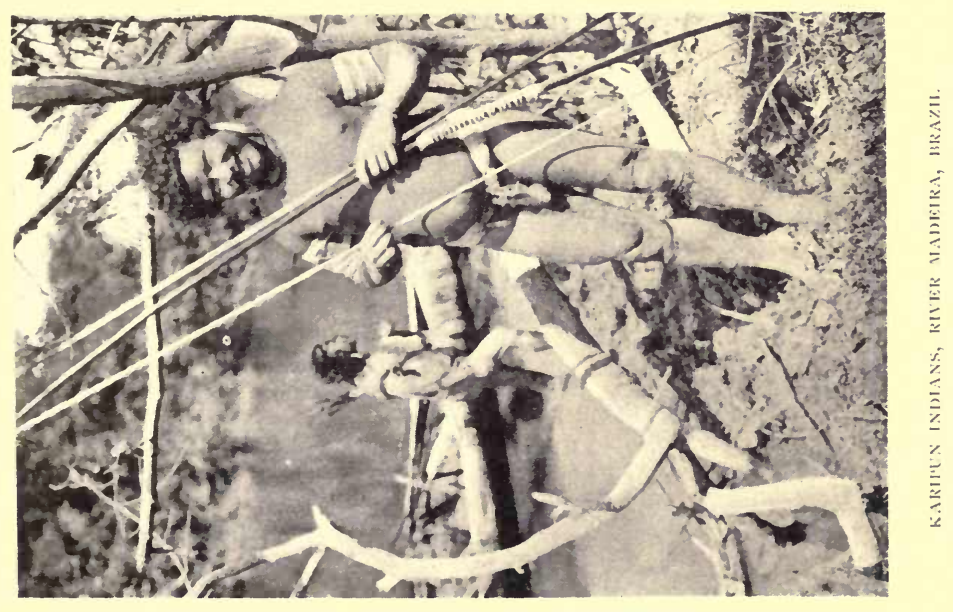





\section{THE PRINCIPAL RUBBER DISTRICTS}

rubber industry, and entirely dependent on that source of wealth for their existence. The population consists for the most part of labourers imported to work on the rubber-producing properties, and they seldom become permanent settlers on the land. There are many tribes of wild Indians in these districts, but they come little in contact with the civilized portion of the community, and retire from the waterways to the interior of the forests as soon as settlements spring up on the banks of the rivers. They show determined hostility in many cases to the advance of civilization, but only attack isolated groups or solitary individuals. 


\section{CHAPTER IV}

\section{DISEASES AND PESTS COMMON TO RUBBER- TREES IN BRAZIL}

Disease little in evidenee-Parasitical growths-Canker-Bark disease-Cambium rot-Experiments in regard to cambium rot in I913-Opinion of Ceylon Government mycologist concerning cambium rot-Why Eastern methods are inapplicable in BrazilCambium rot prevents use of gouge-Decay of latex cells-The borer pest-White ants-The sauba, or red ant.

M ANY of the diseases in connection with the 1 development of Hevea Brasiliensis so familiar to the planter in Ceylon and Malaysia are little in evidence in the Amazon Valley. Doubtless few, if any, are absent, but in the heavy forest they attract no special attention unless carefully searched for with some specific object in view. Of those commonly observed, the most prominent are parasitical growths, canker in various forms, bark disease, and cambium rot. Amongst the injurious insects are the white ant (termes), the red ant, locally known as sauba (Ecodoma cephalotes), and the borer.

Of the parasites, the commonest and most destructive is a growth resembling mistletoe. This pest is found throughout all sections of the Amazon Valley. Its effects are most apparent on old trees, and from these it draws out all vitality, until branch after branch dies away and the tree is killed. It has most tenacious roots, spreads rapidly once it has established a footing, 
and is often propagated from seeds dropped by birds, and lodging in crevices of the bark or in joints where moisture has collected. The injurious character of this parasite is recognized locally, but no effort is made to eradicate it from the trees affected, or in any way check its spread. In every district the annual loss from this plague amounts to many thousands of trees.

Canker is of frequent occurrence on both wild and planted trees. It is found generally at the junction of the main lateral branches with the trunk, where a lodgment of rain-water has taken place. The effect is to rot both branches and stem until the tree becomes exhausted and dies. No attention is paid to it, and the disease is allowed invariably to run its course, although a very little energy at the outset in the direction of pruning away the affected parts would insure a complete recovery.

The most common form of bark disease is a fungoid growth carrying a black powdery substance on the surface. It appears first near the foot of the tree, and gradually spreads up the stem to the main lateral branches. For the most part it is found in low-lying localities, where the soil is a stiff yellow clay. The obvious remedy is adequate drainage and the application of lime; but the circumstances connected with the wild rubber industry render any action of this nature practically impossible, and where it occurs on plantations the cost of labour and the general apathy of the owners prevent any effective attempt being made to grapple with it.

The existence of cambium rot in the Amazon Valley threatens to exercise a most unfavourable influence in 
connection with the future progress of the rubber industry. It is not so much on account of the actual damage caused by this disease at present that it is to be dreaded, but for the fact that recent experiments demonstrate that it breaks out in virulent form when Oriental methods of tapping are attempted. This means that the herring-bone system cannot be employed in order to obtain a greater yield of latex with no additional labour force, and by such means reduce substantially the ultimate cost of production. It will be explained at a later period why this condition is such a very important factor in the prosperity of the industry. The disease occurs on trees tapped with the small axe (machadinho) as well as on those worked with the gouge on the herring-bone system in vogue in the Orient; it is neither so apparent nor so destructive on the former, on account of the fact that the overhanging flap of the axe-cut covers the incision, and because the scrap is not collected from the wound, but allowed to remain and form a protective shield against atmospheric action. Hence, in the case of machadinho tapping the rot remains dormant for all practical purposes, while with the excision of the bark when the herring-bone system is followed no concealment of the disease is possible.

Experiments carried out for some months in Igr3 on trees in the districts adjoining the Rivers Madeira and Purús, and on a smaller scale near Manáos, with the full herring-bone, half herring-bone, and single $\mathbf{V}$ systems, showed that the rot set in on the tapped surface after about one inch of bark had been removed. The tool used for this work was the bent gouge, which 


\section{DISEASES AND PESTS}

in the Orient has given such excellent results, and is preferred by very many planters to the various patent knives placed in the market of recent years. The first sign of the disease is the appearance of the mycelium in the form of a blue mould on the tapped cortex, where the cambium is protected only by a very thin layer of bark, or is entirely exposed by wounds resulting from bad tapping. This mycelium develops rapidly from dark spots on the bast tissues to a stage when its filaments cover the wounded area, and thence extend horizontally and vertically to the remainder of the tapped surface. When the disease becomes firmly established, an exudation of sticky matter of a resinous character frequently takes place on the rotting cortex. In low-lying localities, where the soil is cold and damp, the trees are affected to a greater extent than on higher lands with better natural drainage, but the latter conditions are no guarantee of immunity from the pest. The effect of this disease is not very serious as regards the mortality of the trees, but it is of the utmost importance in so far that it weakens the quality of the latex to a marked degree. Moreover, the labour conditions in the Amazon Valley are of such a nature that the methodical treatment of any outbreak of disease is never sufficiently thorough to insure satisfactory results. The experiments made in IgI 3 proved that in the great majority of cases a healthy bark renewal took place under the diseased cortex after the lapse of a few weeks, but that for several months the proper action of the cambium and latex cells was paralyzed to a very great extent by the injuries sustained. Cambium rot is quite well known in the 
Orient, but is rendered practically harmless by an adequate system of inspection and the application of the necessary remedies. Mr. Petch, the Ceylon Government mycologist, recommends that the affected cortex be painted regularly with a solution of 20 parts of lime, I5 of sulphur, and 50 of water, and he states that the rot is checked immediately if this solution is used when the disease first appears on the tapped portion of the tree.

In the Preangar District of Java this same cambium disease occurs in a form quite as virulent as anything seen in the Amazon Valley, and it frequently appears in the Matale District of Ceylon. It is not regarded as a menace to the future of the industry in Ceylon or Malaysia.

On July 7 last, when lecturing before the Kelani Valley Planters' Association, Mr. Petch made the following remarks in regard to cambium rot, and these apply equally to the Amazon Valley as far as that disease is concerned:

"The second disease I wish to talk about is the decay which often occurs on the tapped cortex. It frequently happens that the thin layer of original cortex which is left overlying the cambium dies in patches. This occurs especially in wet weather, and is more common, apparently, during the north-east than southwest monsoons. The decaying patches usually run vertically, and first appear on the exposed cortex within an inch of the tapping cut. The first thing noticed is the appearance of narrow sunken vertical lines just above the cut. Along these lines the thin residual layer of original cortex is sunken, and if it is 
cut away a narrow black streak will be found extending into the wood. The black line indicates a region of decay.

"What ultimately happens depends to a great extent upon the weather. If it continues wet, the black lines extend upwards and downwards, and at the same time increase in width. If a number of these lines have arisen close together, they may coalesce, and thus a wide horizontal strip of renewing cortex may be destroyed. But more usually a number of parallel vertical wounds are formed. When the dry weather sets in, this decay stops and the wounds begin to heal up. But the renewal is, in any case, rough, and where several wounds have coalesced so much cortex is destroyed that renewal cannot be completed for many years.

"This decay of the tapped surface is often attributed to bad tapping. However, it is as a rule quite easy to distinguish. Wounds due to tapping are seldom vertical; they are more usually horizontal. But there is a better guide than that. When the tapper cuts into the wood, he removes all the cortex overlying the wound, and exposes the wood, which can easily be recognized by its vertical fibres. But when this decay occurs, the thin layer of cortex left after tapping is continuous over the wound. It is usually sunk below the level of the surrounding healthy cortex, but it is unmistakably there. Even when the wounds are six months old and have acquired a swollen margin, the dead layer of cortex may generally be found overlying the wood in the wound.

"This decay occurs both in Ceylon and the F.M.S., 
and in neither country has any explanation of it been found, except that it may be caused by the action of rain-water on the newly-exposed inner layer of the cortex. In Java it is attributed to canker, but there everything is attributed to canker at present. Bacteria and a Nectria have been found in these wounds in Ceylon, but inoculations with both have failed to reproduce the decay.

" Hitherto it has not been considered advisable to stop tapping when this decay appeared. Nor has it been considered necessary to cut out the decayed cortex, because the wounds made by cutting out were in many cases larger than those which would have been caused if it had been untouched.

" A method of treatment, which is said to have given good results, has, however, been adopted in Java, and, as this decay has serious effects as far as regards the renewed bark, it should be adopted here. The Java treatment is as follows :

"As soon as the narrow vertical lines are observed, the tree is put out of tapping. The decaying tapped surface is then washed every four or five days with a 50 per cent. solution of Carbolineum Plantarium. In about four weeks the tree can be tapped again. If a large patch has decayed, the dead cortex is cut out before treating with Carbolineum."

To treat forest trees scattered over a wide area in the manner suggested by Mr. Petch for plantations is impracticable as matters stand in Brazil at present, the principal obstacles being the lack of intelligent supervision and the abnormally high rate of the daily wage earned by labourers in the rubber-producing districts. 
Hence the advantages accruing from a greater yield of latex from the application of Oriental methods of tapping are not possible from a profit-earning point of view, even if further experiments demonstrate that the disease can be controlled provided proper remedies are available.

The scope of the tapping experiments from which the foregoing deductions are drawn extended over the greater portion of the districts adjoining the River Madeira, actual work on some seventy different properties being carried out under the superintendence of competent instructors brought for the purpose from Ceylon and the Malay Peninsula. These different properties were situated at various places between the junction of the Madeira with the Amazon and Porto Velho, and also at two points near the MadeiraMarmoré railway, at distances respectively of 150 and I6o miles eastwards from Porto Velho. Similar operations were conducted on the River Purús, on some thirty properties situated between its junction with the River Solimoes and with the River Pauhiny. Experiments were made also on a smaller scale in localities near Manáos and Obidos, and on the Rivers Tapajoz and Xingu. Practically none of these districts were free from cambium rot in an active or dormant state; it was only after most careful investigation and observation that the decision was reached that the endeavour to introduce any excision system of tapping must be abandoned, in consequence of the difficulty of dealing effectively with this disease. The experiments began in August, 19r2, and were discontinued in November, I9I3, and were conducted at the expense of the various 
interests connected with the Booth Steamship Company and the Port of Pará. It is possible that some sections of the Amazon Valley may be free from this pest; but the area tested included both forest and plantation trees, dry and wet lands, and all classes of soil, and was continued under varying atmospheric conditions. In dry weather the wounds healed and the growth of new bark was rapid; but with the resumption of tapping the disease reappeared immediately a wet period occurred, and this necessitated the suspension of the work.

Another disease of the bark common to rubber-trees in the Amazon Valley is a decay of the latex cells on untapped portions of the stem. The result is a copious exudation of the gum through the outer skin; there it collects moisture, and leads gradually to the putrefaction of the surface bark, thence affecting the cortex, and finally extending to the wood and rotting away the trunk until the tree is killed. The danger from this cause would be minimized if the tree trunks were maintained in a clean condition, but here, again, effective supervision to this end is not available under existing circumstances.

Of the insect pests, the borer is the most destructive to mature forest trees, and no section of the Amazon Valley is free from it. Wherever the wood of the stem has been laid bare it is liable to attack, and this condition occurs to a very large proportion of the rubbertrees, on account of the careless use of the machadinho by the collectors. The borer cuts its way to the centre of the trunk, and in a comparatively short time hollows out the heart of the tree, leaving it without power to resist the force of a strong gust of wind, and with the 
result that it is snapped off a few feet from the ground whenever a gale occurs. In more sheltered positions the tree remains standing, but weakens and gradually dies as the work of the borer progresses. The disastrous effects produced by this pest are quite well understood locally, and attempts are made in some districts to check its devastation by digging out the insect in the early stages of its attack on the stem, and also occasionally by plastering the exposed wood with clay. The borer seldom or never enters the trunk of the tree through live bark, the latex cells providing efficient protection against its depredations. Two species of borer are found in Brazil; they are not unlike in appearance, but differ very much in size.

Another constant source of damage is from the white ant (termes). Every district in the rubber-producing area is infested with this pest, and no effort is made to check its ravages in connection with the wild rubbertrees in the forest or those set out in plantations.

One of the worst enemies to any agriculture development in the Amazon Valley is the red ant (Ecodoma cephalotes), known locally as sauba. This plague attacks the foliage of rubber-trees of all ages, whether in the forest or in planted areas. It strips off the leaves and carries them away, leaving nothing but bare branches, and in the case of young plants, in addition to the foliage, it cuts off the tender growing shoots. In a single night a field of several acres of young beans, maize, or other foodstuffs, is frequently ruined by this pest. The sauba is stated by Bates, in his "Naturalist on the Amazon," to be the most destructive insect in South America, and experience confirms his description 
of its power for evil. It is difficult to destroy, for not only does it excavate immense underground chambers deep down from the surface, but it also travels rapidly and for long distances whenever attracted by any class of vegetation particularly to its liking. The sauba is dreaded by the residents of the Amazon Valley, and efforts are often made to fight against it by digging out or flooding the nests, but such attempts avail little in view of the enormous armies of these ants congregated in every section of the country. If the Amazon Valley should become the centre of a great agricultural development in the future, one of the principal obstacles in the way of successful results will be the constant battle against the ravages of this plague. The means at the disposition of the settlers at the present time are quite inadequate to overcome this evil. For some unexplained reason, the sauba avoids the fertile alluvial deposits on the foreshore available for cultivation when the rivers are low. 


\section{CHAPTER V \\ THE LABOUR-SUPPLY}

No relief suggested by Federal or State Government-Recruiting of labourers-Engagement and transport of labourersRelations between master and man-Housing accommodationAllotment of work-Percentage of labour force employed as collectors-Rates of wages-Supervision of work-Women and children - Discipline on rubber estates - The truck systemMethods of payment-Effects of truck system-Truck system in Bolivia and Peru-Food-supplies.

THE labour-supply is one of the most important Amazon Valley at the present time. No practical solution has been offered by the Federal or State Governments to afford relief to the industry in the direction of a more plentiful provision of hands at a wage rate proportionate to the severe decline in rubber values throughout the markets of Europe and America. The suggestions put forward from time to time for the encouragement of immigration from Portugal, Italy, and Spain, meet with little support, for the climatic and sanitary conditions of the Amazon Valley are not conducive to the employment of full-blooded white men in field and forest. The proposal to introduce Chinese coolies was rejected on the grounds of the initial expense connected with recruiting and transport, a fear that the control of any large number of Orientals would prove to be a difficult matter, and, finally, on account 
of a sentimental feeling that Chinese labourers, by greater industry and thrift, would make the position of Brazilian workmen untenable in the northern States of Brazil. While academic discussion has been busy with this crucial question of an adequate labour-supply, the present acute crisis has overtaken the rubber industry without the adoption of any practical measures to safeguard the individual or national interests involved.

The most prolific recruiting-ground for the laboursupply of the Amazon Valley in recent years has been in the States of Ceará, and to a lesser degree Rio Grande do Norte, Parahyba, and Maranhao. Local circumstances in Ceará, where constant droughts led to a shortage of food-supplies, made life difficult for the agricultural population, and a large proportion of the able-bodied men were attracted by the high rate of earnings prevalent in the rubber districts. A small percentage of these immigrants brought their families with them, although as a general rule their intention was to work for a season, and then return to their homes. So long as rubber prices remained high this annual migration was a common practice, but since the fall in values began, two years ago, the custom has been abandoned to a large extent, in consequence of the reduced profits and the expense of transportation by river and sea. These immigrants from Ceará and the other northern States are descendants of Portuguese settlers, negroes, mulattoes, and half-caste Indians. They live in a poverty-stricken condition in their own country, gaining only a bare pittance whether they work small farms for their own account or hire them. selves out for a daily wage. During the last two years, however, the situation in Ceará has undergone a decided 
change, and the construction of railways, irrigation reservoirs and canals, and other public works, has created a certain local demand for labour, and raised serious obstacles in the way of obtaining recruits freely for the rubber industry.*

To insure a supply of labourers, it is customary for the owners of large properties to send agents to Ceará to engage the men required, and for the less important employers to pay a commission to a resident agent to contract for the number needed. In both cases substantial advances are exacted by the labourers on the pretence of providing for their families during their absence, or to pay off outstanding indebtedness before their departure. After enlistment the men are embarked on board an ocean steamer for transport to Pará or Manáos; they are carried as third-class passengers at the expense of the employer. On arrival at Pará or Manáos the immigrants are landed, and lodged and fed by the employers until transport on a river steamer is available to carry them to their final destination; on these river boats they are given deck passages. The journey from the date of embarkation at Ceará to the time of landing at a property situated on the Upper Purús or Juruá frequently occupies from four to five weeks, and the aggregate average out-of-pocket expenses for passages, advances, and maintenance, is never less than $£ 20$ per head. All this expenditure is recoverable from the labourer, with the result that he begins work with a heavy indebtedness to his employer. For the employer the position is equally unsatisfactory; for he has very little real hold over the men, and practically

* Quite recently revolutionary outbreaks in Ceará have caused the suspension of all public works. 
no punishment can be inflicted on them for desertion. If the employer can ascertain the whereabouts of an absconder, he can take civil process against him for debt, but it is unlikely that he will recover any portion of his claim. These conditions only refer to Brazil; in Bolivia a deserter can be arrested and returned to the estate, and by law must remain and work on the property until the amount of his indebtedness has been discharged.

A certain number of labourers are recruited annually from Pará and the immediate neighbourhood, and a few also from Manáos. Only a small proportion of these belong, strictly speaking, to the permanent resident population, the majority being the flotsam and jetsam from gangs employed on contract work, various trades, deserters from ships, or discharged sailors and others who have drifted to the Amazon Valley from various causes. They comprise Portuguese, Italians, some Spaniards, Brazilians - white, black, and mulattonegroes from the British West Indies, and occasionally coolies from Calcutta who have drifted down from British Guiana. These men are engaged by commission agents, and forwarded to different parts of the rubber-producing districts on the same terms as the immigrants from Ceará and the adjoining States.

From the many thousands of labourers annually brought to the rubber properties, a certain percentage remain permanently on the estates, partly because they find themselves heavily in debt to their employer, and frequently for the lack of funds to pay for a return passage to their homes. As a general rule the men are well treated so far as personal relations between master and man are concerned, and the fact that they are charged 


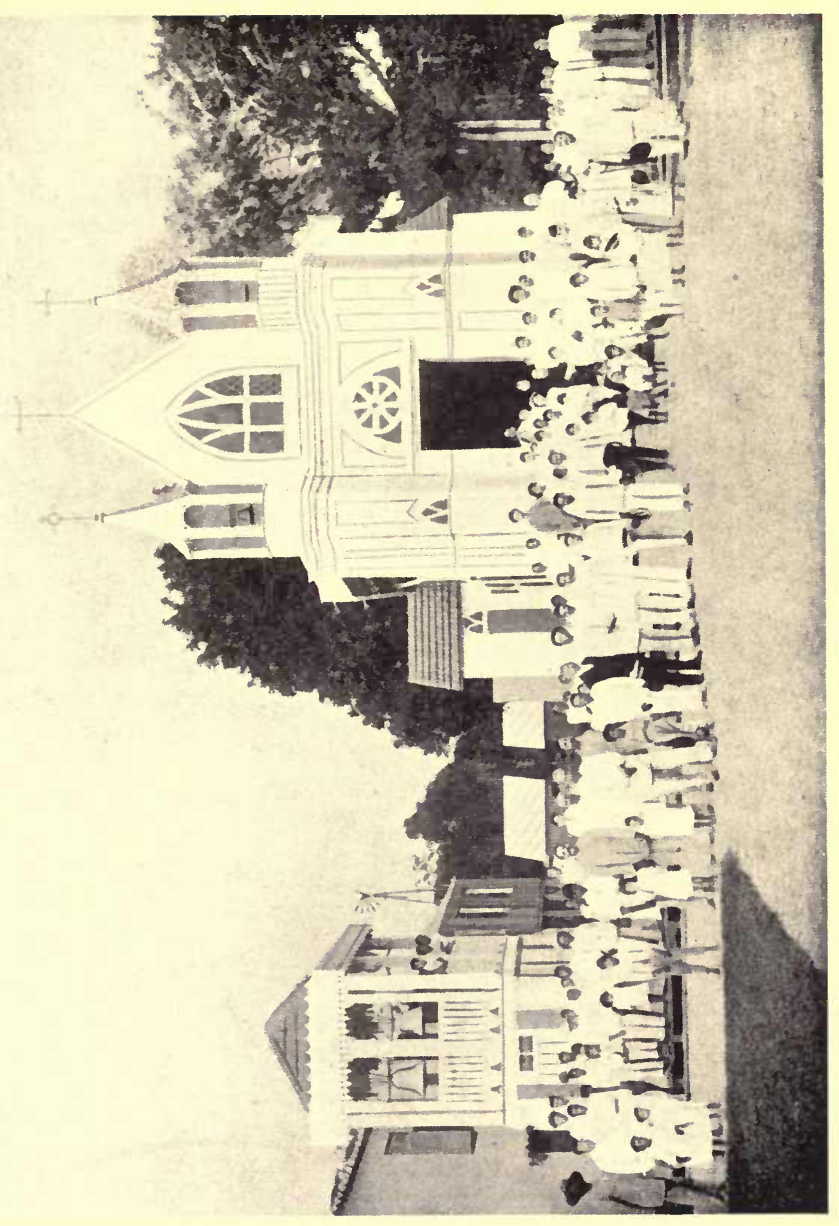

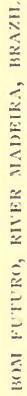



abnormally high prices for the provisions and merchandise they purchase from the estate store carries very little weight with them, provided they are allowed to obtain what they desire without any restriction of credit. The life appeals to them on account of the freedom from restraint and obligation to regular hours of work. So long as a collector delivers a fair weight of rubber during the month, there is practically no interference with his mode of life, and he can, and does, take holidays whenever he is so inclined, without asking the consent of the employer. The present crisis is changing these conditions in many respects; but the old-established habits are hard to suppress, and it will be some time yet before property owners will be in a position to exact regularity of service from the men they employ.

For the most part the housing accommodation for the labourers on the rubber properties, especially those situated on the upper rivers, is of a primitive and temporary character, and consists of huts with walls of reeds, a floor of split palm stems, and the roof thatched with grass or palm leaves. A man may build a hut for himself if he chooses to do so, but no compensation is allowed for the time occupied for this purpose. No attempt is made to enforce hygienic regulations of any description, with the result that the conditions in the vicinity of these dwellings are always offensive. The labourers are not encouraged to cultivate any plots of land in their spare time, the reason being that any foodstuffs produced would mean a proportionate decrease in the quantity of provisions purchased at the store, and a corresponding loss of profit to the owner. 
The allotment of work is made by estradas containing a varying number of rubber-trees. In the Madeira districts the rule is to mark out I30 to I50 trees to each estrada, according to the intervening distances; in the Purús and Juruá districts the number is often 200, and sometimes more. In the former the custom is to set aside one estrada for each collector, and this is supposed to be tapped daily; in the latter two estradas are reserved generally for each man, and these are tapped on alternate days. Once the allotment of estradas is made, the collector becomes a temporary partner with the owners; for he is paid by a percentage of the rubber collected, and this is fixed in most districts at one-half of the amount delivered. The collector prepares the rubber daily, and he brings it fortnightly to the storekeeper to be weighed, with no restrictions as to quantity and very little care as to quality.

Fully 90 per cent. of the labour force employed on the rubber properties is occupied in the collection and preparation of latex, and only some ro per cent. is in receipt of a daily wage. These men are supposed nominally to work for ten hours each day; they are paid at rates varying greatly in different sections of the Amazon Valley. Near Pará a labourer earns from four to five shillings daily without rations, and in the vicinity of Manáos the rate is six to eight shillings without food; in the districts adjoining the River Madeira the average pay is seven shillings per day, or seven pounds sterling per month, with rations. In the neighbourhood of the Madeira-Marmoré Railway men are paid ten shillings a day with rations. In the districts of the 
Purús and Juruá the average daily wage is from ten to twelve shillings with rations. While these rates appear at first sight to be extraordinarily high, the actual value is modified to a very considerable extent by the fact that the truck system is in vogue in connection with all disbursements.

Supervision over the work of the collectors in the estradas and in the preparation of the rubber is delegated to fiscales, or foremen. As a general rule these men perform their duties in a most incompetent and perfunctory manner, and it is the exception to find a man who is willing to make any real effort to protect the interests of his employer, or to attempt to enforce any instructions issued in regard to the careful treatment of trees, or, indeed, any other matters requiring the exercise of authority and influence. These fiscales are paid at rates varying from fifteen to twenty pounds per month, with free maintenance. In charge of the property is a manager, who is sometimes the owner, but more frequently a man receiving his salary in the form of a percentage of the yearly profits. He is responsible for the general conduct of the work and the management of the store and accounts. So long as an average quantity of rubber is delivered each month, these managers pay little attention to any details connected with the collection of the latex, and the condition of the rubber-trees in all districts bears marked evidence of this neglect.

Women and children take no part whatever in the field work of the rubber industry. When a collector is married, his wife cooks his food for him, makes some attempt at keeping the hut in order, and takes care of 
the children. As far as possible, she obtains readymade clothing at the store rather than make her own garments, and in this and in other household matters she is extravagant and thriftless. With very few exceptions, no educational facilities are provided on the rubberproducing properties, and the children of resident families grow up in an absolutely illiterate state.

While the discipline among the labourers is extremely slack, the general conditions in the rubber districts are far more orderly than might be expected in view of the total absence of any police force. Serious crime is of comparatively rare occurrence. Murders and other acts of violence take place occasionally, but only at long intervals. This is the more remarkable in face of the fact that a rifle and ammunition is part of the equipment of every collector. Petty theft is a frequent practice, and larceny in regard to rubber is not uncommon. This latter offence is due principally to the instigation of Syrian pedlars, who ply their trade in boats and launches on all the waterways. They are known locally as regatones, and they carry an assortment of cheap merchandise and strong drinks, and with these inducements tempt the seringueiro (collector) to dispose of rubber far below its market value. These Syrians meet with short shrift when their dealings are discovered by the owners or managers, and their disappearance leads to no very searching investigation on the part of the local authorities. Whenever disturbances do occur on the estates, the onus of restoring order rests with the management; for there is no organized civil or military body to appeal to when trouble arises, and refractory members of the labour force necessitate 
the application of strong measures to reduce them to obedience. Taking all the circumstances into consideration, the general standard of orderliness is better than the isolated situation of the principal districts and the mixed character of the population really warrants.

The truck system is firmly established throughout the Amazon Valley as the basis of all money dealings with the labourers employed in the rubber-producing districts. That it is thoroughly vicious in principle does not admit of discussion, and not a single sound argument can be advanced to support its past or present practice. It is nothing less than legalized robbery, and is one of the most potent causes of the existing crisis in the rubber industry. The abnormally high wage rate is due chiefly to the iniquitous conditions resulting from it, and its influence extends to every branch of commerce and trade in this section of Brazil. The outcome is seen in the high cost of transport, the excessive prices of commodities, the restriction of enterprise in all directions, and the poverty-stricken surroundings of the majority of the inhabitants. The heavy duties on imported merchandise undoubtedly add very largely to the cost of living, but the prevalence of the truck system is more to blame for the difficult situation of to-day than any of the taxation imposed on foreign supplies by the Federal Government.

A glance at a few of the main facts connected with this baneful system demonstrates the depth to which it permeates the present situation. The merchants sell to the aviadores (purveyors of goods to the rubberproducing community) at a large profit; the aviadores furnish supplies to the rubber districts at charges 
allowing a very large margin of gain; the owner of a rubber estate retails these articles to the seringueiro (collector) at prices equal to anything from 50 to 200 per cent. above cost. As a result, the unfortunate consumer pays from 300 to 400 per cent. above the value of the goods when first landed at Manáos or Pará. The excuse for so much profit-snatching is that credit is long, freights high, and payments uncertain. To a limited extent these statements are true; but the reason at the bottom of them is that under existing circumstances a chain of indebtedness is a necessary adjunct to the methods employed throughout the rubber districts, for without it the truck system, and the opportunity it offers for illegitimate gain, would very soon become a thing of the past. The rubber industry of the Amazon Valley can never be conducted on a sound commercial basis until this evil factor is eliminated.

The mode of payment to labourers on the rubber properties is for the manager to credit their accounts at the estate store with the amount of wages earned or the value of the rubber delivered. In the latter case the general practice is to allow the collector one-half the total price for which the rubber is sold at Manáos or Pará, after making liberal deductions for loss of weight and incidental expenses. Against the value of the rubber the collector buys the goods actually required for his personal use, and, in addition, any other articles which may catch his fancy. Brazilians are naturally extravagant, and this characteristic is fostered to the utmost extent by the custom prevailing of late years in the rubber districts to give unlimited credit to the collectors. So long as the value of rubber stood at an abnormally 
high price there was something over for the labourer at the end of the season, in spite of the charges against him at the store; but at the present time, so far from a balance in his favour, there remains only a record of debt. And this situation becomes more hopeless for the men as time passes; for they are not permitted to buy elsewhere than at the store of the property where they work, and hence they have no alternative but to accept the exorbitant prices charged against them, or starve.

The standard of honesty that tolerates the mulcting of the labourer through the truck system reacts on the general commercial situation in hard times, such as have now overtaken the rubber industry. The property owners do not discharge their indebtedness to the aviadores; the aviadores are unable to fulfil their promises to pay the merchants; the merchants fail in their obligations to the manufacturers. Such is the state of affairs that has been reached to-day in the Amazon Valley, and the confusion resulting from these conditions has enmeshed banks, financial institutions, and all varieties of commercial undertakings maintaining business relations with this section of South America. It entails a severe restriction of credit for many years to come.

In Bolivia the truck system is also the paramount feature of all payments to labourers on the rubberproducing properties, and it enjoys State protection in so far that the law of the country does not permit a man to leave the service of his employer unless he can first provide for the discharge of his indebtedness. In dishonest hands this means the condemnation of the labourer to a condition not far removed from what can 
only be described as "virtual slavery." Of course, the fact must not be forgotten that these conditions are relics of feudal habits established many years ago, when the country was beyond the scope of civilizing influences, and when drastic measures were necessary to hold in check the somewhat turbulent semi-Indian population. That they continue in force to-day cannot be ignored in any consideration of the territories comprised within the area of the Amazon Valley.

In Peru a similar state of affairs prevails to that pertaining to Bolivia, and it leads to abuses in many directions. It is a matter for regret that more satisfactory arrangements cannot be enacted to regulate the relations between master and servant; but in a country of such sparse population, and extending over so vast an area, the solution of the problem is beset with diffculties, and much time must elapse before it can be grappled with successfully. Until the spread of education lifts the people out of their present barbaric surroundings, there is small reason to hope that any marked change for the better will become an accomplished fact, or that the existing chains of bondage will be relaxed.

The question of food-supplies for the labourers in the rubber districts is one of the greatest importance in connection with the future development of the industry. The principal commodities absolutely necessary to sustain life on a fairly healthy basis are beans, xarque (dried meat), coffee, farinha (mandioca), maize, lard, salt, sugar, and tobacco. At present the great majority of these products are imported from other sections of Brazil or from the River Plate. The foreshore of the 
waterways in the Amazon Valley during the months when the rivers are low contain an ample area of agricultural land of the finest quality available for the cultivation of beans, farinha, and maize, the staple articles of consumption. Tobacco does well on these alluvial soils, and yields exceptionally heavy crops. While the conditions are not ideal for raising cattle, and the climate does not permit of the preparation of dried meat (xarque), a sufficient number of animals could be bred to provide the necessary rations of fresh meat. Fish can be obtained from the rivers at most seasons of the year. If adequate attention was devoted to these natural resources, the cost of living could be diminished to a substantial extent, and this would help materially to prepare the way for a lower wage rate. To approach this question in a practical spirit and establish local production throughout the Amazon Valley, it is necessary to insist that every labourer should cultivate a patch of ground large enough to supply his own needs. This entails trenching severely on the truck system, and therefore it will be the cause of a great deal of opposition on the part of owners and managers of properties; but unless some such measures are enforced the future existence of the rubber industry will be seriously affected, and it may even reach the point of being threatened with almost complete extinction in many districts. 


\section{CHAPTER VI \\ TAPPING}

Tapping season-Tapping tools-Experiments with the gouge -Collectors supply all necessary implements-Hours for tapping -Overhead tapping-Indian system on the Tapajoz-Pricking the latex cells-Tapping castilloa-Girth of trees-Bark renewal - Lack of cleanliness-Conditions of life for the collectors.

THE tapping season throughout the Amazon Valley 1 extends from the beginning of June to the end of January. In the latter month the prevalence of the heavy rainfall prevents a continuance of production, owing to the cups filling with rain-water and spoiling the latex for the purpose of coagulation. In March the annual inundation of the riparian lands commences, and until the latter part of May the flooded condition of the country makes all work impossible in the forests.

The only tapping tool in general use is the machadinho (small axe). It is in the shape of a tomahawk, and is made in two sizes-the larger sort 4 inches long by 2 inches wide at the edge, and the smaller 3 inches by I inch. It is made of iron, in deference to the widespread superstition that the use of steel is detrimental to the quality of the latex, and eventually causes the death of the tree. These axes are fitted with handles varying from 3 to 4 feet in length, and head and handle together weigh 2 pounds and I pound for the large and small size respectively. Many attempts have been made to invent a patent tapping instrument so 
graduated as to prevent damage to the cambium, but hitherto nothing of a practical description has been evolved.

Experiments with the curved gouge, similar to that used so successfully in the Orient, have not given satisfactory results. The two principal reasons why this is the case are that the trunks of the trees have been so much injured by the machadinho in past years that any form of excision tapping is necessarily slow over the rough renewed bark, and consequently a collector taps only half the number of trees; and because the excision of the cortex renders the tree liable to attacks of cambium disease, resulting in a weakening of the latex. Another and serious drawback to gouge tapping is that constant and competent supervision is required to obtain the full benefits of the system, and this factor is unattainable under present circumstances in the Amazon Valley. Even on planted and also virgin forest trees the use of the gouge is impracticable if it leads to damage from cambium rot, as was the case in the experiments tried in I9I2 and I9I3; and the fact that a greater yield of latex per tree can be obtained by the application of the herring-bone system is insufficient compensation if this additional quantity is of distinctly inferior quality.

The established custom is for the collectors to supply the machadinhos, latex cups and cans, and all other implements required for their work. The charge made for the small machadinho heads in general use is two shillings and eightpence each, at least four times the proper retail value. A proportionately extortionate rate is made for all other articles the collector may require. 
The collector begins work in the early morning, generally about an hour before daybreak. He carries a lantern to enable him to make his way along the estrada allotted to him, and he taps each rubber-tree with an upward stroke of his machadinho, inflicting a wound in the form of an inverted triangle, some 2 inches wide at the base, and almost invariably penetrating to the wood. The number of cuts made depends on the girth and general condition of the tree, sometimes amounting to as many as eight, and in other cases to only three or four. At the apex of each cut a cup is pushed into the bark, to receive the latex dripping from the wounded cells. This process is repeated from tree to tree until the end of the estrada is reached, an average distance of from three to four miles, and containing from I30 to I 50 trees in the Madeira districts and in those of the lower rivers, and as many as 200 trees in the vicinity of the Purús, Juruá, and other sections of the upper waterways. As a rule the collector completes the tapping before 9 a.m., and he then retraces his steps, to gather the latex from the receiving cups and bring it to the smoking-hut for coagulation. He also collects any lumps of rubber formed in the cups, but none of the bark scrap that is such an important item in the returns of Oriental plan. tations. There are two reasons for leaving this bark scrap untouched. The first is that the amount is practically insignificant, owing to the method of tapping, and the value low in comparison with other grades of rubber; and, secondly, this scrap left in the wound forms a protective shield for the cambium and cortex against atmospheric influences, and attacks by borer or other insect plagues. Indeed, it is not too much to say 

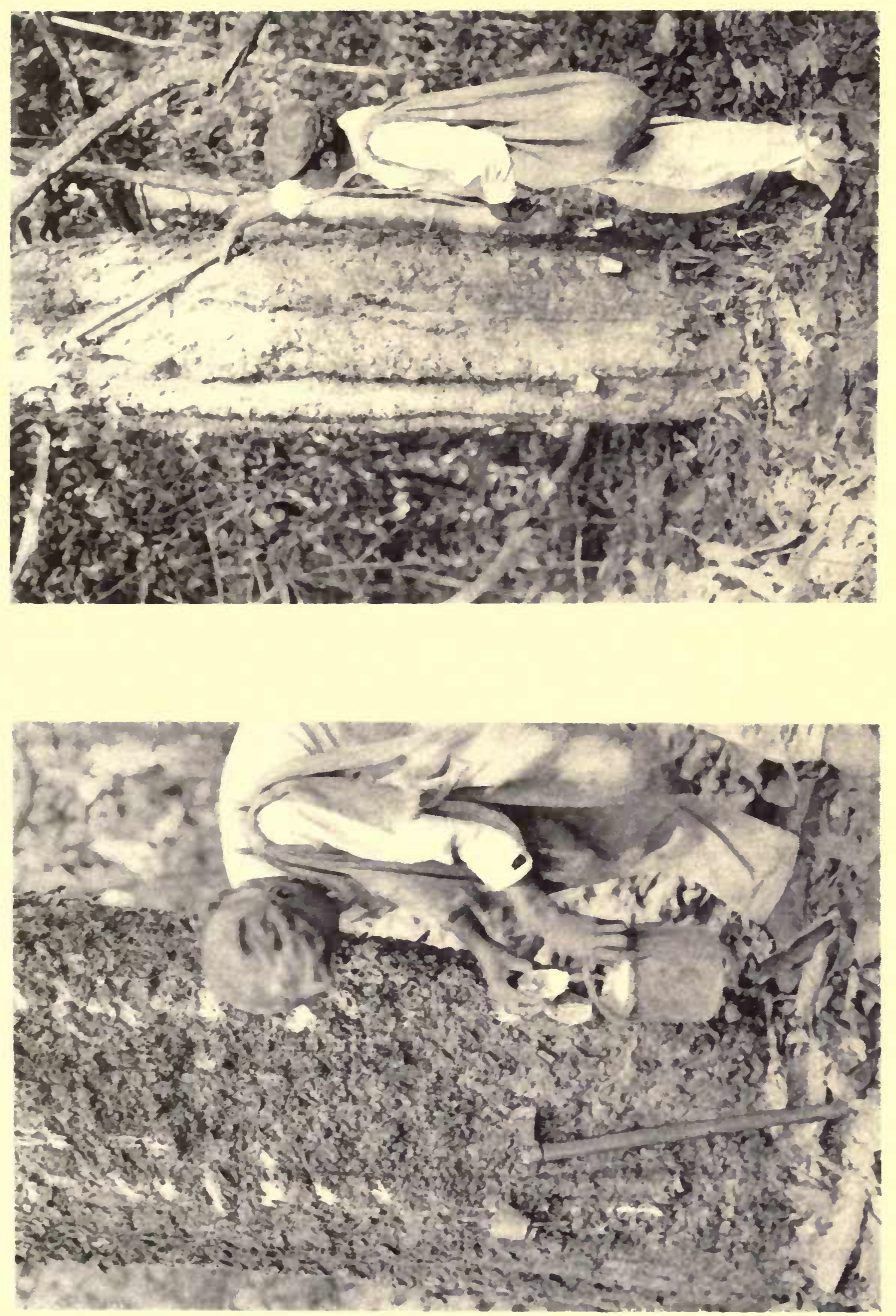


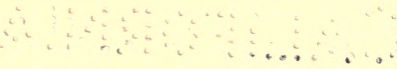


that this residue of latex left in the cut is the salvation of the industry, when the serious injury inflicted on the trees from the constant use of the axe is taken into consideration.

Experiments carried out in 1913 , using a bent gouge instead of the machadinho, showed that a collector could only tap from sixty to seventy trees with two or three cuts regularly each day, or one-half the number possible with the machadinho. It is true that as long as the trees remained healthy and free from bark disease the yield from the herring-bone system was double that obtained by the axe, but in many cases the quality of the latex became thin and the percentage of dry rubber diminished. The natural and probably correct deduction drawn from these results was that the trees were unable to sustain the additional drain upon their resources caused by the greater number of latex cells opened in the length of surface exposed by the gouge, as compared to the triangular incision made by the machadinho.

Overhead tapping - that is, above the reach of a man standing on the ground-is practically prohibited in the Madeira districts, and entirely so in the section of the State of Matto Grosso traversed by the MadeiraMarmoré Railway. However, it is common practice in the vicinity of the Lower Amazon and its tributaries, on the Purús and Juruá, and in the districts of the upper rivers and their affluents. In many cases, especially on the islands of the delta, the tapping is carried up to a height of 40 feet from the base of the tree. To enable the collector to use his axe and gather the latex, rough platforms are constructed of saplings, a notched 
trunk being placed against the tree to give access to the staging. Experience proves that overhead tapping is no more injurious to the rubber-tree than when the latex is drawn from the lower levels; but the yield is not so abundant, and the first cost of erecting the platform, and the loss of time and the danger to life and limb when ascending and descending the primitive appliance doing duty for a ladder, are factors that must be duly taken into account as affecting a final cost of production. It often happens that the lower portions of the stems are so badly scarred by ill usage with the machadinho that tapping is impossible, and then the trees must be abandoned unless the work is continued overhead; in such cases it is absurd to allow old superstitions regarding possible injurious effects to stand in the way of a harvest being obtained by utilizing this method.

A system of tapping in vogue among the Indians many years ago is still practised to a small extent, especially near the River Tapajoz. Split canes about $I_{2} \frac{1}{2}$ inches wide are twisted round the lower part of the tree, and the interstices between the trunk and the cane filled with clay, thus forming a channel round the stem. Above this channel incisions are made with the machadinho, the latex flowing from these cuts to the cane trough, and thence to a tin cup placed at the foot of the tree. This method is interesting as a relic of ancient usage, but in itself has no particular advantages to recommend it as superior to the customary process employed; it has, however, a very important bearing in regard to the application of another form of tapping attempted in Ceylon and Java, and, although not so 
satisfactory as the system of bark incision with a gouge or similar tools, may prove to be the solution of the problem in the Amazon Valley, by procuring a marked increase of latex without additional labour or the exposure of the tree to any danger of damage from cambium disease or borer.

A few years ago in Ceylon a suggestion was put forward by Mr. Northway to establish a system of tapping the latex cells by the use of incision instead of excision methods. The idea was to prick the cells in place of paring away the cortex with a gouge or other species of tapping knife. For this purpose a manypointed rotary disc some 2 inches in dianeter was invented, and this was attached to a handle about 9 inches in length. A shallow cut with a gouge was made in the outer bark to provide a channel leading to the receiving cup ; this cut was reopened daily, and the pricker was run over the exposed cortex with sufficient force to penetrate the latex cells, causing the milk to exude freely and flow down the channel to the receiver at the base of the tree. The objections raised to this system by the Ceylon planters were that it was slow in comparison with gouge work done by expert tappers, that the yield per tree was no greater, and the number of trees tapped daily by each coolie was considerably less than with the existing methods, and that under efficient supervision the prevailing system of bark excision inflicted no practical damage on the trees and admitted of a satisfactory renewal within a reasonable period of time. In these circumstances the ideas of $\mathrm{Mr}$. Northway made little progress in Ceylon or the Malay Peninsula; but they have been applied successfully on his own estate, 
and also practised with quite good effects on several properties in the Malang district of Java.

There is no reason why the Northway system, in conjunction with the principle of the exterior latex channel, both modified to fit the varying local conditions, should not be applied with marked success throughout the rubber districts of the Amazon Valley. In any event the experiment is worth a trial, for it offers a better prospect of a solution of the present difficulties than any practical suggestion hitherto put forward to counteract the crisis precipitated by the rapid fall in the value of the raw material. The exterior latex troughs can be affixed to the trees at a trifling cost of money and labour if made of tin or zinc and supplied in quantities sufficient to meet the requirements of the industry; no excision of bark is necessary, as was the practice in Ceylon, for the exterior channel takes the place of the one formerly cut in the stem of the tree; the injury to the bark surface consequent upon the long previous use of the machadinho will not prevent the free application of the pricker; the collector will be able to tap more trees per day under this system than he does at present with an axe; a minimum of damage will be done in the future to trees handled in this way; and, finally, the yield per tree will be increased by a very appreciable amount, if the results obtained in Ceylon and Java are any criterion for drawing a rational deduction in regard to the application of this method to both forest-grown and planted trees in the Amazon Valley. The experiment of testing this system at different points in the rubber districts can be effected without any heavy expenditure, for all that is necessary 
is strict observance of definite instructions in regard to the use of the pricker, and accurate returns of the labour employed and the yield obtained from the various classes of trees. The experiment may need the attention of one man with practical experience of the Northway method for a time, but a period of six months should be ample to prove the success or failure of the system so far as it applies to existing conditions in Brazil.

The only really serious difficulties in the way of the widespread adoption of the extraction of the latex by means of pricking instead of cutting the cells with the machadinho or gouge are the thickness and irregularity in the bark of forest-grown trees, and in connection with the high density of the milk causing coagulation in the channels before reaching the receiving cups. There is small doubt that these obstacles can be overcome successfully by careful attention to, and intelligent appreciation of, the general circumstances, and to the local conditions in regard to common-sense modifications in the construction of the pricker and the application of the latex troughs to the stems of the rubber-trees.

The collection of rubber from castilloa trees is carried out on quite different principles from the custom established in connection with the Hevea, and it is conducted in the following manner: Gangs of men, varying in numbers from half a dozen to twenty or thirty, travel through the forests where the castilloa is known to be fairly abundant, and tap each group of trees as they are discovered. The trunks are slashed to a height of from 6 to 8 feet from the base, and the latex allowed to flow into cavities hollowed out near the foot of the 
tree. This process of hacking the stem bark is continued for some ten days, or until the milk ceases to run. Then the tree is felled, and the bark of the upper portion of the trunk and branches is subjected to a further slashing to open the remaining latex cells. After a lapse of some thirty hours the exudation of milk stops, the tree is abandoned, and the gang passes on to the next group, and so the process is repeated. The rubber is wound into balls, or the lumps are packed into bales of from 60 to 70 pounds weight, and from time to time these are conveyed to some convenient central locality to await the end of the tapping season, or for shipment as opportunity offers. Many of these caucho-gathering gangs work under agreements to sell their harvest to the owners of the forest tracts where they carry on their operations; others are quite independent, and confine their enterprise to the national territories, and then dispose of the rubber to the nearest dealers.

The destructive methods employed for the extraction of castilloa latex are only tolerated on account of the scanty yield obtained by other systems of tapping, and for the fact that the industry cannot be continued on a profitable basis unless a comparatively large quantity can be gathered, to enable these gangs of men to earn an adequate return for their labour. In view of the fact that nearly one-quarter of the total rubber exports of the Amazon Valley consist of caucho, it is evident that the exhaustion of the sources of supply cannot be far distant, unless the low prices now prevailing for this product act as a restriction on the amount annually collected. 


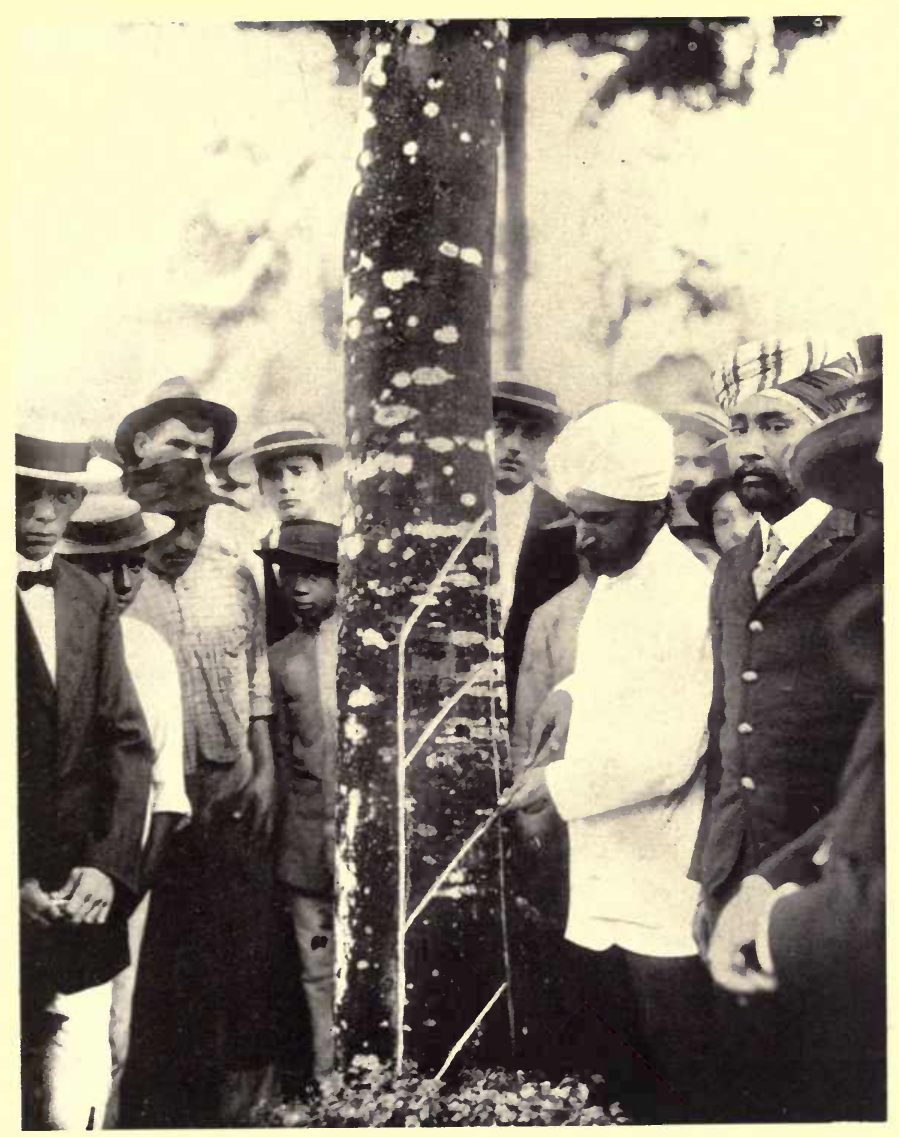

INDIAN COOLIES TAPPING TREES IN THE PIILIC (IARDENS AT PARA 

In Ceylon the tree at Henaratgoda known as No. 2, and planted in 1876 , has a circumference of 137 inches at 3 feet from the ground. It is considered one of the finest in the East, and it is interesting to compare this specimen with trees in Brazil. The girth of forest-grown rubber-trees varies to a marked degree in different localities of the Amazon Valley. For mature trees it ranges from 50 to 200 inches in circumference measured at a height of 3 feet from the base of the trunk. Occasional examples occur of the girth attaining such colossal dimensions as 300 inches. It is safe to consider the average girth of estrada trees in tapping as Ioo inches or thereabouts, and the average height Ioo feet approximately. The age of the trees is extremely difficult to gauge with any degree of accuracy, owing to the absence of all reliable records in this direction. In the Madeira districts and elsewhere many trees are found that have been tapped for sixty years past, therefore they are probably not less than eighty years old; but the growth and development is so far influenced by surrounding conditions of locality, light, air, soil, and exposure, that size cannot be regarded as a criterion of age.

So far as planted trees are concerned, the indications are that the growth in the Amazon Valley is distinctly less rapid than in Malaysia, or even in Ceylon, where the development is much slower than in the Federated Malay States, the Straits Settlements, Java, or Sumatra. Rubber-trees in the gardens of the Museo Goeldi at Pará, carefully cared for during the last fifteen years, are no greater in girth or height than those of seven years old in many of the Malay plantations. In clearings where plants have been set out, they are in even a more 
backward condition, and after twenty years' growth are frequently under 30 inches in girth at 3 feet from the ground. Although slow development is due in part to neglect to keep them clean from the scrub and weeds choking all progress, it does not account for the marked disparity between the rate of growth in Brazil and the Orient, after making ample allowances for lack of cultivation in the former country.

The bark renewal after tapping is exceptionally good in all districts of the Amazon Valley. Even when trees are hacked about unmercifully with the machadinho, the cortex makes the most vigorous effort to repair the damages inflicted by the many careless collectors. On trees of all ages tapped with the gouge in I9I3, and subsequently attacked on the tapped surface by a most virulent form of cambium rot, the renewal of bark was extraordinary; moreover, it was equally strong in the case of forest trees shut out from the free access of air and light, and on those growing close to the river-banks and receiving a full allowance of sunshine. In the Orient, experience shows that deep shade is a deterrent to bark renewal, whereas in the Amazon Valley the evidence available proves that it produces no such effect ; in fact, the idea is deep-rooted in most districts that exposure to the direct rays of the sun causes the latex cells to become barren, and arrests the growth of new bark. It is extremely difficult to reconcile these absolutely reverse conditions of the same tree under atmospheric influences containing practically no difference in the characteristic features of moisture, soil, and temperature, or to attribute them solely to variations resulting from the effects of regular cultivation. 
No attempt is made by the collectors to keep the cups and latex cans in a cleanly state; the former are never washed, and remain in the estradas covered with rust throughout the tapping season, while the latter are not even rinsed out after the latex is brought into the smoking-huts. Naturally, the dirt in cups and cans induces fermentation, and leads to the formation of a larger proportion of lump than would be the case if cleanliness was practised. The profitable character of the industry in past years made the rubber producers careless in regard to the details connected with the collection of the latex, and slovenly habits were permitted without check or hindrance; hence the difficulty of changing established customs now that all possible economy is necessary to meet successfully the competition of Oriental production. A little care in connection with the utensils in use would make a reduction of not less than 5 per cent. in the proportion of lowpriced sernamby (scrap), and add that amount to the output of fine rubber. The managers argue that to enforce rules of cleanliness would entail considerable delay for the collectors when making the rounds of the trees in the estradas, but they forget that the collector would benefit equally with the owner if adequate attention was given to this important matter.

The conditions of life are replete with hardships for the seringueiro (collector) under existing circumstances, and his situation has undergone a marked change for the worse during the last two years. So long as rubber was in the neighbourhood of five shillings a pound the collector made good money in his position of modified partnership with the owner of a rubber-producing prop- 
erty. He prized his independence, and could afford his inclination to make holiday whenever he so desired; moreover, his credit at the store was unlimited for all practical purposes. At present, with more days and longer hours of work, only one-half the money can be earned; this payment is barely sufficient to defray the cost of subsistence during the tapping season, leaving nothing to provide against the necessities of the lean months when the collection of rubber is suspended. Formerly the seringueiro could obtain credit from the end of one working period to the beginning of the next ; but to-day the property owner is unable to afford any such advances, and the slack months must be passed in a state of the utmost poverty, often bordering on a condition of semi-starvation. One of the attractions to the men employed in the rubber districts was the ability to indulge in extravagant purchases of any articles that took their fancy, whereas now, when in full work, their credit is frequently insufficient to meet the cost of the daily rations. In these circumstances it is no matter for surprise that a large proportion of the labourers are drifting back to their homes in Ceará or elsewhere whenever opportunity offers, rather than remain in the Amazon Valley to face the privations and vicissitudes inevitably to be expected in connection with the immediate future of the rubber industry. It is due to this state of affairs that the labour-supply is steadily diminishing, and it is a factor that threatens to bring most serious consequences to an already complicated situation. 


\section{CHAPTER VII}

\section{YIELD AND DENSITY OF LATEX}

Average yield varies in different districts-Yield on the Madeira, Purús, and Juruá-Yield on the upper rivers and in BoliviaExperiments with gouge tapping - Variation in quantity and quality of latex-Tests for density on the Madeira and PurúsFurther tests-Kecords kept at Santa Maria, River MadeiraRecords kept at Sevastopol, River Purús-Exaggerated reports of yields of trees.

THE average yield of rubber-trees in the Amazon Valley varies to a marked extent in different districts, and, in the absence of accurate statistics extending over any lengthy period, the average quantity of latex and amount of dry rubber produced can only be calculated approximately for most sections of the country. In the case of the properties on the Rivers Madeira and Purús more detailed information is available, as a result of a series of experiments and tests conducted under competent supervision in IgI2 and I9I3, in order to ascertain the density, yield and proportion of rubber in comparison with returns obtained in Ceylon and elsewhere in the Orient. These experiments were prompted also by a desire to obtain definite knowledge as to the relative conditions of latex extracted by the use of the machadinho compared to that procured by gouge tapping on the herring-bone system, and for this purpose tests were carried out on both forestgrown and planted trees in districts with many different 
characteristics of soil, elevation above water-level, exposure, and general surroundings.

Throughout the rubber districts of the Lower Amazon and those in the vicinity of the waterways discharging into the delta, the average yield per tree is less than in the other two sections of the Amazon Valley, and a very rough estimate of the number of labourers in comparison with the total output places the weight of dry rubber per tree at slightly under 3 pounds. This is a very small return from fully matured trees; but a great proportion of the trees in these districts have been in tapping for half a century past, and have been so seriously damaged by the careless use of the machadinho that the latex cells cannot respond freely to the demands made upon them. In the neighbourhood of the delta the conditions are worse than on the upper reaches of the Rivers Tapajoz, Xingu, and other tributaries; while the yield in these latter districts probably exceeds the average of 3 pounds per tree, the return on the islands and lower sections of these rivers falls considerably short of that figure.

In the districts of the Madeira, the lower portions of the Purús and Juruá, and the tributaries of these rivers, the annual yield is higher than in the territories mentioned in the last paragraph; and on the same basis of calculation the average return works out approximately at 5 pounds per tree. Local report places the amount at a much higher figure, but is coloured by the quantity obtained from individual free-milking trees scattered through the estradas. The check on exaggerated statements is to take the total output and compare it with 


\section{YIELD AND DENSITY OF LATEX}

the number of collectors employed and the average number of trees allotted to each collector. The shipments from these districts in the season IgI2-I3 amounted to $2 \mathrm{r}, 000,000$ pounds, and to obtain this crop 27,000 tappers were necessary, each working an estrada containing on an average about ${ }_{50}$ trees, for a period of $\mathrm{r} 60$ days extending over seven months, from June to January. Investigations conducted on about Ioo properties revealed the fact that the monthly deliveries of rubber from each collector averaged IIo to II 2 pounds, or 770 pounds, slightly more or less, during the season; this equals a total output of $20,790,000$ pounds from some 4,050,000 trees, or an average yield of $5^{\cdot} \cdot 13$ pounds per tree.

In the third section of the Amazon Valley, comprising the rubber-producing districts of Bolivia, the Acre territories, the Upper Purús and Juruá, the Jutahy, Javary, and other rivers, a higher average yield is obtained. This is due to the fact that the majority of the trees have been worked for a comparatively short period, and also because a large number of virgin trees are brought into tapping annually. In Bolivia the output for the season I9I2-I 3 was $6,700,000$ pounds, and this quantity was produced by 7,500 collectors from $1,100,000$ trees, equivalent to a return of a little less than 6 pounds per tree. In the other districts enumerated the aggregate crop was $25,900,000$ pounds, gathered by 26,000 collectors from $3,770,000$ trees, an average of 6.8 pounds per tree. In these calculations all reference to caucho (castilloa) is omitted, no data of any kind being available at present for working out the average per tree, on account of the methods employed for the collection of 
this class of rubber. Moreover, the number of men comprised in the gangs formed to exploit the caucho industry varies greatly from month to month, and this adds to the difficulty of drawing up any statistics of a reliable character.

Experiments tried in I9I3 with the gouge, working on the herring-bone system for both forest-grown and planted trees, showed that for the first three or four weeks the average yield of latex per tree was double that obtained with the machadinho, but the collector tapped only one-half the number of trees daily. Doubtless this drawback would have been remedied to some extent as the tappers became more expert; but an outbreak of cambium disease occurred soon after the experiments were commenced, and it was of such a virulent nature that the work was abandoned. Another objection to excision methods was that after the first month the quality of the latex weakened even when the trees were free from disease, and the conclusion reached was that the additional milk extracted overtaxed the general functions of the trees. These experiments were carried out over a period of six months in the Madeira and Purús districts to test thoroughly the possibility of increasing the average yield by the introduction of gouge tapping; they were only relinquished in view of the combined effects of cambium disease and the lower quality of latex obtained. The trials were made at some seventy different properties on the Madeira and Purús, and they may be accepted, therefore, as conclusive proof that any system of bark excision is unsuitable for rubber-trees in the Amazon Valley owing to unexplained atmospheric influences. 
The quality and quantity of the latex varies considerably during the tapping season. From the middle of June to the end of July the density is high and the yield abundant; in August and September there is a marked diminution in quantity, and this is attributed locally to the fact that in these two months the trees are wintering, and the rainfall is much less than at any other time of the year; in October the quality falls off, owing to the trees flowering during this month. Towards the end of the tapping season the density is lower than in June and July, showing that the trees feel the effects of the daily extraction of latex. It is interesting to note these facts, as they differ widely from the conditions prevailing in Ceylon and the Malay Peninsula.

A few of the tests made in 19r3 demonstrate clearly the average density of the latex obtained from trees in the districts adjoining the Rivers Madeira and Purús. They also permit some comparison in the quality incidental to the use of the machadinho and the gouge. On the Madeira the tests were made during the first fortnight in September, and the results were-

\begin{tabular}{|c|c|c|c|c|c|}
\hline No. & Name of Property. & District. & $\begin{array}{c}\text { No. of C.C. } \\
\text { taken for } \\
\text { Test. }\end{array}$ & $\begin{array}{l}\text { Tapping Tool } \\
\text { used. }\end{array}$ & $\begin{array}{l}\text { No. of C.C. } \\
\text { to I Pound } \\
\text { of Dry } \\
\text { Rubber. }\end{array}$ \\
\hline I. & Santa Catharina & Madeira & $1, \infty 00$ & Machadinho & $1, \infty 00$ \\
\hline 2. & Santa Maria ... & ", & $1, \infty 00$ & Gouge & I, I 43 \\
\hline 3. & Recreio $\quad$... & $"$ & 950 & " & I,435 \\
\hline 4. & Mirary ... & $"$ & 225 & , & $I, 200$ \\
\hline
\end{tabular}


The latex tested was obtained from trees in regular tapping since the beginning of the season; Nos. I, 2 and 4 from forest-grown trees, and No. 3 from a twelveyear-old plantation.

Another test made was on forest-grown trees in the vicinity of Abuna, on the Madeira-Marmoré Railway, where some experiments in gouge tapping on the herring-bone system had been tried in the previous July. Two sets of trees were tapped for fifteen days, one with the machadinho and the other by the gouge, using the half herring-bone system with two and three cuts, according to the general condition of bark surface and trees. For this work it was necessary to pay wages to each man at the rate of thirteen shillings and fourpence per diem, and it will be seen that such payments entail a severe loss on every pound of rubber harvested. The experiment was commenced on September 29, and concluded on October I5; it furnishes interesting data regarding the relative results obtained by the gouge and the machadinho. On the gougetapped trees indications of cambium disease appeared towards the end of the experiment, and thus confirmed the deduction previously reached, to the effect that any excision system of extracting latex was inapplicable in the Amazon Valley, for the reason that the increased yield did not compensate for the danger from cambium rot and the additional labour force required. The subjoined daily record of the results of this experiment is self-explanatory. An allowance of 20 per cent. for waste should be made to ascertain the dry weight of the lump and scrap in calculating the aggregate amount of marketable rubber : 


\section{MACHADINHO TAPPING}

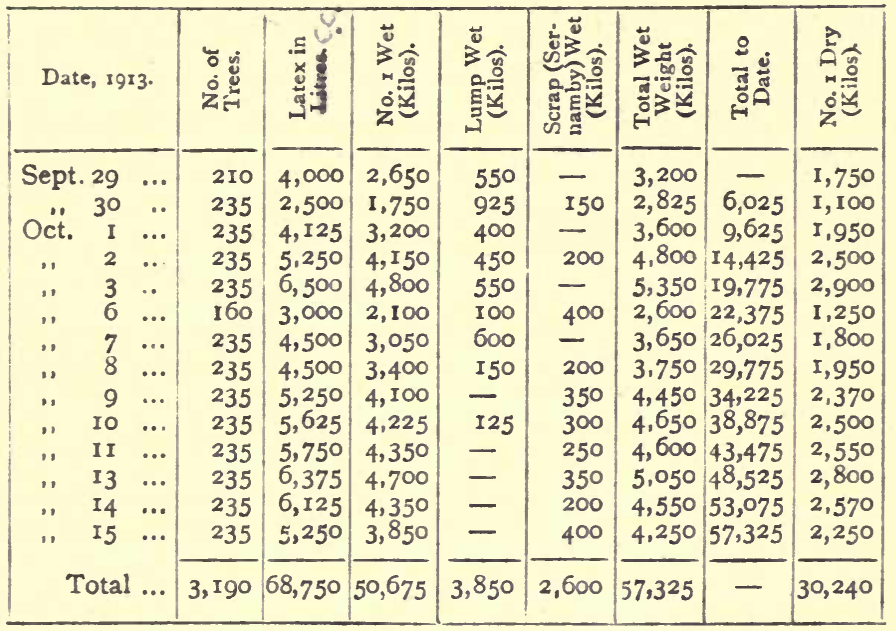

GOUGE TAPPING

\begin{tabular}{|c|c|c|c|c|c|c|c|c|c|c|}
\hline \multicolumn{2}{|c|}{ Sept. 29} & $\ldots$ & 57 & 2,500 & $I, 450$ & 600 & 400 & 2,450 & - & 750 \\
\hline$"$ & 30 & ... & 57 & $1,75^{\circ}$ & I, I 50 & 600 & I50 & 1,900 & 4,350 & 650 \\
\hline Oct. & I & ... & 57 & 2,125 & 1,600 & 400 & 300 & 2,300 & 6,650 & 850 \\
\hline ", & 2 & ... & 57 & 2.750 & 1,900 & 400 & 200 & 2,500 & 9,150 & 1,020 \\
\hline " & 3 & ... & 57 & 2,250 & $1,75^{\circ}$ & 300 & I75 & 2,225 & I I, 375 & 870 \\
\hline$\because$ & 4 & ... & 57 & 2,500 & I, 800 & 250 & 200 & 2,250 & 13,625 & 920 \\
\hline ," & 5 & ... & 57 & 2,125 & 1,550 & 250 & 160 & 1,960 & I 5,585 & 800 \\
\hline , & 6 & ... & 57 & 2,000 & 1,360 & 300 & I 50 & I, 8ro & 17,395 & 670 \\
\hline " & 7 & ... & 57 & 2,500 & 1,700 & 300 & IOO & 2,100 & r9,495 & 820 \\
\hline " & 8 & ... & 57 & 2,375 & 1,400 & 600 & 250 & 2,250 & 21,745 & 700 \\
\hline , & 9 & ... & 57 & 2,250 & $I, 45^{\circ}$ & 250 & 200 & 1,900 & 23,645 & 720 \\
\hline , & IO & ... & 57 & 2,250 & $\mathrm{I}, 500$ & 400 & 200 & 2,100 & 25,745 & 720 \\
\hline , & II & $\ldots$ & 57 & 2,375 & 1,600 & I 50 & I 50 & 1,900 & 27,645 & 800 \\
\hline & 13 & ... & 57 & 2,250 & $I, 250$ & 400 & 300 & 1,950 & 29.595 & 600 \\
\hline & & & 798 & 32,000 & 21,460 & 5,200 & 2,935 & 29,595 & - & Io, 890 \\
\hline
\end{tabular}

From this record it will be seen that the total amount of dry rubber, including lump and scrap after deducting 20 per cent. for loss of weight in drying, was $77^{\circ} 52$ 
pounds from 3,Igo tappings with the machadinho on 235 trees; and 38.27 pounds from 798 tappings with the gouge on 57 trees. This gives $2 \mathrm{I} \cdot 8$ c.c. and $40^{\circ} \mathrm{I}$ c.c. per tree respectively for machadinho and gouge. Briefly summed up, the result of the experiment was-

\begin{tabular}{|c|c|c|c|c|c|c|}
\hline Tool used. & $\begin{array}{c}\text { No. of } \\
\text { Trees } \\
\text { tapped. }\end{array}$ & $\begin{array}{c}\text { No. of } \\
\text { Tappings. }\end{array}$ & $\begin{array}{c}\text { Total } \\
\text { Yield of } \\
\text { Latex. }\end{array}$ & $\begin{array}{c}\text { Quantity } \\
\text { of Latex } \\
\text { per Tree } \\
\text { per } \\
\text { Diem. }\end{array}$ & $\begin{array}{c}\text { Total Dry } \\
\text { Rubber, } \\
\text { including } \\
\text { Lump and } \\
\text { Scrap. }\end{array}$ & $\begin{array}{c}\text { No. of } \\
\text { C.C. to } \\
\text { I Pound } \\
\text { of Dry } \\
\text { Rubber. }\end{array}$ \\
\hline Machadinho & 235 & 3,190 & $\begin{array}{c}\text { C.C. } \\
68,750\end{array}$ & $\begin{array}{c}\text { C.C. } \\
21 \cdot 8\end{array}$ & $\begin{array}{c}\text { Pounds. } \\
77 \cdot 52\end{array}$ & 886 \\
Gouge … & 57 & 798 & 32,000 & $40 \cdot 1$ & $38 \cdot 27$ & 836 \\
\hline
\end{tabular}

Based on these calculations, the yield per tree with machadinho tapping on I80 days in the year would be 4.4 pounds, and for a similar period with the gouge the return would be 8.6 pounds; of these totals, the amount of lump and scrap with the machadinho would be $I 4 \frac{1}{2}$ per cent., while with the gouge the quantity would be equal to $37 \frac{1}{2}$ per cent.

On the Lower Purús experimental tests carried out from September 27 to October 7, I9I3, to ascertain the density of the latex extracted by means of the machadinho and gouge respectively on forest-grown trees, gave the following results:

\begin{tabular}{|c|c|c|c|c|c|}
\hline Locality. & & Tool used. & $\begin{array}{l}\text { Quantity } \\
\text { tested. }\end{array}$ & $\begin{array}{l}\text { Dry Rubber } \\
\text { obtained. }\end{array}$ & No. of C.C. to \\
\hline $\begin{array}{l}\text { Aliança... } \\
\begin{array}{c}\text { Axioma } \\
\text {.... } \\
\text {, } \quad . .\end{array}\end{array}$ & $\begin{array}{l}\cdots \\
\cdots \\
\cdots \\
\cdots\end{array}$ & $\begin{array}{l}\text { Machadinho } \\
\text { Gouge } \\
\text { Machadinho } \\
\text { Gouge }\end{array}$ & $\begin{array}{r}\text { C.C. } \\
\text { I, O00 } \\
\text { I, O00 } \\
500 \\
500\end{array}$ & $\begin{array}{l}\text { Ounces. } \\
\text { I } 5 \cdot 33 \\
\text { I } 6 \\
7 \cdot 50 \\
7 \cdot 66\end{array}$ & $\begin{array}{l}I, 043 \\
I, 000 \\
I, 066 \\
I, 044\end{array}$ \\
\hline
\end{tabular}


At Aliança, in order to make the list as thorough as possible, various methods of tapping were employed ; these are shown in the annexed table:

\begin{tabular}{|c|c|c|c|c|c|}
\hline & $\begin{array}{l}\text { Hours of } \\
\text { Tapping. }\end{array}$ & $\begin{array}{l}\text { No. of } \\
\text { Trees } \\
\text { tapped. }\end{array}$ & $\begin{array}{l}\text { Tool } \\
\text { used. }\end{array}$ & $\begin{array}{l}\text { Daily or } \\
\text { Otherwise. }\end{array}$ & Method employed. \\
\hline I. & $\begin{array}{l}6 \text { a.m. to } \\
\text { a.m. }\end{array}$ & I0 & Macha- & Daily & $\begin{array}{l}\text { Four to six cuts, accord- } \\
\text { ing to girth }\end{array}$ \\
\hline 2. & ", & IO & , & $\begin{array}{l}\text { Alternate } \\
\text { days }\end{array}$ & $\begin{array}{l}\text { Four to six cuts, accord- } \\
\text { ing to girth }\end{array}$ \\
\hline 3. & ", & Io & Gouge & Daily & $\begin{array}{l}\text { Double herring - bone } \\
\text { with four cuts }\end{array}$ \\
\hline 4. & ," & Io & ," & ," & $\begin{array}{l}\text { Single herring - bone } \\
\text { with two cuts }\end{array}$ \\
\hline 5. & $"$ & IO & , & ", & $\begin{array}{l}\text { Double and single her- } \\
\text { ring-bone on a quarter } \\
\text { circumference of tree }\end{array}$ \\
\hline 6. & & Io & ", & & Broad V cuts \\
\hline $7 \cdot$ & , & Io & , &, & Small V cuts \\
\hline 8. & $"$ & I0 & ", & $\begin{array}{l}\text { Alternate } \\
\text { days }\end{array}$ & $\begin{array}{l}\text { Single herring - bone } \\
\text { with two cuts }\end{array}$ \\
\hline
\end{tabular}

A further test taken at the Sevastopol estate, on the River Purús, extended over a period of eight days, on forty trees tapped by the gouge with half herring-bone and two cuts. For the last six days of this experiment the results were-

\begin{tabular}{|c|c|c|c|c|c|c|c|}
\hline $\begin{array}{l}\text { Date, } \\
\text { 1913. }\end{array}$ & Latex. & $\begin{array}{c}\text { Wet } \\
\text { Rubber. }\end{array}$ & $\begin{array}{c}\text { Dry } \\
\text { Rubber. }\end{array}$ & Lump. & Scrap. & $\begin{array}{l}\text { Aggregate } \\
\text { Dry Lump } \\
\text { and Scrap. }\end{array}$ & Remarks. \\
\hline & C.C. & Grms. & Grms. & Grms. & Grms. & Grms. & \multirow{7}{*}{$\begin{array}{l}\text { Forty per cent } \\
\text { deducted from } \\
\text { wet rubber and } \\
20 \text { per cent. from } \\
\text { lump and scrap } \\
\text { for waste in dry } \\
\text { ing }\end{array}$} \\
\hline Oct. I3 & 250 & 180 & I08 & 100 & 30 & I04 & \\
\hline$" 14$ & 359 & $\begin{array}{l}260 \\
360\end{array}$ & 156 & $\begin{array}{l}90 \\
85\end{array}$ & $\begin{array}{l}70 \\
50\end{array}$ & $\begin{array}{l}128 \\
108\end{array}$ & \\
\hline $\begin{array}{ll}10 & 15 \\
& \end{array}$ & $\begin{array}{l}403 \\
616\end{array}$ & $\begin{array}{l}300 \\
400\end{array}$ & 240 & 120 & 60 & $\begin{array}{l}144 \\
144\end{array}$ & \\
\hline " $\quad 17$ & 650 & 460 & 276 & I35 & 47 & 145 & \\
\hline ", $\quad 18$ & $5^{8} 3$ & $35^{\circ}$ & 210 & 100 & 40 & I 12 & \\
\hline Total & $2,94 \mathrm{I}$ & 2,010 & 1,206 & 630 & 297 & $74 \mathrm{I}$ & \\
\hline
\end{tabular}


These figures are equal to a total yield of $70^{\circ} 2$ ounces of dry rubber, or an average of $I^{\prime} 75$ ounces for each of the forty trees tapped during the six days' trial. The density of 670 c.c. to I pound of dry rubber is extraordinarily high, and it compares with an average of I,34I c.c. at the Ceylon Government Gardens of Henaratgoda, according to official returns published in May, Igr3.

In all the foregoing experiments coagulation of the latex was obtained by the use of a solution of acetic acid, preference being given to this method in order to enable the rubber to be dried without the long delay necessary when the coagulation is effected by smoke.

The records kept by $\mathrm{Mr}$. da Costa at the Santa Maria estate, in the Madeira district, furnish some useful information concerning density and yield of latex, and they may be accepted as an accurate basis on which to calculate returns for that section of the Amazon Valley. On this property the quantity of latex extracted in the month of June, I9I3, from gouge tapping with the double and single herring-bone system, was 329,000 c.c.; this latex was coagulated by the smoking process, and yielded 528 pounds of wet rubber, equal to $29 \mathrm{I}$ pounds when dried, not including any lump or scrap. This gives a density of $\mathrm{I}, 038$ c.c. to I pound of dry rubber. On the same property one collector obtained a daily average of 4,000 c.c. from I70 trees, tapping with the gouge on the single-V system during the first three months of the season, an equivalent of $23^{\circ} 5$ c.c. per tree per day; this should give $3^{\circ} 3$ pounds of first-quality rubber per tree during a tapping season of I50 days, and in addition about 
I. I pounds of lump and scrap, making a total of $4^{\circ} 4$ pounds of dry rubber in six months of twenty-five working days each. At the near-by estate of Lembrança two men tapping 300 trees obtained a daily average of latex of 6,000 c.c. each; this yield, on the basis of $I_{50}$ working days in the season, is equal to 5.78 pounds of dry fine rubber, and $I \cdot 73$ pounds of lump and scrap, an aggregate of $7{ }^{\circ} \mathrm{I}$ pounds of dry rubber per tree per annum. These trees were tapped on the single- $\mathbf{V}$ plan with the gouge.

The following details, extracted from the records kept at Santa Maria, are instructive and interesting in regard to density and yield with both gouge and machadinho tapping; they may be relied upon as approximately correct, and are fairly representative of the average conditions, in this section of territory, of old-established properties regularly worked for the last quarter of a century:

\begin{tabular}{|c|c|c|c|c|c|}
\hline Estrada. & Days. & Trees. & System. & Total Litres. & $\begin{array}{c}\text { Average C.C. } \\
\text { per Tree. }\end{array}$ \\
\hline No. I 2\{ & $\begin{array}{l}7 \\
7\end{array}$ & $\begin{array}{l}\text { I } 22 \\
\text { I } 80\end{array}$ & $\begin{array}{l}\text { G.V. } \\
\text { M. }\end{array}$ & $\begin{array}{l}21,000 \\
18,800\end{array}$ & $\begin{array}{l}24 \\
14\end{array}$ \\
\hline ", 3\{ & $\begin{array}{r}13 \\
9\end{array}$ & $\begin{array}{l}\text { I3O } \\
2 \text { IO }\end{array}$ & $\begin{array}{c}\text { G.V. } \\
\text { M. }\end{array}$ & $\begin{array}{l}45,000 \\
31,900\end{array}$ & $\begin{array}{l}27 \\
17\end{array}$ \\
\hline , 4\{ & $\begin{array}{r}3 \\
8\end{array}$ & I00 & $\underset{\mathrm{M} .}{\mathrm{G} .}$. & 61,900 & $\begin{array}{l}47 \\
23 \\
\end{array}$ \\
\hline , 9\{ & $\begin{array}{l}\text { I9 } \\
\text { I8 (July) }\end{array}$ & $\begin{array}{l}176 \\
200\end{array}$ & $\begin{array}{l}\text { M. } \\
\text { M. }\end{array}$ & $\begin{array}{l}53,000 \\
60,000\end{array}$ & $\begin{array}{l}16 \\
16\end{array}$ \\
\hline $\begin{array}{ll}, & 5 \\
, & 8\end{array}$ & $\begin{array}{l}19 \\
24\end{array}$ & $\begin{array}{l}\text { I60 } \\
\text { I IO }\end{array}$ & $\begin{array}{l}\text { G.H. } \\
\text { G. and J. }\end{array}$ & $\begin{array}{l}75,200 \\
80,400\end{array}$ & $\begin{array}{l}25 \\
30\end{array}$ \\
\hline
\end{tabular}

Note. - G.V. stands for gouge tapping with separate V's.
G.H.
M. " " machadinho tapping.
herring-bone system.
J. . jebong tapping.

The average yield of the five sets of gouge tapping is 30 c.c. first latex per tree.

The average yield of the five sets of machadinho tapping is I 7 c.c. first latex per tree. 
Mr. da Costa states that after the first month he obtains only 25 per cent. dry rubber from the gouge tapping, against 40 per cent. from machadinho work. Therefore-

Dry rubber from machadinho, 40 per cent. of $17,6.8$, plus io per cent. scrap $=7{ }^{\circ} 8$.

Dry rubber from gouge, 25 per cent. of $30,7.5$, plus 30 per cent. scrap $=975$.

No. I2 estrada mentioned above was tapped on sixteen days in July with the herring-bone system, and averaged $32 \frac{1}{2}$ c.c. per tree per day.

No. 4 estrada was tapped altogether only for twenty days with the gouge, and this may account for the higher yield in comparison with the others.

A fairly accurate idea of the uncertain position of the rubber collectors in the central section of the Amazon Valley may be gathered from the following figures, extracted from the books kept at the Sevastopol estate, on the Lower Purús: In IgI2 the total production of a division comprising twenty-two estradas of r.20 trees each was 3,406 kilogrammes, consisting of 2,887 kilogrammes of fine rubber and 5 I9 kilogrammes of lump and scrap (sernamby); this equals I $54^{\circ} 9$ kilogrammes for each estrada, or I,290 grammes per tree, equivalent to 2.84 pounds. The trees were tapped on alternate days with the machadinho, and eleven men were employed throughout the season at this work; therefore the average amount of rubber delivered by each man was $262^{\circ} 45$ kilogrammes of fine rubber and $47^{\circ} 18$ kilogrammes of scrap, equal to $577^{\circ} 45$ pounds and $93^{\circ} 8 \mathrm{I}$ pounds of fine rubber and scrap respectively. The collector is entitled to one-half of 
this amount, less ro per cent. for loss in weight and Io per cent. for expenses on fine, with no deduction on scrap, or $210^{\circ} 5^{8}$ pounds of fine and $46^{\circ} 9$ pounds of scrap. With the price in London at $3 \mathrm{~s}$. per pound, the equivalent rate on the Lower Purús is 2s. per pound; therefore the money value to the collector is $£ 2 I$ Is. for the fine rubber, and $£ 3$ 2s. 6d. for scrap, a total of $£ 24$ 3s. 6d. for seven months' work. Against this sum take the cost of the absolute necessities of life at the comparatively moderate prices charged on this estate. The monthly requirements for each man are-

\begin{tabular}{|c|c|c|c|c|}
\hline Rice : 3 kilos at $2 \mathrm{~s} .7 \mathrm{~d}$. & & $=$ & & 7 \\
\hline Beans : 4 kilos at 2 s. 7 d.... & ... & $=$ & o & IO \\
\hline Coffee : I kilo at 2 s. rod. & $\ldots$ & $=$ & o & 2 \\
\hline Sugar: 2 kilos at 2 S. $1 \frac{1}{2} \mathrm{~d}$. & $\ldots$ & $=$ & o & 4 \\
\hline Dried meat : 4 kilos at 3 s. $2 \frac{1}{2} \mathrm{~d}$. & $\ldots$ & $=$ & 0 & 12 \\
\hline Salt : 2 kilos at $9 \frac{1}{2} \mathrm{~d}$. & $\ldots$ & $=$ & o & I \\
\hline Soap : $\frac{1}{2}$ kilo at Is. $6 \mathrm{~d}$. ... & $\ldots$ & $=$ & o & $\rho$ \\
\hline Farinha : 20 litres at $8 \mathrm{~d} . .$. & $\ldots$ & $=$ & 0 & I3 \\
\hline Kerosene : I litre at Is. ... & ... & $=$ & o & I \\
\hline Lard : 2 kilos at 2 s. 4 d. ... & $\ldots$ & $=$ & o & 4 \\
\hline Tobacco: I kilo at I3s. $4 \mathrm{~d}$. & ... & $=$ & 0 & 13 \\
\hline Matches : 2 packets at 2 s. 2 d. & $\ldots$ & $=$ & o & 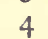 \\
\hline Cigarette-papers: 2 packets at I & & & o & I \\
\hline
\end{tabular}

Living in the most frugal manner possible on the above scale, a collector will spend not less than $£^{27}$ in the tapping season of seven months, receiving $£ 24$ for his work during that period. He remains with a debt of $£ 3$, and no credit to help him to tide over the five months of the year before he can resume his occupation. In the circumstances the situation for many properties must be considered most precarious. 
Throughout all districts of the Amazon Valley extraordinary tales are told of the yield from individual trees, and often of whole estradas of such trees. There is no doubt that the proportion of very free milkers is comparatively large, especially on the properties more recently opened for regular work in the national territories in the vicinity of the Acre, the upper portions of the Purús and Juruá, the Javary, and other waterways. There are many authenticated cases of individual trees yielding as much as 500 c.c. in one tapping, equal to half a pound of dry rubber, but no reliable data is extant to show for what period this rate of yield was maintained. In the districts of the upper rivers it is not an unusual occurrence for a collector to deliver 1,000 kilogrammes (2,200 pounds) of dry rubber in the tapping season, equal to 15 pounds per tree on an estrada of I50 trees; but this only happens in localities where virgin trees are fairly abundant. In many parts of the central section, covering the Madeira and the lower portions of the Purús and Juruá, the returns in a season from single estradas of I50 trees frequently amount to I,200 pounds, and sometimes I,500 pounds, of dry rubber; but the average is lowered by the very much smaller deliveries on the older-established properties, as is demonstrated quite clearly by the tests made during I9I3. When all the circumstances are given due consideration, it is evident that the future of the industry is dependent on the average returns, and not on any abnormal yield from exceptionally favoured estates. All the conditions will be altered for the worse if the price of rubber falls to a point which compels a cessation of work on the older properties. 


\section{CHAPTER VIII}

\section{CURING AND PREPARATION OF RUBBER}

Method of coagulation-Latex not strained-Disadvantages of present system-Difficulty of introducing improved methodsReasons against radical alterations-Various modes of smoking latex-Delivery of rubber by collectors-Weighing of rubberNecessity of readjustment of terms of remuneration to collectors - Transport of rubber to port of shipment-Cost of transport by land and river-Payment of freights-Expenses at Manáos and Pará-Ocean freight rates-Grading of rubber at Manáos and Pará-Classification of crop for season 1912-13-Origin of crop for season 1912-13-Estimated output for season July I, I913, to June 30 , IgI4.

T $\mathrm{N}$ the East a tapper finishes his daily task when he makes delivery of the latex at the factory; in Brazil the seringueiro not only taps his trees and collects the yield, but must also coagulate the latex before his work for the day is done. In place of the up-to-date establishment, maintained in scrupulously clean condition, common to Oriental plantations, all the appliances used in Brazil for the preparation of rubber are of the most primitive description. A thatched hut with mud floor serves as the coagulating shed; a hole in the centre of this floor surmounted by a battered coneshaped tin funnel constitutes the smoking apparatus. A dirty basin receives the latex, and a tin cup or shell of a gourd is utilized as a ladle to pour it little by little over the stick or paddle as the coagulation proceeds. A 
fire of Urucury nuts creates a dense smoke containing a large percentage of carbonic acid gas, and this, passing through the tin funnel, reaches the paddle or stick turned slowly by hand, and constantly basted with coatings of latex from the receiving basin. This process continues until the balls of rubber accumulate to the required size, and it is then begun afresh. If balls (pelles) are to be made a stick is used; for knapsack the paddle is employed. Lump and scrap are thrown down on the mud floor in the corner of the hut without the slightest attempt to prevent the admixture of dirt or a rapid putrefaction.

Amidst these squalid surroundings, and in an atmosphere dense with smoke and impregnated with carbonic acid gas, the collector passes two to three hours every afternoon. It is often sundown before the day's yield of latex is coagulated, and this means that the man has been at work since 4 a.m., with the exception of the noontide rest of some two hours or so. In a climate such as that prevailing in the Amazon Valley, the tax on health and strength from these conditions is unusually severe, and it is no matter for wonder that the number of men constantly incapacitated for work is abnormally high.

No effort is made to clean the latex by straining before coagulation, and this accounts for a large proportion of the impurities so frequently apparent in the rubber. The statements sometimes put forward, that foreign substances are mixed deliberately with the latex during the process of smoking, have very slight foundation in fact; when they are found in the finished product, they are due as a rule to excessive carelessness 

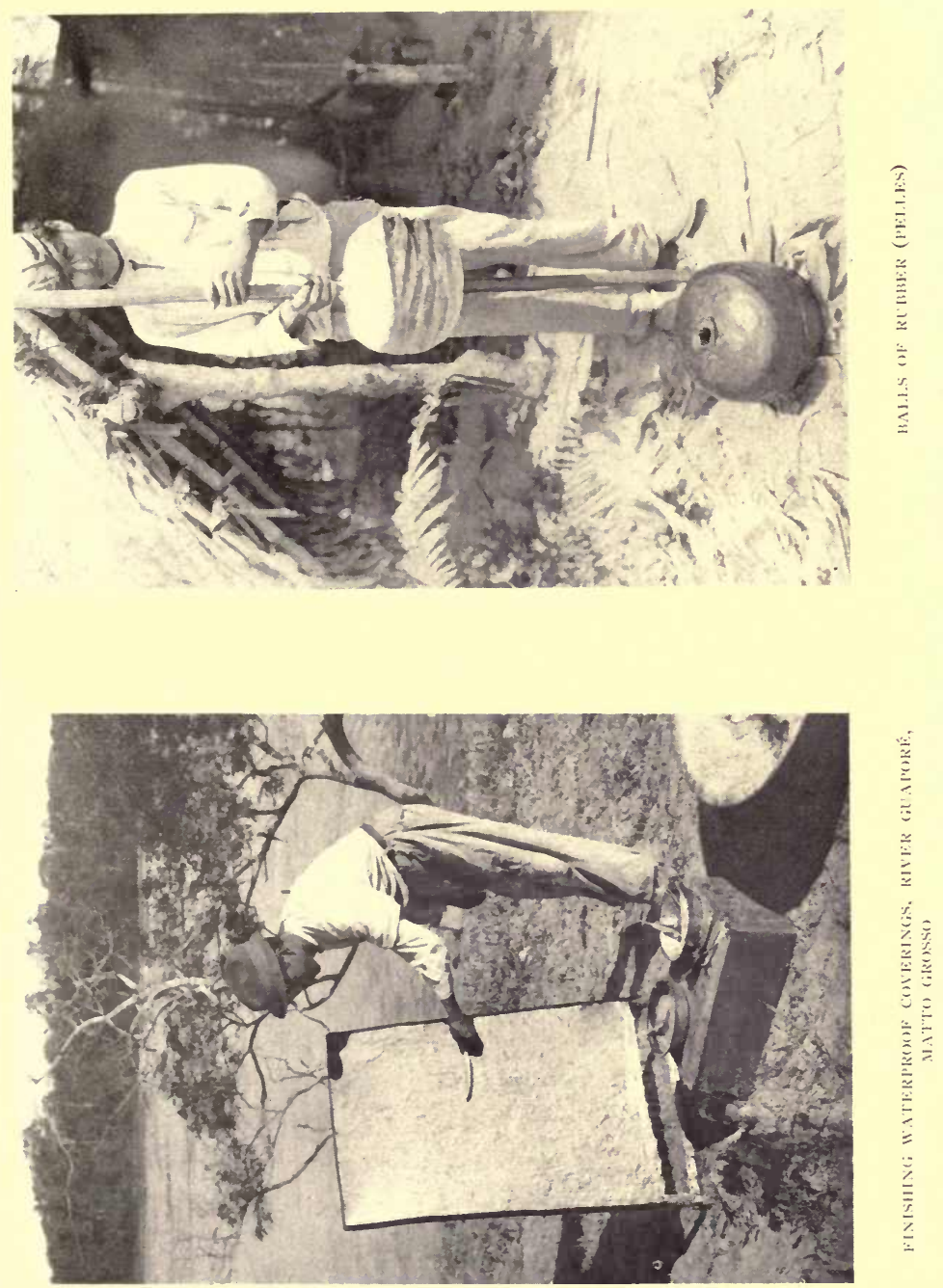
$\because \div \quad \because \vdots \vdots \vdots \cdots$

$\therefore \vdots+\because \vdots \cdots+\cdots \vdots \vdots \vdots \cdots+\cdots$ 
and absolute neglect of every principle of cleanliness while the preparation of the latex is taking place.

The disadvantages of the present system of manufacture are obvious. Any undue proportion of impurities reduces the selling value of the rubber, and frequently it results in the classification in a lower grade than should be the case after arrival at Manáos or Pará. Under existing conditions the pelles and knapsacks contain an abnormally high percentage of moisture; they lose from Io to I5 per cent. in weight from the time of shipment at the estate to the date when they are reweighed in Manáos or Pará before the sale is effected. A further loss of importance occurs between the time of embarkation at Manáos or Pará and disposal to manufacturers in Europe or the United States. These losses of weight represent extra freight charges; therefore the matter calls for most serious consideration in view of the present crisis in the rubber industry, and the fact that every fraction of a penny per pound is of the utmost importance.

In spite of the crude methods of the existing system of preparing the latex, and the many disadvantages it entails, there are several very strong points favourable to it in connection with prevailing conditions in the Amazon Valley. In the first place, the coagulation of the latex in central factories means additional labour and incidental expense on account of the wide distances separating the estradas, and the consequent length of time required to convey the daily yield to any central point; then the question of the quality of the latex delivered by individual collectors would crop up, and cause constant friction between the manager and the 
seringueiro, so long as the present practice of working on the share system is continued, and to pay daily wages would increase the cost of production to a marked degree. It is doubtful if a higher price for a cleaner rubber would compensate for the expenditure necessary for the construction, equipment, and maintenance, of a modern factory, apart from the difficulty of competent supervision to insure any satisfactory results. Moreover, it would entail the complete reorganization of the labour system.

There is another and very important reason why the present method of coagulation should not be abandoned without the most careful consideration of the possible effects on the quality of the rubber. When the latex is coagulated by the smoking process on paddle or stick, the rubber produced is not subjected to any form of pressure, or to the unavoidable maceration entailed by the use of the creping machinery common to factories on Eastern plantations; therefore no injury can be inflicted upon the product by the Brazilian methods as generally practised at the present time. The consequences to Eastern rubber produced by the severe treatment accorded to it in the great majority of plantation factories have never been clearly demonstrated, and it may be that the higher standard of elasticity and length of life so often claimed for the Brazilian product may be due in some measure to the absence of all crushing or tearing during the preparation of the latex. In any case, the most careful laboratory investigation in general, and special tests in particular, should be made before a marked alteration is attempted in regard to the substitution of any new system in place of the methods now employed. 
Various experiments have been tried for the purpose of finding a more convenient means of fumigating the latex without the necessity of using either paddle or stick, and at the same time maintaining the principle exercised in the use of those implements. The nearest approach to success in this direction has been the invention of a tin cylinder revolving over the smoke funnel. This drum is turned slowly by hand, and the latex poured on to it in the same manner as with the paddle or stick. When a thickness of about half an inch has been attained, the sheet is taken off the cylinder and the process repeated. The advantages of this system are that the rubber dries easily, should show a saving in freight charges on account of the lower percentage of moisture than in pelles or knapsacks, and can be packed for shipment without difficulty. This method, however, has not been adopted to any great extent, in consequence of the opposition of agents and brokers at Manáos and Pará, who have refused persistently to give any higher price for it than for pelles or knapsacks containing at least ro per cent., and often 15 per cent., greater percentage of moisture. A large proportion of the owners of rubber-producing properties are so deeply indebted to their agents that they are powerless to resent their attitude in this matter, and this explains why no systematic effort has been made to bring the cylinder into more general use in order to manufacture sheet in place of ball rubber. In I9I3 some small consignments of sheet rubber made by this process, and shipped to Manáos by the Madeira-Marmoré Railway Company, were sold at the price then ruling for fine rubber; but in no case was a higher rate paid 
than that quoted for the first quality of pelles or knapsacks.

Simple and inexpensive improvements in connection with the cylinder system can be made without difficulty if the process should come into popular favour. A receiver fitted with a conducting channel can be adapted to distribute the latex automatically and evenly over the drum in order to replace the hand dipping; a slight alteration in the form of the cone-shaped funnel would allow the smoke to penetrate directly to every part of the revolving cylinder, instead of rising in a dense column and being dissipated throughout the hut; moreover, a flue could be adjusted above the cylinder so as to permit the escape of the smoke after passing over the latex, and thus relieve the collector from the injurious effects of the daily immersion in an atmosphere saturated with carbonic acid gas.

The general rule is for collectors to make delivery of the rubber once a fortnight on the properties located near the river-banks, but how often it is received is left to the decision of the manager. The longer the rubber is kept by the collector, the greater the loss in weight ; this consideration is a factor seldom ignored, and occasionally the seringueiro insists on a weekly weighing. In the districts of the upper rivers, where the estradas are often two or three days' journey from the headquarters of the estate, the delivery is delayed frequently by difficulties of transport, especially during the period of low-water in the rivers, and the rubber is brought in only twice or thrice during the tapping season.

The weighing of the rubber takes place at the estate store. Each collector receives a note of the amount he 


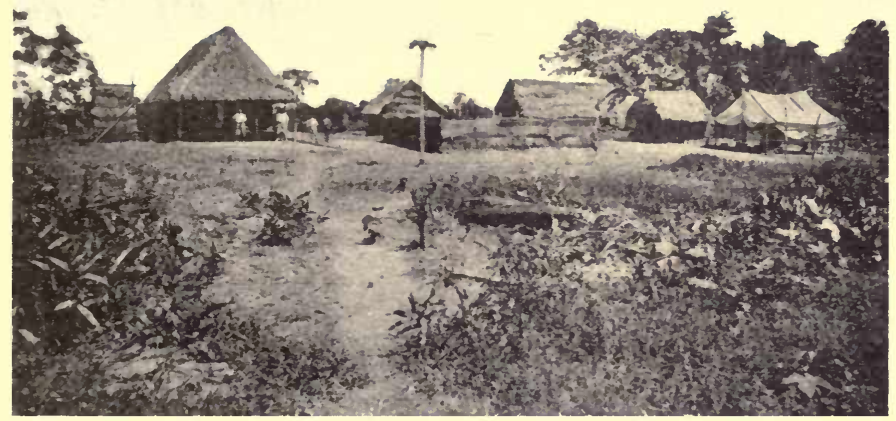

A RLBBER PROPERTY, WATTO GR(ISSO

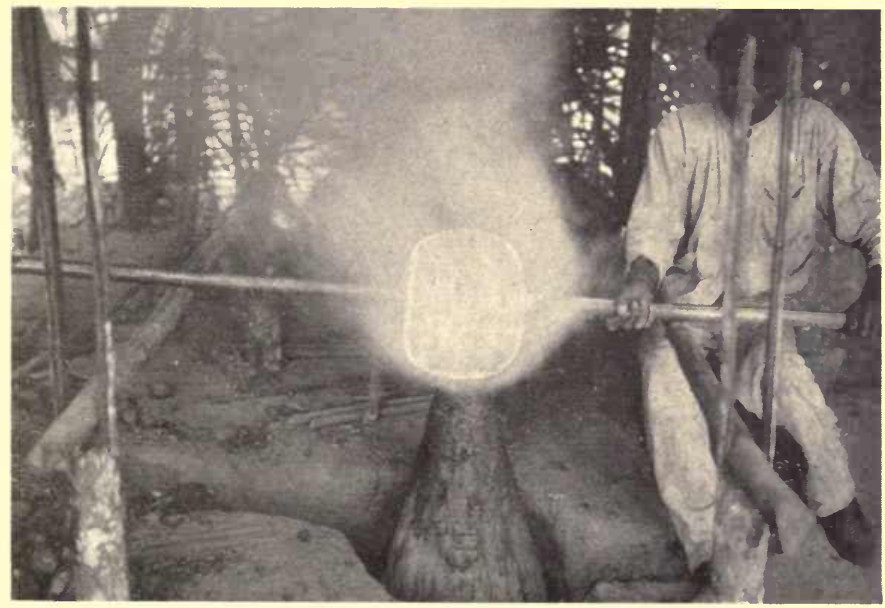

SMOKING; LATEX, KIIEK MADEIRA 

delivers, less a deduction for waste pending shipment. This deduction varies in different districts and according to the period of the tapping season, the average allowance being Io per cent. for the first four months, and 15 per cent. during the last three. Of the total quantity, one-half is credited to the collector at the market value in Manáos or Pará, less a further deduction of ro per cent. to cover cost of freight commissions and incidental expenses up to date of sale. Practically the outcome is that the collector receives one-half of the total amount less a deduction of 25 per cent.

It is abundantly evident from the facts given in con. nection with tapping, the yield of rubber-trees, and the cost of living, that the question of the remuneration of labour on the rubber-producing properties needs a thorough readjustment. If the relationship between owners and collectors is to continue on the co-partnership basis prevailing at present, the percentage to the latter must be increased to a substantial extent, and the deductions for loss in weight and expenses sensibly diminished. In view of the rapid rise in Eastern production, it is necessary to look for lower prices than have been reached hitherto, and for this reason all calculations should be made at a value not exceeding two shillings and sixpence per pound for fine hard Pará rubber. To enable the seringueiro to earn a living wage, his share must be increased to at least 75 per cent. of the total amount he delivers, and any deductions made should be for actual, not possible, loss of weight and general charges. Unless most drastic innovations in this direction are introduced in the immediate future, the rubber industry in the Amazon Valley will dwindle 
away to vanishing-point for the lack of labourers to keep it alive.

After the rubber is weighed, it is shipped to Manáos or Pará with as little delay as possible. The matter of transport presents no difficulty so far as the Lower Amazon and its affluents are concerned, or in connection with the districts of the Madeira and those of the lower portions of the Purús and Juruá. Bolivia has an outlet always open by way of the railway to San Antonio or Porto Velho, on the Madeira. Throughout all these districts a regular service of steamers belonging to the Amazon Steam Navigation Company, and also many vessels privately owned, provide ample space for all cargo requirements. The conditions in the Acre territory and the upper rivers are more complicated, for there navigation is interrupted for six months in the year by the insufficiency of water to permit the passage of steamers through the numerous cataracts.

The cost of transport is a constant source of complaint, and the charges undoubtedly are extremely high. This is due in great part to the heavy expenditure for wages, the dearness of fuel, and to the Federal Government regulations in regard to the crew to be carried on coasting and river craft. The rates vary according to the distance, but an average cost struck for the whole Amazon Valley brings out the charge for transport by water at about one halfpenny for each pound of rubber in a crop of 40,000 tons.

On many properties where the estradas are far distant from the central homestead, a further expenditure is incurred for transport of the rubber to the point of shipment. In some districts creeks are available for 


\section{CURING AND PREPARATION OF RUBBER 99}

the use of steam-launches, flat-bottomed boats, and canoes, for this purpose ; in connection with a large proportion of estates water carriage is impossible, especially during the dry season, from July to October, and the employment of pack animals is necessary. In these circumstances the cost of transport becomes a heavy item, for the traffic must be taken over the rough jungle tracks doing duty for roads, and nowhere is resort to wheeled vehicles a possibility. The value of mules for transportation work varies from $£ 35$ to $£ 40$ per head, and even at that high price the supply is limited; moreover, the climate and grasses are not well suited to either mules or horses, and consequently the mortality is exceptionally heavy. These additional expenses add approximately another halfpenny per pound to the cost of the rubber, bringing the total average charge to one penny per pound for land and river transport to Manáos or Pará.

The cost of freight on inward cargo is at a higher rate, especially in regard to any description of fine goods, steamship owners relying on this source of income for earning profits. In the years of prosperity following the rubber boom of I909, the question of freight rates attracted very little attention; but with the fall in prices this factor has become one of the most serious problems in the situation, and it has resulted in scores of steamers being dismantled and laid up at Manáos and Pará, on account of the diminution in the quantity of imported merchandise.

Bolivian rubber is subjected to the abnormally high charges made by the Madeira-Marmoré Railway Company, but in this connection a reduction in rates of at 
least 50 per cent. in the immediate future must result as a consequence of the present crisis.

Owing to the scarcity of ready money throughout the rubber districts, freight charges are paid in Manáos or Para. For inward cargo the payments are made at the time of shipment by the commission agents (aviadores) forwarding goods to the different sections of the country, and the amount debited against the accounts of the various estates. In the case of downriver consignments, the value of the freight is collected by the shipping agent at the point of destination, before the rubber or other cargo is delivered to the consignee.

In order to obtain freight, a common practice, especially with privately-owned vessels, is for the master of a steamer to make cash advances up to 60 per cent. of the value of the rubber shipped, and to hold the consignment after arrival in port until the loan has been discharged. It is very seldom that any loss takes place in connection with these transactions, for the margin allowed is always ample to cover any fluctuation in the market price.

On arrival at Manáos or Pará an agent takes charge of the rubber, and defrays the necessary expenses in regard to dock dues, cartage, weighing, storage, and grading, and he arranges also for the sale. For these services a commission of $2 \frac{1}{2}$ per cent. is made on the price realized and on the amount of all disbursements incurred, these latter being deducted from the payments received. As soon as the rubber is sold, accounts are rendered to the owner or manager of the property whence the consignment originated, giving full details of the transaction.

The exporter into whose hands the rubber passes 


\section{CURING AND PREPARATION OF RUBEER, IOI}

before shipment to Europe or the United States must pay the export duty, the municipal and other taxes, the port charges, consular fees, cost of delivery at the quay, and the charges for boxes and packing in cases containing 350 pounds for the small and 700 pounds for the large size.

Freight rates to Europe and the United States are by measurement of 40 cubic feet, at the rate of sixty-five shillings and sixty shillings from Manáos and Pará respectively. This is equal to nearly double that amount per ton weight.

A question asked frequently is why fine rubber from the Amazon Valley obtains a higher price than plantation in the European and American markets. Although the age of the trees undoubtedly exercises an influence, the great difference existing in favour of the Brazilian product is not due altogether to the quality of latex or to the method of preparation, as is supposed generally to be the case, but also to the systematic manner of careful grading employed to separate the fina, the entre fina, and fraca. This work is done in the warehouse at Manáos and Pará by a totally uneducated class of men who often can neither read nor write; but long experience has taught them to distinguish accurately the various grades of rubber passing through their hands, and when they have completed this work the classification of the raw material is practically without a flaw. It is no exaggeration to say that less than $\frac{1}{2}$ per cent. of the total export from the Amazon Valley is of other quality than is specified in the shipping documents. In view of this fact manufacturers pay a higher price for the security of obtaining an even quality. Brazilian methods of grading may be cum. 
bersome and costly, but the drawbacks to them are more than compensated for by the effective result. Should smoked sheet take the place of pelles or knapsacks, it is an open question whether the present high standard of grading will be maintained.

For the twelve months from July I, I9I2, to June 30 , I9I3, the crop of rubber in the Amazon Valley was $3 I, 73 I$ tons, and to this must be joined the stock of I,500 tons, making a total of 33,23 I tons available at Manáos and Pará; in addition, the harvest of caucho (castilloa) was IO,I3I tons, bringing the aggregate amount to 43,362 tons. The classification of this output was-

UPPER RIVERS

\begin{tabular}{|c|c|c|c|c|}
\hline & & & Tons. & $\begin{array}{l}\text { Percentage to } \\
\text { the Output. }\end{array}$ \\
\hline \multirow{5}{*}{\multicolumn{2}{|c|}{$\begin{array}{ll}\text { Fina } & \ldots \\
\text { Entre Fina and } \dddot{\text { Fraca }} & \ldots \\
\text { Sernamby (Scrap) } & \ldots \\
\text { Caucho (Castilloa) }\end{array}$}} & \multirow{5}{*}{$\begin{array}{ll}\ldots & \ldots \\
\ldots & \ldots \\
\ldots & \ldots \\
\ldots & \ldots\end{array}$} & I $5,77 \mathrm{I}$ & 50 \\
\hline & & & 4,060 & I3 \\
\hline & & & 3,200 & IO \\
\hline & & & 8,331 & $27^{*}$ \\
\hline & & & 31,362 & - \\
\hline
\end{tabular}

LOWER RIVERS

\begin{tabular}{|c|c|c|c|c|}
\hline $\begin{array}{lll}\text { Fina } & \ldots & \ldots \\
\text { Fraca } \quad \ldots & \ldots \\
\text { Sernamby (Scrap) } \\
\text { Caucho (Castilloa) }\end{array}$ & $\begin{array}{l}\cdots \\
\cdots \\
\cdots \\
\cdots\end{array}$ & $\begin{array}{l}\cdots \\
\cdots \\
\cdots \\
\cdots\end{array}$ & $\begin{array}{l}1,200 \\
4,800 \\
4,200 \\
1,800\end{array}$ & $\begin{array}{l}\text { rot } \\
40 \\
35 \\
15\end{array}$ \\
\hline & & & 12,000 & - \\
\hline Total & $\ldots$ & $\ldots$ & 43,362 & - \\
\hline
\end{tabular}

* Ball and scrap.

$\dagger$ From the Araguaya and upper sections of the Tapajoz, Xingu, Tocantins, and Matto Grosso. 


\section{CURING AND PREPARATION OF RUBBER IO3}

The percentages and quantities of the total output of the Amazon Valley for I9I2-I3 were-

Fina

\begin{tabular}{|c|c|c|c|}
\hline & & Tons. & Percentage. \\
\hline $\begin{array}{l}\text { Fina } \ldots \\
\text { Entre Fina and } \ldots \text { Fraca } . . \\
\text { Sernamby } \ldots \\
\text { Caucho }(\text { Castilloa) }\end{array}$ & \begin{tabular}{l|l}
$\cdots$ \\
$\cdots$ \\
$\cdots$ \\
$\cdots$
\end{tabular} & $\begin{array}{r}16,97 \mathrm{I} \\
8,860 \\
7,400 \\
\text { I0,131 }\end{array}$ & $\begin{array}{l}39^{\circ} 11 \\
20^{*} 43 \\
17^{\circ} \circ 6 \\
23^{*} 3^{*} \\
\end{array}$ \\
\hline Total $\ldots$ & $\ldots$ & 43,362 & - \\
\hline
\end{tabular}

The distribution of this production for I II2-I3 as to origin was-

UPPER RIVERS

\begin{tabular}{|c|c|c|c|}
\hline District. & Rubber. & $\begin{array}{c}\text { Caucho } \\
\text { (Castilloa). }\end{array}$ & Total. \\
\hline 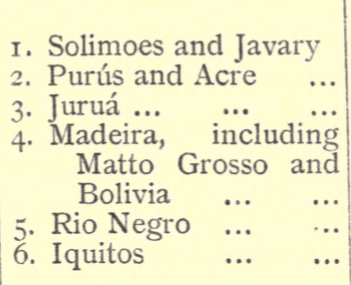 & $\begin{array}{r}\text { Tons. } \\
2,360 \\
10,700 \\
4,224\end{array}$ & $\begin{array}{r}\text { Tons. } \\
298 \\
3,549 \\
645\end{array}$ & $\begin{array}{r}\text { Tons. } \\
2,658 \\
14,249 \\
4,869\end{array}$ \\
\hline & $23,03 \mathrm{I}$ & 8,331 & $31,3^{62}$ \\
\hline
\end{tabular}

LOWER RIVERS

\begin{tabular}{|ccc|c|c|c|}
\hline $\begin{array}{c}\text { Including the Tapajoz, } \\
\text { Xingu, Tocantins, the }\end{array}$ & & & \\
Islands, etc. $\ldots$ & $\cdots$ & I0,200 & I,800 & I2,000 \\
\cline { 2 - 3 } Total & $\ldots$ & $\ldots$ & $33,23 \mathrm{I}$ & I0,I3I & 43,362 \\
\hline
\end{tabular}

* Ball and scrap. 
The shipments of rubber from Manáos and Pará during the season July I, I9I2, to June 30, I9I3, amounted to $4 \mathrm{I}, 862$ tons. To this must be added the stock of 1,500 tons, making the total output for the season 43,362 tons. All the indications for the twelve months July I, I9I3, to June 30, I9I4, are to the effect that the output will equal if not exceed that of last year. Therefore the probable total for this season may be taken as not less than 43,000 tons.

In spite of an equal quantity in IgI3-I4 as com. pared to last year, the total value will be quite 25 per cent. less than in I9I2-I3, in accordance with the lower prices ruling during the present season in Europe and the United States. 


\section{CHAPTER IX \\ COST OF PRODUCTION}

Export duties-Total charges levied before shipment-Actual average minimum cost of production per pound of rubberAverage value per pound in January, I9I4-Necessary measures for the Brazilian industry-Production during past eighty-six years-Rubber industry and general prosperity of Brazil-Defesa de Boracha-Why Government measures of relief are barren of results-How the Federal Government can afford immediate relief.

THE export duties and other charges levied on rubber shipments from Brazil have been the subject of much controversy during the last two years. The Federal Government has urged the State administrations of Pará, Amazonas, and Matto Grosso, to make an immediate and substantial reduction in the duties, and at one time even suggested a suspension of all these taxes for an indefinite period. The State Governments, however, argued that the suppression of these charges practically entailed a condition of bankruptcy, especially in the case of Pará and Amazonas, where 80 per cent. of the public revenue is derived from this source. A counter-proposition put forward was that the Federal authorities should make good any loss of income resulting from an abatement in the toll on exports; but this was rejected on the grounds that, if any such principle was applied for the relief of industrial enterprise in the Amazon Valley, a corresponding concession would be demanded by every 
State in the Union. Finally Pará and Matto Grosso agreed to an annual diminution of 10 per cent. in the existing charge of 20 per cent. until the tax was reduced to Io per cent. on the value of all shipments, the Federal Government on its part undertaking to apply similar terms for the rubber produced in the national territories of the Acre and elsewhere. Amazonas refused to join this compact, giving as a reason that the tax in force in that State was only I 8 per cent. on the export value, and therefore the action taken by Pará, Matto Grosso, and the Federal Government, effected nothing more than the establishment of equal conditions so far as the immediate future was concerned. The agreement in regard to the ro per cent. reduction for Pará, Matto Grosso, and the national territories, became operative on January I, I9I4, but it is quite inadequate to meet the exigencies of the situation created by the fall in the price of rubber. Moreover, the Governor of Para has stated publicly that he favours the retention of the full 20 per cent. for financial reasons and continues to levy that rate.

At present (January, Igr4) the charges on a valuation of two shillings per pound of rubber, including the payment of duties at Manáos or Pará, the only shipping ports in the Amazon Valley, are as follows:

\section{MANÁos}

\begin{tabular}{|c|c|c|}
\hline Designation. & $\begin{array}{l}\text { Description of } \\
\text { Contribution. }\end{array}$ & Amount. \\
\hline 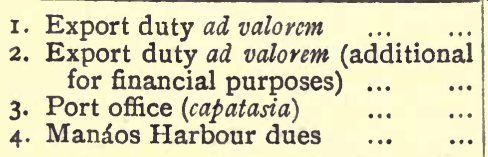 & $\begin{array}{l}\text { State } \\
\text { Federal } \\
\text {,. }\end{array}$ & $\begin{array}{l}\text { I8 per cent. } \\
\text { I reis" per kilo } \\
3\end{array}$ \\
\hline
\end{tabular}




\section{PARÁ}

\begin{tabular}{|c|c|c|}
\hline Designation. & $\begin{array}{l}\text { Description of } \\
\text { Contribution. }\end{array}$ & Amount. \\
\hline 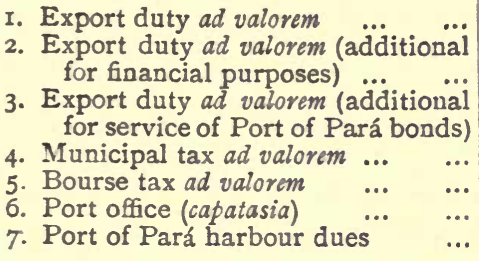 & $\begin{array}{c}\text { State } \\
\text { ", } \\
\text { Federal }\end{array}$ & $\begin{array}{l}\text { I8 per cent. } \\
2 \frac{1}{2} \\
2 \\
\begin{array}{l}\frac{3}{8} \\
9\end{array} \text { reis " per kilo } \\
3\end{array}$ \\
\hline
\end{tabular}

Federal Territories

\begin{tabular}{|c|c|c|c|}
\hline $\begin{array}{l}\text { 1. Export duty ad valovem } \\
\text { 2. Port office (capatasia) } \\
\text { 3. Harbour dues at Manáos }\end{array}$ & \begin{tabular}{ll|}
$\ldots$ & $\ldots$ \\
$\cdots$ & $\cdots$
\end{tabular} & $\begin{array}{c}\text { Federal } \\
\quad "\end{array}$ & $\begin{array}{l}18 \text { per cent. } \\
9 \text { reis per kilo, } \\
\text { or } \$ 1.600 \text { per } \\
\text { case } \\
3 \text { reis per kilo }\end{array}$ \\
\hline
\end{tabular}

The value of rubber for the payment of duties is announced officially weekly, or more often if any violent fluctuations occur in the price.

There is a very great difference in these charges. At Pará the taxation is equal to 5.80 pence per pound of rubber; at Manáos $4^{\circ} 60$ pence; and for rubber from the Federal Territories only $4^{\circ} 40$ pence per pound is paid. Rubber from Matto Grosso is subject to the export duty of 18 per cent., the port office charges, dock dues, and the additional 2 per cent. tax if shipped from Pará, but is exempt from the $2 \frac{1}{2}$ per cent. financial impost and from the municipal and bourse contributions. These charges compare with an export duty of $2 \frac{1}{2}$ per cent. in the Federated Malay States; a tax on the trees in bearing equivalent to $2 \frac{1}{2}$ per cent. on production in 
the Straits Settlements; and no direct contribution of any kind in Ceylon, Java, or Sumatra.

The question of the cost of production in the Amazon Valley is a matter eliciting many differences of opinion in Brazil and abroad. Individual views are coloured by an imperfect general knowledge, and they reflect the expenditure incurred in particular districts rather than the average cost of gathering the total output, and the subsequent expenses up to date of sale in Europe or the United States. A careful investigation of all the principal factors in the situation demonstrates that the minimum average cost per pound of rubber sold is 28.3 pence in Europe or America, and 20.7 pence previous to shipment, at Manáos or Pará, before payment of export duties, ocean freight, and foreign commissions and charges. The details of this average cost are instructive and not uninteresting. They are-

I. Maintenance of Collector.-For the crop season July I, I9I2, to June, 30, I9I3, the total production of rubber, exclusive of caucho (castilloa), was 32,000 tons, and the number of collectors employed 94,000, approximately. This gives an average per seringueiro of $75^{\circ}$ pounds in round figures. It has been shown elsewhere that the minimum value of the necessaries of life, during the tapping season of seven months, for each collector is $£ 27$ I6s. 6d., equal to ro.7 pence per pound of rubber delivered, and to this must be added not less than ro per cent. for clothing and other essential articles, bringing the total to II'7 pence per pound.

2. Transport to Manáos or Pará.-The cost of handling and conveyance by land and river to the port of shipment averages about one penny per pound. 
3. Commissions and Expenses at Port of Shipment.These include a charge of $2 \frac{1}{2}$ per cent. for brokerage, carting, grading, and storage; at the lowest possible calculation they cannot be reduced below an average expenditure of $\mathrm{I} \cdot 8$ pence per pound.

4. Administration, including Labour Expenses apart from the Collectors. - This item covers charges for salary of managers and assistants and wages of the labourers on daily or monthly pay, together with the maintenance of the staff. The average cost is not less than fourpence per pound of the annual output.

5. Disbursements on Account of Charges for recruiting Labourers, Interest on Loans, and Depreciation of Buildings.-Under this heading a reasonable allowance would be Io per cent., equal to 2.4 pence on the present local price of rubber; in most cases this amount is exceeded, and the average is probably slightly higher than the figure now given.

6. Ocean Freight. - The rates to Europe or the United States are sixty and sixty-five shillings per ton of 40 cubic feet from Pará and Manáos respectively; this is equivalent to slightly less than three-quarters of a penny per pound weight of rubber.

7. Export Duty and Other Charges previous to Shipment.-Including the dock dues, the average amount of these charges on the total exportation is $4^{\circ} 9$ pence per pound.

8. Commissions and Expenses in Europe or the United States.-At the present value of rubber the average aggregate of these charges for brokerage, handling, storage, and incidental expenses, is $r \cdot 8$ pence per pound. 
These various items summarized per pound of rubber are-

Pence.

I. Maintenance of collector $\quad \ldots \quad \ldots \quad \ldots \quad \ldots \quad$ II ${ }^{\circ} 7$

2. Transport $\quad \ldots \quad$... $\quad \ldots \quad$... $\quad \ldots \quad$ ro

3. Commissions and expenses at port of ship$\begin{array}{ccccccc}\text { ment } . . & \ldots & \ldots & \ldots & \ldots & \ldots & \mathrm{I} \cdot 8\end{array}$

4. Administration $\quad \ldots \quad$... $\quad \ldots \quad$... $4^{\circ}$

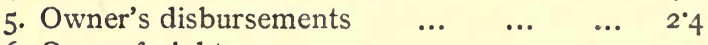

$\begin{array}{lllllll}6 . & \text { Ocean freight } \ldots & \ldots & \ldots & \ldots & \ldots & 0\end{array}$

7. Export duty and other expenses $\quad . . \quad \ldots \quad \ldots \quad 4^{\circ} 9$

8. Foreign commissions and charges ... $\quad \ldots \quad$ I.8

$\begin{array}{llllll}\text { Total } \quad \ldots & \ldots & \ldots & \ldots & 28 \cdot 3\end{array}$

If the prices ruling in January, I9I4, are applied to the total shipments of 33,23 I tons of fine, soft, and scrap rubber for the season I9I2-I3, the average price of these three qualities combined is $3 I$ pence per pound. A profit on the total output of 3 pence per pound is a very small margin to meet the competition of the Orient and the rapid expansion of production that must inevitably occur in connection with the increased acreage coming into bearing in the course of the next three years, and also on account of the greater yield from the trees as they grow older. In view of the present situation, it is probable that the production of the lower grades of Brazilian rubber will diminish to a marked extent; in such case the average amount for each collector would show an increase, and the average selling price would be enhanced in direct proportion to the shrinkage in the quantity of the inferior qualities.

To put the rubber industry of the Amazon Valley on a safe and sound basis, three main objects must be achieved. The first is to discover means of augment- 
ing the yield per tree without additional labour; the second, a substantial reduction in the cost of maintenance for the collector; and the third is the suppression of all, or a very substantial part of, the export duties and charges. Unless far-reaching and immediate action is taken to cope successfully with these three factors, production will decline rapidly, and in a very few years the situation will become practically hopeless.

The very great importance of the rubber industry to the general prosperity of Brazil is best shown by the record of production for the past eighty-six years. From 1827 to 1893 the returns are for the period January I to December 3I; from I894 to date the figures are for the crop season July I to June 30 . Since I827 the output has been-

\begin{tabular}{|c|r||r|r|}
\hline Years. & Tons. & Years. & \multicolumn{1}{|c|}{ Tons. } \\
\hline I827 & 31 & 1870 & 6,591 \\
1828 & $5 I$ & 1880 & 8,679 \\
1829 & 91 & 1890 & 16,394 \\
1830 & 156 & 1891 & 17,790 \\
1840 & 388 & 1892 & 18,609 \\
1850 & 1,467 & 1893 & 19,430 \\
1860 & 2,673 & & \\
\hline
\end{tabular}

\begin{tabular}{|c|c|c|c|}
\hline Crop Seasons. & Tons. & Crop Seasons. & Tons. \\
\hline I 894-95 & 19,470 & $1905-06$ & 34,680 \\
\hline $1895-96$ & 20,975 & 1906.07 & 37,540 \\
\hline I 896.97 & 22,320 & I907-08 & 36,650 \\
\hline $1897-98$ & 22,260 & I908-09 & $3^{8,5}$ I I \\
\hline 1898.99 & 25,355 & - 1909-10 & 39,494 \\
\hline I899-I900 & 28,695 & I9IO-II & 38,177 \\
\hline I g00-0I & 27,650 & I9II-I2 & 44,296 \\
\hline I9OI-02 & 29,971 & $19 I_{2-13}$ & 43,23 It \\
\hline 1902.03 & 29,890 & $I^{9} 3-I_{4}$ & 43,000 \\
\hline $1903 \cdot 04$ & 32,590 & & (estimated) \\
\hline $1904-05$ & 33,090 & & \\
\hline
\end{tabular}

* Stock, 3,39r tons inclusive.

$\dagger$ Stock, 1,500 tons inclusive. 
With the exception of produce from Bolivia, which is transit cargo, and passes through the Brazilian ports in bulk, all rubber is packed in boxes before shipment. Records kept at Pará in I9I2 show that the average weight of these cases in that year was-

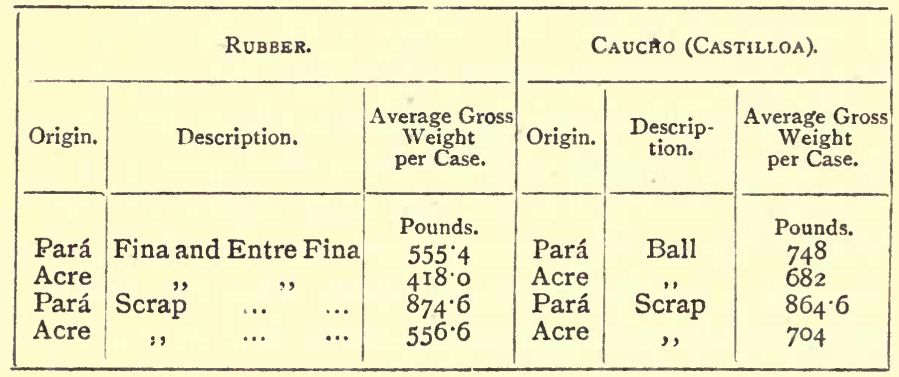

The Federal Government is quite aware of the disastrous effect the ruin of the Amazon rubber industry would entail in connection with the general prosperity of Brazil, but in Rio de Janeiro generally the economic conditions of the Northern States are not appreciated or understood. The necessity of a journey of fifteen days' duration between the Federal capital and the city of Manáos creates a barrier effectually blocking any free intercourse between the two sections of the country; furthermore, this lamentable ignorance of the true circumstances underlying the existing critical state of affairs in the rubber districts enables self-seeking politicians to distort the real facts of the case to suit their own purposes. The natural consequence of this isolation between north and south is a complete lack of sympathy on the part of the southern Brazilians with their northern compatriots. Serhaps no better illustra. 
tion of this feeling can be found than in the fact that the price and market movements of rubber are ignored completely in the commercial sections of the Rio de Janeiro and other southern newspapers, and a similar policy is maintained in regard to coffee by the Press in the northern States.

In January, IgI2, a law was sanctioned by the Brazilian Congress for relieving the industrial situation in the Amazon Valley, and on April I7 of that year the measure was declared operative by the Executive authority. Under this legislation a sum of $£ 520,000$ was provided by the National Treasury to meet the necessary disbursements for the establishment of various spheres of work in connection with the rubber industry, and an office designated the Superintendencia da Defesa de Boracha was created to carry into effect the provisions of the Act. This organization was placed under the direction of Dr. Raymundo Pereira da Silva, a clever and energetic administrator, who immediately set afoot plans for the betterment of conditions in Pará, Amazonas, and the National Territories. From the beginning, however, his efforts were crippled in many directions, not the least of his difficulties being the class of men available for service in the northern States. In Rio de Janeiro commercial business was flourishing and employment easy to obtain ; therefore the Amazon Valley presented no attractions to capable persons, in spite of the high salaries offered. In these circumstances it was not surprising that the results achieved by the various expeditions despatched for the purpose of opening experimental farms for the cultivation of food products and the encouragement of agricul- 
tural enterprise generally were attended by complete failure, in spite of the lavish expenditure incurred.

In great measure the law of January, I9I2, proved abortive, on account of the lack of knowledge of the characteristic features of the Amazon territories. It provided for immigration for the purpose of creating agricultural settlements, although the prevailing conditions are such as to render the establishment of small isolated communities futile of any benefit to the settlers themselves or to anybody else. Provision was made for the betterment of the sanitary state of the population, without realizing the magnitude of a task of this nature. None of the methods embraced by the new law were of any practical value as remedies to counteract the effects emanating from Oriental competition; therefore, after its application had been attempted for eighteen months, it was abandoned, and the department of the Defesa de Boracha suppressed.

It is possible for the Federal Government to afford effective and immediate relief to the rubber industry by taking action in two directions: the first by an agreement with the States interested to suspend the export duties, and the second by temporarily rescinding all charges levied upon the necessities of life imported into the Amazon Valley. So far as the first suggestion is concerned, the equitable basis for any such arrangement is for the Federal and State revenues to bear the loss equally. This would entail an annual subsidy of an aggregate sum of $£ \mathrm{I}, 000,000$, approximately, from the Federal Treasury to the States of Pará, Amazonas, Matto Grosso, and the administration of the National Territories; for the local Governments concerned, the 
suppression of the export duties infers a drastic retrenchment of all public expenditure, and a compromise with all creditors in regard to the partial suspension of interest payments on foreign and home indebtedness. If the Federal Administration offer to guarantee the principal of the internal claims and external loans, and one-half of the subsidy be devoted to the debt service, any hardship incidental to reduced cash payments could be mitigated to a very large extent.

The suspension of duties on imported merchandise is entirely within the province of the Federal Government, and in no way affects the State revenues. A special Act of Congress may be necessary to allow this step to be taken without any infringement of the Constitutional Law of the Republic ; but no serious objection could be raised to the passage of the measure in view of the existing situation, and it is unlikely that any strong opposition would be offered to such a proposal put forward by the Executive as an immediate and urgent necessity to save the rubber industry from partial ruin in the present, and possibly total extinction in the near future, at a loss of revenue to the Federal Exchequer of approximately $£ 650,000$ annually.

The effect of the suspension of the export duties would benefit the rubber producers to the extent of fivepence per pound; the suppression of the Customs charges on the necessities of life imported from abroad would diminish by not less than 25 per cent., the average cost of maintenance for the collector. Together these two items permit the substantial reduction of eightpence per pound in the average cost of production, bringing it down to twenty pence per pound. On this 
basis the rubber industry of the Amazon Valley could make a strong fight against the competition of Eastern plantations, even allowing for a considerable fall in the value of the product below the present level of prices.

The immediate relief afforded by the suppression of export and import duties is not sufficient to insure the future of the industry; it is essential that methods of tapping should be introduced increasing the yield per tree without the employment of additional labourers. A Commission should be appointed to investigate thoroughly this vexed question, and also to carry out practical experiments until the desired end be attained. For the purposes of this Commission, the services of scientific experts would be necessary, but this entails no difficulty whatever at the present time; in Dr. Willis, the Director of the Botanical Gardens at Rio de Janeiro, and formerly in charge of the Peradenyia station in Ceylon, and in Dr. Jacques Huber, the head of the Museo Goeldi at Pará, the country has two men of sound knowledge and ripe experience in Brazil and the Orient.* The remaining members of the Commission should be selected from men actually engaged in the business of rubber production in the Amazon Valley, and from that section of the commercial community directly connected with the rubber industry.

Briefly summed up, these suggestions for meeting the present crisis in a practical way are-The Federal Government to arrange with the States interested for

* Dr. Huber died after the above was written. His successor should be selected with special reference to the knowledge of the rubber industry. 
the suppression of the export duties, in consideration of an annual grant of $£ \mathrm{I}, 000,000$ for such period as may be required; to suspend temporarily the Customs charges on imported foodstuffs and other necessities of life, at an annual cost to the National Exchequer of some $£_{650,000 ;}$ and to appoint a competent Commission to investigate the question of the extraction of latex, in order to ascertain in what direction improvements can be made to increase the yield. The obligation to the State Governments is the introduction of drastic financial reforms and economies with a view to reduce public expenditure to one-half the present amount. It remains with the Brazilian people to decide whether the conservation of the rubber industry is worth the inevitable sacrifices it entails. 


\section{CHAPTER X}

\section{A COMPARISON OF THE BRAZILIAN AND ORIENTAL RUBBER INDUSTRIES}

Collective and individual energy-Sources of production-Area -Varieties of Hevea in Brazil and the Orient-Soil-Climatic conditions-Labour-supply-Wage rate-Cost of living-Administration-Age of production for rubber-trees-Girth and height of trees-Yield-Method of tapping-Preparation of latex -Transport facilities-Comparative exportation in I9r3-Initial expenditure-Cost of production-Future costs of production.

T I $876 \mathrm{Mr}$. Wickham obtained from the Amazon 1 Valley the seed for the foundation of the rubber industry of the Orient, and for that reason a comparison of the conditions and methods employed in connection with the two principal sources of the world's supply is instructive and interesting, in view of the present critical situation in both Brazil and the East.

In the Orient an abundant and cheap labour-supply permits the employment of large bodies of workmen, under efficient superintendence, for the daily performance of any manual labour required for plantation or other purposes. In Brazil the high wage rate practically prohibits the use of collective force, and all enterprise is dependent on the result of individual energy, with little or no supervision over the work in hand. In the former case the man is paid a specified sum and a fixed amount of work is exacted from him; in the latter the individual devotes as much or as little 
of his time to the task as he pleases, and receives pay. ment for results only.

With collective force methodical practices become an absolute necessity; with individual energy the line of least resistance is followed by instinct, and the outcome is often slovenly and uneven. If the work on the plantations of the Orient is compared with the exploitation of the rubber-trees in the Amazon Valley, the truth of this definition becomes apparent at once, and it is to the fundamental principles thereby involved that the great difference in the conditions of the rubber industry in Brazil and the East is due. It is more convenient to contrast the general physical features of the two centres of production to illustrate clearly the dissimilarity in existing conditions.

In the Orient the rubber-trees are carefully and systematically cultivated, and all possible assistance extended to foster rapid development and afford protection against disease. In Brazil the tree is a natural product of the forest, and no effort whatever is made to aid its growth or check the spread of pests of any kind. In the East the seed is selected with care, planted in specially prepared nurseries, and the young trees transferred subsequently to properly prepared land where the conditions afford every possible chance for both branch and root growth.

In Brazil the trees are self-sown, and only a very limited proportion of those germinating come to maturity in the dense shade of the surrounding forest. The acreage of planted trees in the Amazon Valley is of such limited extent that it does not affect the general conditions, and calls for no special consideration. 
The planted area in the East may be taken approximately as $I, 500,000$ acres, containing from I $80,000,000$ to $200,000,000$ trees. In the Amazon Valley no secure basis exists for an accurate estimate of the number of trees, but there is no reason to suppose that the figure of $200,000,000$ constantly put forward in official statements is an exaggeration. Indeed, many well-informed persons are of opinion that the total greatly exceeds that number.

In the East the industry was founded from seed taken by Mr. Wickham from the River Tapajoz in 1876 ; resulting in the reproduction of the white variety, and yielding rubber classified as "weak" (fraca) in the markets of Manáos and Pará. In the Amazon Valley the species principally utilized are the black (preta), the white (branca), the red (vermelha), and the Itapuru (Hevea Guayanensis). The first of these stands out preeminently for the resilient quality of the rubber it yields, while the product of the remaining three species is designated as "weak" (fraca), and sold on the Brazilian markets for 20 per cent. less value than that of the black (preta) variety.

It is needless to refer to the yield of rubber from the castilloa, always designated in Brazil as caucho, for it exists in such small quantities in the East that it is not a factor of any importance when discussing the comparative production of Brazil and the Orient; moreover, the exportation of this rubber from the Amazon Valley will be a thing of the past in the course of a few years, for reasons explained in the section dealing with the general conditions of the Brazilian industry.

In the East the rubber-tree is planted upon many different classes of soil, and with the aid of careful 
cultivation it thrives in a surprising manner in nearly all localities selected with reasonable foresight in regard to the avoidance of undrained swampy lands or those exposed to strong prevailing winds. Throughout the Amazon Valley the soil is alluvial deposit on yellow or red clay, and rich in vegetable matter brought down by the rivers and distributed over the land by the annual floods. In many districts of the Lower Amazon the trees have their roots permanently below the water-level, and are flourishing under such circumstances in direct contrast to the result of all experience in the Orient.

In the matter of rainfall, there is no great difference between the Amazon Valley and the Malay Peninsula. Both receive an average quantity of a little over Ioo inches annually; but in Malay the distribution is more even than in Brazil, where a dry season, beginning in June and ending in October, is a regular occurrence. The temperature records show no very great variation, although they are slightly lower in the Amazon Valley. The heat, however, is less trying in Brazil than in Malaysia, for during the dry season there is only a comparatively small amount of moisture in the atmosphere.

The labour for working the rubber plantations in the Orient is drawn from China, India, or local sources, and it is sufficiently abundant to insure large num. bers being available at a comparatively low cost for all classes of work in the fields or factories. Skilled mechanics are also cheap and plentiful, and the supply of domestic servants is ample.

In the Amazon Valley the labourers are brought from the States of Ceará, Rio Grande do Norte, Maranhao, 
and Parahyba, where the bulk of the population is of negro or half-caste blood. Skilled labour is scarce and expensive, no matter whether Brazilians or Europeans are employed, and trained household servants are not obtainable.

In the Orient the average daily wage rate is under one shilling, without rations, for able-bodied men, and women and children receive a much smaller remuneration. In the rubber districts of Brazil the average rate is six shillings and eightpence per day, with rations, together nearly eight shillings when allowance is made for the price of the food.

The rubber collector receives no money wage, but is a partner with the owner of the estate, and is entitled to 50 per cent. of the rubber he delivers during the season.

In the East the coolie lives on rice and curry, at a cost of a few pence a day. In the Amazon Valley the labourers cannot buy the necessities of life for a less expenditure than two shillings and sixpence per day.

Throughout the Orient large numbers of competent men, experienced in the management of agricultural and plantation enterprises, are always to be found, while in the rubber districts of Brazil it is seldom that the services of any capable administrators or managers are available. In the East a modest salary suffices for such men; in the Amazon Valley a princely income is demanded for the indifferent performance of the duties essential to any responsible post.

In the Orient rubber-trees begin to produce when four years old. In Brazil young trees are left untouched at this period, and the generally accepted 
theory is that they cannot be tapped without injurious effects until they are twelve or fifteen years of age.

In the East a rubber-tree 75 feet high with a girth of 100 inches at 3 feet from the ground is looked upon as a giant. In the Amazon Valley a tree of 150 feet high and 200 inches in girth is not considered anything out of the common.

On account of the lack of reliable records in the past, it is practically impossible to compare the yield of forest trees in Brazil with those cultivated in the plantations of the Orient. In the districts of the River Madeira and the River Purús, the average return for thoroughly mature trees works out approximately at 5 pounds per tree; in the country adjoining the upper rivers, where the trees have been tapped only in recent years, the average yield is higher, and reaches nearly 7 pounds per tree. This would correspond to a crop in Malay from good trees of from twelve to fifteen years of age.

In the districts of the Lower Amazon, where the trees have been damaged severely by bad tapping extending over half a century, the average return does not exceed 3 pounds per tree.

In the Orient the excision system of herring-bone tapping, with occasional modifications, has become the basis for the extraction of latex from all trees of the Hevea species. It has been reduced to something approaching perfection by expert tappers under competent and vigilant superintendence, and it has been so far developed as to allow of thirty cuts to the inch of bark without injury to the cambium. An average of twenty to twenty-three cuts to the inch is expected 


\section{THE RUBBER INDUSTRY}

from tappers on the majority of the estates, and this is done with gouge, farrier's or Burgess knife, or other tools constructed on like principles.

In the Amazon Valley the incision method is universal, and the implement used is the small axe known as the machadinho, with which a triangular gash is made. Every cut so inflicted penetrates to the cambium, and in a large proportion of cases renders the trees open to the ravages of the borer and white ant. The result of this ruthless slashing of the trunk is that in a few years the tree is covered with warts, over which the bark grows very slowly, and tapping becomes extremely difficult and uncertain. Sometimes overhead tapping is resorted to; more often the tree is abandoned for several years, until Nature repairs the damage done. The work is left entirely in the hands of the ignorant freguez (collector), who cares nothing about the welfare of the trees, and looks only to the amount of latex he can obtain to repay him for his work of collection and preparation.

On the River Madeira a little supervision has been attempted, but elsewhere the proprietors have regarded with apathy in the past the practical destruction of their trees, owing in great part to the fact that the number untouched in the forest was so great that fresh sources of supply could be opened up when those in tapping became worthless.

In the East the preparation of latex takes place in systematically-arranged factories where cleanliness is always kept in view. Coagulation is attained generally by acids, and effective machinery is employed to prepare and dry the rubber for the market. Economy is 


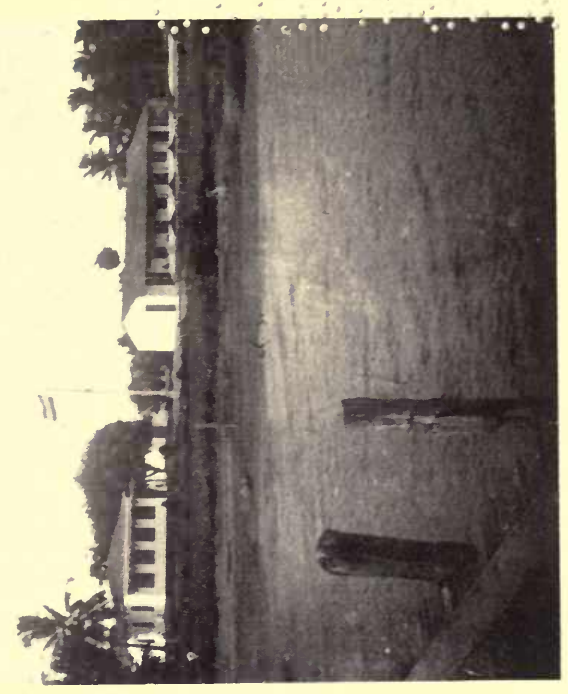

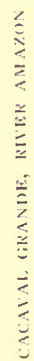

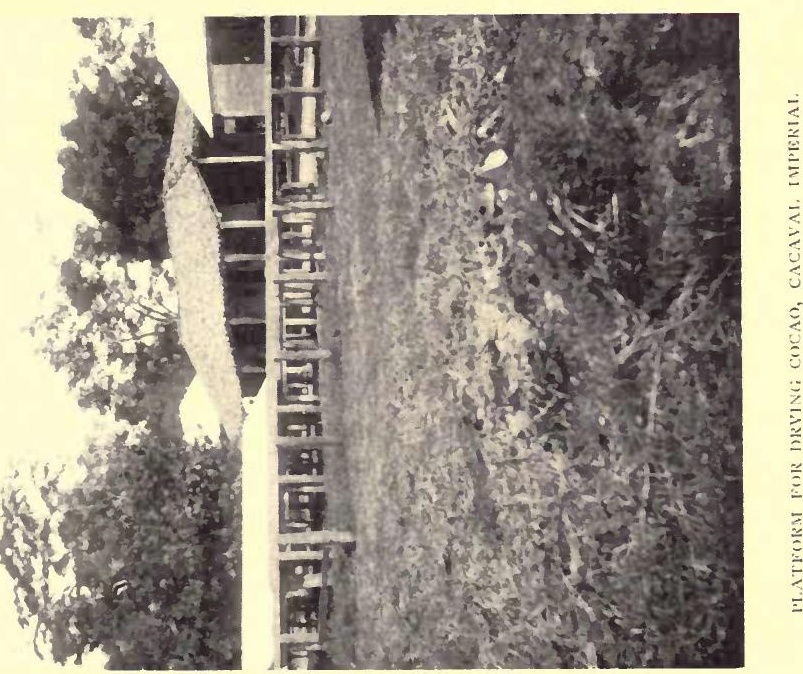





\section{BRAZIL AND THE EAST COMPARED}

practised in all details from the time of the collection of the latex and scrap in the field to the date of shipment for exportation. In Brazil the latex is carried to a temporary shack and coagulated with the smoke of the Urucury nut. No effort at cleanliness is attempted, and grit, sand, and other foreign matter from the dirty surroundings, invariably find their way into the rubber to more or less extent. No systematic effort is made to dry the rubber before shipment, and it contains as a rule not less than 20 per cent. of moisture, and not infrequently over 25 per cent. Very little of the tree scrap is collected, and the cup coagulations brought in are thrown on the mud floor of the hut, there to remain until the accumulated quantity is sufficient for delivery. This scrap is shipped to the market in a semi-putrid condition, and in that state finds its way to Europe or the United States. Economical methods are unknown on a Brazilian rubber property, and consequently the loss in value on the quality of fine rubber and quantity in the scrap from the time the latex is extracted from the tree to the date of sale is certainly not less than to per cent., and is often very much greater.

In the East transport to the port of shipment is easy and inexpensive, no matter whether the production be in Ceylon, Malay, Java, or Sumatra. In the Amazon Valley the rubber properties are for the most part situated on rivers far distant from Manáos or Pará, and the cost of steamer freight to one or other of those ports is a considerable item in the cost of production.

The total exportation of rubber from the Orient in IgI3 was stated to be 56,000 tons. From the Amazon 
Valley the shipments for the season July I, IgI2, to June 30 , I9I3, were 43,230 tons, including IO, I30 tons of castilloa. For I9I4 the total export of the East is calculated at 84,000 tons, while that of Brazil for the season I9I3-I4 is estimated at 43,000 tons. For the first time in history, last year saw a greater supply of rubber from the Orient than from the Amazon Valley. This means that plantation rubber becomes the dominant factor in the market, and prices for the raw material will depend more and more in future on the plantation industry, and not on the forest product.

In the Malay Peninsula a fair basis of price for bringing $I, 000$ acres of rubber into bearing is $£ 30$ per acre. In the Amazon Valley the only initial expenditure required is for the construction of houses for the administration, and the cost of bringing the collectors to the property, this latter expense being recoverable nominally from the men.

In the Malay Peninsula in IgI 2 the average cost of producing a pound of rubber was-

Cents.

I. Collection (including cost of cups, deprecia. tion, etc.)

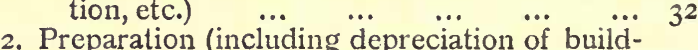
(Including depreciation of buildings, factory, and machinery) $\quad \ldots \quad$... 6

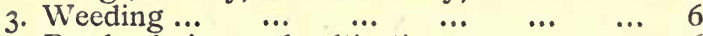

4. Roads, drains, and cultivation $\quad \ldots .61 . .66$

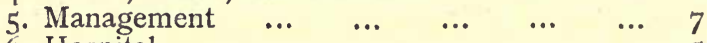

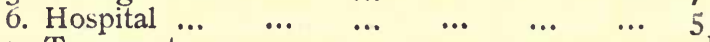

7. Transport

8. Commission

9. Rent

$\begin{array}{lll}\cdots & \ldots & \cdots\end{array}$ 


\section{BRAZIL AND THE EAST COMPARED}

To this must be added the following expenses to date of sale in Europe:

Pence.

$\begin{array}{lllllll}\text { I. Freight } \ldots & \ldots & \ldots & \ldots & \ldots & \ldots & 0 \\ & & & \end{array}$

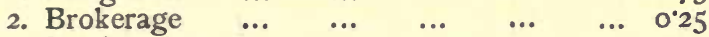

3. Sundry charges $\quad \ldots \quad$... $\quad \ldots \quad$... 1 1 75

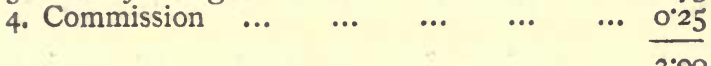

This brings the total cost up to date of sale to Is. Iod. per pound.

In Brazil the cost per pound of rubber up to date of sale in IgI3 was-

to Manáos or Pará ...

2. Commission and charges $\quad \ldots \quad \ldots \quad \ldots \quad \ldots \quad r \cdot 8$

3. Administration and owners' disbursements $6{ }^{\circ} 4$

4. Cost of maintenance of collector delivering $\begin{array}{lllll}750 & \text { pounds of rubber } \quad \ldots & \ldots & \ldots & \mathrm{II}^{\circ} 7\end{array}$

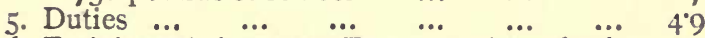

6. Freight and charges to Europe to date of sale $\quad 25$

$28 \cdot 3$

For the purposes of this calculation, the average value of all qualities of rubber is taken at $2 \mathrm{~s}$. $7 \mathrm{~d}$. per pound sold in London.

It is stated on good authority that as the trees grow older and yield more freely, and the expense of weeding diminishes, the costs in the Orient can be reduced to a substantial extent, and that these factors, combined with a lower range of prices affecting all ad valorem charges, will enable an average cost of Is. $3 \mathrm{~d}$. to be reached within five years. I see no reason to doubt that this lower figure will be attained within the time indicated, especially as it is already an accomplished fact on many Ceylon properties.

In the Amazon Valley a similar position can be 
achieved if improved methods of tapping, largely increasing production without additional labour, can be introduced; by more systematic administration; by opening up the reserves of untouched trees; by cheapening the price of living by a reduction in the charges on imported foodstuffs; and by diminution or abolition of the export duties.

By such means only is it possible for Brazil to meet successfully the competition of the Orient in the world's markets. That such reduced costs can be brought about there is no doubt whatever, if the measures indicated in detail elsewhere in this description of the Brazilian rubber industry are adopted without undue delay. 


\section{PART II}

\section{'THE RUBBER INDUSTRY IN THE ORIENT}

\section{CHAPTER XI \\ CEYLON}

Locality-Extent-Tenure of land-Taxation-Elevation above sea-level-Rainfall-Soil-Origin of the rubber industry-Health of rubber-trees-The rubber "boom" and Ceylon-Capitalization of rubber estates - Working expenses - Revenue from young plantations-Organization of estates-Frequency of tappingRecent experiments in regard to preparation of latex.

CEYLON has taken a leading place in the development of tropical agriculture in the past, and with the establishment of the proposed School of Tropical Agriculture at Peradeniya the island will become the scientific training centre for the British possessions in the East.

Since Ceylon was separated from the Madras Presidency in I80r, and created into a Crown colony, the main source of industry and wealth has been agricultural. The island has experienced many phases of existence during the past century, and more than once has been on the verge of bankruptcy. From 1875 to I 880 the community was faced with ruin by the devastation of the coffee plantations from leaf disease (Hamilia vastatrix); in five years this pest assumed such 
alarming proportions that the majority of the coffee estates were abandoned. In this extremity the planters turned their attention to the cultivation of cinchona and tea, and for several years struggled hard against adverse circumstances. At the time when the yield from the cinchona plantations should have brought relief, all hopes in this direction were shattered by a heavy drop in the value of the bark owing to over-production. With the cultivation of tea the community was more fortunate, and after a long period of constant struggle this industry was successfully established on a profitable and sound basis. The training undergone by the planters in the successive experiences of the cultivation of coffee, cinchona, and tea, served them in good stead when the question of the creation of rubber estates came to the front, and they are now reaping the reward of the knowledge they acquired under less prosperous conditions. The most important facts concerning the Ceylon rubber industry are summarized in the following brief description of the present situation:

It is in the districts of the south-west portion of the island where the principal rubber plantations are situated. They are comprised within an area lying five miles in a direct line from the seaboard, and extend from Galle on the south coast, northwards to Kandy and Matale; from the latter point westward to Kurunegala, and from that place in a south-westerly direction towards Negombo; thence to Colombo, Kalutara, and Alutgama. Nine-tenths of the rubber-producing industry is within this zone.

The total extent of the rubber estates of Ceylon in IgII was 2 I 5,000 acres; in I9I 2 it increased to 234,000 
acres; and in I9I3 a further extension to 247,000 acres took place. There remains a large reserve of forest, probably not less than 200,000 acres, suitable for rubberplanting. These lands are owned partly by the Crown, and partly by private persons. In the latter case the values have risen very greatly during the past five years, and as a result planters are unwilling at present to pay the price demanded by the proprietors, who for the most part are Sinhalese. Crown lands are sold by public auction on the application of the would-be purchaser. In this case also the average price per acre has advanced to three and four times the value ruling a few years ago. The reserve price is placed at a low figure, but not less than Rs. I5 per acre; but sales at Rs. Ioo per acre are not infrequent, and even higher prices are occasionally recorded when the land adjoins established plantations.

Nearly all real estate is freehold, with title direct from the Crown. The only exceptions are certain tracts claimed by Sinhalese in virtue of long occupation and cultivation. On these areas no rubber plantations have yet been opened.

No direct taxation is imposed on the rubber-growing industry. The public revenue is derived from import duties, licences, stamps, sales of land, and other indirect sources. A small contribution of Rs. I $\frac{1}{2}$ per capita is enacted for the maintenance of public roads, but members of any volunteer military organization in Ceylon are exempted from payment. Indian coolie labourers are also exempt from this tax.

The altitude of the rubber-growing districts varies from a few feet above sea-level in the Kalutara, Kelani 
Valley, and other districts, to that of $I, 700$ feet at Peradeniya and the vicinity of Kandy. The development of Pará rubber-trees at elevations from sea-level to a height of 700 feet in the districts of Kelani Valley, Kalutara, and those lying to the south of Adam's Peak, is undoubtedly much greater than is obtained at the higher altitudes around and to the north of Kandy, but this may be accounted for to a very great extent by the more abundant rainfall in the former area.

The rainfall is very unevenly distributed throughout the island. To the south of the range of mountains of which Adam's Peak is the central point, the annual fall varies from 132 inches to I70 inches; in the neighbourhood of Kandy it is from 72 inches to 92 inches; in the district of Matale it averages 75 inches. In the northern section of the island, at Anuradhapura and the surrounding districts, the annual fall is frequently below 40 inches. The moisture brought by the northeast and south-west monsoons is precipitated by the mountain ranges in the vicinity of Adam's Peak, 7,200 feet above sea-level.

The soil throughout the rubber-growing districts is a gritty and somewhat sandy red loam. A large proportion of the planted sections were cultivated many years before the introduction of the rubber industry, and humus and topsoil have been washed away by constant heavy rainfall. Many plantations are located on rocky hillsides, and the trees are thriving under those conditions. To remedy the effects of the loss of topsoil, the practice of manuring has become accepted as a necessity on nearly all plantations, and, as a general rule, this work is commenced immediately the young trees are planted. The usual practice is to 
apply 840 pounds of superphosphates, mixed with other artificial fertilizers, per acre during the first six years of the plantation, and subsequently to continue this treatment after the trees reach the tapping stage. Green crops also are grown amongst young trees for purposes of manuring, and this method has given some excellent results. It remains to be seen how far manuring will benefit the trees when further development causes them to resume a forest character.

The rubber industry in Ceylon owes its foundation to seeds collected in 1876 , by $\mathrm{Mr}$. Wickham, in the Amazon Valley. These were germinated at Kew, and plants were then sent to Ceylon, and set out in the gardens at Heneratgoda and Peradeniya. Seeds from these trees were distributed freely to owners of estates between $\mathrm{I} 88 \mathrm{I}$ and $\mathrm{r} 8 \mathrm{gI}$; but the idea prevailed that only marshy ground was suitable for their growth, and therefore little interest was taken in their cultivation. A few experiments, however, were made for planting them on hillsides, and these proved of so successful a character that the area rapidly increased. Between I 898 and I904 a large number of tea plantations were interplanted with rubber-trees, and from the latter date the extension of existing plantations and the opening up of new ones has been pushed forward with energy and method. The industry to-day is firmly established in Ceylon, and promises to become quite as staple and valuable as the cultivation of tea, rice, cacao, or coconuts. An indication of the permanent manner in which it has taken root is seen in the small patches of rubber-trees planted by many Sinhalese near their houses and villages.

In all the districts the trees are in a sound and 
healthy condition, whether at high or low altitudes. A little fungus leading to canker exists in some localities, but not to an extent threatening any serious loss to plantations. Cambium rot and bark disease is prevalent in some districts, especially Matale, but is kept in check by adequate measures and remedies. A certain percentage of the older trees have been damaged by bad tapping through inexperience, but the majority of these show every indication of practically complete recovery. A few insect pests are noticed, such as borer and white ants, but none that cannot be controlled by proper treatment. A liberal estimate of the loss of trees from all causes on the existing rubber plantations should not exceed 3 per cent. The worst enemy of the rubber industry in Ceylon is wind. Where continuous strong winds prevail a stunted growth results; but these conditions are only found in a few localities -for instance, certain sections of the Matale district, where plantations are exposed to strong prevailing winds on the higher ridges.

A large number of the rubber estates established previous to I904 were due to the fact that rubber was interplanted with tea as a shade tree for the latter. As the trees developed and rubber became more valuable, the tea was abandoned owing to the shade becoming too dense to allow of profitable cultivation, but not until the tapping of the rubber-trees had begun. In these conditions the initial cost of the rubber estates for all practical purposes has been nil. When the rubber boom began, many of these properties were purchased by companies formed in London and elsewhere. In some cases exorbitant 
prices were paid, but as a general rule the valuation was not excessive, in view of the price at which rubber was then selling in Europe. Since I904 new estates have been opened up and additional acreage added to existing estates, but as a rule this work has been carried out on a conservative basis of cost. The same conditions apply to estates being planted at the present time, with the exception of paying a higher price for suitable land.

Close investigation of all essential details shows the following expenditure to be necessary for the establishment of new plantations on forest lands :

Distribution of Cost when opening an Estate: Expenses FIRST SIX YEARS

Vupees.

I. Value of 1,200 acres of forest land at Rs. 60 per acre $\quad \ldots \quad \quad \ldots \quad \ldots \quad \quad \ldots \quad 7^{2,000}$

2. Felling, lopping, burning, and cleaning

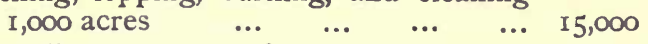

3. Weeding $I, 000$ acres for six years $\quad \ldots \quad 90,000$

4. Draining 1,000 acres $\quad \ldots \quad \ldots \quad \ldots \quad \ldots \quad 15,000$

5. Roads and bridges ... $\quad \ldots \quad$... $\quad \ldots \quad 20,000$

6. Holing, lining, and filling, on I,000 acres 4,000

7. Planting and supplying $\ldots \quad$... $\quad \ldots \quad 2,000$

8. 200,000 two-year-old plants $\quad \ldots \quad \ldots 6,000$

9. Building and equipment of factory $\quad \ldots \quad 50,000$

ro. Building bungalows for manager, assist. ant, and conductors $\quad \ldots \quad \ldots \quad \ldots \quad \ldots \quad 20,000$

I I. Building lines for coolies ... $\quad \ldots \quad \quad \ldots \quad 24,000$

I2. Purchase of tools, etc. $\quad \ldots \quad$... $\quad \ldots$ ro, 000

13. Manuring $\quad \ldots \quad$... $\quad \ldots \quad$...

I4. Management for six years $\quad \ldots \quad$... 90,000

Total $\quad \ldots \quad \ldots \quad \ldots \quad \ldots 463,000$

Value of 200 acres forest $\quad \ldots \quad 12,000$

Capital value 1,000 acres rubber 451,000 
This allows a high rate of cost for all work and for the erection of first-class permanent buildings, but does not include the capital employed for recruiting coolies, which on an estate of $I, 000$ acres would amount to the sum of from Rs. I5,000 to Rs. 20,000. Nominally these so-called "noast advances" are recoverable; in reality they are very seldom refunded.

As has been pointed out already, the older plantations, where rubber has taken the place of tea, can hardly be said to have any original capital value, unless the cost of bringing the tea under cultivation in former years is taken into consideration. What frequently happened was that local companies were formed to obtain control of groups of these former tea estates. These, again, were sold to London companies with sterling capital. One such group was the Grand Central, which now has 12,500 acres under rubber. In this case the properties were turned over by the vendors at a valuation of $£ 9 \mathrm{I}$ per acre. Another instance is the small property of Doranakandy, which was purchased for $£ 44,000$, contains 220 acres of rubber now averaging twelve years old, and yielded II2,000 pounds of rubber in r9I3. In very few instances do any fixed interest charges exist, nearly all development being carried out by money subscribed for the ordinary shares. As shown in the foregoing calculation, the actual necessary cost of opening up a new plantation, and maintaining it properly until the trees are six years old, should not exceed $£ 30$ per acre for estates of from 500 to $I, 000$ acres, this including purchase price of land and the necessary buildings and machinery. A carefully checked estimate furnished by a most reliable and practical planter places the cost of a thoroughly well 


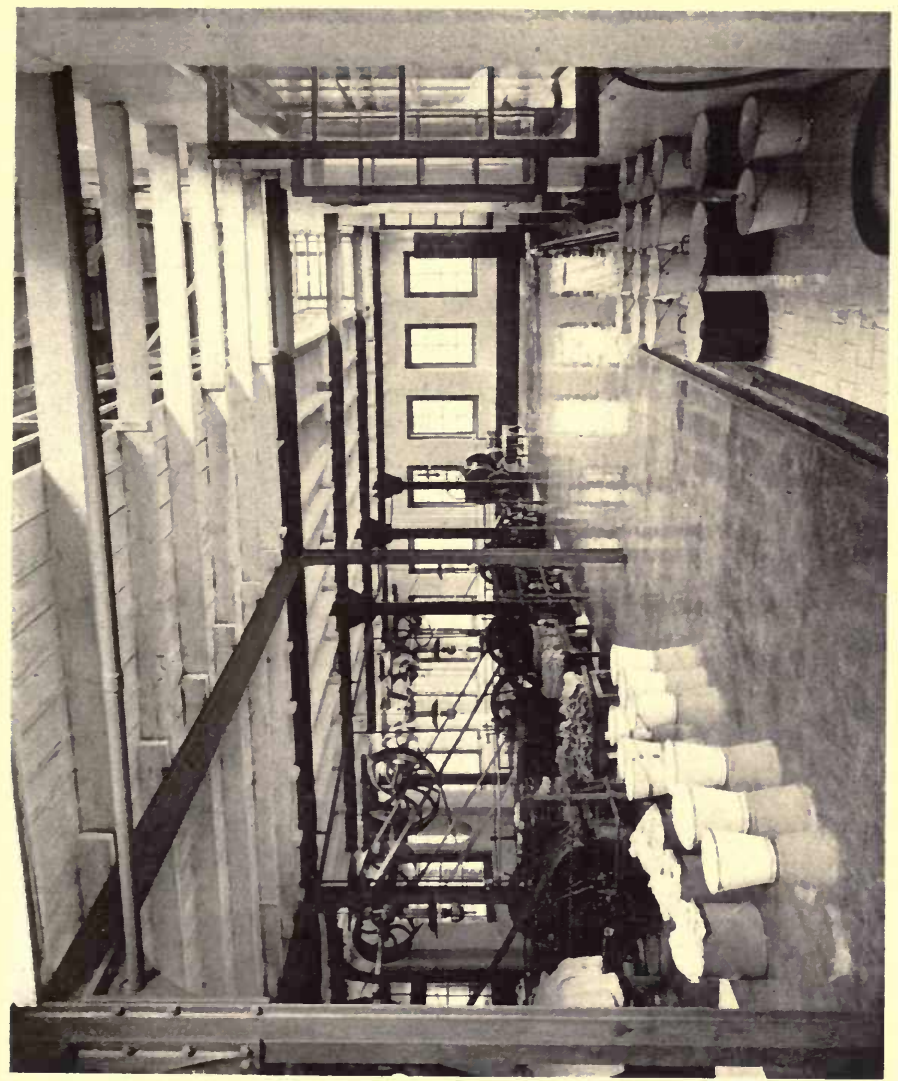

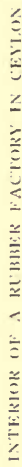



equipped factory, capable of handling not less than 400,000 pounds of rubber annually, at a sum not exceeding $£ 3,300$. The machinery now in general use is simple, effective, and not costly. Oil-engines burning liquid fuel provide the required motive power. These engines in Ceylon are generally supplied by Hornsby and Co. or Crossley and Co., and other British manufacturers, and the fuel for them costs approximately threepence per gallon, delivered on the estate. The price of the creping and washing machines is $£ 95$ each, delivered at the factory. The most modern washing machines for scrap are more expensive, and they run as high as $£^{250}$, but only one is required when handling a crop of 400,000 to 450,000 pounds of rubber. The only other machine is the dryer; one with two chambers of the Passberg patent would be required for a crop of the size mentioned, and could be installed for approximately $£ 800$. A less costly dryer, but not so effective, is supplied by the Colombo Commercial Company for $£ 260$.

For an estate of 1,000 acres of rubber six years old the working expenses should be approximately as follows :

I. Collecting and curing

2. Maintenance of roads and drains

Rupees.

3. Weeding $\ldots$...

50,000

4. Manuring

5,000

6,000

5. Cultivation (forking over land, etc.)

18,000

6. Management (manager, two European assistants, chemist, two conductors, clerks, etc.)

... 25,000

7. Depreciation on buildings and machinery $\quad \mathbf{I} 5,000$

8. Transport $\quad \ldots \quad$... $\quad \ldots \quad$... $\quad \ldots \quad 3, \infty, 00$

9. Colombo agents' commission $\quad \ldots \quad$... 4,000

Io. Contingencies

... $\quad$...

... $\quad \ldots \quad 10,000$

Total

... I 48,000 
Allowing for the high rate of exchange now ruling, this equals $£$ Io,0oo. Of this total expenditure, twothirds, or Rs. I00,000, is for payments to labourers employed on the estate. The average rate of wages for men, women, and children, is 35 cents per day for Tamil coolies, and for an estate of I,000 acres about I,000 in all are required, these working twenty-four days in each month.

The total yield from an estate of I,00o acres of sixyear-old trees in districts such as Kalutara or Kelani Valley should be not less than I50,000 pounds of fine dry rubber, equal to I pound per tree of dry rubber, or one-third of a gallon of latex. In addition to this yield of fine quality there will be $I_{5}$ per cent. scrap. Values in Colombo to-day (January, I9I4) range from 2s. 2 d. to $2 \mathrm{~s}$. $4 \mathrm{~d}$. per pound for fine plantation. At these prices the value of the crop of $1_{50,000}$ pounds of first latex would be in round figures $£$ I6,708, and in addition $£ 2,000$ for the value of the lump and scrap, making a total of $£$ I 8,700 , leaving a net profit of $£ 8,700$ to the estate. If prices fall to half the present value, the net deficit would be $£ 300$ on an estate of 1,000 acres of six-year-old trees, representing a capital investment of $£ 30,000$, unless expenditure is curtailed below the present scale, as probably would happen. The yield should increase steadily during the succeeding years in much greater ratio than the costs of production, and when the trees are twelve years old the output from $I, 000$ acres of 150 trees per acre should not fall short of 450,000 pounds of dry rubber. When this period of development is reached, the average cost per pound 
of dry rubber placed f.o.b. Colombo should be as follows :

Cents.

I. Collecting (including maintenance of drains $\begin{array}{lllllll}\text { and roads) } & \ldots & \ldots & \ldots & \ldots & \ldots & 20\end{array}$

2. Curing (including depreciation of factory and

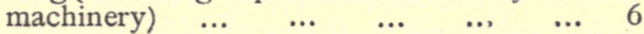

3. Management (including all charges connected $\begin{array}{lllll}\text { with administration) } \ldots & \ldots & \ldots & \ldots & 7\end{array}$

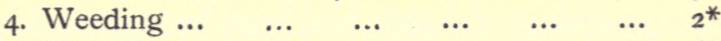

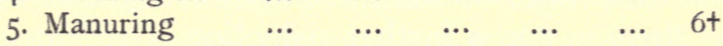

6. Cultivation (forking over land, cutting out,

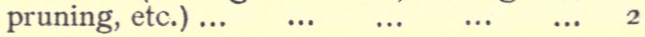

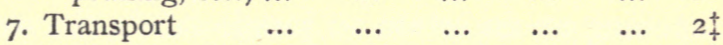

8. Colombo agents ... $\quad \ldots \quad \ldots \quad \ldots \quad \ldots \quad 2 \frac{1}{2}+$

Total $\quad \ldots \quad \ldots \quad \ldots \quad \overline{47 \frac{1}{2}}$

Allowing $2 \frac{1}{2}$ cents per pound for all unforeseen contingencies, production should not cost more than 50 cents per pound, equal to 8d., f.o.b. at Colombo. At this rate a crop of 400,000 pounds would cost $£$ I3,300 to collect and place in Colombo. At Is. per pound it would be worth $£ 20,000$, and return a profit of 20 per cent. on $£ 30$ per acre.

The charges per pound from Colombo to London at present are-

Pence.

I. Freight at 65 s. per 50 cubic feet $\quad \ldots \quad \ldots \quad \ldots$

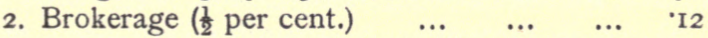

3. Insurance, sale charges, and other expenses

$\begin{array}{llllll}\left(\mathrm{r} \frac{1}{2} \text { per cent.) }\right. & \ldots & \ldots & \ldots & \ldots & 37\end{array}$

4. Merchants' commission (I per cent.) $\quad \ldots \quad \stackrel{25}{\square}$

Total $\ldots \quad \ldots \quad \ldots \quad \ldots \overline{r^{\circ} 44}$

(Calculated on a price of 2 s. per pound.)

- This figure is considered somewhat high.

+ Allows Rs. 27 per acre per annum.

$\ddagger$ Practically a permanent charge. 
With a drop in the value of rubber to Is. $6 \mathrm{~d}$. per pound, these charges, with the exception of that for freight, will be reduced automatically.

From the data given, it will be seen that the actual necessary cost of Ceylon rubber from estates with trees averaging twelve years of age should not exceed gd. to rod. per pound placed in the London market. In several cases the total cost has been brought below that figure already, and a further reduction is anticipated in the near future.

In opening up an estate on jungle lands, the work of felling the timber, lopping, and burning, is given out to contractors, the usual price paid being Rs. I5 per acre. Lining, holing, and filling, costs Rs. 4 per acre. Weeding is done by contract at Rs. $2 \frac{1}{2}$ per acre per month for the first year, Rs. 2 per acre per month the second year, and Rs. I $\frac{1}{2}$ per acre per month the third year. The price is then gradually reduced until it reaches 60 cents, or sometimes as low as 50 cents, per acre per month, and it continues to be an annual charge at this rate. In Ceylon trees have been planted at varying distances apart during past years, but the measurements hitherto accepted as most satisfactory are 20 feet by I 5 feet, giving I49 trees to the acre; there is, however, a growing tendency towards wider planting and a reduction of the number of trees to Ioo or less per acre. As a rule two-year-old stumps are used in planting an estate; but some very successful results have been obtained from planting seeds, although there is always danger of injury from rats and other pests. The planting of catch crops between the lines of rubber-trees is now generally deprecated as 
seriously retarding the growth, and the practice has been abandoned, with few exceptions. Tapping is begun on trees of five years old if the girth is 18 inches or more at 3 feet from the base, the methods in general use being the single $\mathbf{V}$, the half-spiral, and the herringbone. Women, and children of fourteen to sixteen years, are frequently employed at this work, and become expert tappers. Tapping begins at daybreak, and by ro a.m. the bulk of the latex is delivered at the factory, where it is mixed with an equal quantity of water and then treated with acetic acid in the proportion of $I$ part acid to $\mathrm{I}, 000$ parts latex, or an even weaker solution if the density is high, to produce coagulation; it is then passed through the washing and creping machines, and thence to the vacuum dryer or the drying-rooms. The proportion of rubber to latex of average density should be I pound of dry rubber to one-third of a gallon of latex. When the drying machine is used, the rubber after treatment is conveyed to well-ventilated rooms, where it is hung for some days; when no artificial heat is possible, the rubber is suspended in sheds for several weeks to allow the moisture to evaporate. It is then packed in wooden boxes containing II2 pounds each, and is ready for shipment to Colombo, where it is received and stored by agents until shipped or sold locally.

Opinion is much divided on the question of frequency of tapping. In some quarters it is stated that practical experience shows the trees tapped daily or on alternate days yield an equal quantity of latex at the end of a year. A few planters maintain that tri-weekly tapping will produce as much latex as in the case of trees 
opened daily. Various experiments have been undertaken at Peradeniya and on private estates with the object of deciding this very important point, but the evidence brought forward hitherto is not conclusive in regard to the general average results over large areas. The tendency of the trials made in different districts is to demonstrate that results are very largely dependent on local conditions of rainfall, soil, and atmospheric influences, and the state of health of the trees. It may be possible to adjust conditions to some extent by the application of various classes of manure. Some tests in this direction have been made recently, but these have not yet been carried out to a sufficient extent to permit of the formation of any definite opinion on the subject. It is of the utmost importance that this question should be solved, for fewer tappings mean economy in labour and a substantial reduction in the cost of production of every pound of rubber, and also additional time for the recovery of the latex cells and the general health of the tree.

The renewal of the cortex over the tapped surface is fairly satisfactory in Ceylon, although not nearly so rapid as the growth in the Malay Peninsula or in the Amazon Valley. At the higher altitudes the renewal is slower than in the districts of the Kelani Valley and Kalutara. In order to counteract any unsatisfactory results in connection with the somewhat slow growth, the experiment is being made of tapping with one cut only in place of two or three excisions; on one estate in Matale where this test has been made the average yield of latex per acre showed no diminution at the end of a trial extending over six months. If further experience 
proves that fewer cuts mean no substantial reduction in the quantity of rubber, a most important advance will be achieved, for the constant drain on the resources of the trees will be lightened to an appreciable extent.

In view of the lower prices for plantation rubber as compared to the fine product from Brazil, various experiments were made in I 913 to apply Brazilian methods of coagulating the latex by the smoking process. In this connection Mr. H. A. Wickham, the "father of the rubber industry," has taken an active part; he has succeeded in producing an article closely resembling fine hard Pará, and a small consignment of this was sold recently in the London market at the same price as that quoted for the highest-grade Brazilian product. The inference is that some change in the established methods of preparing the latex may prove of distinct advantage to the producers. To cure the latex without any injury to the nerve of the rubber is a consideration calling for very close attention, and the present system of maceration after coagulation obviously does not tend in that direction, although the tearing apart of the tissues in the creping machines inflicts less harm on the crude material than might be expected. As matters are to-day, the curing process is convenient and rapid; but it remains to be seen if more tardy results obtained by a partial reversion to the means employed in the Amazon Valley are not justified by higher values in the markets, and whether the additional price does not more than compensate for the cost of the extra labour employed. Reference to this subject has been made in the section of this book devoted to the Brazilian rubber industry; but many of the principal difficulties in con- 
nection with preparation of latex in the Amazon Valley do not exist in Ceylon, and experiments on a comparatively large scale can be conducted throughout the East at comparatively trifling expense to test any process likely to prove beneficial to the industry generally. 


\section{CHAPTER XII \\ CEYLON-Continued}

Yleld and density of latex-Bulletin of the Ceylon Government Department of Agriculture-Advantages of Ceylon for rubber production-The labour question-Discipline on estates-Standard of living-Future development and cost of production-Ceará and castilloa-Exportation of rubber from Ceylon since I904.

W ITH the exception of the period covered by February and March, when the weather is dry and the trees are wintering, tapping in Ceylon is continued regularly throughout the year. On some - states it is not suspended during the time mentioned, but the general rule has been to stop the work for these few weeks to allow the trees to recuperate from the exhausting effects of the constant extraction of latex during the previous ten months. When tapping does take place in this latter portion of the dry season, the yield deteriorates both in quality and quantity.

The ages of trees on Ceylon estates vary so greatly that it is difficult to obtain accurate statistics of yields over any large acreage. At Culloden Estate, in the Kalutara District, a section comprising seventy-nine trees gave the following results:

\begin{tabular}{|c|c|c|}
\hline Year. & Age of Trees. & Yield. \\
\hline $\begin{array}{l}1908 \\
\text { I909 }\end{array}$ & $\begin{array}{l}5 \text { years old } \\
6 \text {," }\end{array}$ & $\begin{array}{l}\text { •77 pound } \\
\text { I } 02 \text { pounds }\end{array}$ \\
\hline I9Io & $7 \quad$, & $2 \cdot I I \quad$, \\
\hline I9I I & $8 \quad$, & $2 \cdot 90$ \\
\hline
\end{tabular}


On the same estate a field of 62 acres of ten-yearold trees yielded 700 pounds per acre of dry rubber in I9II; while another field of 46 acres, also of ten-yearold trees, gave a return of 500 pounds of dry rubber to the acre. At Doranakandy 220 acres with trees averaging twelve years old yielded 85,000 pounds of dry rubber in IgII, and 80,000 pounds and II2,000 pounds in IgI2 and IgI3 respectively. This shows the average yield per acre to be approximately 500 pounds of dry rubber. On the Sunnycroft Estate, 4,950 trees seven and a half to eight and a half years old yielded in Igro-II an average of 2.55 pounds of dry rubber in ten months' tapping, equal to 380 pounds to an acre.

The following interesting statistical information concerning density of latex, yield, girth, root growth, and spacing of trees, was published in I9I3 by the Ceylon Government Department of Agriculture:

\section{HEVEA : YIELDS OF SOME HENARATGODA TREES}

The fame of the Henaratgoda trees as rubber yielders rests upon the performance of the great tree known departmentally as No. 2, which in three and a half years yielded 275 pounds of dry rubber. There are other trees at Henaratgoda equal in age and size to this great tree, but, never having been subjected to systematic tapping, their capacities were unknown. Some of these trees, though they could hardly be expected to equal No. 2, might nevertheless, it was thought, be good yielders.

At Henaratgoda there are three old Hevea plantations, known as the First, Second, and Riverside. 
The First Plantation is from the original seed procured by Mr. Wickham from the Amazon in 1876 . The plants reached Ceylon towards the end of that year, and were planted at Henaratgoda in 1877 ; this plantation is therefore thirty-six years old. It contains forty trees planted irregularly; the inside trees congested and small in circumference, the outside trees large.

The Second Plantation was planted about ten years later-that is to say, in about I886-with seed from the original trees; it is therefore of the second generation. It contains 2 II trees planted I 2 feet by I 2 feet. The contrast between the size of the outside trees and that of the inside is also very marked.

In the Riverside Plantation, also of the second generation, there are eighty-one trees scattered about, the trees being larger than those of the second. The outside trees also show a superiority of growth over their companions.

In October last it was decided to place the outside trees of the three plantations under systematic tapping, with the object of ascertaining (I) whether any other trees besides No. 2 were good yielders; (2) the effect of room on the yield of Hevea trees.

Table I. brings out very strikingly the effect of room on the girth of Hevea. The average girth I yard from the ground of the ten trees in the outside row in the Second Plantation is 76 inches; that of the trees in the row next inside 44 inches. The trees are tabulated as they grow; for example, No. 220, with a girth of 32 inches, is next to No.22I, with a girth of $\mathrm{IIO}_{\frac{3}{4}}$ inches. The famous No. 2, measuring $I I 7 \frac{1}{2}$ inches, is not the largest tree, No. 39 (not in the table) being ro inches 
larger in girth ( $127 \frac{3}{4}$ inches). Some of the inside trees of the First Plantation, which are crowded and overtopped, are very poor specimens, though presumably equal in age to the others. Thus, No. 20 is 40 inches in circumference; No. 13,33 inches.

Table I.: Girth Measurements

First Plantation: ${ }_{5}$ Trees, 37 Years old (Original Trees)

\begin{tabular}{|c|c|c|c|}
\hline No. of Tree. & Girth Measurement. & No. of Tree. & Girth Measurement. \\
\hline $\begin{array}{r}\text { I } \\
2 \\
3 \\
4 \\
6 \\
7 \\
\text { I I } \\
\text { I5 } \\
\text { I6 }\end{array}$ & $\begin{array}{c}\text { Inches. } \\
77 \frac{1}{4} \\
\text { I I } 7 \frac{1}{3} \\
\text { II } 56 \\
66 \\
\text { I0 } 5 \frac{1}{2} \\
84 \\
76 \\
79 \frac{1}{2} \\
83 \frac{1}{4}\end{array}$ & $\begin{array}{l}22 \\
23 \\
36 \\
37 \\
31 \\
40\end{array}$ & $\begin{array}{c}\text { Inches. } \\
76 \\
82 \\
88 \frac{1}{2} \\
80 \frac{1}{2} \\
76 \\
80 \frac{1}{2} \\
1,288 \frac{1}{4}\end{array}$ \\
\hline
\end{tabular}

Mean girth $=85.88$ inches.

Second Plantation: Io Trees, 27 Years old (Second Generation)

\begin{tabular}{|c|c||c|c|}
\hline No. of Tree. & Girth Measurement. & No. of Tree. & Girth Measurement. \\
\hline & Inches. & & Inches. \\
84 & 71 & 90 & $64 \frac{3}{4}$ \\
85 & 78 & IOO & 63 \\
86 & $67 \frac{1}{2}$ & II I & 98 \\
87 & 62 & 221 & $110^{\frac{3}{4}}$ \\
88 & 75 & & $\overline{762 \frac{3}{4}}$ \\
89 & $72 \frac{3}{4}$ & & 7 \\
\hline
\end{tabular}

Mean girth $=76 \cdot 27$ inches. 
Table I.: Girth Measurements-continued

Second Plantation: io Adjacent Trees next Row inside

\begin{tabular}{|c|c|c|c|}
\hline No. of Tree. & Girth Measurement. & No. of Tree. & Girth Measurement. \\
\cline { 2 - 3 } & Inches. & & Inches. \\
\cline { 2 - 4 } 99 & 36 & 9 I & $44^{\frac{3}{4}}$ \\
97 & $62 \frac{1}{4}$ & 99 & 36 \\
95 & $34 \frac{1}{2}$ & IIO & $49 \frac{1}{2}$ \\
93 & $48 \frac{1}{4}$ & 220 & 32 \\
92 & $52 \frac{1}{4}$ & & $440 \frac{1}{4}$ \\
91 & $44^{\frac{3}{4}}$ & & \\
\hline
\end{tabular}

Mean girth $=44^{\circ} \mathrm{O} 2$ inches.

Riverside Plantation: I3 Trees, 27 Years old (Second Generation) No. of Tree. Girth Measurement. No. of Tree. Girth Measurement.

\begin{tabular}{|c|c|c|c|}
\hline & & & Inches. \\
\hline 390 & $63 \frac{1}{4}$ & 407 & 56 \\
391 & $78 \frac{1}{4}$ & 438 & $83 \frac{1}{3}$ \\
395 & 64 & 439 & 65 \\
396 & $55 \frac{1}{2}$ & 444 & $66 \frac{1}{2}$ \\
397 & 70 & 445 & 96 \\
400 & $89 \frac{3}{3}$ & & $929 \frac{3}{4}$ \\
401 & $75 \frac{3}{3}$ & & \\
\hline 406 & $65^{\frac{3}{4}}$ & & \\
\hline
\end{tabular}

Mean girth $=7 \mathrm{I}^{\circ} 5 \mathrm{I}$ inches.

Tapping on the three $\mathbf{V}$ system half round the tree of these thirty-eight outside trees was begun on November I, I9I2, and continued to February I5, I9I3, when, dry weather having set in, the trees were rested. Tapping therefore took place daily for three and a half months. Tables II., III. and IV. give the weight of biscuit and scrap produced from these trees in the three plantations respectively. 


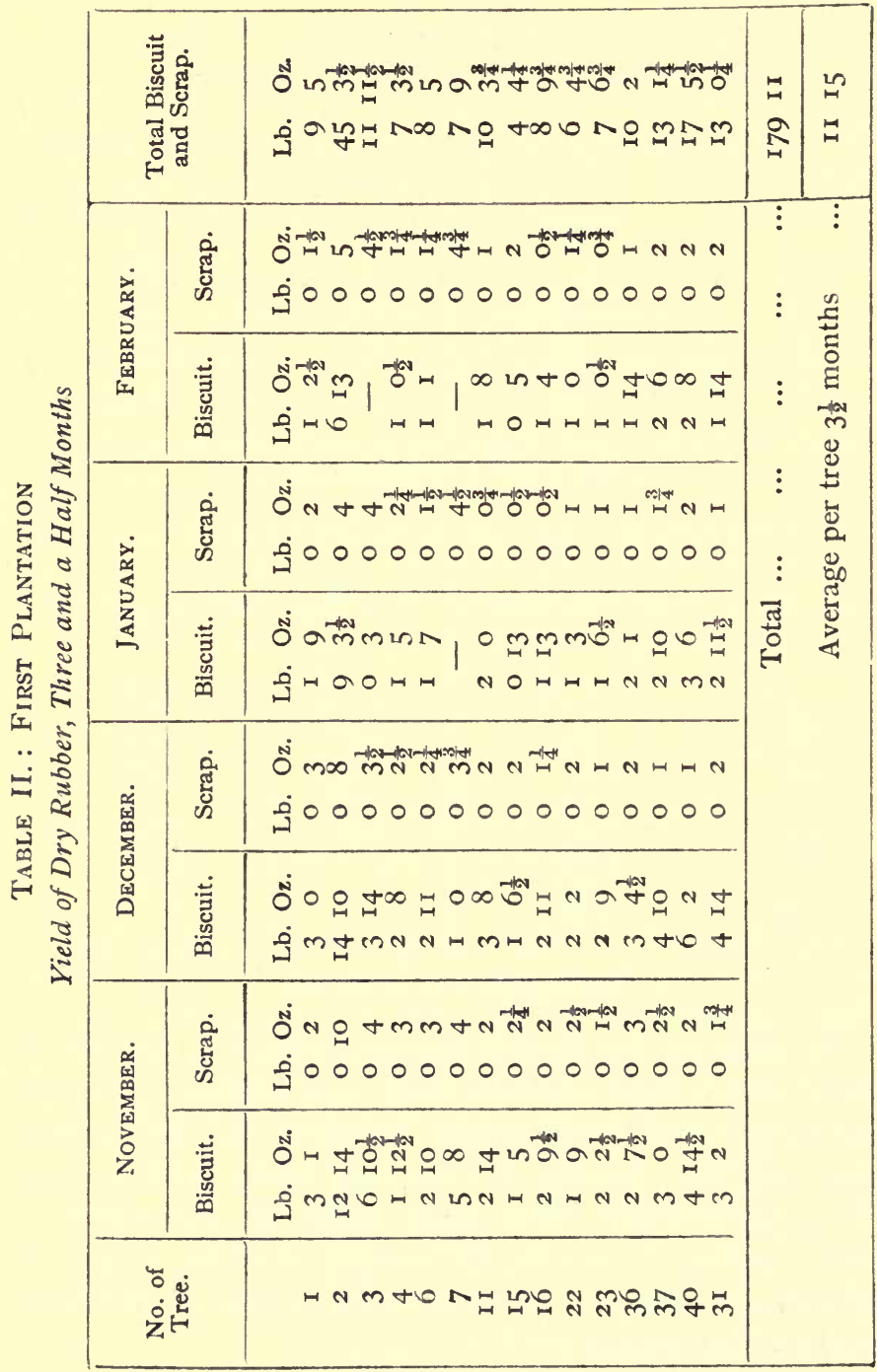




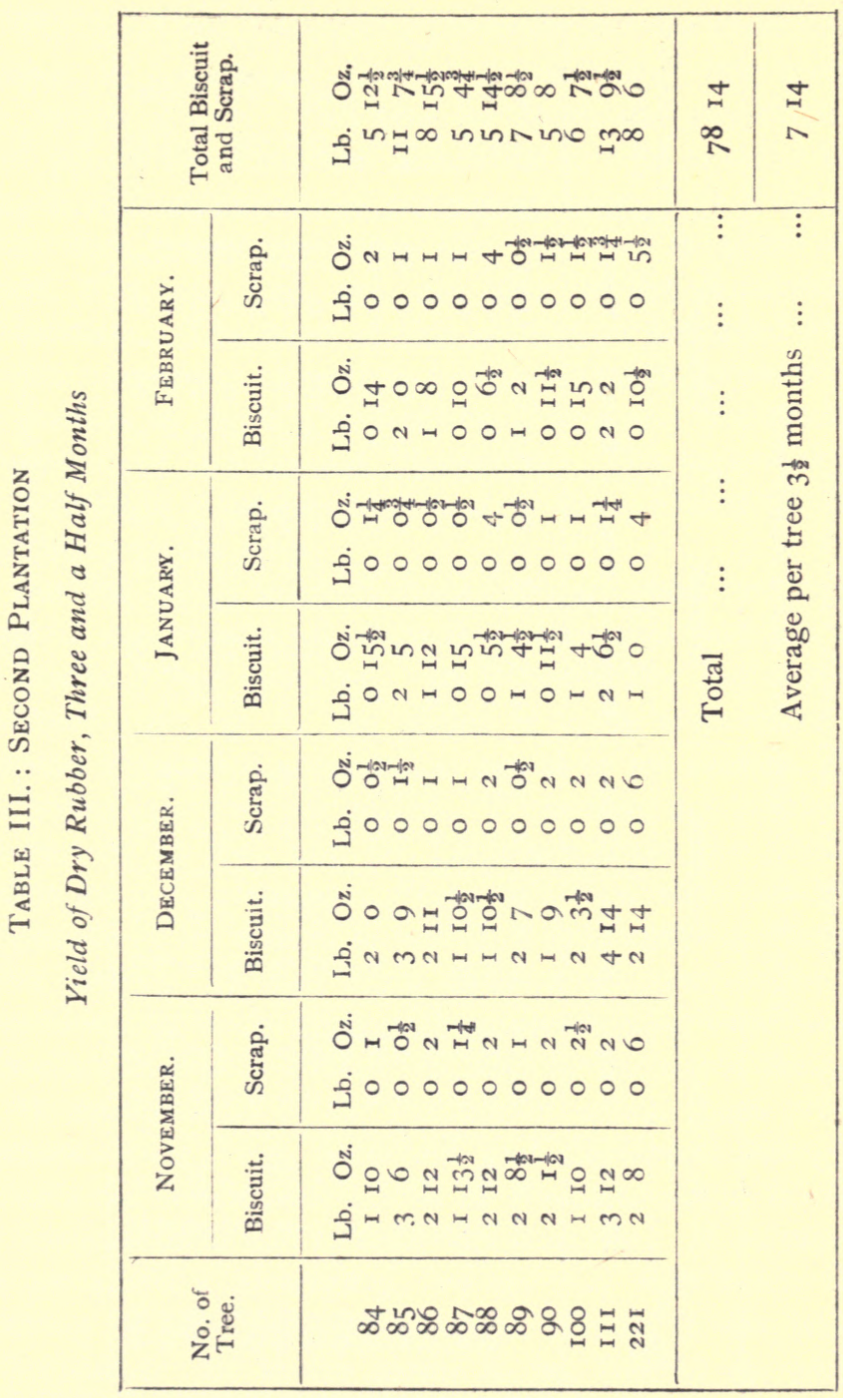




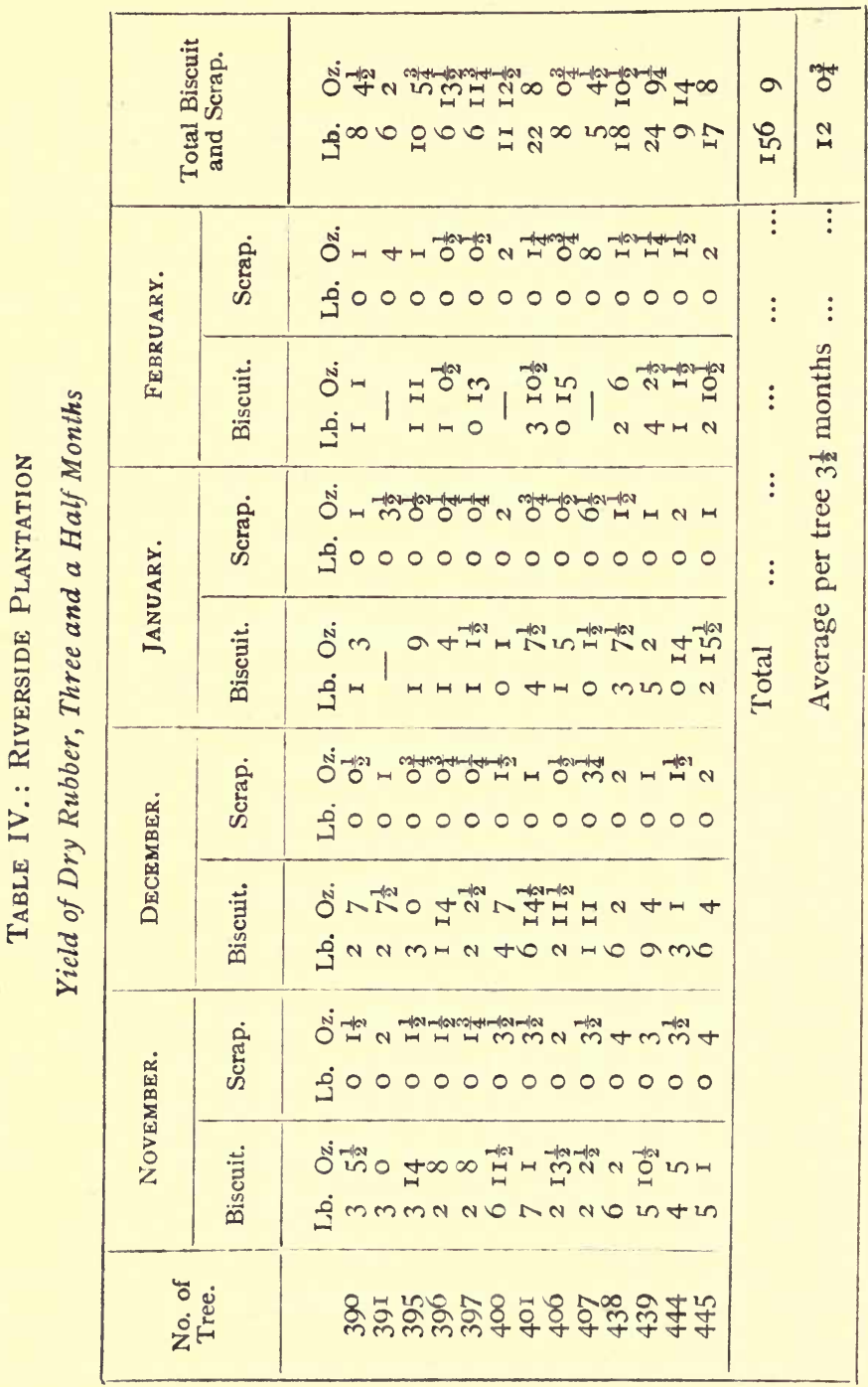


The great No. 2 yielded 45 pounds $3 \frac{1}{2}$ ounces of dry rubber in seventy-six days, an average of just over $9 \frac{1}{2}$ ounces a day. This tree far surpassed any other. No. 439 in the Riverside Plantation is next in order to No. 2, with 24 pounds $9 \frac{1}{4}$ ounces, an average of a little more than 5 ounces a day. The next two in point of yield, Nos. 40 I and 438, are also in the Riverside Plantation. The trees of this plantation averaged for the thirteen trees 12 pounds $\frac{3}{4}$ ounces, against II pounds I5 ounces of those a generation older, and 7 pounds r2 ounces of the Second Plantation. The superiority of Riverside must be attributed to some extent to its proximity to the river.

But the yields from all these trees are good, and can only be attributed to the fact that they have had room to extend in one direction. In Bulletin No. I of September, I9I2, p. 8, the yields of some trees of the Second Plantation are given as equal to an average of $I^{\prime} 4$ pounds per tree per annum. These trees are planted I2 feet by I2 feet, and Dr. Lock attributes the small yields to close planting. From this view there would appear to be no escape, as within a few yards of these trees others, I2 feet from their neighbours in one direction, but in the other with ample room for roots and branches to extend unchecked, have far surpassed them.

An examination of the manner in which these productive trees have branched and developed foliage reveals the remarkable power of Hevea to adapt itself to circumstances and to take opportunities. If we may be permitted a pleasantry, we can say that there is nothing of the Turveydrop about Hevea; it despises deportment. Its motto seems to be, Get to air and 
light; elegantly if you can, but get there. This power of reaching light regardless of symmetry of dome is a valuable characteristic in the tree, and should be taken advantage of by planters. It possesses this power in a greater degree than any tree with which the writer is acquainted, resembling in this respect a bamboo more than an ordinary tree.

The famous No. 2, the butt of which, with Mr. Wickham at its side, figured so prominently in a photograph at the recent New York Rubber Exhibition, possesses no symmetry of form whatever at the top. It has a magnificent upright trunk dividing into two at a height of 12 feet from the ground. These two stems then continue upwards, but soon begin to lean outwards, finally expanding into a mass of branches and foliage bending in one direction-outwards. The shape of the whole tree but for the fork is not unlike that of an ostrich plume. Other of these trees exhibit the same disregard of shape, though all alike possess large leaf areas.

The foliage of No. 2 extends to a distance of 55 feet laterally from the base of the trunk.

No. 439, the second heaviest yielder, is isolated. The foliage of $40 \mathrm{r}$ extends outwards about 40 feet; there is a nutmeg within 8 feet of it; No. 445 has a very fine crown, overtopping small clove-trees in the vicinity. The foliage of No. I extends to 44 feet, No. 7 to 3 I feet.

No definite conclusion can be drawn as to the effect of early branching. The two heaviest yielders branch early: No. 2 at 12 feet and No. 439 at $I_{5}$ feet; No. 438 also at $I_{5}$ feet, No. I at 5 feet, No. 3 at 7 feet, No. 390 at I2 feet, No. $39 \mathrm{I}$ at I 5 feet. On the other hand, 40I, 
$85,90,221,23,36,40$, run up to from 20 to 40 feet before branching.

No. 439, the best yielder after No. 2, is one of the smallest trees under trial. The trees of the Riverside Plantation, which gave the highest average yield of dry rubber, have a mean girth of $7 \mathrm{I}$ inches, against an average of 89 inches in the thirty-seven-year-old trees. All are large trees, but as far as they go these trials seem to show that after a certain size has been reached increased girth measurement does not necessarily mean increased yield.

Given room, the trees have extended their roots to a greater distance than their branches. At 55 feet the roots of No. 2 were of the size of a lead pencil and still extending, but they were not visible at the surface. A root of No. I, I $\frac{1}{4}$ inches in thickness, was observed at the surface 60 feet from the base of the trunk. It then descended into the ground. A root of No. 40 outcrops at 80 feet from the trunk. This tree gave $I 7$ pounds $5 \frac{1}{2}$ ounces of dry rubber in the three and a half months. These trials seem to bring out very strongly the importance of giving Hevea room to extend in one direction. It is perhaps reasonable to suppose that had these trees room in every direction even better results would have been obtained; but it is not the object of this paper to attempt to evolve the ideal plantation, but to record facts and to offer suggestions based on those facts. The Henaratgoda trees are particularly happy in not having the issue complicated by subsidiary influences. The soil is poor, the trees have never been manured, the ground is not forked or weeded or grazed. Twice a year the bents are cut with 


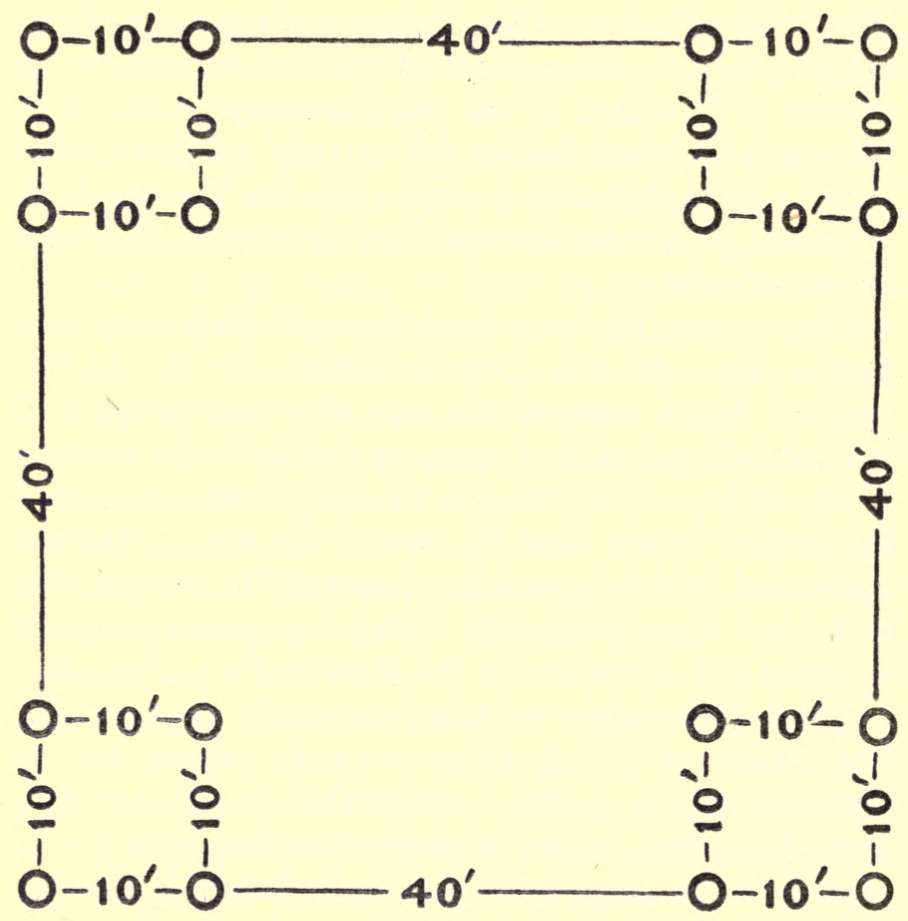

Fig. I.-Plan of Plantation

At spacings of to feet by 40 feet as shown, an acre would carry sixty-nine trees. 
$0-12^{\prime}-0-40^{\prime}$
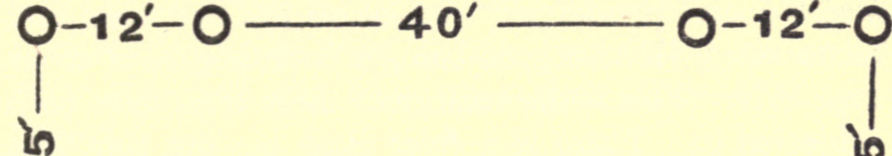

$0-12-0$

ใ

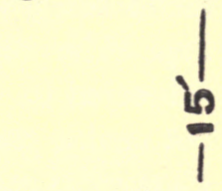

1

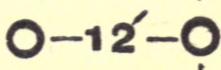

$0-12^{\prime}-0$

$0-12^{\prime}-0$

$\int_{0-12}^{1}$

1

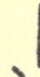

18

$0-12-0$

$0-12-0$

$0-12-0$

is

$40^{\prime}$
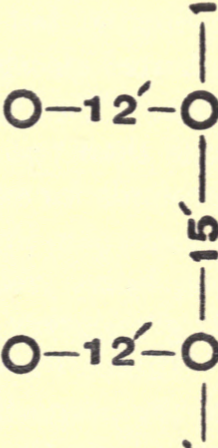

in

$\int_{0-12}-0$

$0-12-0$

Fig, 2.-Modification of The System shown in Fig. I. 40 feet by 12 feet by 15 feet gives 112 trees per acre. 
a sickle, and periodically the leaves are swept up and taken away, Henaratgoda being a botanic garden to be kept tidy. This is the treatment these trees have been subjected to. There is a river close by, but this does not enable the inside congested trees to give more than I' 4 pounds per annum. We are driven to the conclusion that the controlling factors have been air, light, and root room, these trees having had room at least on one side to extend.

It has not escaped some observers that Hevea trees growing in pairs do not seem to suffer from the fact, and at the meeting of the Committee of Agricultural Experiments held at Peradeniya on March 16 it was decided to lay out a plantation to test this principle. Fig. I (p. I56) is a plan of a plantation based on this principle, but carried one step farther, four trees being planted closely together (ro feet by ro feet) instead of two. Two would perhaps be better than four, and one than two; but the Henaratgoda trials afford good grounds for expecting a plantation laid out on the foursquare plan illustrated in Fig. I would be in time returning heavy yields as compared with present standards. It gives every tree room to extend freely on two sides.

Tables V., VI. and VII. give interesting comparisons of the proportion of latex to dry rubber in the various trees. In the great No. 2 tree the latex is rich, though one or two trees showed a slightly higher proportion of rubber. With the old original trees a mean of I, $253^{\circ} 44$ C.c. of latex produced I pound of dry rubber; with those of the Second Plantation, I,330.88; the Riverside, $1,416 \cdot 96$. Taking the figures of the old trees as unity, the proportions may be represented as 
$\mathrm{I}, \mathrm{I} \cdot 077, \mathrm{I} \cdot \mathrm{I} 63$-i.e., I.032 times as much latex was required from the trees of the Second Plantation as from those of the First to make I pound of dry rubber.

\section{Table V.: First Plantation}

Cubic Centimetres of Latex to One Pound of Dry Rubber

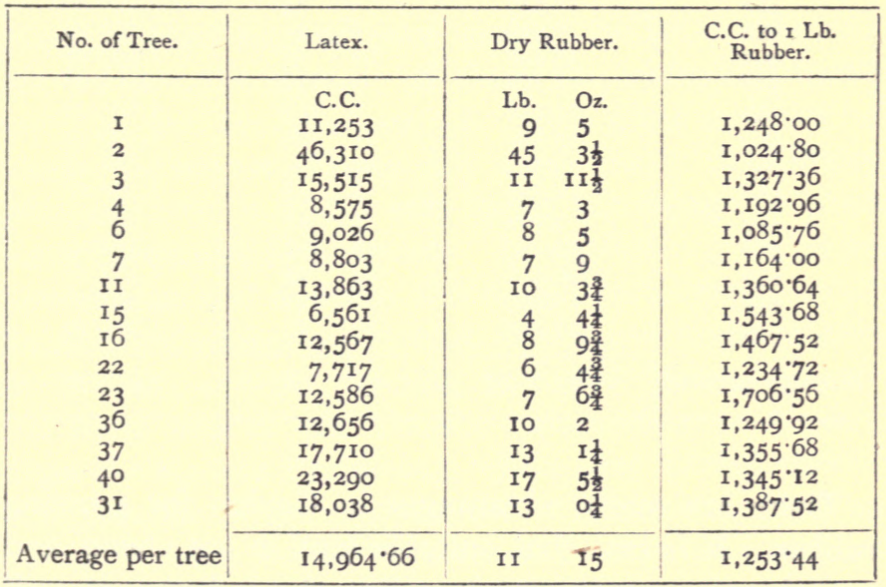

Table Vi.: Second Plantation

Cubic Centimetres of Latex to One Pound of Dry Rubber

\begin{tabular}{|c|c|c|c|}
\hline No. of Tree. & Latex. & Dry Rubber. & $\begin{array}{l}\text { C.C. to r Lb. } \\
\text { Rubber }\end{array}$ \\
\hline $\begin{array}{r}84 \\
85 \\
86 \\
87 \\
88 \\
89 \\
90 \\
\text { IOO } \\
\text { II I } \\
221\end{array}$ & $\begin{array}{r}\text { C.C. } \\
7,369 \\
17,308 \\
13,574 \\
7,749 \\
6,266 \\
11,727 \\
6,762 \\
8,239 \\
17,128 \\
8,686\end{array}$ & $\begin{array}{rr}\text { Lb. } & \text { Oz. } \\
5 & \text { I } 2 \frac{1}{4} \\
\text { II } & 7 \frac{3}{4} \\
8 & \text { I } 5 \frac{1}{2} \\
5 & 4 \frac{8}{4} \\
5 & \text { I } 4 \frac{1}{2} \\
7 & 8 \frac{1}{2} \\
5 & 8 \\
6 & 7 \frac{1}{2} \\
\text { I3 } & 9 \frac{1}{2} \\
8 & 6\end{array}$ & $\begin{array}{l}1,28 \mathrm{I} \cdot 44 \\
\mathrm{I}, 5 \mathrm{I} \cdot 28 \\
\mathrm{I}, 5 \mathrm{I} \cdot 8 \cdot 72 \\
\mathrm{I}, 476 \cdot 00 \\
\mathrm{I}, 066 \cdot 40 \\
\mathrm{I}, 563 \cdot 52 \\
\mathrm{I}, 229 \cdot 49 \\
\mathrm{I}, 279 \cdot 84 \\
\mathrm{I}, 262 \cdot 88 \\
\mathrm{I}, 037 \cdot 12\end{array}$ \\
\hline Average per tree & I0, $480 \cdot 8$ & $7 \quad \mathrm{r} 4$ & $1,330 \cdot 88$ \\
\hline
\end{tabular}




\section{Table VII.: Riverside Plantation}

Cubic Centimetres of Latex to One Pound of Dry Rubber

\begin{tabular}{|c|c|c|c|}
\hline No. of Tree. & Latex. & Dry Rubber. & C.C. to I Lb. \\
\hline $\begin{array}{l}390 \\
391 \\
395 \\
396 \\
397 \\
400 \\
401 \\
406 \\
407 \\
438 \\
439 \\
444 \\
445\end{array}$ & $\begin{array}{r}\text { C.C. } \\
\text { I I,539 } \\
7,536 \\
\text { I } 5,44 \text { I } \\
\text { I } 2, \text { I } 25 \\
\text { I I, I } 38 \\
\text { I } 5,386 \\
33,3 \text { I } 3 \\
11,834 \\
5, \text { I } 99 \\
25,002 \\
36,4 \text { I } 8 \\
13,448 \\
23,522\end{array}$ & $\begin{array}{rc}\text { Lb. } & \text { Oz. } \\
8 & 4 \frac{1}{2} \\
6 & 2 \\
\text { Io } & 5 \frac{3}{4} \\
6 & \text { I } 3 \frac{1}{2} \\
6 & \text { I I } \frac{9}{4} \\
\text { II } & \text { I } 2 \frac{1}{2} \\
22 & 8 \\
8 & 0 \frac{3}{4} \\
5 & 4 \frac{1}{2} \\
\text { I } & 10 \frac{1}{2} \\
24 & 9 \frac{1}{4} \\
9 & 14 \\
17 & 8\end{array}$ & $\begin{array}{r}I, 398 \cdot 56 \\
I, 230 \cdot 24 \\
I, 497^{\circ} \cdot 28 \\
I, 779 \cdot 68 \\
I, 665^{\circ} 44 \\
I, 309^{\circ} \cdot 44 \\
I, 480^{\circ} \cdot 48 \\
I, 479 \cdot 20 \\
990^{\circ} \cdot 24 \\
I, 342 \cdot 24 \\
I, 482 \cdot 56 \\
I, 361 \cdot 76 \\
I, 344^{\circ} \cdot 00\end{array}$ \\
\hline Average per tree & $17,069^{\prime} 3$ & I2 O & $I, 416 \cdot 96$ \\
\hline
\end{tabular}

There are many advantages in Ceylon for growing rubber. It is true that suitable land is not cheap, and not always easy to obtain. But the industry is well established, transport facilities are excellent, the organization of estates is based on long experience gained in the cultivation of tea and coffee, competent superintendents can be obtained to undertake the important task of administration, and taxation is practically nonexistent. The general conditions and productiveness of the trees is distinctly satisfactory. The renewal of bark after tapping is fairly rapid. Third renewals in both the Kelani Valley and Kalutara districts are exceptionally healthy, and yield latex freely. While malarial fever is not uncommon amongst the labourers, it is rarely of sufficient importance to affect seriously 
the work on the plantations. Government dispensaries and hospitals are established in all districts, and these are attended to by resident Government Medical Officers.

In I9I2 official statistics showed 550,000 Indian coolies and 150,000 Sinhalese and other nationalities engaged in agricultural work in Ceylon. On September 30, I9II, the published returns gave 42I,305 Indian coolies employed in I,830 estates; of these the males numbered 218,709 , and females 202,596 . The great majority of these labourers are thoroughly conversant with ordinary plantation work, and a very large percentage of them have become skilled tappers. The children grow up on the estates, and develop ability and intelligence in all branches of rubber production, as occurred in connection with coffee and tea planting in former years. Nearly all these coolies are Tamils, immigrating to Ceylon from the Madras Presidency, where they formed part of a population of some $30,000,000$. With the linking up of the Ceylon railway system with that of Southern India the transport facilities for these immigrants will be greatly improved, and the agricultural industry of Ceylon reap a corresponding benefit. These coolies are recruited by kanganies sent out from the estates, and the cost of their passages is advanced by the owners of plantations. They are under no indenture, although an indenture ordinance exists in Ceylon, and after due notice and payment of any indebtedness they are legally free to leave the estate for employment elsewhere. Many complaints are heard in regard to this condition of affairs, but on the whole the system works on fairly satisfactory lines. The wage rate varies from 40 cents for men to 25 cents for women, and I8 cents 
for boys and girls from thirteen to sixteen years of age. There is a slight tendency to a higher wage rate, induced, probably, by the demand from the Malay Peninsula for this same class of labourers.

The hours of work in Ceylon are from 6 a.m. to 4 p.m. on six days in the week for ordinary labour, and seven for tapping; but a very great proportion of the work is by task, and can as a rule be finished much earlier in the day. Discipline on the estates is well maintained, and it is seldom any serious dispute arises between employer and labourer. The standard of living is low according to European ideas, but adequate for the class of labourer engaged. They are well housed in permanent lines, constructed with steel frames, galvanized iron roofing, plastered walls, and 6 -foot wide verandas. These barracks are divided into rooms io feet by I 2 feet, and four coolies are allotted to each room. The usual custom is for these buildings to contain twelve rooms, built at a cost of Rs. I20 per room. The distribution of the rooms is left to the discretion of the head kangany. The food consists of rice, supplemented by curry, dried fish, vegetables, and fruit. Occasionally meat and chicken are eaten, but not as a regular diet. Rice is supplied at cost price by the estate, and always at a cheaper rate than in the bazaars. The estates are compelled to establish and maintain free primary schools for the benefit of the children of the Indian coolies employed.

In addition to the Tamil labourers, the Sinhalese are now employed much more frequently than formerly. The objection raised by the planters to this class of coolie labour is that the wage rate is higher, averaging 


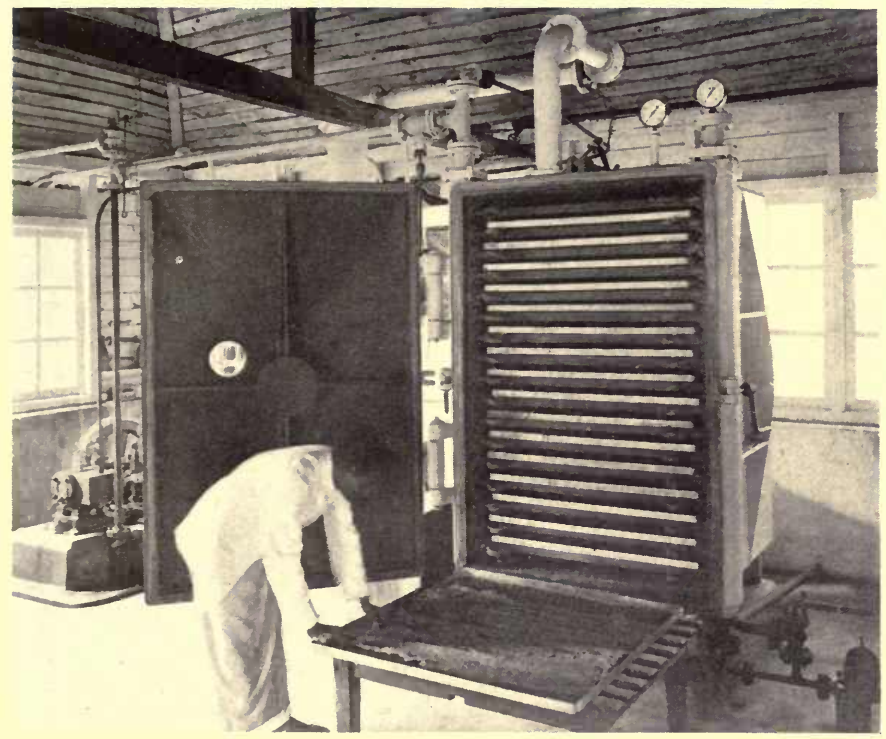

A RLBHER FACTORY IN CFYLON, SHOWING A PASSBERG YACULM DRVER

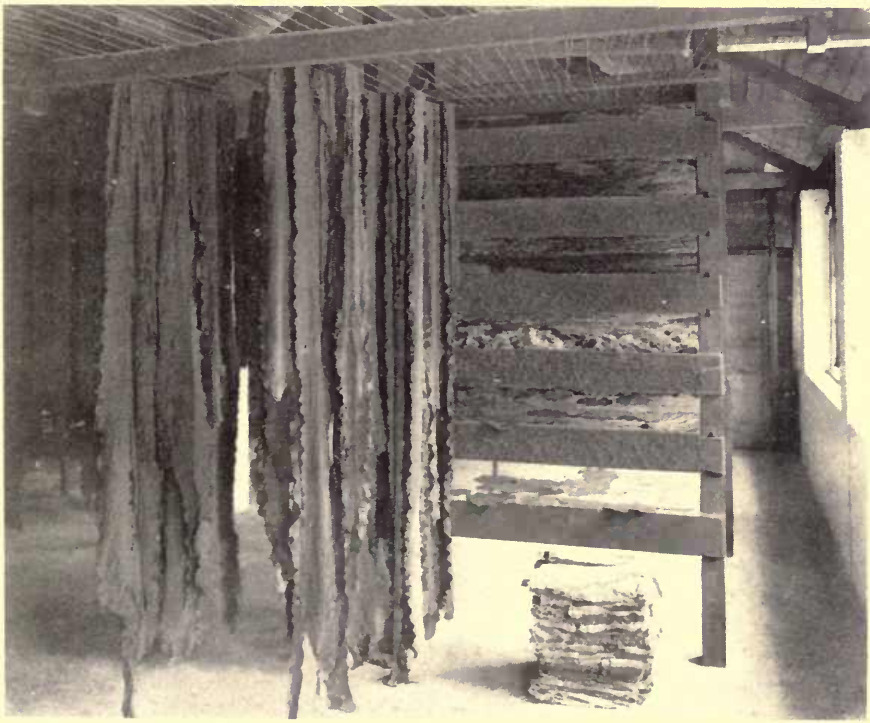



50 cents per diem in place of 35 cents; also that it is not possible to maintain with them the same standard of discipline as with the Tamils. The Sinhalese is close to his own home, and when he is tired of work he takes his wage and departs. In wet weather he will not turn out, and when his village is busy harvesting rice or other products he prefers that occupation to the work on an estate.

There is every reason to anticipate satisfactory conditions in regard to future production of rubber in Ceylon within the next seven years. If the present average yield is applied to 225,000 acres, and is taken as a basis for calculation, there can be small doubt that in rgrg the average production should be at the rate of not less than 4 hundredweights per acre. This would give a total output available for exportation of 50,000 tons. This may be regarded as a minimum figure when calculating probable exports after I9I9, for extensions of the present cultivated area will assuredly occur from year to year, and these may even duplicate the area of the existing plantations in the course of another fifteen or twenty years. In IgIo the exportation of local origin from Ceylon in round figures was $I, 500$ tons; in IgII it rose to 3,000 tons; in IgI2 it was 6,200 tons; in rgr 3 the amount reached ro, 686 tons; in I9I4 the export will exceed 15,000 tons; in I9I5 additional large areas come into bearing, and the exportation will not fall far short of 25,000 tons. Steady increases will take place in the three years following, and in IgIg the production will be approximately 45,000 tons, with the prospect of further steady development. 
So far as can be seen at present, the average cost of Ceylon plantation rubber f.o.b. Colombo should not exceed $8 \mathrm{~d}$. per pound, although the cost may be considerably below that figure, and in the case of some estates has been reduced already to $6 \frac{1}{2} \mathrm{~d}$. per pound.

The question of Pará rubber (Hevea Brasiliensis) only has been dealt with. Ceará grows well in various districts; but it is not much in favour, owing to difficulty in tapping, therefore the acreage cultivated is insignificant. Castilloa has been tried, but proved a failure wherever its cultivation was attempted, on account of the smallness of the yield.

The following statistics show clearly the development of the Ceylon rubber industry during the past ten years:

\begin{tabular}{|c|c|c|}
\hline Years. & Acres planted. & Export (Tons). \\
\hline 1904 & 25,000 & 35 \\
1905 & 40,000 & 75 \\
1906 & 100,000 & 150 \\
1907 & 150,000 & 250 \\
1908 & 180,000 & 400 \\
1909 & 184,000 & 681 \\
1910 & 204,000 & 1,500 \\
1911 & 215,000 & 3,000 \\
1912 & 225,000 & 6,250 \\
1913 & 234,000 & 10,686 \\
\hline
\end{tabular}

In I9I3 the total exports of rubber from Colombo were $\mathrm{II}, 835$ tons, but of this amount I,I49 tons were imported and reshipped after sale at the local auctions; in Igr 2 some 200 tons were classified as re-exported. 
The estimated exportation for the next six years is-

\begin{tabular}{|c|c|c|}
\hline Year. & Acres planted. & Export (Tons). \\
\hline I914 & 247,000 & 15,000 \\
I915 & 250,000 & 25,000 \\
I916 & 250,000 & 30,000 \\
I917 & 250,000 & 35,000 \\
I918 & 250,000 & 40,000 \\
I919 & 250,000 & 45,000 \\
\hline
\end{tabular}




\section{CHAPTER XIII \\ THE MALAY PENINSULA}

1 Origin of the Malay rubber industry-Diseases and pests common to rubber-trees in Malay $/$ Principal localities of the rubber plantations - Area of rubber estates-Reserve lands suitable for cultivation-Acquisition and tenure of land-Taxation of the rubber industry-Altitude of rubber estates-Characteristic features of the soil-Meteorological conditions-Variations of temperature-Capitalization of Malay rubber estates-Excessive capitalization, and its effects on the Malay rubber industry.

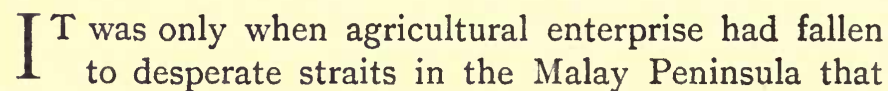
the planting community began to consider the possibilities of rubber production to avert a ruinous condition of affairs. The coffee industry was no longer profitable, and the cost of labour was too high to enable successful competition with Ceylon and India in the cultivation of tea. The cost of planting the coffee estates with rubber-trees was comparatively trivial, and many proprietors adopted that course as a last resource to save the capital already invested. The trees flourished to an amazing degree, and an extraordinary prosperity has resulted to the whole Malay Peninsula. Perhaps no better comparison is possible than to glance at the thriving circumstances of to-day in the Federated Malay States, and to remember that less than forty years ago the city of Kuala Lumpur was the headquarters of one of the most bloodthirsty hordes of pirates that ever existed. 
The rubber industry in the Malay Peninsula originated from plants sent from Kew Gardens in 1877 , and germinated from seed collected by Mr. Wickham during the previous year in the Amazon Valley. The establishment of plantations of rubber-trees was due mainly to the persistent efforts of Mr. Henry N. Ridley, the late chief of the Botanic Gardens at Singapore. For years " his voice was as the voice of one crying in the wilderness," for nobody was inclined to give credit to his assurances of the profitable future of rubber production. At length he induced a few planters to give the new cultivation a trial, but it was not until 1898 that any serious attention was devoted to it, and only then because the production of coffee and sugar-cane became unremunerative. Then coffee and sugar estates were interplanted with Pará trees, and many tapioca plantations, owned in great part by Chinamen, were treated in the same way. It was not until I905 that the true value of Pará rubber plantations was appreciated and understood. Since that date the area has increased from some 40,000 acres to the extent of 680,000 acres. It says much for the hardy character of the Hevea Brasiliensis that this development has taken place; for very little attention or care was given to the trees in the early stages of the industry, and even when large areas were opened up a great lack of knowledge existed in regard to methods of cultivation and treatment. Evidence of this is seen everywhere on the older estates, where trees are crowded together without any regard to adequate space for future development, and also in the damage done to the stems when tapping was begun. It is only within the last fire years that planters gener- 
ally realized the mistakes that had been made, and the necessity of careful and methodical cultivation and treatment to insure successful results.

After visiting the principal centres of the rubberplanting industry, the conclusion reached can only be that healthy conditions are the rule. The usual diseases exist, but not in an aggravated form; the most serious obstacles in this direction are : (I) Root canker, or fomes; this disease produces disastrous results if neglected; but it is understood, and when found is immediately treated by isolating the immediate surroundings of the tree, digging up and burning the roots, and applying lime to the infected area. (2) White ants are attacked as soon as they appear. (3) "Die-back" rarely does much damage. (4) Probably the worst pest, and one found in every district of the peninsula to more or less extent, is the formation of burrs or nodules in the bark. While these do not materially affect the general health conditions of the tree, they are a serious interference to tapping. They occur principally on old trees that have been badly tapped in past years, but they are found also on trees that have never been tapped. Dr. Huber of Para considers that they are the result of suppressed bud expansion in conjunction with bad tapping, and this diagnosis is supported by Mr. Lewton Brain, Director of Agriculture in the Federated Malay States. Dr. Huber further thinks they may be induced by the action of hot sunshine on renewed bark causing some form of irritation. In the earlier stages of growth these burrs can be removed without damage to the cambium, but if neglected they spread, and unite with the wood of the tree. Taking a 
broad view, however, of this and other pests, and even of the bad tapping in past years, the actual proportion of trees affected certainly does not exceed 2 per cent. of the total number in cultivation, and probably, if an accurate census was taken, would be found to be much below that figure. All well-conducted estates maintain a special gang of coolies whose duty it is to search constantly for any signs of disease, and report immediately any indication of an outbreak.

The most important centres of the rubber-producing districts are situated between Singapore and Penang, and include the Native State of Johore, the Federated Malay States of Negri Sembilan, Selangor, and Perak, and the Settlements of Malacca, Province Wellesley, and Penang. In the State of Johore the development of rubber estates has been retarded by lack of transport facilities, but it is now making rapid progress. In Pahang similar difficulties exist, and these, in conjunction with the mountainous nature of the country, have resulted in only a limited number of plantations being opened. In Kelantan, where the soil is well adapted for rubber-growing and local labour is abundant, insufficient means of communication have hitherto restricted planting enterprise ; but the construction of railways and roads is being pushed forward rapidly, and will alter these conditions very shortly. Similar considerations also apply to the Native State of Trengganu. In Kedah the area planted with rubber is extending ; communication by road is now open between the principal centres and the Province Wellesley, and railway connection will be established shortly.

Along the railway-line from Tampin, in the State of 
Negri Sembilan, to Penang, the cultivation of rubber estates is practically continuous, although broken at intervals by Government forest reserves, and occasionally by tin-mining operations. For the greater part of this distance the planted area to the west of the railway extends to the seaboard, and to the east to the foot-hills of the mountain ranges intersecting the Peninsula. To give an idea of the extension of this area, it may be approximately calculated at 200 miles long, averaging five miles wide, and containing a total of some 640,000 acres, including 500,000 acres of rubber estates. From Tampin to Singapore, a distance of 150 miles through the State of Johore, the cultivation is much more scattered along the line of railway; but it is rapidly increasing, and it now exceeds 100,000 acres.

Absolutely accurate returns of the acreage planted throughout the Peninsula are not available to show the present cultivated area. In rgro the figures were given officially as 362,000 acres, but all inquiries tend to indicate that the statement was only an approximate one. The difficulty lies in the fact that many Chinese proprietors of large holdings do not make any return, nor do the very numerous class of Malay and Chinese owners of small patches planted with rubber, but also cultivated with other crops between the trees. In the Federated Malay States the export duty of $2 \frac{1}{2}$ per cent. on the value is no check upon the acreage, as the ages of the trees vary from those newly planted to others twenty years old. In the Straits Settlements of Malacca the assessment tax on trees is an equally unreliable guide, for it only takes effect on trees of six years and upwards. In the Native States no returns 

$3 x^{2}+2$

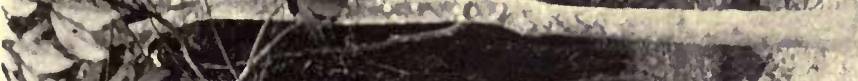

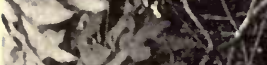

surs

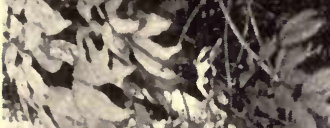

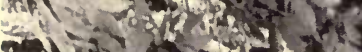

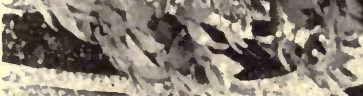

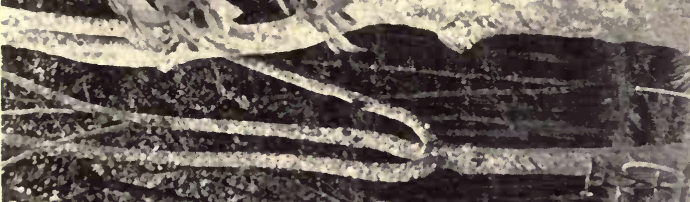

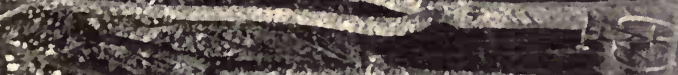

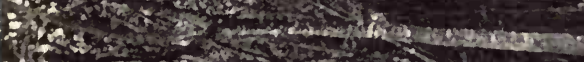

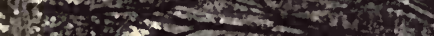

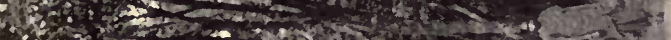

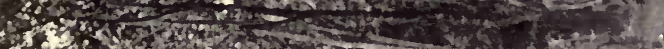

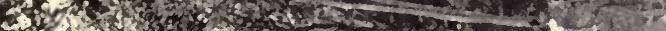

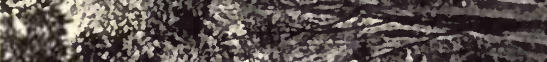

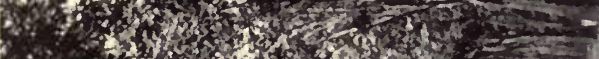

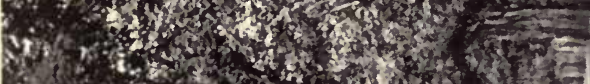

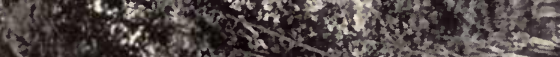

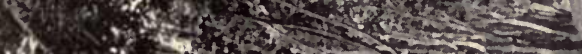

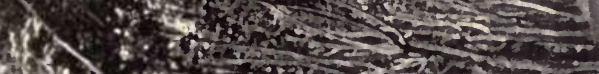

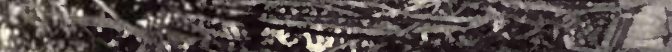

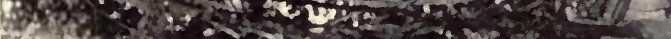

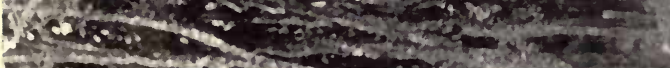

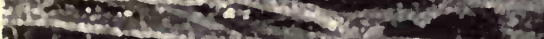

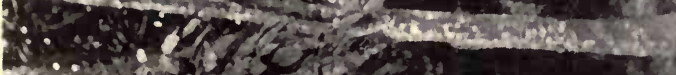

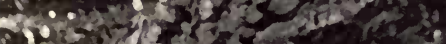

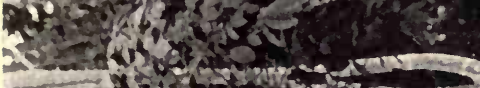

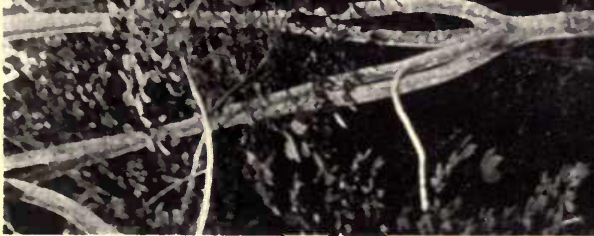



are available, and the area can only be estimated. In view of these circumstances, the only method of obtaining approximately accurate estimates of acreage at each centre of cultivation is from visiting agents, resident planters, Government officials, business men, and also from secretaries of planters' associations and others interested in the industry. The estimates now given were revised with the assistance of the Secretary to the Planters' Labour Association, who has returns from 485 estates in connection with the distribution of all Indian immigrants brought to Penang in accordance with the quarantine regulations. If the official figures are taken from 1906 to I9I2, together with an allowance of 5 per cent. for the area planted in I9I3, the total result shows 685,000 acres under rubber. The very large area planted in IgII and I9I2 was due to the great amount of capital subscribed for rubber enterprises during the boom of I909-IO. The following table shows the expansion of the rubber in. dustry in the Malay Peninsula during the last eight years :

\begin{tabular}{|c|c|c|c|}
\hline Year. & Acreage. & $\begin{array}{c}\text { Planted Each } \\
\text { Year. }\end{array}$ & $\begin{array}{c}\text { Rubber } \\
\text { exported. }\end{array}$ \\
\hline & & & Tons. \\
\hline 1906 & 99,230 & - & 430 \\
\hline 1907 & 179,227 & 79,997 & 485 \\
\hline Igo8 & 241,138 & $6 \mathrm{I}, 9 \mathrm{II}$ & 1,629 \\
\hline 1909 & 292,035 & 50,897 & 3,340 \\
\hline I910 & 362,853 & 70,818 & 6,504 \\
\hline I9II & 538,000 & I 76,000 & 10,700 \\
\hline 1912 & 650,000 & I I $2, \infty 00$ & 23,400 \\
\hline I9I3 & 685,000 & 32,500 & $35,35^{2}$ \\
\hline
\end{tabular}


This area of 685,000 acres is distributed as follows :

$\begin{array}{lcccccr}\text { I. Federated Malay States } & \ldots & \ldots & \ldots & 408,000 \\ \text { 2. Malacca } & \ldots & \ldots & \ldots & \ldots & \ldots & \text { I } 10,000 \\ \text { 3. Province } & \text { Wellesley and Penang } & & \ldots & 25,000 \\ \text { 4. Kedah } & \ldots & \ldots & \ldots & \ldots & \ldots & 10,000 \\ \text { 5. Kelantan } & \ldots & \ldots & \ldots & \ldots & \ldots & 15,000 \\ \text { 6. Johore } & \ldots & \ldots & \ldots & \ldots & \ldots & 10,000 \\ \text { 7. Singapore } & \ldots & \ldots & \ldots & \ldots & \ldots & 15,000 \\ \text { 8. Trengganu } \ldots & \ldots & \ldots & \ldots & \ldots & 2,000 \\ \end{array}$

In April, I9I2, the Director of Agriculture for the Federated Malay States published a statement that the total area under cultivation with rubber in the Malay Peninsula was $62 \mathrm{r}, 000$ acres, exclusive of all holdings of less than Ioo acres in extent. If due allowance is made for these small estates and for the expansion in IgI3, this statement tallies with the figures now given.

The area of II2,000 acres planted in IgI2 was as follows :

\begin{tabular}{lllllllr} 
I. Federated & Malay States & $\ldots$ & $\ldots$ & $\ldots$ & 55,000 \\
2. Johore & $\ldots$ & $\ldots$ & $\ldots$ & $\ldots$ & $\ldots$ & 18,000 \\
3. Malacca & $\ldots$ & $\ldots$ & $\ldots$ & $\ldots$ & $\ldots$ & 17,000 \\
4. Kelantan & $\ldots$ & $\ldots$ & $\ldots$ & $\ldots$ & $\ldots$ & 10,000 \\
5. Kedah & $\ldots$ & $\ldots$ & $\ldots$ & $\ldots$ & $\ldots$ & 5,000 \\
6. Singapore & $\ldots$ & $\ldots$ & $\ldots$ & $\ldots$ & $\ldots$ & 5,000 \\
7. Province & Wellesley and & Penang & $\ldots$ & 2,000 \\
\hline
\end{tabular}

Apart from the 685,000 acres now under cultivation, an area of 400,000 acres has been alienated under permanent title in the Federated Malay States for planting, and of this about two-thirds, or 260,000 acres, is available for rubber cultivation, and the remaining 
I 40,000 acres for coconuts. It is reasonable to suppose that a large proportion of this alienated land will be planted in the course of the next few years, in view of the fact that it represents a considerable capital expenditure for premium paid, annual rent, and survey fees, already disbursed.

The number of small holdings of under I acre belonging to Chinese settlers and Malays is a remarkable feature. They amount to many thousands, but in the aggregate do not comprise 5 per cent. of the total rubber acreage.

In addition to the land occupied in the Federated Malay States for agricultural purposes, there remains in Johore, Kedah, Kelantan, and Trengganu, a very large area suitable for rubber cultivation. The extent of this acreage cannot be gauged with any proper degree of accuracy, as the lands in question have not been surveyed; but it embraces several million acres, and of this probably not less than I 5 per cent. will be available for plantation purposes. In Johore the percentage is certainly higher than 15 per cent. In point of fact, the question of suitable land will not check extensions for many years to come, especially in the case of established estates with reserves of forest lands, for with the existing organization the cost of additional development will be comparatively low. The only real checks to future extension will arise from a further fall in the value of rubber, a marked increase in the wage rate of coolies, or a shortage of labour. It is possible that one or all of these circumstances may occur.

Conditions for acquiring land for agricultural purposes differ in the various States and in the Straits 
Settlements. In Perak, Selangor, and Negri Sembilan, for land exceeding ro acres in extent, a premium of 3 dollars per acre is paid if with frontage to a public road, and 2 dollars per acre if without such frontage. The rent may be fixed by the Resident, with a minimum of I dollar per acre per annum for the first six years, and thereafter at 4 dollars per acre per annum for firstclass lands, and 3 dollars per acre per annum for secondclass lands. For lalang (grass) lands no premium is paid, but no difference is made in the annual rent. For lands planted with coconuts, fruit-trees, or rice, a rebate can be obtained reducing the annual rent to 2 dollars per acre per annum, but no such reduction is granted in the case of rubber plantations. In Pahang the annual rent for the first six years is 50 cents per acre, and thereafter 2 dollars per acre per annum. These provisions apply to all lands alienated in the Federated Malay States since January I9, I906.

In the Native States of Johore, Kedah, Kelantan, Perlis, and Trengganu, land grants are obtained from the Sultans on constantly varying terms, and seldom conceded without the approval of the British Resident. As these States will undoubtedly come into the Federation in the near future, the tenure of land will be similar to that applied in the present Federated States.

In the Straits Settlements, comprising Singapore, Malacca, Dindings, Province Wellesley, and Penang, the premium on agricultural lands is 3 dollars per acre. An annual rent of 50 cents per acre is charged for the first six years, and thenceforth 3 dollars per acre. No difference is made between lalang (grass) lands and forest. 
In many cases existing estates are held under conditions ruling before the present land regulations came into force in the Federated Malay States or the Straits Settlements. Some properties are freehold, or pay only a small quit-rent, while others are subject to a revision of the rent-charge at the end of thirty years; but the majority of the plantations are now held under the terms in force since 1906.

The following fixed charges are exacted in connection with all agricultural lands granted in the Federated Malay States :

I. Preparation of grant Dol. Ct.

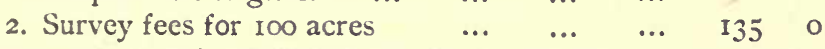

For each additional acre up to 300 acres... 00 $\begin{array}{lllllll}\text { Survey fees for } 300 \text { acres } & \ldots & \ldots & \ldots & 315 & 0\end{array}$

For each additional acre up to 500 acres 080 $\begin{array}{lllllll}\text { Survey fees for } 500 \text { acres } & \ldots & \ldots & \ldots & 475 & \text { o }\end{array}$

For each additional acre up to 1,000 acres $\quad 0 \quad 70$

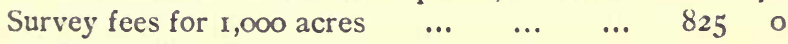

For each additional acre up to 2,000 acres $0 \quad 60$

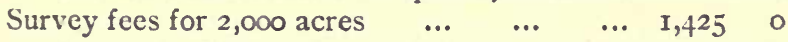

For each additional acre up to 4,000 acres $0 \quad 50$

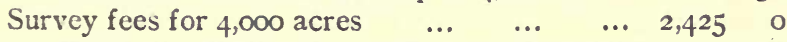

For each additional acre up to 6,000 acres $0 \quad 40$

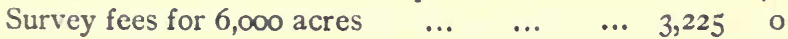

For each additional acre up to 10,000 acres 030 $\begin{array}{lllllll}\text { Survey fees for } 10,000 \text { acres } & \ldots & \ldots & \ldots & 4,425 & \text { o }\end{array}$

For each additional acre above 10,000 acres $\quad 0 \quad 20$

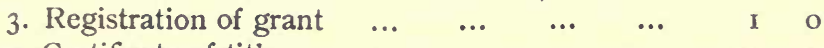

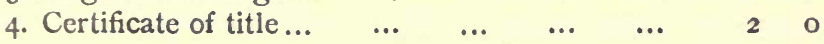

The charges and fees in the Straits Settlements are practically similar, and need not be repeated, especially in view of the fact that the remaining area of land available for rubber plantations in those sections of the 
Peninsula is extremely limited. In the four Native States of Johore, Kedah, Kelantan, and Trengganu, the same scale will be applied as soon as they become units of the Federation.

In the Straits Settlements the method of taxing rubber varies. In Malacca there is an assessment tax on rubber-trees over six years old of 7 cents per tree, the rate altering from time to time, but fixed at that amount for IgI3. It is not an easy tax to collect, especially in the case of Chinese and native holdings, but was imposed in this form in order to avoid any portion of the revenue becoming liable to contribution towards national defence, as is the case with all receipts from Customs duties. In Penang a tax not exceeding 5 per cent. on the profits of an estate is exacted.

In the Federated Malay States an export duty of $2 \frac{1}{2}$ per cent. ad valorem is collected on all shipments of rubber, and the revenue so derived is employed for the maintenance of roads and other public works.

The general revenue of the Straits Settlements and the Federated Malay States is derived from export duties on tin and tin ores, agricultural, miscellaneous and forest products, licences to sell and manufacture opium (chandu) and for the sale of alcoholic liquors and other purposes, premium and rent on lands alienated for agricultural and mining operations, revenue from posts and telegraphs, profits from State railways, and import duties on opium, petroleum, and intoxicating liquors. With the exception of the latter charges, all imported merchandise is duty-free.

The elevation above sea-level of the rubber estates is best classified under four headings: (I) Old sugar 
lands near the seaboard situated about 4 feet above sea-level; (2) lands formerly cultivated with tapioca and other products, and having an elevation of from Io to 50 feet; (3) old coffee estates lying some 50 to I 50 feet above sea-level; and (4) forest lands opened up during the past seven years, with an elevation of roo to 300 feet. Above 300 feet practically no rubber cultivation has been attempted as yet; but several experimental stations have been established in the Federated Malay States, and at these Pará rubber is planted at varying elevations up to 2,000 feet, in order to ascertain the suitability of the highlands for its cultivation.

The three characteristic varieties of soil in the rubbergrowing districts of Malaya are-(I) A strong, grey loam in the low lands near the seaboard, where sugarcane was formerly cultivated, and where the waterlevel is only some 4 to 5 feet from the surface; (2) a hard, laterite soil preponderating in Malacca, in some of the southern sections of Negri Sembilan, and appearing in portions of Selangor and Perak; (3) a deep, red loam lying on a laterite subsoil, and found over a great extent of Negri Sembilan, Selangor, and Perak. The Pará rubber-tree flourishes in all three of these soils. In the first the root growth is chiefly lateral, the taproot disappearing when the water-level is reached. Sluice-gates are necessary on these lands to prevent inundations from high tides. The trees mature early and yield well, but are subject to damage from strong winds, on account of the absence of deep tap-roots. In the laterite soils the growth is slower, and the yield of latex is smaller during the first two or three years of 
tapping; but trees from ten to twelve years yield more freely proportionately than at the earlier stages, and at that stage of development show little difference to those grown on the grey loam of the low lands near the seaboard and river estuaries. The third soil, extending to the foot-hills of the mountain ranges in Negri Sembilan, Selangor, and Perak, is, in the opinion of impartial experts, best adapted of all for the cultivation of the Para rubber-tree. The growth is rapid in the earlier stages, and the tree sends down a deep tap-root which gives a firm hold for resistance to strong winds. Occasionally these trees are snapped off by a violent gust, but seldom thrown down. The trees grow evenly, mature well, and they give a satisfactory return of latex from four years upwards ; moreover, they show steadily increasing yield with additional age. There are large areas of this red loam soil in Johore, Pahang, Kelantan, and Kedah, and these will undoubtedly be a great attraction to practical planters in the future development of rubber estates in the Malay Peninsula. The objection to it is that on steep hillsides it washes badly in heavy rains, on account of its friable nature; even with a system of drainage scientifically applied there is great difficulty in saving the topsoil, especially when an estate is clean-weeded in the earlier stages of its development.

Throughout the Federated Malay States the rainfall varies greatly, and is influenced to a marked degree by the proximity of different localities to the mountain ranges forming the backbone of the Peninsula. The following records for seven years ending Igro show the average distribution : 


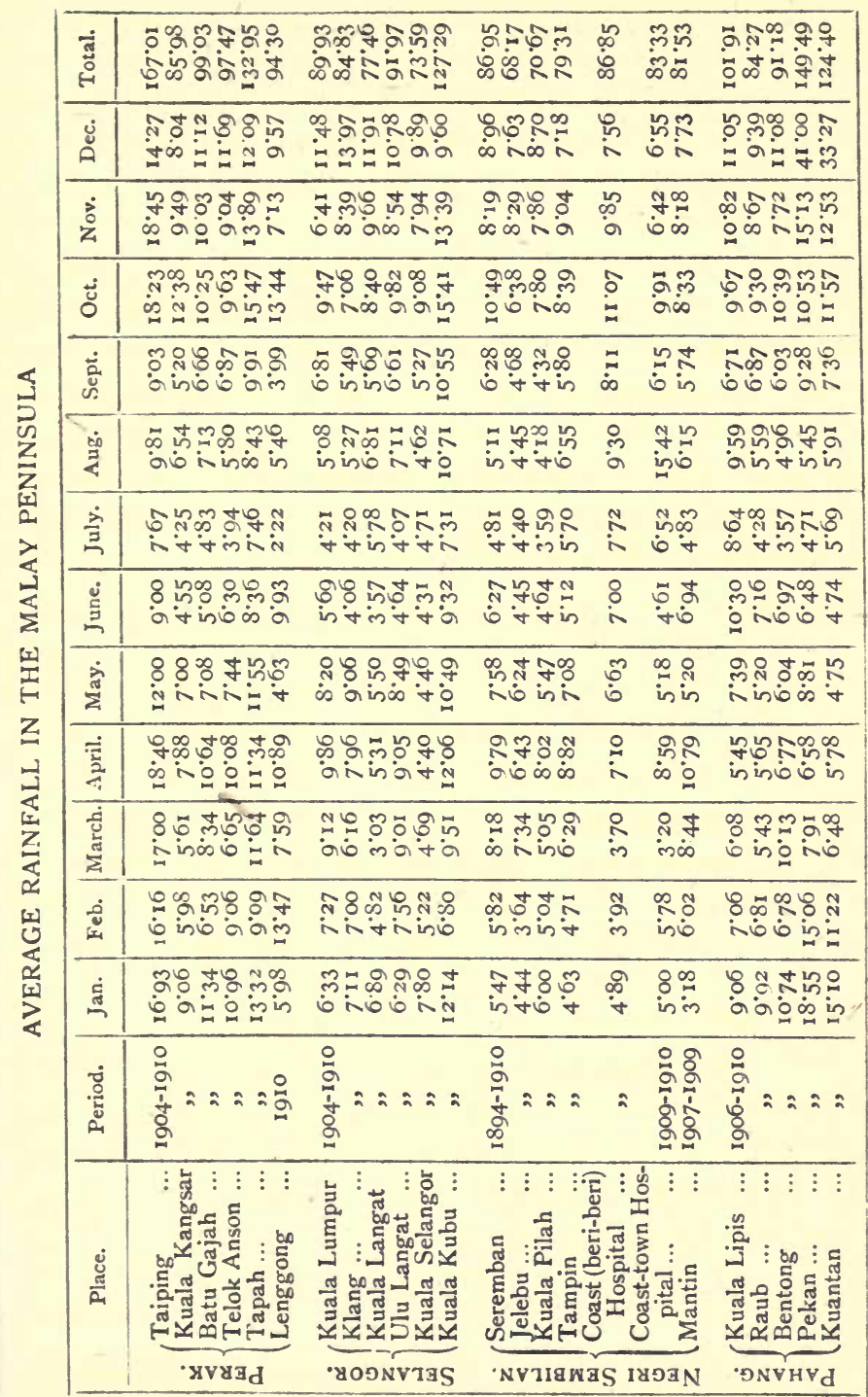


January and February, I9I2, were exceptionally dry months, rain falling on very few days during that period. This drought did not materially affect the yield of latex as far as can be judged by the output for that year. In IgI3 another dry period occurred in the middle of the year, and in this case a decided shortage of latex resulted in several districts.

Throughout the Malay Peninsula a very even temperature prevails in the low lands. The following gives the average mean maximum and minimum returns for fifteen years, from 1896 to I9Io:

\begin{tabular}{|c|c|c|c|c|c|}
\hline & & & & Maximum. & Minimum. \\
\hline \multicolumn{4}{|c|}{ PERAK. } & \multirow{7}{*}{$\begin{array}{l}90 \cdot 52 \\
90 \cdot 58 \\
90 \cdot 30 \\
89 \cdot 89 \\
90 \cdot 22 \\
89 \cdot 38\end{array}$} & \multirow{7}{*}{$\begin{array}{l}72 \cdot 21 \\
72 \cdot 46 \\
72 \cdot 63 \\
70 \cdot 88 \\
69 \cdot 16 \\
72 \cdot 66\end{array}$} \\
\hline Taiping ... & $\ldots$ & ... & $\ldots$ & & \\
\hline Batu Gajah & $\ldots$ & ... & $\ldots$ & & \\
\hline Ipoh $\quad \ldots$ & $\ldots$ & $\ldots$ & $\ldots$ & & \\
\hline Telok Anson & $\ldots$ & ... & ... & & \\
\hline Tapah $\quad \ldots$ & ... & ... & ... & & \\
\hline Parit Buntar & ... & ... & ... & & \\
\hline \multicolumn{4}{|c|}{ SELANGOR. } & \multirow{6}{*}{$\begin{array}{l}89^{\circ} 90 \\
86 \cdot 80 \\
87 \cdot 00 \\
86 \cdot 80 \\
89 \cdot 80\end{array}$} & \multirow{6}{*}{$\begin{array}{l}71^{\circ} 30 \\
71 \cdot 80 \\
74^{\circ} 40 \\
76 \cdot 00 \\
72 \cdot 40\end{array}$} \\
\hline Kuala Lumpur & ... & $\ldots$ & $\ldots$ & & \\
\hline Klang $\quad . .$. & ... & ... & ... & & \\
\hline Kadjang ... & ... & $\ldots$ & $\ldots$ & & \\
\hline Kuala Selangor & ... & $\ldots$ & $\ldots$ & & \\
\hline Kuala Kubu & ... & ... & $\ldots$ & & \\
\hline \multirow{2}{*}{\multicolumn{4}{|c|}{\begin{tabular}{cccc}
\multicolumn{4}{c}{ Negri } \\
Seremban & $\ldots$ & $\ldots$ & $\ldots$
\end{tabular}}} & \multirow[b]{2}{*}{$88 \cdot 40$} & \multirow[b]{2}{*}{$69 \cdot 20$} \\
\hline & & & & & \\
\hline \multicolumn{4}{|c|}{ PAHANG (IgIo only). } & & \multirow{5}{*}{$\begin{array}{l}68^{\circ} 70 \\
64^{\circ} \circ 0 \\
71^{\circ} 90 \\
66^{\circ} \circ 0\end{array}$} \\
\hline Kuala Lipis & $\ldots$ & $\ldots$ & $\ldots$ & $92 \cdot 80$ & \\
\hline Raub $\quad .$. & ... & $\ldots$ & $\ldots$ & $92^{\circ} 00$ & \\
\hline Pekan $\quad$... & $\ldots$ & $\ldots$ & $\ldots$ & $89 \cdot 60$ & \\
\hline Bentong ... & $\ldots$ & $\ldots$ & $\ldots$ & $92^{\circ} 00$ & \\
\hline
\end{tabular}

For the consideration of the capital cost and present 
value of rubber plantations in the Malay Peninsula, it is convenient to separate them into three groups, each with its distinctive heading. With the present comparatively low price for the crude material, an adjustment of the market value of shares in rubber companies is a natural corollary to the inflation of the quotations ruling from I 909 to I 912 , for the rubber industry has passed the phase of exaggerated speculation, and has now entered the stage of providing sound opportunities for the investment of capital on a solid and dividendearning basis. Because profits are reduced, it does not follow that the industry is any less staple than formerly; indeed, quite the reverse is the case, for present developments are more attractive to the conservative investor than was the case when market values were subject to wild fluctuations at the hands of irresponsible gamblers. Tropical agricultural enterprise should receive a high rate of profit, on account of the inevitable risks attending such undertakings, and a fair remuneration on capital so employed may be placed at not less than I5 per cent. per annum. The majority of Malay plantations can earn this rate of dividend on a valuation of the actual cost of establishing an estate and defraying all necessary charges for the first five years, such expenditure not exceeding a total outlay of $£ 30$ per acre. Experience shows this figure to be ample to cover all expenses when the work is carried out on practical lines and stripped of all extravagant ideas.

The following classification gives the characteristic factors of each of the three groups of plantations: (I) Estates opened and worked before I908 by private enterprise or joint-stock companies, before the situation 
was influenced by high prices for rubber and conducted on strictly economical principles; (2) estates purchased at high prices by syndicates and joint-stock companies in I909-Io from Group No. I, together with new estates opened up during the "boom" period; (3) estates established during IgII-I 2 by public companies or private enterprise.

The first of these groups originally comprised about 250,000 acres, and they consisted principally of coffee, sugar, and tapioca estates, converted into rubber plantations by interplanting existing crops with Pará rubbertrees; they were owned partly by British capital, and partly by Chinamen resident in the Malay Peninsula. The original capitalization was small, and the cost of interplanting with rubber exceptionally low. When the rubber boom occurred, some two-thirds of these properties were purchased at high prices by joint-stock companies formed in Europe, Shanghai, Hong-Kong, and Singapore. The remaining area of this group, containing approximately 80,000 acres, continued working and producing on their original low capital basis, and they naturally succeeded in paying very high dividends. Among these were Bukit Rajah, Cicely, Federated Selangor, Inch Kenneth, Linggi, Pataling, Selangor, Vallambrosa, and many others.

Group No. 2 comprises some 500,000 acres owned by joint-stock companies formed chiefly during 1909 and IgIo; it consists of estates purchased from Group No. I at boom prices, and of new plantations opened in I909, IgIo, and IgII. This group must be regarded as decidedly over-capitalized in relation to the necessary cost per acre for bringing plantations to the yielding stage. 
The third group consists of companies and individuals who have established new plantations on a conservative basis under careful and experienced management, and limited the total expenditure up to the time the trees are yielding to a sum of from $£ 25$ to $£ 30$ per acre. Under these conditions some 70,000 acres are comprised. In this group are to be found many practical planters and successful estate managers who are opening up properties for their own account.

Briefly summed up, the position is this: If $£ 30$ per acre is taken as a fair basis of cost for bringing an estate to the dividend-paying stage-and it will be shown presently that this is the case-the groups may be classified as follows:

I. Old-established estates working on original Acres. $\begin{array}{lllllll}\text { capital ... } & \ldots & \ldots & \ldots & \ldots & \ldots & 80,000\end{array}$

2. Companies formed during the "boom" ... 500,000

3. New plantations limited to a capital expenditure of from $£_{25}$ to $£_{30}$ per acre $\quad \ldots \frac{100,000}{680,000}$

The first noticeable effect of over-capitalization is a marked inclination on the part of many estates to extend the area under cultivation on strictly economical principles, and so reduce the average capital charge per acre. With the price of rubber at $5 \mathrm{~s}$. per pound or thereabouts, it was easy to find money to effect these extensions, but with the great fall in the value of the raw material, the raising of fresh capital has become more and more difficult. It is only natural to suppose that many of the rubber companies launched during the "boom" will be subject to the usual vicissitudes of any great industry, 
and meet with unforeseen contingencies requiring most substantial financial assistance. Failing such aid a deadlock must ensue, and the liquidation of the company follow. In cases where debentures have been issued, the assumption is that the holders will foreclose, and obtain possession of the property on a low capital basis. Where no fixed charges exist the estates will be absorbed by more fortunate concerns, or purchased at a comparatively low cost by European, Chinese, or local capitalists. There does not appear to be any likelihood of such properties going out of cultivation unless in very exceptional circumstances. It is safe to assume that the general effect of over-capitalization will be towards the extension of the present cultivated area and the consolidation of properties into larger holdings.

As an indication of the amount of over-capitalization resulting from the rubber boom of 1909 -10, it is necessary to refer to the value of the flotations made in those years in Europe, Hong-Kong, Shanghai, and locally. It is not possible to give exact figures, but the approximate amount, certainly on the cautious side, may be taken as-

British, subscribed in I909-I9II $\quad \ldots \quad \ldots \quad £ 24,000,000$ Local and Chinese, subscribed in I909-I9I I 3,000,000 $£ 27,000,000$

This gives an average capitalization of $£ 54$ per acre, distributed over 500,000 acres comprised in Group No. 2. Groups Nos. I and 3 may be capitalized at $£ 4,000,000$, or an average of $£^{27}$ per acre.

From 1907 to the end of I9II, the nominal capital of rubber companies floated in London for all countries 
was $£ 74,122,325$; in IgI2 the amount increased to $£ 76,500,000$, and in I9I3 to $£ 78,000,000$ in round figures. In the latter year the new capital provided for rubber enterprises in the Orient was $£ \mathrm{I}, 292,250$, apportioned as follows :

$\begin{array}{lcccccr}\text { I. Malay Peninsula } & \ldots & \ldots & \ldots & £ 740,000 \\ \text { 2. Sumatra } & \ldots & \ldots & \ldots & \ldots & \ldots & 285,000 \\ \text { 3. Ceylon } & \ldots & \ldots & \ldots & \ldots & \ldots & 105,250 \\ \text { 4. India } \quad \ldots & \ldots & \ldots & \ldots & \ldots & 60,000 \\ \text { 5. British North Borneo } & \ldots & \ldots & \ldots & 50,000 \\ \end{array}$

In addition to this amount for Eastern undertakings, a sum of $£$ I02,500 was subscribed for concerns in Africa, bringing the total new issues in London for I9I3 to $£$ I,342,750. Money for rubber plantation purposes was provided also in France, Belgium, and Holland, although to a lesser extent than in London. The combined capital invested in European and local companies in the rubber industry of Malay, Ceylon, Java, Sumatra, India, Burmah, Borneo, and Saigon, is certainly not less than $£ 100,000,000$; probably it exceeds that figure by a substantial amount, the greater part of this enormous sum having been subscribed in the five years from I 907 to Igr2. 


\section{CHAPTER XIV}

\section{THE MALAY PENINSULA-Continued}

Cost of opening and bringing into bearing an estate of 1,000 acres-Cost of maintaining $\mathrm{I}, 000$ acres containing I08 six-yearold trees to the acre - General conditions concerning maintenance costs +Estate management-Equipment of factories and preparation of rubber - Numbers and nationality of estate labourers-Tamil coolies-The Tamil immigration fund-Labour from Java-Malay labourers-Population of the Malay Peninsula-Varying rates of wages-Daily work-hours-Only small percentage of skilled labour required-Sanitary conditions and medical regulations.

$\mathrm{HE}$ cost of establishing a rubber plantation and
maintaining it until it reaches the profit-earning stage has been the subject of much difference of opinion in the past, due in great measure to the fact that abnormally high prices for the crude material led to many extravagant practices in estate management. With rubber at three times the present value, shareholders cared little whether the expenditure was $£ 30$ per acre or half as much more. To-day matters are on a different basis, and all expenses must be reduced to the lowest possible point consistent with thoroughly efficient results. The figures now given for the average necessary cost of plantations are the outcome of practical experience, but they are, of course, subject to slight variations occasioned by possible exceptional circumstances. The detailed description of the labour conditions is for the purpose of permitting a full appre- 
ciation of this essentially important factor in the situation. Assertions are made frequently that a shortage of labour exists for the plantation industry, and that consequently the output of rubber will be curtailed. Speaking broadly, there is no foundation for any such statements; for with Canton and Shanghai only three days distant, and the cost of passage I2 dollars per head from those centres of population, it is absurd to regard the labour problem as a serious difficulty, or one that offers a grave menace to the Malay rubber industry.

In opening an estate on forest land not less than 50 feet above sea-level, the estimated cost includes all necessary charges up to the end of the fourth year, when the yield should be sufficient to allow the capital account to be closed. Felling and cleaning up after the burning of the timber is done by contract. Weeding may be by contract or day labour, whichever the manager considers the cheaper method. Prices vary slightly according to the situation of the estate, and whether it is close to or distant from the native labour employed for felling and clearing. No allowance is made for the removal of the stumps of trees or big logs, as the great majority of practical planters do not consider the possible benefit compensates for the expense; as a rule they prefer to maintain a vigilant lookout for fomes, white ants, and other pests, and to treat individual cases as they occur. The distribution of costs is self-explanatory.

The cost of opening up lalang (grass) land is more or less the same as forest. There is no premium on this land, but the expenditure for eradicating the lalang is very heavy. On forest land the total for felling, cleaning, and weeding, for four years amounts to $66 \frac{1}{2}$ dollars 
per acre; on lalang land the cost is 45 dollars for cleaning and 24 dollars per acre for weeding for four years, or 69 dollars altogether. Some planters are inclined to prefer lalang land because it is free from stumps and

Cost of opening i,OOO Acres aNd Four Years' Maintenance

Premium Dollars.

I. Premium on land, $x, 000$ acres $\quad \ldots \quad$... 3,000

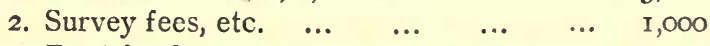

3. Rent for four years $\quad \ldots \quad$... $\quad \ldots \quad$, 4,000

4. Felling, clearing, and burning $\ldots \quad \ldots \quad$ I5,000

5. Cleaning up after burning $\quad \ldots \quad \ldots \quad \ldots \quad 7,500$

6. Weeding: First nine months $\ldots . \quad \ldots \quad 18,000$

Second year $\quad . . \quad \ldots \quad \ldots \quad$ I2,000

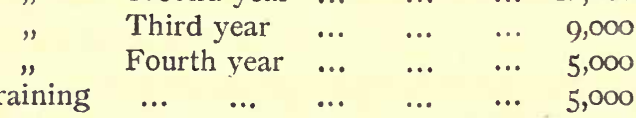

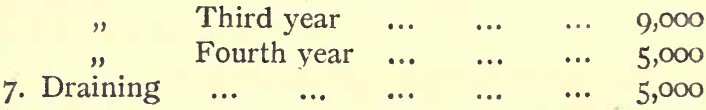

8. Roads and bridges... $\quad \ldots \quad \ldots \quad \ldots \quad \ldots \quad 7,500$

9. Holing, lining, and filling $\quad \ldots \quad \ldots \quad$... 4,000

ro. Planting and supplying $\ldots \quad$... $\quad \ldots \quad 2,000$

II. r $^{\circ}, 000$ plants two years old (providing
for supplies)

I2. Manager's bungalow (6,000 dollars), assis-

tants' bungalow (4,000 dollars) $\quad \ldots \quad$ ro,000

I3. Factory and machinery $\quad \ldots \quad$... $\quad \ldots \quad 25,000$

14. Lines for coolies $\quad \ldots \quad$... $\quad \ldots \quad$... 20,000

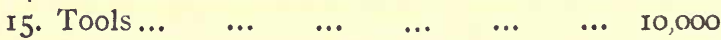

I6. Management $\quad \ldots \quad \ldots . \quad \ldots \quad \ldots \quad$... 50,000

17. Hospital, medical attendance, etc. ... I5,000

I8. Contingencies $\quad \ldots \quad$... $\quad \ldots \quad$... $\quad 8,000$

$$
\text { Total } \ldots . \quad \ldots-\ldots \overline{230,000}
$$

This is equal to $£_{2} 6$ ros. per acre.

timber; against this is the fact that it has been already under cultivation, and has lost a large proportion of its topsoil.

If the land to be opened up is low-lying and swampy, 
the extra cost of draining will be approximately $£ 3$ per acre.

The following estimate has been compiled after most careful inquiry :

Maintenance of Six.Year-Old Plantation

Dollars.

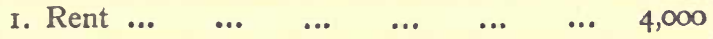

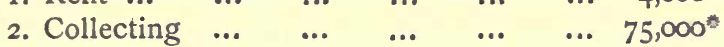

3. Curing and preparation $\quad \ldots \quad \ldots . \quad \ldots \quad$ I $4,000+$

4. $2 \frac{1}{2}$ per cent. duty on 300,000 pounds $\begin{array}{llllllll}\text { rubber } & \ldots & \ldots & \ldots & \ldots & \ldots & 7,500\end{array}$

5. Transport, shipping charges, and com$\begin{array}{lllllll}\text { mission } & \ldots & \ldots & \ldots & \ldots & \ldots & 6,000\end{array}$

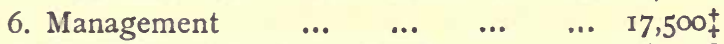

7. Hospital and medical attendance $\quad \ldots \quad 6,000 \S$

8. Weeding $\quad \ldots \quad$...

9. Maintenance of roads and drains $\quad \ldots \quad 3,500$

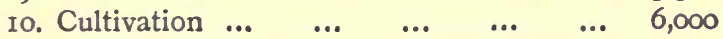

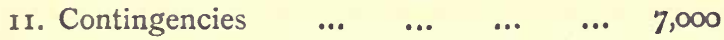

12. Depreciation of buildings other than \begin{tabular}{lllllll} 
factory & $\ldots$ & $\ldots$ & $\ldots$ & $\ldots$ & $\ldots$ & 5,250 \\
\hline
\end{tabular}

Total $\quad \ldots \quad \ldots \overline{155,250}$

With a yield of 300 pounds of rubber to the acre, the cost would be $5 \mathrm{I} \frac{1}{2}$ cents, or $\mathrm{I}_{4} \frac{1}{2}$ pence, per pound f.o.b. at port of shipment. At present the average actual costs of production are higher than stated; but in most cases estates contain trees of various ages, a large proportion of them yielding for the first time, and therefore more expensive to tap and collect; or they have been allowed to become overgrown with lalang and weeds, and this has entailed a heavy additional expenditure charged

: Includes depreciation on all tools and materials.

+ Allows 20 per cent. depreciation on factory and machinery.

† Allows for manager, two assistants, and two clerks.

$\S$ In conjunction with neigh bouring estates. 
against revenue. Therefore the estimate given is a fair one for an estate of I,000 acres planted with roo trees to the acre, and properly cared for from the commencement. As the trees grow older and the yield increases, the costs of tapping and collecting per pound of rubber should substantially diminish; this should be the case also in somewhat lesser proportion with the other items of expenditure. At the present rate of costs from the Malay Peninsula to date of sale in London or Liverpool, a sum of $I \frac{1}{2} \mathrm{~d}$. per pound of rubber must be added to the aforesaid cost of production, and this will bring the total costs per pound to Is. $4 \mathrm{~d}$. If the price of rubber drops below 2s. per pound, the ad valorem charges for duty, commissions, and brokerage, will be proportionately reduced, and the total cost up to date of sale would be approximately Is. 2d., still leaving a substantial net profit to the producer.

The yield of an estate properly cared for is taken at 300 pounds of dry rubber per acre at six years old; but, as is shown later on, all the indications are that wellgrown six-year-old trees in Malay frequently give a greater return than 3 pounds per tree. It is better, however, to be on the safe side. The quality of the rubber made in nearly all the factories, whether crepe or sheet, is distinctly good, although the colour is not quite so bright as the Ceylon product, probably on account of the discoloured water common to the Peninsula. The percentage of first latex and lump is low; on many estates it only averages 70 per cent., and scrap bark and earth scrap 30 per cent. In a few cases, as at Kamuning, the return was 82 per cent. first latex and lump, and 18 per cent. scrap bark and earth scrap. 
There is a ready sale in Singapore and Penang for the produce of the estates, but as a rule a margin is allowed for commission. In Ceylon the reverse obtains, and the relative price in Colombo is frequently higher than in London, and for this reason a certain quantity of Malay rubber has been shipped to Colombo for sale during I9I2 and IgI3.

The managers of the Malay estates are nearly all men of trained planting experience and good education. Many of them came to the country twenty years ago, and learnt their work as planters on the coffee and sugar plantations, and then helped to convert those properties into rubber estates. Others have been recruited from Ceylon and Southern India, and several officials resigned the Government service for planting. All are required to be efficient in the handling of labour and the organization of the routine work of estates. They are responsible in every way for the well-being of the estates and their personnel, and it is seldom that any serious fault is found with their administration abilities. When the rubber boom was at its height, a certain number of incompetent men obtained employment, but they are fast being weeded out. Over the managers are the visiting agents appointed by companies and private owners to inspect estates from time to time, and to advise on the general policy to be followed in connection with the administration.

Until three years ago it was only on a comparatively small proportion of the rubber estates that factories specially designed and equipped for the curing and preparation of rubber existed. In very many cases old coffee-stores and sugar-houses were utilized, and tem- 
porary buildings erected for the treatment of the latex, drying, and smoking. Frequently hand machines were used for creping and for rolling out sheets. In fact, most primitive methods were customary on the great majority of plantations. During the last three years, however, a complete change has occurred, and modern machinery driven by Tangye, Diesel, Hurnsby, Blackstone, Crossley, and many other types of engines, has been installed on all estates of any importance. Hitherto many estate managers have preferred to send their latex to a neighbouring factory for treatment; but, as greater areas of trees begin to yield, it is found more economical and satisfactory to undertake the curing and preparation on the estate than to pay for having the work done outside. On many large estates where the fields are far distant coagulating stations are established, and the latex treated with acid before being sent to the factory.

The expense of a modern factory is comparatively light apart from the cost of the building. This, as a general rule, is steel-framed, with corrugated iron roof and sides. Concrete floors are laid down, with adequate guttering to allow free drainage for constant sluicing and washing, for cleanliness is regarded as a necessity in the preparation of the latex. On one side of the factory are installed the machines for washing, creping, or rolling sheets, and these are driven from overhead or underneath shafting served by engines of the type already mentioned. The machines most in use are the Shaw or the Bridge patent, and these are of three grades, for the purposes of breaking down the coagulated latex, rolling, and finishing. Opposite the machines 
are the coagulating jars or tanks; if the former they are made of glazed earthenware, and if the latter they are lined with glazed tiles and built in oblong, form. Coagulation is effected by the use of acetic, formic, or fluoric acid. Down the middle of the building are tables for handling the coagulated latex before it passes into the machines, and the crepe or sheet after passing through them. Where sheet is made, it is coagulated in flat pans 15 inches long, ro inches wide, and 2 inches in depth; in these the latex is allowed to set for some hours before machining. The fuel for generating the necessary engine power varies, liquid fuel, suction gas, and anthracite, being employed, the latter being most commonly used at present. The washing machines for scrap of the Werner, Pfleiderer and Perkins patent work smoothly and give excellent results.

From the factory creped rubber is taken to the dryingsheds, and hung for a period varying from twelve to twenty days, or sometimes longer, until the moisture has evaporated, the time required for this operation being dependent very largely on weather conditions. Sheet rubber is taken from the factory to the smokinghouse, and remains in smoke produced by burning cocoanut husks or wood for four to five days. It is then removed to the drying-shed and hung up until fit for packing. Scrap, bark scrap, and earth scrap, are made into crepe and dried in the same manner as first latex and lump. In the Malay Peninsula the practice of smoking crepe has been abandoned on many estates, and a light, bright colour is the object desired. In this connection the bad water-supply occasions many difficulties, on account of its muddy and discoloured 
character, and it is frequently necessary to filter it before use in the creping and washing machines. Another result of this condition of the water-supply is the heavy wear and tear on the rollers of the machines on account of grit.

On only very few estates are mechanical dryers in use. On three plantations-Kent, Wardiebrun, and Bukit Rajah-vacuum dryers on the Passberg system were erected, but the managers had received orders from London not to make use of them. It is difficult to understand this policy, as the results obtained from these machines in Ceylon are distinctly satisfactory, and the saving in labour and economy in time is of undeniable advantage. With a dryer the latex can be ready for shipment twenty-four hours after its delivery at the factory, and, moreover, the expense of dryingsheds is avoided. Many managers state that artificial dryers must come widely into use very shortly, in view of the rapidly increasing output of the factories.

When dry the rubber is packed in wooden boxes and despatched to the port of shipment. The cases used are the "Venesta " imported from Russia, the "Momi" from Japan, and various kinds manufactured from native woods. The weight of rubber in these boxes varies on different estates from II2 pounds net to 230 pounds net. The ton weight far exceeds the 50 cubic feet measurement settled by the Shipping Convention, and for which the charge is $65 \mathrm{~s}$. from Singapore, Port Swettenham, or Penang, to London or Liverpool or the Continent of Europe.

In connection with this high charge for freight, some experiments are now being made in the direction of 


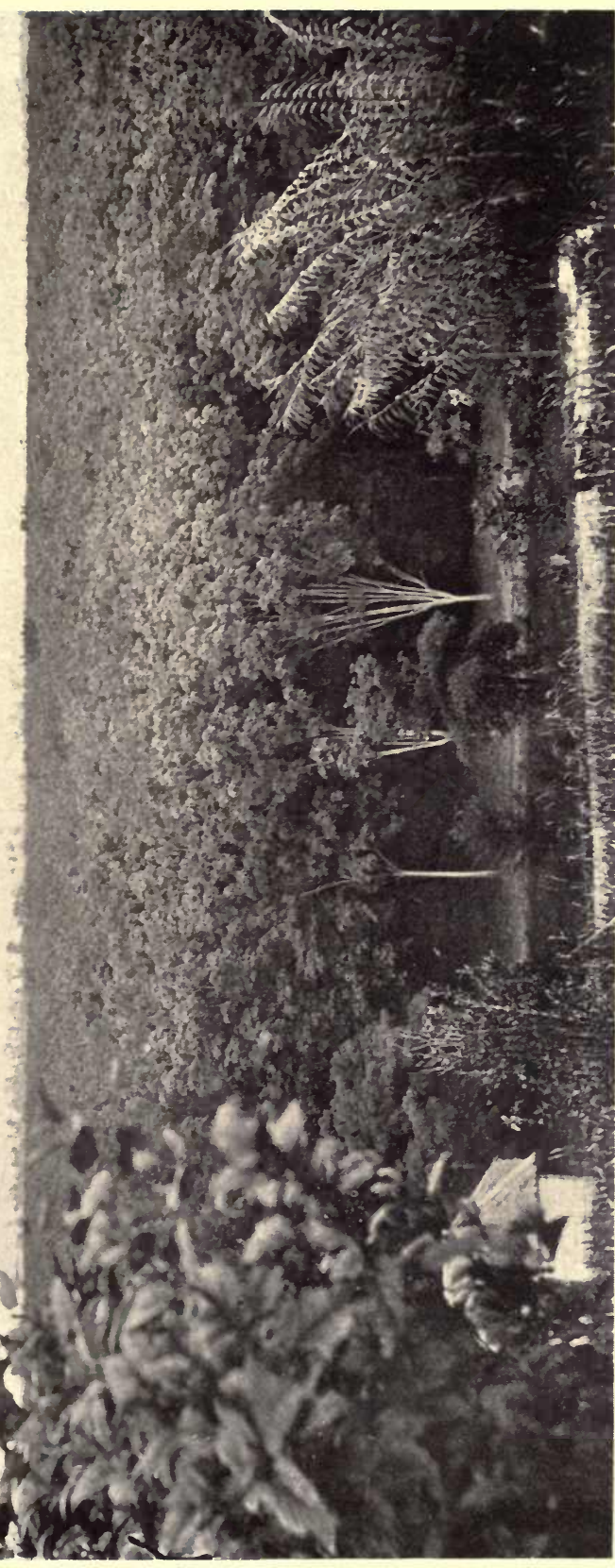



reducing the rubber in presses similar to those used in Sumatra for tobacco, and then baling with Javanese mats. By this method something more than a ton weight of rubber can be shipped in the 50 cubic feet allowed by the Shipping Convention, and by this means a considerable saving in the freight charge can be effected. There is little doubt that, if the trial shipments in this form are successful, boxes will be discarded for bales in the near future throughout this country.

Official returns show that the labour force, not including contractors to fell and clean up new estates, in IgII was-

\begin{tabular}{|c|c|c|c|c|c|}
\hline Tamils. & Javanese. & Malays. & Chinese. & Others. & Total. \\
\hline $98,988^{*}$ & I $7,760+$ & 14,258 & 45,663 & 2,361 & $\mathbf{1 7 9 , 0 3 0}$ \\
\hline
\end{tabular}

In 1912 the Superintendent of Indian Immigration supplied the following data: The total number of deck passengers from India during the previous twelve months was IOI,2I 8 adults and 7,253 minors, making $108,47 \mathrm{I}$ in all ; of these, 78,376 adults and 6,013 minors were sent to plantations, and of the remaining 24,082 who had paid their own passages from India no record was kept, but the majority probably went to different estates. The number of coolies returning to India during the same period was 48,103 , thus leaving a balance in favour of Malay of 60,268. From these figures the Indian coolies working on estates or on

\footnotetext{
*-Males, 74,966; females, 24,022.

+ Males, 13,003; females, 4,757.
} 
public works may be placed at not less than I50,000 at $^{2}$ the end of Igr2. Recruiting in India is being carried out actively, and only a few days ago 300 men from various estates left for India for recruiting purposes. The Superintendent of Indian Immigration stated that he fully expected a large increase in the number of Tamil coolies during Igr2-I3.

The method of recruiting Indian coolies for work on the Malay rubber estates is best explained by the following notice, issued by the Superintendent of Indian Immigration for the Malay Peninsula:

\section{THE TAMIL IMMIGRATION FUND}

For years previous to I 907 there had been continual complaints from employers importing Tamil labour that coolies imported by them were attracted away to the service of other employers who paid no portion of the expense of importation.

The Immigration Committee, appointed by the Government in that year, recommended that the cost of the importation of Tamil labourers should be distributed amongst all those who employed them; and the Tamil Immigration Fund Enactment, based on the recommendations of the Committee, was subsequently passed.

Under this law an assessment on the amount of work done by their coolies is levied upon all employers of Tamil labour, and the proceeds are paid into a fund styled the Immigration Fund. Employers are required to send in to the Superintendent of Immigrants, Penang, on printed forms which may be obtained from 
him, certified returns of their Tamil labour for every quarter; the returns must be sent during the months of April, July, October, and January.

The amounts at which they are then assessed must be forwarded to the Superintendent to be credited to the Immigration Fund. This Fund is not part of the general revenue of the Government. It is administered by the Superintendent of Immigrants under the authority of the Immigration Committee solely in the interests of importers of Tamil labour. The Government is, in fact, the largest contributor to the Fund through the assessments which it pays on all Tamil coolies employed on the railway and in the Public Works Department.

The purposes for which the Fund can be used are expressly laid down in the enactment as follows :

(a) The payment of free passages for Tamil labourers and their families from the Madras Presidency to this country.

(b) The general expenses incurred in connection with the recruiting of labour in the Madras Presidency.

The Government bears all the expenses of administering the Fund, paying the salaries of officials and clerks; maintains large kangany camps at Madras and Negapatam, where coolies recruited by kanganies are housed pending shipment by steamer; provides officials in India (the Emigration Agent at Madras and the Superintendent of Emigration Depot at Negapatam), who superintend these camps and generally assist in matters connected with recruiting; provides coolie depots at Penang and Port Swettenham; and grants a large annual subsidy to the steamship company which 
maintains the weekly coolie service from India to the Straits.

The Immigration Committee pay from the Fund passage money from India and trainage in India, as explained below, and also maintain native agents (at present eleven in number) in India at various places, whose duties are to assist kanganies, help in forwarding their coolies, and arrange the payment of their train fares.

Whenever the balance to the credit of the Fund after paying the above expenses justifies such a course, a recruiting allowance is paid to employers in respect of each coolie imported by them from India under the Committee's licences. At one time an allowance of 3 dollars per head was paid, and this was subsequently increased to $4 \frac{1}{2}$ dollars. The number of coolies imported in the summer of Igro was, however, so large, and the bills for steamer tickets consequently so high, that the Immigration Fund became temporarily depleted. As the assessment on the increasing number of Tamils now in the country is received, the Fund will again have a balance to dispose of, but at the time of writing (November, I9I0) it has been necessary to suspend for the present the payment of recruiting allowances. The allowances will, however, be renewed as soon as possible.

It will be seen that practically all the money collected from employers in the form of assessment goes back directly or indirectly to those employers who import labour, the only portion that does not do so being the small amount paid in connection with the native agents appointed at various places in India. 


\section{INSTRUCTIONS FOR RECRUITING BY KANGANIES IN INDIA}

Kanganies receive licences to recruit in the Madras Presidency from the Superintendent of Immigrants, Penang. The licences are granted free of charge.

Forms, to be filled in by the employer, will be sent on application to the Superintendent of Immigrants; when the required details have been filled in by the employer, the licences should be sent to the Superintendent of Immigrants for registration and signature.

The usual procedure is as follows:

The employer sends his kangany over to India, and generally makes arrangements with either the Madura Company in Negapatam or Messrs. Binny and Co. in Madras (these firms are the British India Steamship Company's agents in each case) to finance him; the custom is for the firm to pay the kangany so much per head for each coolie actually produced by him and shipped.

By this system the risk is avoided of giving to the kangany large advances in cash, which he might very likely squander. These two firms have agents in the Straits and Federated Malay States to whom they cable information of the number of coolies shipped for each estate; the local agents inform the employers, and it is thus possible for each estate manager to know before arrival of the steamer the number of coolies shipped for him.

There are officers of this department stationed at Negapatam and Madras; at the former he is styled Superintendent of the Emigration Depot, and at the 
latter Emigration Agent. They give assistance and advice to kanganies, and they superintend the kangany camps at Negapatam and Madras respectively, where coolies are accommodated until shipment.

Kanganies holding registered licences will be granted-

(a) The train fares of coolies from various centres in the Madras Presidency to Negapatam or Madras.

(b) The steamer fares of coolies from Negapatam or Madras to Penang or Port Swettenham.

The local train fares are paid to the kanganies themselves by the Committee's agents in India. The system by which they are paid is simple and works easily, and is explained to every kangany on his arrival in the recruiting districts.

The steamer fares are paid direct to the steamship company by the Committee's agents in India, and all coolies for shipment must be brought to the kangany camps at Negapatam and Madras, and shipped from thence by the contract steamers to Penang or Port Swettenham.

All Tamil coolies are entitled to leave their employer after a month's notice, whether they are imported from India or recruited locally, and no deductions may be made from their wages for any sums advanced them or expended in their recruitment before their arrival at their place of employment.

\author{
L. H. CLAYTON, \\ Superintendent of Immigrants, \\ S.S. and F.M.S.
}

Penang,

November 24, 1910. 
Employers of Tamils were assessed at the rate of 8 dollars per coolie for IgI2. If coolies are engaged locally, and not through the Immigration Department, an additional assessment of 4 dollars per head is imposed, the object being to stop the crimping of coolies from other estates. Out of the funds so obtained free passages are provided from the recruiting districts in Southern India to the estate in the Malay Peninsula. Hitherto a rebate has been allowed to estates despatching kanganies to the recruiting districts, but this practice has been suspended for the present.

Javanese labourers are divided into two classes: (I) Those imported under indentures to serve on estates for a period of three years; and (2) those recruited locally as day labourers without any time contracts. The indentured Javanese are obtained through agents in Java and under conditions imposed by the Javanese Government. A copy of the approved contract is reproduced, showing the responsibilities of both parties to the agreement. The cost of recruiting and importing these coolies varied from 92 to roo dollars per head in 1912 , and is a most serious consideration for many employers. The advantages of possessing a permanent labour force must be set against this high initial expenditure. Endeavours have been made to reduce the cost of importation and arrange for a more plentiful supply; a Commission with this purpose in view was despatched to Java in I9I2, to approach the Government on the subject, but met with no practical success.

The Javanese recruited locally in the Malay Peninsula are labourers who have come to the country in 
past years under indenture, and not cared to return to their homes. They do not form a large proportion of the estate labourers.

The following is the form of agreement between labourers and employers approved by the Javanese Government :

\section{LABOUR AGREEMENT}

As per Government resolution dated 28th of February, I 894 , No. 5 (Supplement No. 4,964; Juncto No. 5,826 and 7,073). The recruiting is permitted by Government resolution dated

We the undersigned [Register No.; Running No.; Name; Age; Origin ; Last Residence; Remarks], contractors on the one side, and Soesman's Emigratie Vendu en Commissie Kantoor, acting in this instance as the attorneys of

, situated

, contractors on the other side, hereby declare to have mutually agreed as follows :

I. The contractors on the one side undertake to perform the following work on behalf of the estate of

For Men.-Field and manufactory labour in connection with the cultivation of rubber, sugar, coffee, and tobacco, laying out water-courses (gutters) and roads should they be able to do so, building sheds and houses (carpentering which requires more skill excepted), felling forests, performing the duty of a carter and rendering assistance in case of danger caused by fire or water-in short, all such labour as generally performed by natives.

For Women.-Cleaning the seedlings beds and gardens, 
cleaning buildings and premises, and performing all such work as can be done by and demanded from women.

2. The extent of the labour to be performed on behalf of the estate is at most nine hours on every working day, provided always that the contractors on the one side shall not work for more than six hours at a stretch. Only under exceptional circumstances the contractors on the one side may be required to work for more than nine hours. In such cases, and in case the contractors on the one side out of their own free will perform labour beyond the working time, extra wages will be paid to them on the first pay-day, such wages to be calculated per hour and under the condition that such extra payment shall be at least 50 per cent. more than the contracted wages per hour.

3. The contractors on the other side shall pay to the party on the one side daily wages of 25 dollar cents to a man and I $_{5}$ dollar cents to a woman, to be settled on or before the $5^{\text {th }}$ of the month during which the wages are earned. The wages shall also be paid for the days during which labour is not performed owing to inability beyond the labourer's fault. In case of sickness not caused by misbehaviour, half-wages shall be granted for only one-tenth of the contracted period. No wages are due for the rest and holidays mentioned in this agreement. Deductions from the contracted wages are only allowed for settling advances or debts due to the contractors on the other side.

4. The contractors on the one side acknowledge having received an advance of $f$. I 5 for each unmarried person and f. 20 for each married couple, which advances 
shall be paid off in monthly instalments of not exceeding 2 dollars each.

5. The contractors on the one side are free from labour during one day of every week and during two days on the occasion of native New Year.

6. The contractors on the other side supply to the contractors on the one side, as well as to their family, free lodging, free medical attendance, free board, and free drink-water.

The free board shall consist of-Raw rice $I_{2}^{\frac{1}{2}}$ pounds, spice I ounce, tamarind I ounce, fish (fresh or salted) 6 ounces, salt I ounce, onions I ounce, vegetables 6 ounces, cocoanut-oil $\frac{1}{2}$ ounce, fresh cocoanut; blachan I ounce, green pepper I ounce. Children, whether doing any work or not, shall receive the following ration:

Children between 12 and $\mathrm{I}_{5}$ years, full ration.

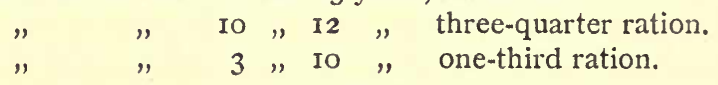

The free board is furnished for the days when work is done, for those days which the labourers may count as working days, and for the holidays as per agreement.

7. The labourers shall not be separated from their families against their will.

8. Contractors on the other side shall pay the passage money for conveying the labourers and their families (if any) to their destination, and at the termination of the contracted period, or in the event of the agreement being dissolved by force majeure, convey them back to their residences free of charges. In case the contract is renewed, the labourers and their families shall be entitled to a free passage to their respective homes, this 
right holding good for five years after the lapse of the last contract. Should a labourer die in the course of his service-time, the contractors on the other side shall for their account send back the family to their original residences within three months after the decease if desired, and keep them pending a shipping opportunity.

9. The time lost by the contractors on the one side on account of the consequences of a misbehaviour or sickness during more than one-tenth of the contracted period, leave, desertion, or punishment in gaol, shall not be counted as a part of the contracted time.

I0. At the expiration of any agreement, contractors on the other side shall at their expense send home the labourers and their families, and keep them pending shipping opportunity.

II. Any agreement lapsed and any renewal of contract must be reported to the Dutch Consul at Singapore. The contractors on the other side must also report to the above Consul whether any of the released labourers have renewed the agreement or whether they have been sent home, and, if so, by what opportunity and whether they have settled down somewhere else.

I2. The contractors on the one side shall present themselves to the manager of the estate on the day of the month of the year 19 .

I3. This agreement has been made to hold good for from date of presentation to the manager

Thus agreed at Samarang on this date, the day of the month

I9.

The contractors on the other side. 
After having explained the above-mentioned to the contractors on the other side and to the contractors on the one side in their own language, and after they have agreed to the above-mentioned, and the contractors on the one side have declared that the above conditions are well known to them and that they accept these conditions, the advance of $f .2 .50$ for the unmarried and $f .5$ for the married was paid in my presence, while another f. 2.50 to the unmarried and $f .5$ to the married shall be paid before embarkation, and the remaining f. Io per head at Singapore, in presence of the Dutch Consul, to which they agreed.

The Recruiting Commissioner.

SAMARANG, I9.

Malays do not constitute a large section of the estate labour. They do excellent work in felling timber and opening up land on contract, but care little for the steady drudgery of day-to-day work throughout the year. They are not very numerous in the planting districts, except in Kelantan, where the development of the rubber industry is only beginning, and there they are employed to a considerable extent.

Next to the Tamils the most important factor in the labour question is the Chinese element. The class known as the Singkeh was indentured for one year, and agreed to perform 300 days' work. The men received only 8 cents per day as pay, but were provided with rations and other articles costing 20 cents per day. The cost of recruiting these men and bringing them to the estates was approximately 60 dollars per head. Notwithstanding this high charge, the average cost for the day's 
wage was reasonable if it had not been for the heavy percentage of desertions, frequently amounting to 25 per cent. of the total force. The tin-mining industry attracted these men so strongly that they were unable to resist the temptation of breaking their contract for agricultural labour in order to take their chance in the mining districts. In this respect conditions have become so unsatisfactory of late years that this class of indentured labour was prohibited in IgI3.

The Chinese labourers now employed on estates are free from any form of indenture. They are a most valuable addition to the labour force; but they demand high wages, and in some cases are paid as much as 90 cents a head per day. They do better work on contract than for a daily wage, and in this manner are employed, with most satisfactory results, on many estates for tapping, weeding, and all other labour which can be contracted out on reasonable terms.

According to the last census, taken on March Io, IgII, the total population of the Malay Peninsula was 2,649,970, divided as follows:

\begin{tabular}{|c|c|c|c|c|c|}
\hline & & & Males. & Females. & Total. \\
\hline Europeans & & & 7,875 & 3,190 & I 1,065 \\
\hline Eurasians & $\ldots$ & $\ldots$ & 5,296 & $5,5^{\text {I I }}$ & 10,807 \\
\hline Malays ... & $\ldots$ & $\ldots$ & 720,110 & 692,086 & $1,412,196$ \\
\hline Chinese ... & $\ldots$ & $\ldots$ & $734,3^{84}$ & I8I,499 & $91_{5}, 883$ \\
\hline Indians ... & $\ldots$ & $\ldots$ & 204,220 & 62,950 & 267,170 \\
\hline Others $\quad \ldots$ & $\ldots$ & $\ldots$ & I $6,48 \mathrm{I}$ & 16,368 & 32,849 \\
\hline
\end{tabular}

The indentured Javanese are the only estate labourers receiving fixed remuneration under contract. The former are paid at the rate of 25 cents a day for men, 
and 15 cents for women. With the cost of rations added, this means the equivalent of 40 cents for men and 26 cents for women per diem, plus the cost of importation, amounting to not less than 92 dolarsdistributed over three years-and a sum of 5 dollars for repatriation. This brings the actual value of a day's work to 54 cents for men and 40 cents for women.

The Tamil coolie is free to obtain such daily wages as he can bargain for, but the rate varies in every district, and often even on neighbouring estates. On an old-established and popular estate, such as Linggi, the average rate for men is 27 cents, and 22 cents for women. Tappers receive 30 cents and 25 cents. On Devon Estate, only thirty miles distant, men are paid 45 cents and women 35 cents, with higher rates for tappers. In the Klang district the average rate paid is 30 cents for men and 25 cents for women, with 33 cents and 28 cents for tappers. In fact, the rate paid depends very largely on the management of the estate and the reputation it has in Southern India. Taking an average on a number of estates employing Tamil labour in the Federated Malay States and the Straits Settlements, the daily rate isapproximately 38 to 40 cents for men and 33 to 35 cents for women, including the amount of the assessment for the Indian Immigration Fund.

Malay labourers receive 45 cents for men and 35 cents for women as a general rule. Occasionally higher rates are paid when the demand for labour is urgent.

Chinese labourers ask a higher wage than any other nationality. It varies from 60 to 90 cents per day, and in some cases even a dollar is paid. When calculating contract work, the usual custom is to allow 
60 cents per day per man, and at this rate arrangements can be made for nearly all classes of estate work, whether tapping, weeding, roading, or draining. Many managers prefer to work with Chinese contractors rather than by daily employment of Tamils or Javanese, and assert that the labour is better and more expeditiously accomplished.

During the last two or three years the demand for coolies has been very great, on account of the large area being opened for new plantations, and this has created a decided tendency towards a rise in the rate of wages. For the present, however, prices appear to have reached as high a scale as they are likely to average for some years to come, unless unexpectedly large additions should be made to the area under cultivation. The satisfactory annual increase in the importation of Tamil labour is an important factor in keeping down the wage rate, especially in regard to the Chinese. If for any reason Tamil immigration should decline, and the estate owners become dependent on Chinamen, there is small doubt that increased wages would result.

A day's work is nominally nine hours; but the distribution is by task which coolies can finish by 2 p.m., and often at an earlier hour. In the factories, as a rule, work continues until the day's delivery of latex has been put through the machines, and special rates are paid to the men detailed for this purpose.

The only skilled labour required on an estate is for tapping and factory work. Intelligent coolies learn both very quickly under competent supervision. On a plantation where all trees are yielding latex, at least 80 per cent. of the men, women, and children, will be 
employed at tapping and collecting. For factory work specially intelligent men are selected, but the whole process of the curing and preparation of rubber is so simple that there is seldom any difficulty in connection with the labour employed. Cleanliness is one of the principal factors, and that depends on supervision.

Health conditions vary very greatly throughout the Malay Peninsula, but the three principal diseases found in more or less degree in all districts are malaria, dysentery, and diarrhœa. The deaths amongst Indian coolies from the former in Igro numbered 2,597 , and from dysentery I,350, while 683 were due to diarrhœa.

Sanitary regulations are now enforced by Government ordinance on all estates. Adequate hospital accommodation must be provided, with properly qualified medical attendance and supervision, and these hospitals are constantly visited by official medical officers. The cost of the erection and equipment of the estate hospitals is a serious item of expenditure; but in the case of smaller properties it is not uncommon for an arrangement to be made to contribute to the cost of a joint hospital situated in a central position, and to pay pro rata of the coolies employed to defray the expenses of the resident doctor and the maintenance of the wards. Naturally, planters grumble a good deal at the strict medical inspection practised by the authorities; but it is obviously necessary to enforce all possible measures for the health of the labourers, both on account of the loss of work occasioned by sickness, and also in order to maintain a good reputation for the Malay plantations in the districts of Southern India where the coolies are recruited. 


\section{CHAPTER XV}

\section{THE MALAY PENINSULA-Continued}

lOrganization of rubber estates - Catch crops - Tapping Housing accommodation - Discipline \& Dietary - Educational facilities-Yield of trees-Cost of production-Analysis of expenditure-Charges after shipment_-" All in " costs-Past and future production +Future development.

THE organization of a rubber estate in the Malay 1 Peninsula offers no very serious difficulties to an experienced planter. If Government forest land is required, an application for the area in question is submitted to the authorities, and this request will be attended to without undue delay. The land is then surveyed and the fees charged, according to the scale set out in the Land Enactment Act. If the area chosen lies low and near the water-level, under conditions such as exist in sections in Malacca, Klang, Teluk Anson, Province Wellesley, and other districts, it must be drained before the timber is felled, otherwise the débris after felling and lopping will not burn. On the undulating forest lands away from the seaboard this preliminary draining work is unnecessary.

Contractors for felling and cleaning the requisite acreage can be engaged without difficulty, Malay labour doing this work most effectively at a cost of from I2 to I5 dollars per acre for felling and lopping, and $7 \frac{1}{2}$ dollars per acre for the subsequent cleaning up. After the burn has taken place, the work of lining 
and holing is carried out, the holes being cut 2 feet in diameter and 2 feet deep. If the estate is to be clean-weeded, the planter will arrange for weeding by contract or day labour, to begin shortly after the burn. He must buy the necessary plants, if he has not made his own nurseries the previous year. Before the planting season comes, the holes will have been filled in ready for planting. This operation takes place in all months, but October and November are regarded as most suitable, on account of weather conditions.

The distance apart for planting Pará rubber varies so much that no hard-and-fast rule can be laid down. Close planting means a greater yield of latex during the first few years the trees are tapped; but wider distances apart insure better development after the first seven or eight years. Gradually the custom is being established of planting 20 feet by 20 feet (108 trees to the acre), 30 feet by Io feet, or 36 feet by I2 feet, the two latter systems termed in Malaya " avenue planting." Considerations of land and general conditions must influence any decision as to what distance the trees should be apart.

The planting of catch crops is condemned universally in Malaya. A few estates still continue the practice, but the opinion of the great majority of planters is distinctly adverse to it, on the grounds that it seriously retards the development of young rubbertrees. Tapioca has been the principal catch crop grown by both Europeans and Chinese when rubber estates are opened in this manner. Robusta coffee is found in certain districts, and in Province Wellesley a little sugar-cane is still cultivated. One effect of any 
catch crop is to produce an uneven growth in young plantations, and this adds considerably to the cost of tapping when the trees begin to mature.

As showing the detrimental effects of sugar-cane as a catch crop, the following return, furnished by the Penang Sugar Estates Company, is sufficient proof. These young trees were grown for two years interplanted with sugar-cane, and their yield at seven and eight years old is far below the average :

\begin{tabular}{|c|c|c|c|c|}
\hline Field. & Acres. & Planted. & Per Tree. & Per Acre. \\
\hline $\begin{array}{ccc}4 & \ldots & \ldots \\
6 & \ldots & \ldots \\
7 & \ldots & \ldots \\
\text { Chankat } & \text { Dain }\end{array}$ & $\begin{array}{r}\mathrm{r} 50 \\
68 \\
\mathrm{x} 52 \\
52\end{array}$ & $\begin{array}{l}1903 \text { and } 1904 \\
1904, " 1905 \\
1904, " 1905 \\
1904,1905\end{array}$ & $\begin{array}{l}\text { Lb. } \\
2 \cdot 17 \\
2 \cdot 53 \\
2 \cdot 20 \\
2 \cdot 55\end{array}$ & $\begin{array}{l}\text { Lb. } \\
227 \\
265 \\
239 \\
270\end{array}$ \\
\hline
\end{tabular}

These trees are planted on the average 20 feet by 20 feet, or, say, ro8 to the acre.

In the colony of Singapore and in the south of the State of Johore a considerable area of rubber is interplanted with pineapples as a catch crop, the estimated area being I2,000 acres for Singapore and I0,000 for Johore. The reason is that a pineapple canning industry has been established in Singapore for some years past, and has proved to be a profitable enterprise. From a rubber planter's point of view nothing can be said in favour of this product as a catch crop; it exhausts the soil of both nitrogen and phosphates, and the serrated edges of the leaves occasion constant damage to the bark on the lower portion of the stems of the rubber-trees. One can well understand, however, the attractions of this cultivation for the Chinese 
agriculturists, who possess the principal interest in it. Within a few months of planting a remunerative crop is obtained, and this profitable return continues for some three years, with no other expenses for cultivation than keeping the ground free from weeds and picking the fruit when ripe. Moreover, the fruiting season extends practically over the whole year, and so causes no inconvenience in regard to any addition or reduction of the labour force employed.

Tapping begins when the trees have attained a girth of 18 inches at 3 feet from the base, and as a rule in Malaya this development occurs when they are about three and a half years of age. In three or four days after the first tapping of the trees the latex runs freely. The yield is not great during the first year of tapping, generally not more than $\frac{1}{2}$ pound to $\frac{3}{4}$ pound per tree, and the cost of collection is high. Provided the tapping is well done, with a single $\mathbf{V}$ at the base, no apparent damage is occasioned to the trees by beginning at this early age ; in fact, they appear to gain in girth when compared to trees left untapped. The latex, however, is undoubtedly inferior to latex from trees of more mature age. Throughout Malaya the Jebong or Burgess knife, a replica of the farrier's knife with very slight modifications, or the bent gouge, is preferred to any of the more modern implements. After tapping for two years with the single $\mathbf{V}$ on alternate sides, the tree is divided into quarters above the $\mathbf{V}$ tapping, and is then tapped on the half herring-bone system. This allows four years' time for the renovation of the bark, and in the opinion of practical planters this period is sufficient for the 
purpose. The cups used are glass, porcelain, aluminium or other metal, but the two former are preferable.

By the end of the fourth year, when the estate is yielding evenly throughout, the planter will have thoroughly established his methods of work, and also his connections in Southern India for recruiting purposes, if he employs Tamil labour. Similarly, if he prefers Chinese or Javanese coolies, he will have made his arrangements in the proper quarters, and should have no serious difficulty in regard to his annual labour requirements. During the first four years of an estate, the bungalows, lines for coolies, factory and other buildings, should have been erected in accordance with the scale laid down in the estimate already given for the cost of opening up a plantation. The method of the curing and preparation of rubber is given under the description of factories, and need not be repeated.

On estates averaging six to eight years old, a good tapper will look after 300 trees, tapping daily with three cuts to the tree, collecting the scrap, washing the cups, and delivering the latex and scrap at the factory. On some estates the average is 400 trees per day with three cuts. One estate averaged 420 trees with three cuts per tree. On the majority of estates daily tapping is the rule, but on quite a large number the trees are tapped on alternate days only. Many different opinions are expressed as to the class of labourer most suitable and efficient for tapping. On the estates equally good and bad tapping is done by Tamils, Javanese, Chinese, and Malays. The best work was invariably found where the most competent supervision existed, and it is safe to say that the general standard of tapping on an estate 
depends on the attention and care devoted to the superintendence of the work by the manager and his assistants.

The Governments of the Straits Settlements and the Federated Malay States insist that housing accommodation for estate labourers shall be provided in accordance with certain requirements in regard to space and elevation of floors above the ground. The usual type of lines now erected are built on brick pillars, with an open air space 4 feet high below the flooring. Steel or hard-wood framing is used, with galvanized iron or attap (palm leaf) thatch roofing. The sides are of galvanized iron or hard-wood, and a plank flooring is provided. As a rule a 6 -foot veranda is constructed on both sides of the building. The rooms are generally I2 feet by Io feet, to accommodate four coolies, but on a few estates the size is ro feet by $8 \mathrm{feet}$, and in these two coolies are housed. Proper drainage is necessary round the lines, and the regulations require that adequate latrines be erected. The cost of these barracks varies considerably, in accordance with the material employed in construction, but the price may be taken approximately at Ioo to 150 dollars per room of 12 feet by ro feet.

Ample hospital accommodation is required, with separate wards for men and women, and equipped with dispensary, cook-house, and other necessary adjuncts. The wards are furnished with beds fitted with mosquitonets, and supplied with all modern sanitary requirements.

Bungalows on estates may be expensive or economical, according to the ideas of the planter, but thoroughly serviceable plantation houses with accom- 
modation for two persons can be built at a cost of from 5,000 to 6,000 dollars, and these fulfil all requirements on a young estate.

On estates the standard of discipline depends on the tact and common-sense of the manager and his assistants. Tamils are tractable and give little trouble when justly treated; Chinese are more difficult, and are best handled through their own headmen; the same remark applies to Javanese. As a general rule there is very little serious trouble with estate labourers; but recently the Chinese have been unsettled by the events taking place in their own country; they have shown a turbulent spirit on several estates and in various towns in the Malay Peninsula, and on several occasions the assistance of the military and the police has been necessary to quell disturbances.

Rice forms the principal food of all classes of coolies working on estates in Malaya. In addition, the diet comprises dried fish, cocoanut-oil, curry stuff, fruit, and vegetables. Meat of any kind is a luxury, and never an article of everyday use. Rice is supplied at cost price to all estate coolies, and below cost when prices are unduly high.

There is no obligation on the part of the planter, and no efforts are made, to provide any sort of schools for the children of estate coolies. In the villages public schools have been established for native children taught in the vernacular, but none for those of Chinese or Indian parentage.

It has been no easy task to obtain accurate returns of the yield per acre of rubber plantations, for the reason that on every estate the ages of trees vary, and 
only in comparatively few instances have separate records been kept for different fields. Reliable data from twenty estates scattered throughout the Federated Malay States and the Straits Settlements enable the approximate yield to be defined. The returns show-

\begin{tabular}{|c|c|c|}
\hline Age of Tree. & No. of Acres. & Yield per Acre. \\
\hline Years. & & Lb. \\
4 to 5 & 3,814 & 188 \\
5 " 6 & 5,266 & 306 \\
$7 " 7$ & 3,973 & 349 \\
7 " I2 & 7,438 & $501 \frac{1}{2}$ \\
\hline
\end{tabular}

The only efficient method of calculating the yield is by dividing the production at each stage of development by the number of acres. It would be much more satisfactory if a larger acreage could be taken, but to secure this result nothing short of an estate-to-estate visitation would serve, and in the great majority of cases the inquiry would be barren of any useful result for lack of definite records on the different plantations. The calculations of yield now made are based on returns obtained from the following properties:

\begin{tabular}{|c|c|c|c|c|c|}
\hline Estates. & Acres. & Age. & $\begin{array}{l}\text { Trees } \\
\text { to } \\
\text { Acre. }\end{array}$ & $\begin{array}{c}\text { Yield } \\
\text { per } \\
\text { Acre. }\end{array}$ & Locality. \\
\hline I. Wardieburn & $\begin{array}{r}400 \\
400 \\
400 \\
400 \\
\text { 15 } \\
15\end{array}$ & $\begin{array}{c}4 \\
5 \\
6 \\
7 \\
5 \frac{1}{4} \\
\mathrm{r} 2\end{array}$ & $\begin{array}{l}150 \\
150 \\
150 \\
150 \\
120 \\
130\end{array}$ & $\left.\begin{array}{c}\text { Lb. } \\
\text { I05 } \\
316 \\
435 \\
460 \\
230 \\
1,339\end{array}\right\}$ & $\begin{array}{l}\text { Kuala Lumpur, } \\
\text { Selangor }\end{array}$ \\
\hline
\end{tabular}




\begin{tabular}{|c|c|c|c|c|c|}
\hline Estates. & Acres. & Age. & $\begin{array}{c}\text { Trees } \\
\text { to } \\
\text { Acre. }\end{array}$ & $\begin{array}{c}\text { Yield } \\
\text { per } \\
\text { Acre. }\end{array}$ & Locality. \\
\hline \multirow{4}{*}{ 2. Kumendore } & & Yrs. & & Lb. & \multirow{4}{*}{ Malacca } \\
\hline & 1,200 & 4 & 150 & IIO) & \\
\hline & I,200 & 5 & $\begin{array}{l}150 \\
150\end{array}$ & 230 & \\
\hline & \begin{tabular}{|l|}
1,200 \\
1,200
\end{tabular} & 7 & 150 & $\begin{array}{l}320 \\
470\end{array}$ & \\
\hline \multirow{3}{*}{$\begin{array}{l}\text { 3. Bernham, Perak } \\
\text { 4. Nova Scotia ... } \\
\text { 5. Changkat Salak }\end{array}$} & 135 & 4 & 200 & 150 & \multirow{3}{*}{$\begin{array}{l}\text { Teluk Anson, Perak } \\
\text { Kuala Kangaar, } \\
\text { Perak }\end{array}$} \\
\hline & 1,600 & $4 \frac{1}{2}$ & I50 & 273 & \\
\hline & 300 & 4 & 150 & I 73 & \\
\hline 6. Kent ... & 89 & $4 \frac{1}{2}$ & I5O & 250 & $\begin{array}{l}\text { Kuala Lumpur, } \\
\text { Selangor }\end{array}$ \\
\hline 7. Lauderdale & $\begin{array}{l}300 \\
100\end{array}$ & $\begin{array}{l}5 \frac{1}{2} \\
4 \frac{1}{2}\end{array}$ & $\begin{array}{l}160 \\
180\end{array}$ & $\left.\begin{array}{l}350 \\
242\end{array}\right\}$ & Taiping, Perak \\
\hline 8. Pegoh ... & 651 & $5 \frac{1}{2}$ & 150 & 323 & Malacca \\
\hline 9. Kamuning & $3^{8}$ & $8 \frac{1}{2}$ & 150 & $650)$ & Sungei Siput, Perak \\
\hline Io. Bukit Rajah ... & $\begin{array}{r}000 \\
1,200\end{array}$ & $\begin{array}{l}5 \frac{1}{2} \\
8 \frac{1}{2}\end{array}$ & $\begin{array}{l}\text { I50 } \\
150\end{array}$ & $\begin{array}{l}500\} \\
650\end{array}$ & Klang, Selangor \\
\hline II. Belmont $\quad \ldots$ & 700 & $7^{2}$ & 150 & 437 & Kajang, Selangor \\
\hline 12. Vallambrosa ... & $\mathrm{I}, 5 \mathrm{I} 7$ & 8 & I 50 & 391 & Klang, Selangor \\
\hline 13. Linggi ... $\quad \ldots$ & 600 & 8 & 150 & 520 & $\begin{array}{l}\text { Seremban, Negri } \\
\text { Sembilan }\end{array}$ \\
\hline I4 Rubana & 1,100 & $7 \frac{1}{2}$ & I6I & $5^{6} 3$ & Teluk Anson, Perak \\
\hline I5. Lab & 1,350 & 6 & 150 & 437 & $\begin{array}{l}\text { Labu, Negri Sem- } \\
\text { bilan }\end{array}$ \\
\hline I6. Cicely ... & $\begin{array}{l}139 \\
700\end{array}$ & $\begin{array}{l}\text { I I } \\
5 \frac{1}{2}\end{array}$ & $\begin{array}{l}\text { I5O } \\
\text { I50 }\end{array}$ & $\left.\begin{array}{l}900 \\
375\end{array}\right\}$ & Teluk Anson, Perak \\
\hline I7. Gedong & 2,000 & 5 & $\left\{\begin{array}{l}150 \\
180\end{array}\right\}$ & 314 & $"$ \\
\hline 18. Tali Ayer & 1,023 & 6 & $\left\{\begin{array}{l}12 I \\
16 I\end{array}\right\}$ & 234 & $"$ \\
\hline $\begin{array}{l}\text { I9. Caledonia } \\
\text { 20. Caledonia }\end{array}$ & 29 & I I & 240 & 780 & Province Wellesley \\
\hline (Krian) & 400 & 7 & 130 & 375 & $"$ \\
\hline
\end{tabular}

The variation in the cost of production per pound of rubber has been very great during the past few years, as will be seen from the following returns: 
Cost of Production on Forty Estates in I909-10 Furnished by Messrs. Kennedy and Co., Agents and Stockbrokers, Penang

\begin{tabular}{|c|c|c|c|c|c|}
\hline \multicolumn{3}{|l|}{ Company. } & \multirow{2}{*}{$\begin{array}{c}\text { Year. } \\
1909\end{array}$} & \multirow{2}{*}{$\begin{array}{c}\text { Crop } \\
\text { Rubber: } \\
\text { Lb. Dry. } \\
517,550\end{array}$} & $\begin{array}{l}\text { Inclusive Cost } \\
\text { per Lb. } \\
\text { (f.o.b.). }\end{array}$ \\
\hline Anglo-Malay & $\cdots$ & $\cdots$ & & & $\begin{array}{cc}\text { s. } & \text { d. } \\
\text { o } & \text { 10 } 68\end{array}$ \\
\hline Batu Caves... & $\ldots$ & ... & ", & 45,769 & $24^{\circ} 23$ \\
\hline Bukit Rajah & $\ldots$ & $\ldots$ & I909-IO & 314,778 & I 431 \\
\hline Carey United & $\cdots$ & $\cdots$ & $"$ & 107,I94 & I 577 \\
\hline Cicely $\quad \ldots$ & $\ldots$ & $\cdots$ & $"$ & 85,280 & I $3 \cdot 18$ \\
\hline Consolidated Mala & & $\cdots$ & I909 & 215,893 & I II 22 \\
\hline Damansara ... & $\ldots$ & ... & $"$ & 202,440 & I $9^{\circ} 00$ \\
\hline Federated Malay & $\ldots$ & ... & rgog-10 & 293,066 & 20.68 * \\
\hline Federated (Selang & (̧or) & ... & , & IOI, 444 & I $4^{\circ} 4^{I}$ \\
\hline Golconda $\ldots$ & $\ldots$ & $\ldots$ & 1909 & 96,260 & I 10.54 \\
\hline Golden Hope & $\ldots$ & $\cdots$ & " & 5,420 & I $4^{\circ} 9^{I}$ \\
\hline Highlands and Lo & wlai & s... & , & 346,259 & I I.O3 \\
\hline Inch Kenneth & $\cdots$ & $\cdots$ & I909-IO & 127,677 & $2 \quad 236$ \\
\hline Jugra Estate & $\ldots$ & $\cdots$ & $"$ & 60,017 & $243^{8}$ \\
\hline Kamuning ... & $\ldots$ & $\cdots$ & $"$ & 67,046 & I $6.4 \mathrm{I}$ \\
\hline Kuala Lumpur & $\ldots$ & $\ldots$ & $"$ & 489,807 & I $7^{\circ} 40$ \\
\hline Labu $\quad \ldots$ & ... & $\cdots$ & 1909 & 86,763 & 20.72 \\
\hline Lanadron $\quad .$. & $\ldots$ & $\ldots$ & $"$ & 249,247 & I $2^{\circ} 94$ \\
\hline Ledbury $\quad \ldots$ & $\cdots$ & $\cdots$ & , & $66,88 \mathrm{r}$ & $2 \quad 376$ \\
\hline Linggi $\quad \ldots$ & $\cdots$ & $\cdots$ & $"$ & 545,219 & I $\quad I 48$ \\
\hline London Asiatic & $\cdots$ & $\cdots$ & $"$ & 75,427 & $2 \quad r \cdot 68$ \\
\hline Mabira Forest & $\cdots$ & $\cdots$ & ", & 82,424 & $355^{\circ} \mathrm{3}$ \\
\hline Malacca $\quad$... & $\ldots$ & ... & $"$ & 236,969 & $20.2 \mathrm{I}$ \\
\hline North Hummock & $\ldots$ & $\ldots$ & Ig09-IO & 47,994 & I 6.76 \\
\hline P. P. K. $\quad \ldots$ & $\cdots$ & $\cdots$ & I909 & 45,474 & $24: 15$ \\
\hline Pataling & $\cdots$ & $\cdots$ & $"$ & I 52,090 & I $\quad 0.62$ \\
\hline Perak & $\cdots$ & $\cdots$ & I909-10 & I I 5,895 & I 2.19 \\
\hline Sagga & $\cdots$ & $\cdots$ & ", & 49,534 & $34: 25$ \\
\hline Seafield & $\ldots$ & $\ldots$ & I909 & 43,746 & 23.18 \\
\hline Sekong & $\ldots$ & $\ldots$ & I909-10 & $4 \mathrm{I}, \mathrm{I} 78$ & $36 \cdot 72$ \\
\hline Selangor & $\ldots$ & $\cdots$ & roog & 326,654 & I I.58 \\
\hline Seremban ... & $\cdots$ & $\cdots$ & $"$ & I 24,02 I & I $9^{\circ}$ I 4 \\
\hline Shelford $\ldots$ & $\cdots$ & $\cdots$ & $"$ & 33,097 & 27.60 \\
\hline Singapore Pará & $\cdots$ & $\cdots$ & rgog-10 & 60,437 & I $7 \cdot 77$ \\
\hline Straits (Bertam) & $\ldots$ & $\cdots$ & $"$ & 99,097 & I 2.64 \\
\hline Sumatra Pará & $\ldots$ & $\cdots$ & " & I 22,248 & $2 \quad 0.73$ \\
\hline Sungei Kapar & $\ldots$ & $\cdots$ & 1909 & I I 4,970 & $16 \cdot 16$ \\
\hline United Serdang & $\cdots$ & $\cdots$ & I909-10 & 67,828 & $2 \quad 2 \cdot 24$ \\
\hline Vallambrosa & $\cdots$ & $\cdots$ & $"$ & 371,316 & I 2.83 \\
\hline Yam Seng $\ldots$ & $\cdots$ & $\cdots$ & $"$ & 49,937 & $24^{\circ} 07$ \\
\hline
\end{tabular}


This shows an average cost of $22 \cdot 17$ pence per pound in $I 909-10$, as compared to $17^{\circ} 30$ pence per pound in IgII.

To ascertain further the cost of production f.o.b. at Singapore, Penang, or Port Swettenham, the returns of twenty-two representative estates scattered throughout the Straits Settlements and the Federated Malay States are given. Careful investigation in connection with these estates shows that the proportionate adjustment of expenses has been made to revenue and capital accounts, although there is invariably an inclination to charge more to revenue and less to capital when any doubt exists on the subject.

The average cost of production on the twenty-two estates selected was $I 7^{\circ} 30$ pence in IgII-I2 f.o.b. The distribution of these charges was approximately-

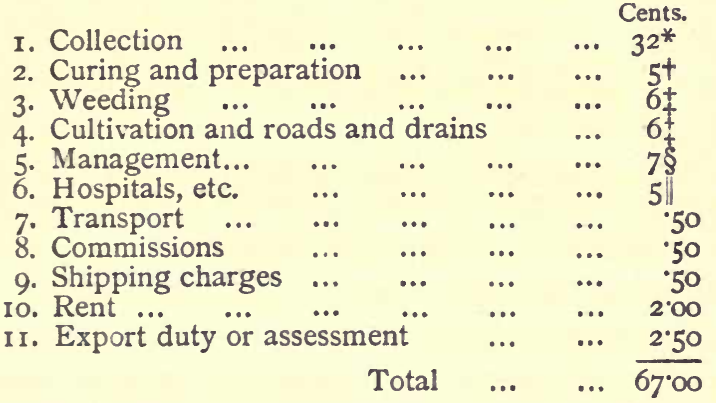

( 67 cents $=17.30$ pence per pound of dry rubber. $)$

* Includes cost of implements, cups, etc., and a proportion of depreciation on buildings.

+ Includes depreciation on machinery and factory.

¥ Includes a proportion of depreciation on buildings.

$\S$ Includes depreciation on bungalows and all salaries.

|| Includes salary of doctor and all expenses. 
Costs F.o.B. Port Sivettenham, Penang, or Singapore, I9I I-I 2

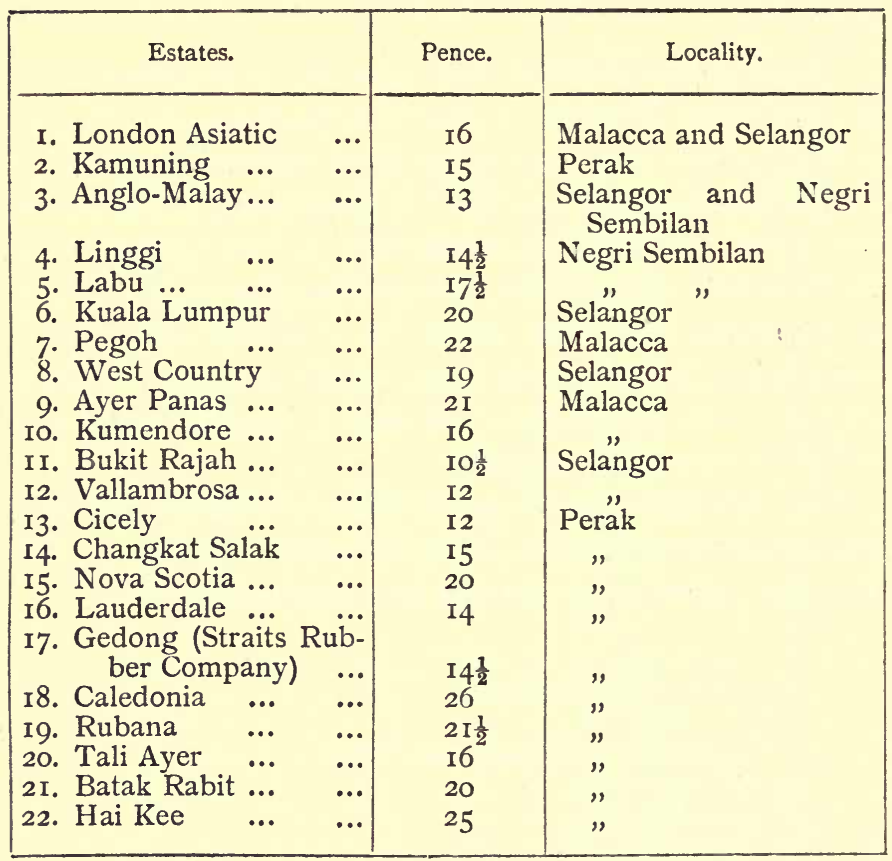

The average from the foregoing figures is $17^{\circ} 3^{\circ}$ pence per pound of rubber f.o.b.; but for January and February, I9I2, the costs at Gedong were at the rate of 38 cents per pound, equal to II pence sterling, and several others show substantial decreases in I9I3, while in very few instances are higher costs recorded than in I9II-I2.

All practical planters are agreed that there will be a substantial reduction in costs when a larger acreage comes into bearing and trees average a greater age. 
Indeed, many experienced men are strongly of opinion that a marked decrease will take place in I9I4. The minimum average cost for the next five years should not exceed I shilling ( $42 \frac{1}{2}$ cents) per pound of rubber f.o.b., distributed as follows, and with the same conditions regarding depreciation, etc., as in IgII :

Cents.

I. Collecting and tapping ... $\quad \ldots \quad$... $\quad \ldots \quad 20$

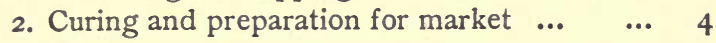

3. Weeding $\ldots \quad$... $\quad \ldots \quad$...

4. Cultivation and roads and drains $\quad \ldots \quad$...

$\begin{array}{llllllll}5 . & \text { Management } \quad \ldots & \ldots & \ldots & \ldots & \ldots & 5\end{array}$

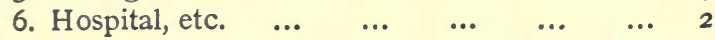

7. Transport

8. Commissions

9. Shipping charges

I0. Rent

II. Contingencies

12. Export duty or assessment

Total

(Equal to I shilling per pound of dry rubber f.o.b. Port Swettenham, Penang, or Singapore.)

From the average cost of production and the estimate of ultimate minimum cost, it will be seen that the principal expenditure is for the collection of latex, weeding, and cultivation-all items dependent on the wage rates. It has been pointed out that the cost of collection of latex should decrease rapidly as the trees become older and the yield greater. So, also, weeding will become cheaper as the trees give more shade; indeed, when the trees on an estate average eight years old, the cost of weeding should be reduced to, practically, a negligible quantity, as the work will 
consist only of a general cleaning up once or twice a year. Cultivation will remain to some extent a permanent charge, as pruning of trees, treatment of diseases, and manuring, will be necessary for old trees. The remaining items must be considered as permanent recurring charges, with the exception of the value of the export duty, which will vary with the fluctuations in the price of rubber. Of course, this refers only to estates worked on the principles in force to-day; great amalgamations of plantation interests may be able to reduce expenditure to a much lower level.

The present scale of charges from the Malay Peninsula to London or Liverpool, dating from January, I9I4, are shown in the following table. The freight under the last Shipping Convention is fixed at 65 shillings for 50 cubic feet from Singapore, Penang, Port Swettenham, and all other ports. Commissions are calculated on the basis of an average selling value of 24 pence per pound, and would, of course, rise or fall with any fluctuation in prices. Previous to I9I4 the allowances for rebates and draft added about a penny to the present costs :

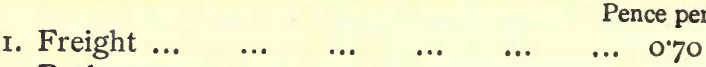

2. Brokerage $\quad \ldots \quad$... $\quad \ldots \quad$...

3. Sale charges, insurance, storage, and sun-

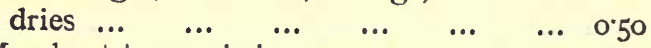

$\begin{array}{rrrrr}\text { 4. Merchants' commission } & \ldots & \ldots & \ldots & \frac{0^{*} 20}{\mathrm{I}^{\prime} 5^{2}}\end{array}$

Shipments to Antwerp work out slightly cheaper, on account of smaller commissions; similar conditions, though not quite to the same extent, occur in connection with Hamburg. 
The average cost per pound f.o.b. Malay Peninsula in I9II-I2 was I7.30 pence. The cost from port of shipment to London or Liverpool was 2.52 pence in I9I3, and allowance must also be made for London and other headquarter office expenses, directors' fees, percentage of preliminary expenses incurred in the formation of companies, income-tax, and other items. In the circumstances it is safe to conclude that the total average cost of every pound of rubber sold in London during I9I 3 was not less than 20 pence sterling.

That the cost of production in the immediate future will be substantially reduced may be regarded as assured. In the next three or four years the average cost f.o.b. in Malaya should not exceed I shilling per pound. A saving of I farthing per pound can be effected by shipping in Java mat bales in place of boxes, thus reducing cost of freight and packing. Taking these facts into consideration, the average cost per pound up to time of sale should not exceed $13^{*} 25$ pence plus the London office charges for directors' fees, etc.

In calculating future production, the most satisfactory method is to take the area under cultivation in I9I2, 650,000 acres, and allow for it a yield based on the average returns already given. In IgIg the trees comprised in this acreage will be of an average age of from ten to eleven years. The average yield from 7,438 acres situated in different sections of Malaya, from trees of seven years upwards, was shown to be 5 or $\frac{1}{2}$ pounds of rubber per acre. Taking the average yield of ten-yearold trees at 4 hundredweights per acre, the total yield in I9I9 would be 130,000 tons. Young trees planted after IgI2 will add considerably to the output, but it is 
safer to allow this extra yield to compensate for any shortage of sections that may from unforeseen circumstances fall below the estimated ultimate average yield of 4 hundredweights to an acre.

The following table gives the actual yield from 1906 to I9I3, and the estimated output from I9I4 to I9I9:

Actual Yield, 1906 To I9I3

\begin{tabular}{|c|c|c|}
\hline Year. & Acreage under Tapping. & Output in Tons. \\
\hline 1906 & 9,600 & 430 \\
I907 & 10,800 & 485 \\
I908 & 24,300 & 1,629 \\
I909 & 37,400 & 3,340 \\
I910 & 66,200 & 6,504 \\
I911 & 95,800 & 10,700 \\
I912 & 180,000 & 19,400 \\
I9I3 & 241,000 & 35,750 \\
\hline
\end{tabular}

Estinated OUtput, I9I4 to 1919

\begin{tabular}{|l|r|r|}
\hline 1914 & 292,000 & 43,800 \\
I915 & 362,000 & 63,300 \\
I916 & 538,000 & 80,700 \\
I917 & 650,000 & 97,500 \\
I918 & 650,000 & II 3,750 \\
I919 & 650,000 & 130,000 \\
\hline
\end{tabular}

The estimated return is calculated on the ages of trees in tapping, allowing 260 pounds per acre for trees averaging six years old, 336 pounds for seven-year-old trees, and 392 pounds for an average of eight years. For I9I6 and I9I7 only 336 pounds per acre is calculated, on account of the large proportion of young trees yielding for the first time; in 1918 an average return of 392 pounds per acre is estimated for nine-yearold trees; and in IgI9 a yield of $44^{8}$ pounds per acre is 


\section{THE MALAY PENINSULA}

calculated for 650,000 acres averaging ten years of age.

In another ten years the rubber estates will form, practically, a continuous forest from Penang to Singapore, and the natural inference is that this great area of rubber-trees will be treated as a forest proposition in place of being exploited in the shape of comparatively small estates, as is now the case. The principal motives for this change of system will be greater economy of administration and the necessity of standardizing methods of production. It is too soon to lay down the lines for this probable evolution of the industry, but there does not appear to be any insuperable difficulty in the direction of an amalgamation of existing interests on the basis of acreage or number of trees with a fair quota of the total output. The future of the industry would be more secure under the control of a great central corporation than can be the case if the numerous properties remain in the hands of individual owners. A pooling of interests does not mean a tendency towards depreciation; indeed, the result of any such action would be, probably, to enhance values to a substantial extent. 


\section{CHAPTER XVI}

\section{THE NETHERLANDS EAST INDIES: SUMATRA}

Principal rubber-producing districts-Extension of the rubber plantations-Available lands for new plantations-Land tenureFreedom from taxation-Altitude of rubber estates-Characteristic features of the soil-Meteorological conditions-How the rubber industry originated-Custom of planting catch cropsGeneral health of the rubber-trees-Value of rubber plantationsCost of opening, equipping, and maintaining, an estate of $\mathrm{I}, 000$ acres-Maintenance of an estate six years old.

NTIL I 890 the development of the eastern section
of Sumatra was confined to a comparatively narrow strip of land adjoining the seaboard in the provinces of Deli and Asahan. Previous to that year active military operations were constantly in progress between the Dutch troops and the followers of the Sultan of Acheen, and even the comparatively settled districts near the sea-coast were not infrequently subjected to raids made by the hostile tribes of the country in the interior of the island. Under these circumstances access to the inland districts was forbidden by the authorities until I899, and for some years after that date permission was only granted with a chary hand. The first section of the island to enjoy settled conditions was the province of Deli; this soon became the centre of a most profitable tobacco-planting industry, which has developed to important proportions during the past twenty years. At a later period Liberian coffee planta- 
tions were established at various points on the east coast, and extending as far as the valley of the River Bila. Liberian coffee has now given place to rubber, cultivated in many cases in conjunction with Robusta coffee; but this latter product as a general rule is only grown as a catch crop, and it will disappear as the rubber-trees approach maturity. From Belawa, the port for the city of Medan, to Penang is only a journey of some eight hours by coasting steamer, and constant communication is maintained between the two places. Belawa is connected with Medan by railway, the distance of twenty miles occupying less than an hour in transit.

The principal rubber-growing districts of Sumatra lie on the east coast of the island, and include the districts of Lankat, Deli, Serdang, Padang, Batoe-Bahra, Asahan, and Bila. A few estates have been opened in other sections of the country, but difficulties of transport have prevented any extensive cultivation outside the districts mentioned. Roads and railways are in course of construction, or projected, to link up the existing planted areas and to give access to forest lands hitherto lying idle; but some years must elapse before these undertakings materialize, for the Dutch Colonial Government is slow to move in such matters, and requires very substantial proof of the necessity and financial value of such enterprises before becoming in any way responsible for them. It is for this reason that the rubber-planting industry has been practically confined hitherto within the districts where coffee and tobacco estates were established many years ago and transport already existed, or to certain sections along 
the Bila River where communication by water is available.

Statistics regarding the extent of cultivated rubber in Sumatra vary considerably, and no official return is made of acreage or number of trees. A handbook published in Medan estimates the area at 126,000 acres in I 9 II, but qualifies this by stating that details of many plantations are omitted. A census furnished by the Nederlandsche Handel Maatschappij gives the number of trees in IgII as $16,733,470$, or approximately I67,000 acres.

The Secretary of the Planters' Association of Sumatra stated that the returns for I9II, on which subscriptions were based, showed about I45,000 acres under cultivation, but that these did not include isolated estates on the west coast or any Chinese or Malayan holdings. In the circumstances the returns of the Nederlandsche Handel Maatschappij must be accepted as much the most reliable, on account of the facilities of that very important corporation for acquiring accurate information; therefore, the estimate of 167,000 acres may be taken as a conservative calculation of the area under cultivation in December, IgII. The area planted during I9I2 was not less than 60,000 acres; of this area 55,000 acres lie in the districts on the east coast, and 5,000 in the south-eastern and western sections of the island. Many planters insist that this figure of 60,000 acres for I 9 I 2 is too low, but confirmation as to any greater area is not forthcoming. In I9I3 an additional Io,000 acres was placed under cultivation.

The following table shows the expansion of the rubber-planting industry during the past eight years: 


\begin{tabular}{|c|c|c|}
\hline Year. & Area under Cultivation. & Increase in Acres. \\
\cline { 1 - 2 } 1906 & 6,140 & - \\
1907 & 20,150 & r 4,010 \\
1908 & 38,800 & 19,650 \\
1909 & 67,000 & 28,200 \\
$1910^{*}$ & 100,000 & 33,000 \\
$1911^{*}$ & 167,000 & 67,000 \\
$1912^{*}$ & 227,000 & 60,000 \\
1913 & 237,000 & 10,000 \\
\hline
\end{tabular}

The ficus-trees, of which 351,000 were planted previous to I909, are not included in the above figures, as they are being gradually cut out on the majority of the estates. The holdings of Malays and Chinese settlers are numerous, but are of limited extent, and in the aggregate are only a small proportion of the total acreage.

During the last five years the tendency has been to open larger plantations than formerly, a notable case in point being the Holland-American Company at Asahan, where 30,000 acres have been planted in the last four years, and further extensions are contemplated to bring the total area under cultivation to 50,000 acres.

The amount of land available for the extension of rubber-planting in Sumatra must be counted by millions of acres, for two-thirds of the island remain untouched to-day. Other considerations, however, besides suitable land must play a most important part in the future development of the industry. The question of the labour-supply enters largely into the problem; although at present no complaint is heard of any

* Shows effect of rubber boom of IgIo-Ir. 
scarcity on the estates, the demand will be increased substantially as the existing young plantations reach the tapping stage. Then, again, means of communication require additions and improvements before the necessary foreign capital will be attracted for the extension of the industry to the forest lands of the interior. It is more probable that expansion in the near future will take place along the banks of navigable rivers, or in the localities hitherto reserved for growing tobacco, and it is in this latter direction that a rapid development is possible. For many years Deli has been the centre of the tobacco industry, and to the east and west of that district an area of some 400,000 acres has been devoted to the cultivation of that product. After one or at most two crops have been gathered, the land is allowed to lie fallow for seven years before replanting, and therefore 400,000 acres in reality only means some 60,000 acres of cultivation. It is easy to plant rubber-trees after the tobacco crop is harvested, and practically no further expense is involved, beyond keeping the land clean, to allow the trees to come to maturity. If any substantial drop in the value of tobacco occurs, there is small doubt that a very considerable portion of these tobacco lands will be converted into rubber estates.

Land is held in Sumatra under long leases from the native Sultans, these concessions requiring the approval of the Dutch Colonial Authorities. As a rule the contracts are for not less than fifty, and not exceeding one hundred, years. The rental varies, but is generally at the rate of I guilder ( 20 pence sterling) for each bouw, equal to $I_{\frac{3}{4}}$ English acres. These land grants comprised 
a large acreage when they were obtained for tobaccogrowing, on account of the necessity of fallowing the land for seven years before replanting; and this resulted in the alienation of practically all the territory on the east coast of Sumatra between the seaboard and the foothills of the mountain ranges in the Lankat districts on the west to Asahan on the east.

No direct taxation is imposed on the rubber industry, and to assist the planters the Colonial Government has promised that no export duty should be levied on the raw material in the immediate future. It is the general opinion, however, that this condition will be revised before many years have elapsed, and that an export duty will be collected. The general revenue of the colony is derived from a I2 per cent. duty on all imported merchandise, a 4 per cent. income-tax, and from various municipal and local charges.

The rubber estates are situated at elevations of from 3 to 4 feet above sea-level to a height of not more than 120 feet at the foot-hills of the mountain ranges. The former elevation covers the fat lands near the banks of navigable rivers, such as the Bila, and certain sections of the tobacco districts, the latter those of the undulating country stretching up to the mountains.

There are three distinct varieties of soil in the rubber districts of Sumatra :

(I) A black, friable topsoil mixed with sand overlying a strong clay subsoil, forming the low-lying lands adjoining the larger rivers; (2) a black, friable topsoil mixed with sand on a subsoil of clay and sand, found chiefly in the tobacco districts; (3) a friable, chocolate topsoil on a hard laterite subsoil, these latter charac- 
teristic features extending over the undulating lands reaching to the foot-hills of the mountain ranges. In Nos. I and 2 the water is near the surface, extensive drainage is necessary, and the root growth of the trees is principally lateral, the tap-root not penetrating below the water-level. On the laterite soils the tap-root penetrates to great depth, frequently as much belowground as the height of the tree is above the surface. Intelligent appreciation, amongst planters, of this radical difference of root growth is lacking, and no allowance or consideration is given to it when laying out estates. Trees are planted the same distance apart on high lands, where a deep tap-root develops, as on low lands, where the tap-root disappears, and its place is taken by abnormal lateral growth. The trees develop rapidly on both low or high lands; but on the former they are specially liable to serious damage from the severe storms which constantly occur on the east coast of Sumatra, and at times reach hurricane force.

The rainfall on the East Coast varies considerably; it is controlled to a great extent by the high mountain ranges intersecting the whole length of the island. The following records for I9II give a general idea of the precipitation of moisture in different districts:

\begin{tabular}{|c|c|c|}
\hline Place. & District. & Rainfall in Inches. \\
\hline I. Medan & Deli & 79 \\
\hline 2. Soengei Poetih ... & Serdang & 93 \\
\hline 3. Soengei Roean ... & Lankat & II7 \\
\hline 4. Soengei Gerpa ... & Lankat & II9 \\
\hline 5. Tanah Besih ... & Padang (Tebing-Tinggi) & 109 \\
\hline 6. Lima Poeloeh ... & Batoe-Bahra & 94 \\
\hline 7. Telok Dalam & Asahan & 108 \\
\hline
\end{tabular}




\section{THE NETHERLANDS EAST INDIES}

The temperature varies very slightly throughout the rubber districts, as is shown by the following observations, taken in March, rgr2:

\begin{tabular}{|c|c|c|c|c|}
\hline \multirow{2}{*}{\multicolumn{2}{|c|}{ Place. }} & \multirow{2}{*}{ District. } & \multicolumn{2}{|c|}{ Degrees Fahrenheit. } \\
\hline & & & Maximum. & Minimum. \\
\hline r. Medan & & Deli & 94 & 71 \\
\hline 2. Soengei Poetih . & $\ldots$ & Serdang & 92 & 70 \\
\hline 3. Soengei Gerpa . & $\ldots$ & Lankat & 93 & 68 \\
\hline 4. Tanah Besih & $\ldots$ & Padang & 90 & 69 \\
\hline 5. Telok Dalam & $\ldots$ & Asahan & 92 & 68 \\
\hline 6. Tandjong Balei . & $\ldots$ & Asahan & 95 & 70 \\
\hline 7. Bila & & Laboean Bilik & 93 & $7 \mathrm{I}$ \\
\hline
\end{tabular}

The origin of the Sumatra rubber industry was the severe depression in the price of coffee some twelve years ago, due to the large increase in the Brazilian output. A small area of rubber had been planted previous to that period in the vicinity of the Bila River, and it was known, therefore, that Hevea Brasiliensis thrived on the east coast. The planters, looking for a new product to take the place of coffee, were encouraged to grow Pará rubber by the successful results obtained in the Malay Peninsula, and gradually the area cultivated with coffee was interplanted with trees grown from seed imported from Vallambrosa and other wellknown estates in Malaya. The cultivation was fostered by the Colonial Government, and promises were given of freedom from internal taxation and export duty. Following the lead of the coffee planters, a certain number of tobacco growers also turned their attention to rubber, and gave for that purpose a portion of the 
lands already under cultivation. In I909, when abnormal prices for rubber were realized, large sums were subscribed for opening up estates in Sumatra, and forest lands, as well as old estates, were cleared and planted, until from an area of 38,000 acres in 1908 the cultivation in I9I3 has reached 237,000 acres.

On the majority of the older estates in Sumatra the rubber has been grown amongst other cultivations, and many of the younger plantations are now planted with Robusta coffee as a catch crop. There is not the smallest doubt that the Pará trees planted amongst Liberian coffee have suffered severely in the past as regards development, and in some cases this damage is permanent. For the first two years the shade of the Liberian coffee shuts out light and air from the young trees, and the detrimental result is everywhere seen in the uneven growth, plantations of five and six years old often not tapping more than 50 per cent. of the trees. Another product equally harmful is rice of the dry land variety, which is frequently grown; it only stands to reason that a crop yielding 1,500 pounds of grain and a large amount of straw to the acre must be harmful to a plantation of young trees. Tobacco also has been tried as a catch crop, but is universally condemned. Robusta coffee, apparently, is the only product that can be grown in conjunction with Pará rubber without any serious prejudicial effect, so far as present experience goes. It certainly retards the growth to some slight extent; but the rubber-trees are not shut out from air and sun, and amazing returns of Io and I2, and even I 5 hundredweights to the acre are harvested when the bushes are two and a half to three years of age. At the present 
time this coffee is selling at 50 shillings per hundredweight, and at this price the temptation is certainly very great to pick two or three crops before cutting it out from the lines of rubber-trees. This is especially the case when old coffee machinery exists on an estate, and can be utilized for preparing the Robusta coffee for the market.

In spite of the fact that many trees on the older estates are stunted in development owing to interplanting with Liberian coffee and other crops, the general condition of the plantations is distinctly good. There is very little fomes in evidence, and small damage has been done by white ants; this is due, in great measure, to the fact that the land is exceptionally clear of decaying timber and roots, on account of its former cultivation for coffee and tobacco. In new clearings also, the general rule, however, is an absence of pests. Many estates show the effect of strong prevailing winds, and a considerable proportion of trees of two and three years of age were so bent over at two or three feet from the ground as to interfere seriously with tapping operations. Many managers in Sumatra without experience in planting rubber quite failed to grasp the importance of straight-stemmed trees on an estate. In spite of the defects alluded to, the general development on young plantations is fair, and the growth, especially in sheltered situations, quite equal to, if not more rapid than, that of Malaya. The trees suffer from nodules in the bark in the same manner as in the Malay Peninsula and Ceylon.

To calculate the value of rubber plantations in Sumatra, it is necessary to divide them into five groups: 
I. Those consisting of the old Liberian coffee estates interplanted with Pará rubber, and from which the coffee-trees are now rapidly disappearing.

2. The small area planted some twelve years ago on low-lying forest lands and cultivated without catch crops.

3. The various tobacco plantations converted into rubber estates.

4. Plantations opened since Igog on undulating forest lands and cultivated without catch crops.

5. Recently-opened estates interplanted with catch crops of Robusta coffee in order to defray the cost of bringing the rubber-trees to the tapping stage.

In group No. I there is practically no capital cost, although it is customary to estimate expenditure at the rate $£ 25$ per acre; the coffee has paid the expenses of cultivation until the rubber-trees have become selfsupporting, but the result is an uneven development of the trees adding greatly to the cost of collecting the latex. No. 2 has given satisfactory results as regards growth, but the area is so small that it does not affect the aggregate production to any appreciable extent. No. 3 has proved both successful and economical to bring into bearing, but these advantages are counterbalanced by high prices paid for the lands. No. 4 is only now beginning to give returns, but promises well as to growth and is remarkably healthy in appearance. No. 5 is in a satisfactory state so far, but it is too soon to say what the final result of interplanting with Robusta coffee will be in regard to the development of the young trees, and as to whether the immediate financial gain from two or three heavy 
coffee crops will compensate for the damage such cropping may do in the direction of exhausting the soil.

Approximately the area of these different groups is-

\begin{tabular}{|c|c|c|c|c|c|c|c|}
\hline No. I & $\cdots$ & $\cdots$ & $\ldots$ & $\cdots$ & $\cdots$ & $\ldots$ & $\begin{array}{r}\text { Acres. } \\
47,000\end{array}$ \\
\hline, 2 & $\cdots$ & $\cdots$ & $\ldots$ & $\cdots$ & $\ldots$ & $\ldots$ & 3,000 \\
\hline 3 & $\cdots$ & $\ldots$ & $\ldots$ & $\ldots$ & $\ldots$ & $\ldots$ & $100, \infty 00$ \\
\hline " 4 & $\ldots$ & $\ldots$ & $\ldots$ & $\ldots$ & $\ldots$ & $\ldots$ & 20,000 \\
\hline 5 & $\ldots$ & $\cdots$ & $\ldots$ & $\ldots$ & $\cdots$ & $\ldots$ & 87,000 \\
\hline & & & & Total & $\ldots$ & ... & 237,000 \\
\hline
\end{tabular}

The immediate effect of the rubber boom of I909-Io was to increase the area under cultivation by more than Ioo per cent. In Igog the rubber estates covered I00,000 acres; in I9I2 the area planted was 227,000 . The total capital invested in the enterprise by public companies and private individuals at the beginning of IgI2 was-
I. British
$\begin{array}{llll}\ldots & \ldots & \ldots & \ldots, 068,000\end{array}$
2. Dutch
3. Belgian
4. United States
5. German ...
6. Hong-Kong
7. Shanghai ...
8. Private enterprise

$$
\begin{array}{cccr}
\ldots & \ldots & \ldots & 3,552,000 \\
\ldots & \ldots & \ldots & 350,000 \\
\ldots & \ldots & \ldots & 800,000 \\
\ldots & \ldots & \ldots & 72,000 \\
\ldots & \ldots & \ldots & 40,000 \\
\ldots & \ldots & \ldots & 25,000 \\
\ldots & \ldots & \ldots & 513,000 \\
\text { Total } & \ldots & \ldots & \text { I0, } 420,000
\end{array}
$$$$
\begin{array}{lllr}
\cdots & \cdots & \cdots & 513,000 \\
\hline
\end{array}
$$
Total

This capital value must be divided into the amount represented by estates established on conservative lines and those created as the outcome of the boom. In the former case the cost of bringing a plantation to the bearing stage may be taken at $£ 25$ per acre, as will be shown in detail later on. Under the latter circumstances the capitalization is out of all relation to the 
actual necessary expense for the establishment of estates. The area of plantations existing on a conservative basis is approximately 100,000 acres, and that affected by the "boom" about I20,000 acres. Therefore the position may be summed up briefly as-

\begin{tabular}{|c|c|c|}
\hline Area. & Capitalization. & Cost per Acre. \\
\hline Acres. & $£$ & $£$ \\
I00,000 & $2,500,000$ & 25 \\
I20,000 & $7,920,000$ & 66 \\
\hline
\end{tabular}

It is evident that the concerns capitalized under the " boom" conditions at an average cost of $£ 66$ per acre must suffer severely when increased supplies throughout the world bring the value of rubber down to the actual cost of production plus a fair profit, say I 5 per cent., to the producer. In any consideration of this subject, the essential factors to remember always are that the reserve of land available for rubber cultivation in Sumatra and elsewhere is practically unlimited; that new plantations begin to yield in the fourth year; and that the present condition of the labour-supply in the East offers no serious obstacle to the extension of the industry.

The estimated cost of opening a rubber plantation of I,000 acres on forest land situated at 50 feet above sealevel includes all necessary charges up to the end of the fourth year, when the yield should be sufficient to allow the capital account to be closed. Allowance is made for the cost of obtaining a grant of $I, 000$ bouws of land ( $I, 750$ acres) in order to hold a reserve available for future extensions. Felling and cleaning up after 


\section{THE NETHERLANDS EAST INDIES}

the timber is burnt can be done by contract; but constant delays occur in Sumatra owing to the unpunctuality of the native contractors in regard to work, and it is more satisfactory to employ daily labour for these preliminary operations, although the expense is slightly higher. No allowance is made for the removal of the stumps of big trees or the destruction of the large logs; the majority of practical planters do not consider such expenditure justified by results, and they prefer to keep a keen watch for any appearance of fomes, white ants, or other pests, and to deal with each case as it occurs. The subjoined estimate of the distribution of costs explains itself; it is slightly lower in sterling value than similar work in the Malay Peninsula, but this is due to the lesser value of the Dutch guilder as compared to the Straits dollar :

I. Expenses of land grant of 1,000 bouws, $\begin{array}{lllll}\text { survey fees, etc. } \ldots & \ldots & \ldots & \ldots & 7,000\end{array}$

2. Rent, I,000 bouws (I,750 acres), I guilder per bouw per annum for four years ... 4,000

3. Felling, clearing, and burning 1,000 acres 23,000 7,000

4. Cleaning up $\mathrm{r}, 000$ acres $\ldots$
5. Weeding : first nine months, $\ldots$ i 8,000 guilders; second year, 12,000 guilders : third year, 9,000 guilders; fourth year, 5,000 guilders

6. Draining

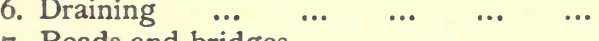

8. Lining, holing, and filling ... $\quad \ldots \quad \ldots \quad \ldots \quad 2, \infty 00$

9. Planting and supplying $\ldots \quad \ldots \quad \ldots \quad \ldots \quad 2,000$

I0. Nurseries or plants ... $\quad \ldots \quad \ldots \quad \ldots r, 2,000$

II. Manager's bungalow, 6,500 guilders ; assistant's bungalow, 4,500 guilders ... I I, 000

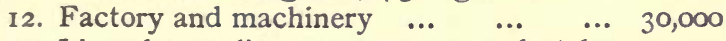

13. Lines for coolies: 100 rooms, ro feet by I 2 feet, at I 50 guilders per room

... 15,000

Carried forward

... 159,000 
I4. Tools, etc Brought forward $\ldots$... I 59,000

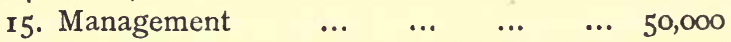

16. Hospital, medicines, attendance, etc. ... I 5,000

I7. Cost of importing 300 coolies : first three

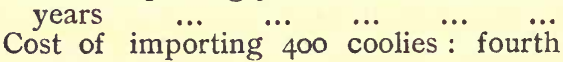
$\begin{array}{lllllll}\text { year } & \ldots & \ldots & \ldots & \ldots & \ldots & 14,000^{*}\end{array}$

18. Contingencies $\quad \ldots \quad \ldots \quad \ldots \quad \ldots \quad$ II, 500

Total $\quad \ldots \quad \ldots \quad \ldots \overline{291,000}$

This sum of $29 \mathrm{I}, 000$ guilders is equal to $£ 24,250$ sterling, or $£ 24$ 5s. for each acre brought into bearing. Between the fourth and fifth year the estate should be self-supporting.

The yearly cost of maintaining in first-class order an estate of 1,000 acres with a forest reserve of $75^{\circ}$ acres should not exceed the following estimate:

2. Tapping and collecting (including de-

preciation on cups and implements) $\ldots \quad 65,000$

3. Curing and preparation (including 20 per cent. depreciation on factory and machinery

Guilders.

I,000

12,500

4. Transport, shipping charges, and commission $\quad \ldots \quad$... $\quad \ldots \quad \quad \ldots \quad \quad \ldots \quad 5,000$

5. Management (allows for manager, two assistants, and two clerks) $\quad \ldots \quad \quad \ldots \quad$ I7,500

6. Hospital and medical attendance $\quad \ldots \quad 5,000$

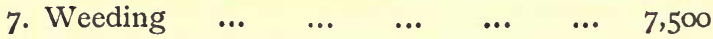

8. Maintenance of roads and drains $\quad \ldots \quad 5,000$

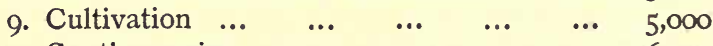

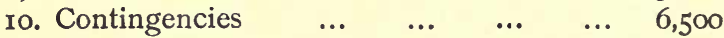

II. Depreciation of buildings other than $\begin{array}{lllllll}\text { factory } & \ldots & \ldots & \ldots & \ldots & \ldots & 7,500\end{array}$

Total $\quad \ldots \quad \ldots \quad \ldots \overline{137,500}$

* Proportion of cost of three years' contract. 


\section{THE NETHERLANDS EAST INDIES}

This sum of 137,500 guilders is equal to $£^{\mathrm{II}, 45^{8}}$ sterling. With an average crop of 250 pounds of rubber to an acre containing I08 trees, the cost per pound f.o.b. Sumatra works out at II pence sterling. It is understood that the amount allocated to hospital and medical attendance is for a share in a central hospital in combination with two or three other estates. If a separate hospital is maintained this charge would be doubled.

The yield per acre should show a steady increase as the trees grow older, and the cost of collection, curing, weeding, management, and maintenance of roads and drains, will be proportionately reduced per pound of rubber.

In addition to the expenditure already set out, the charges from Sumatra to date of sale in Europe come to $x^{\circ} 60$ pence per pound with rubber selling at 2 shillings per pound. Therefore the total cost up to date of sale would be 12.60 pence sterling, leaving a net profit of $\mathrm{II}^{\circ} 40$ pence per pound of rubber. A well-cared-for plantation planted with ro8 trees to the acre will certainly yield $25^{\circ}$ pounds per acre between six and seven years of age. Under these conditions, a crop of 250,000 pounds from 1,000 acres will leave a clear profit of $£$ II,875 sterling with the average price of rubber at 24 pence per pound. A fall in the value would automatically reduce the European charges for commissions.

This lower cost of production in Sumatra as compared to Malay is accounted for by (I) the smaller value of the monetary unit, and (2) the absence of any export duty or direct taxation on the industry. 


\section{CHAPTER XVII}

\section{THE NETHERLANDS EAST INDIES: SUMATRA-Continued}

Spacing of rubber-trees-Plantation management-Establishment of rubber factories-The labour-supply-Hours of work and rate of wages-Maintenance of labourers-Chinese cooliesNo necessity for skilled labour-Sanitary conditions and medical supervision-Organization of plantations-Catch crops-Tapping -Plantation buildings-Maintenance of discipline-Approximate yield of trees-Average cost of production-Analysis of costsCosts after shipment-Average cost per pound of rubber soldExports of rubber since 1906, and estimate of future production.

7 HE proximity of Sumatra to the principal centres 1 of the rubber industry of the Malay Peninsula has been an important factor in the development of the plantations of the east coast. The example of the methods employed in the Federated Malay States has saved many errors in Sumatra, and would have effected even greater benefit in this direction if less antipathy existed on the part of the Dutch planters towards British nationality; it is difficult to explain this attitude, for it is not in evidence on the part of the British planters, who have shown no hesitation in furnishing any information requested in connection with general plantation work. A substantial benefit derived by the geographical position of Sumatra was the facility for obtaining rubber seed and plants from the Malay estates, thus overcoming what would have been a most serious and costly difficulty at the outset of the 
industry if the need had existed for importation from Ceylon. The nearness of Penang and Singapore has also been of great advantage, obviating many of the difficulties of transport that would otherwise have handicapped the pioneers of the industry. In the matter of the construction and equipment of factories for rubber plantations, the experiences of the Malay Peninsula have been an invaluable guide for the Sumatra estates.

The most satisfactory distance apart for planting rubber-trees in Sumatra is now generally accepted as 20 feet by 20 feet, and the majority of the estates opened up during the last five years have followed that rule. In view of the rapid growth of the trees, this distance is certainly not too great, but still it gives ample room for expansion during the first ten years' development. This spacing gives 108 trees to the acre.

The expansion of the rubber industry in Sumatra is of such recent date that the number of experienced planters in the country is not large. Naturally, the ranks have been recruited from the coffee and tobacco planters, and these men, accustomed to plantation work, are rapidly acquiring a useful knowledge of rubber cultivation. The majority of the managers and assistants are of Dutch or Swiss nationality; a few Englishmen are scattered through the planting districts, but the number is extremely limited. The demand for both managers and assistants in the Malay Peninsula has been so great of late years that few men from that community have cared to take up plantation work in Sumatra under the Dutch flag; and so it happens that, although many estates in Sumatra 
are owned by British companies, and more than half the capital invested is of British origin, the work is superintended by Dutch or Swiss representatives, with very few exceptions. Probably the fact that fixed salaries are 40 per cent. lower in Sumatra accounts for this to some extent; on the other hand, a liberal bonus based on profits is customary. The system of plantation management and accounts in vogue in Ceylon and Malaya is gradually being introduced on all rubber estates, and will become universally established in the course of the next two or three years.

The erection of factories has been pushed forward rapidly on the many young estates where tapping has commenced. They are constructed on the model of those working in Malay and Ceylon, and therefore no need exists for a repetition of the description already given in connection with those two countries. The same machinery and the same methods are employed in the curing and preparation of the rubber. One point, however, merits notice. Attention has been attracted to a new process for preparing the latex, and, if successful, it will undoubtedly be adopted extensively. It is the invention of a Swiss, Mr. Freudweiler, the manager of the Sennah estates. The principle is to coagulate and dry the latex by means of hot smoke charged with carbonic acid gas, and without washing or creping or using any acids. Briefly described, the method is to pass the latex from a receiving tank through fine sieves into a secondary tank, the latter overflowing into three smaller settling basins. From the last of these the latex falls gradually on to a wheel of some ${ }_{5} 5$ feet in diameter, fitted with a I5-inch 


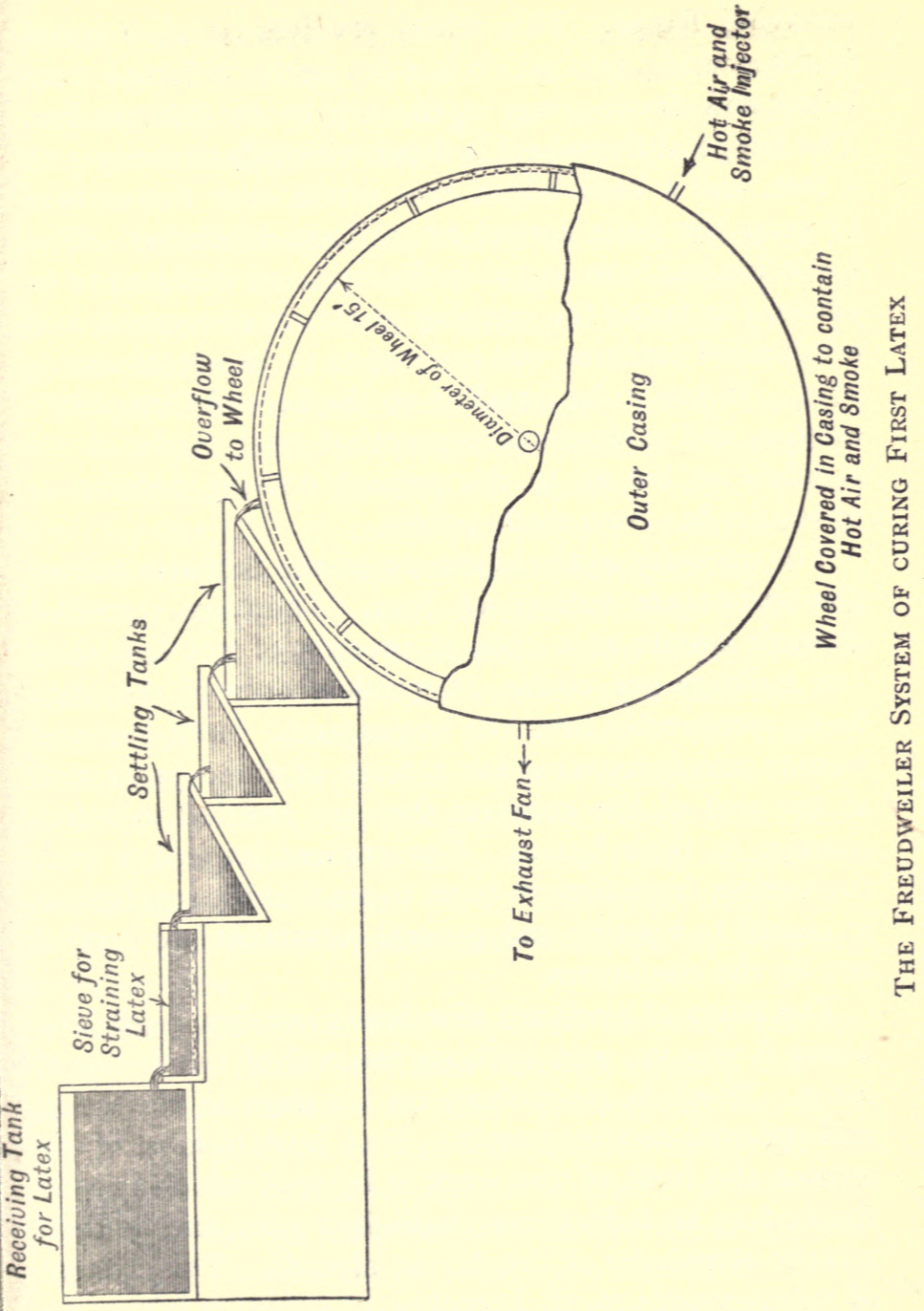


receiving flange. This wheel revolves at slow speed inside a casing, into which hot dry smoke is forced from below and drawn away at the top by an exhaust fan. The flange of the wheel is fitted with rills at every 3 or 4 feet, and a knife-edged arm works over the surface to keep the latex spread at uniform thickness. The invention has been tested in Europe, and declared to be efficient so far as the working model is concerned, and a full-sized machine was ordered to be in actual use in 1913. It was to be installed on the Sennah Company's estates, and a thoroughly practical trial made of its capabilities, but up to the present nothing definite as to results has been made public.

The majority of the labourers on the Sumatra rubber plantations are natives of Java. They are recruited through agents at a cost, at present, of not less than I20 guilders per coolie, I5 guilders only of this sum being recoverable from the wages paid. Both men and women are indentured for a term of three years, and at the end of the contract they are entitled to a free passage to their homes. Government inspectors visit the estates from time to time, to see that the regulations in regard to housing and general treatment are carried out by the employers.

The hours of work are nine hours per day, beginning about 6.30 a.m., and with an interval of two hours at noon. Work is compulsory on six days in the week, and optional on the seventh. On a large number of the estates the bulk of the work is by task which can be finished by an industrious coolie by 2 p.m., and he then has the remainder of the day to himself. This system of tasks extends to all branches of ordinary labour on 
an estate, including tapping and collecting, weeding, road-making, cutting drains, and hoeing. On the majority of the plantations the managers express themselves satisfied with the work done by the Javanese.

The rate of wages paid to indentured Javanese is 33 cents a day for men and 28 cents for women under the contract, but on some plantations a higher wage is given voluntarily to expert tappers.

When the three years' contract expires, a large number of the coolies prefer to remain on the estates instead of returning to Java. To such men as elect to follow this course a wage of 40 cents per diem is given, but the women continue to receive only 28 cents per day.

Rice is supplied by the employers at cost price, but no other food. On most estates a store is established and rented out to Chinamen, subject to certain restrictions in regard to prices on goods sold to the coolies. This is a necessary prevision when the estate is at any great distance from any village, for the labourers require dried fish, cocoanut-oil, curry stuffs, fruit, vegetables, and many other articles. Fresh fish, when obtainable, forms a part of the regular diet, but meat, except pork, is rarely eaten.

Chinese coolies are also employed on many estates. They are recruited in China through agents, and indentured to serve for one year, or, excepting holidays, for 300 days. The cost of introduction at present is 85 guilders per head, no part of which is recoverable. The wages rate for these indentured Chinese is 33 cents per diem. They do fairly satisfactory work, but, owing to the heavy preliminary cost and the short term of 
contract service, they prove much more expensive than the Javanese.

Free Chinese labourers are also employed on the plantations. For these the usual wage is from 50 to 60 cents per diem, but in some cases as much as a guilder a day is paid when their services are urgently needed.

The Malay population in Sumatra rarely work as day labourers on the estates, although occasionally they take contracts for felling and clearing forest lands.

At present there is no scarcity of labour on the east coast of Sumatra so far as the principal rubber and tobacco districts are concerned, but the demand will increase greatly as tapping becomes more general.

The only skilled work required from estate coolies is for tapping and factory work, and any fairly intelligent labourer becomes proficient at both in a very short time under careful supervision. On many estates in Sumatra quite as good tapping is done by Javanese as any accomplished in Malaya by Indians or Chinese, and the same remark applies to the work in the factories.

Throughout the east coast of Sumatra the health conditions are exceptionally good. There is, comparatively speaking, very little malarial fever or dysentery, and the parade of coolies for the daily muster seldom shows a greater proportion than 2 to 3 per cent. on the sick list. Sanitary regulations are enforced by the Dutch Colonial Government, and properlyequipped hospitals are maintained for all estates. The large plantations each have their hospital and resident doctor; the smaller estates, when possible, combine to establish a central hospital for the use of three or four 
plantations, in order to reduce the cost of accommodation and medical attendance.

The organization of a rubber estate in Sumatra presents no exceptional difficulty. A grant of suitable land must be secured from the Sultan of the district, and this concession must be ratified by the Dutch Assistant Resident. Arrangements are then made with agents to secure the requisite number of Javanese or Chinese coolies, and lines are erected to house the labourers on arrival. Felling and clearing are commenced immediately and, probably, a portion of this work is given out to Malay contractors. As soon as the land is cleaned up after the débris of the timber has been burnt, the work of lining and holing at once begins. The planter will probably follow the custom of the last five years, and cut holes 20 feet apart. When holing is finished the work of filling takes place, and planting commences as soon as the weather is favourable.

If nurseries have not been formed, plants or stumps can be purchased at prices of from 15 to 18 guilders per I,000. Many planters prefer planting seeds at stake, and on several estates this method has given excellent results. Weeding should commence immediately the land is cleaned after the burn; if this work is thoroughly carried out, the estate will be free of weeds at the end of the first year, and monthly weeding can then be established at a low cost. Roads should be made at the time the holes are cut, and, if any draining is necessary, that work should have been taken in hand simultaneously with the road-making.

During the first year arrangements must be completed for the construction of bungalows and other necessary 
buildings. Beyond this work and the weeding there is little to be done after the estate is planted, until the end of the third year, except to supply fresh plants where those originally set out have died or been damaged, and to keep a vigilant watch for the appearance of disease, white ants, or other pests. In the third year preparations should be made for the erection of the factory, and an appropriate site selected. This work should be completed in the course of the fourth year, when a census of the trees must be taken and those of sufficient girth marked for tapping. The tapping begins when the trees measure 16 to 18 inches in circumference at 3 feet from the ground.

If a catch crop of Robusta coffee is grown, more work is entailed. The bushes give a first crop when two and a half years old, and the question of setting up the necessary machinery and appliances for curing and preparation for the market has to be considered. The coffee buildings are so erected that they can be converted into a rubber factory at small expense when the shade from the rubber-trees causes the further cultivation of coffee to be abandoned.

However tempting a catch crop of coffee may appear to be, it must not be forgotten that it entails certain detrimental effects to young rubber. Whenever such a crop is cultivated, the result under most favourable circumstances leads to an irregular growth of the rubbertrees; this means that, in place of tapping 70 per cent. of the trees in the fourth year, only some 30 to 40 per cent. will be available. The outcome is extra expense in tapping and collecting, and also a reduced yield during the fourth and fifth years. 
The system of tapping in Sumatra is copied from that practised in the Malay Peninsula and Ceylon, and has been fully described in connection with the industry of those countries.

The buildings on Sumatra rubber estates are similar to those in use in Malaya; but hard-wood frames and thatched roofing are the general rule, and only in very few cases does one meet with steel frames and galvanized iron roofing. The principal difference is in the expense of construction, those in Sumatra costing the same number of guilders of 20 pence as the Malayan in dollars of 28 pence.

The standard of discipline varies on plantations. On some estates no complaints are made by the managers; but on others the reverse is the case, and much bitter sentiment is expressed in connection with the attitude of the Colonial Government. The pith of the matter is that the planters are strictly forbidden to impose punishment by fine or otherwise, and the authorities will take no effective methods to correct abuses. This condition is confirmed by quite independent and reliable sources, such as the managers of the Nederlandsche Handel Maatschappij and many agents and merchants in Medan and elsewhere. In the Bila district during IgrI, one English and two Swiss managers were murdered by estate labourers, and inquiries failed to show any reasonable provocation for these acts. Apparently the managers were dissatisfied with the work of certain coolies, and insisted that the men should do it in better fashion; disputes followed in each case, and the coolies attacked the managers with hoes and knives and killed them. One of the murderers is now in the gaol at 
Tandjong Balei, where he is serving a term of four years' hard labour for his crime. The other men received similar sentences. Obviously, such punishment is quite inadequate to meet the case.

Accurate records of the yield per acre have not been kept on the Sumatra estates. This is principally due to the fact that the majority of the tapping hitherto has been on trees planted amongst Liberian coffee and other catch crops, and the growth has been so irregular and uneven that the number of pounds of rubber to the acre conveys no definite idea of the real condition of the industry. Some returns of the yield per tree in I9II-I2 are available, and they are given for what they are worth; but they must be considered as only an approximate indication for a basis of calculation:

\begin{tabular}{|c|c|c|c|c|}
\hline Name of Estate. & District. & Age. & $\begin{array}{l}\text { No. of } \\
\text { Trees } \\
\text { tapped. }\end{array}$ & $\begin{array}{l}\text { Yield per } \\
\text { Tree. }\end{array}$ \\
\hline $\begin{array}{lc}\text { I. Soengei Gerpa } & \ldots \\
\text { 2. } " ~ & \ldots \\
\text { 3. Blankahan"... } & \ldots \\
\text { 4. Soengei Roean } & \ldots \\
\text { 5. Soengei Poetih } & \ldots \\
\text { 6. Te" } & \ldots \\
\text { 7. Telok Dalam } & \ldots \\
\text { 8. Se" } & \ldots \\
\text { 9. Sennah Rubber } & \ldots\end{array}$ & $\begin{array}{c}\text { Langkat } \\
\quad ", \\
\text { Serd̆ang } \\
\text { Asahan } \\
\text { Bila" }\end{array}$ & $\begin{array}{l}\text { Years. } \\
6 \frac{1}{2} \\
5 \\
6 \frac{1}{2} \\
6 \frac{1}{2} \\
6 \\
5 \frac{1}{2} \\
5 \frac{1}{2} \\
\text { II } \\
4\end{array}$ & $\begin{array}{r}37,000 \\
35,000^{*} \\
49,000 \\
30,000 \\
17,000 \\
5,000 \\
18,083 \\
800 \\
30,000\end{array}$ & $\begin{array}{l}\text { Lb. } \\
3.42 \\
0 \cdot 85 \\
2 \cdot 45 \\
3 \cdot 31 \\
1 \cdot 50 \\
1 \cdot 90 \\
\text { I.92 } \\
7 \cdot 00 \\
1 \cdot 33\end{array}$ \\
\hline
\end{tabular}

No useful purpose can be served by quoting further instances. As conditions in Sumatra are so very similar to those existing in the Malay Peninsula, it is safe, and more satisfactory in every way, to apply the Malay averages to Sumatra.

* From August I, I9I I, to March I, I9I2. 
Owing to the method hitherto in vogue of keeping estate accounts in Sumatra, it is no easy matter to arrive at exact figures in regard to the cost of production of a pound of rubber f.o.b. at port of shipment. At present the expenses connected with coffee cultivation are bulked with rubber where the two products are interplanted, or, where an estate has young trees and older trees in bearing, the expense of weeding has not been allocated in proper proportion to capital and revenue accounts. This confusion will be eliminated when the rubber industry has further developed, but for the moment the only practical course is to pick out the different items, and not rely implicitly on the general returns from estates. As a case in point take Telok Dalam Estate, where the cost of production f.o.b. for IgI I was placed at 58 cents per pound of rubber. An examination of the accounts discloses an item of 3,000 guilders for a supply of cups, sufficient to last for three years, charged against tapping and collecting for IgII. Similarly, all the recruiting charges for indentured coolies brought to the estate in I9II were charged against the cost of production in that year, instead of being proportioned over the contract term of three years. Then, again, depreciation on buildings had been omitted. Taking account of these errors, the results worked out at I 2 cents per pound less than 58 cents, and the cost f.o.b. was 48 cents, or $9^{\circ} 20$ pence sterling. The explanation afforded by the general manager was that he only wished to pay 8 per cent dividend for I9II, and so debited many unusual costs against the revenue for that year. After very careful consideration of all details, the average cost of production f.o.b. Sumatra for IgI3 should work out as follows: 
Cents.

I. Tapping and collecting (includes depreciation on cups and implements) $\quad$... $\quad$.. $\quad 29$

2. Curing (includes depreciation on factory and $\begin{array}{lllllll}\text { machinery) } & \ldots & \ldots & \ldots & \ldots & \ldots & 5\end{array}$

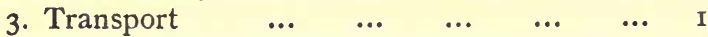

4. Commissions and shipping charges $\ldots \quad \ldots \quad$...

$\begin{array}{lllllll}5, \text { Weeding } \ldots & \ldots & \ldots & \ldots & \ldots & \ldots & 3\end{array}$

$\begin{array}{lllllll}\text { 6. Cultivation } & \ldots & \ldots & \ldots & \ldots & \ldots & 2\end{array}$

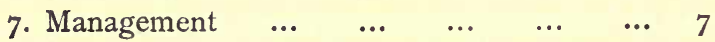

8. Depreciation (on buildings other than factory) 3

9. Hospital (share of central hospital with other

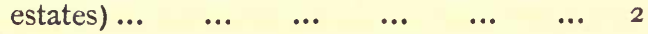

Io. Maintenance of roads and drains $\quad \ldots \quad$... 2

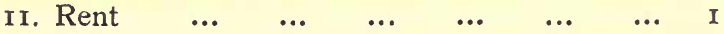

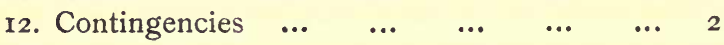

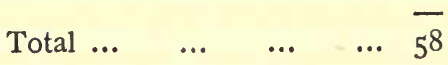

This is equal to $I I_{\frac{1}{2}}$ pence sterling. As the trees become older, and the yield in the former coffee plantations less uneven, the cost should show a substantial decrease; the average minimum cost in I9I5 should not exceed 50 cents, or Io pence, per pound of rubber f.o.b. at port of shipment.

An analysis of the foregoing cost of production shows that 70 per cent. is for labour charges. Therefore any increase or decrease in expenditure principally depends on the wage rate of coolies and an efficient supervision to insure economy of labour wherever possible. Management and labour combined sum up 47 cents out of a total cost of 58 cents for each pound of rubber produced. The lower cost in Sumatra as compared to Malaya is due to the smaller intrinsic value of the monetary unit.

The charges from port of shipment, Sumatra, to 
London, Liverpool, Antwerp, or Amsterdam, are the same as those ruling from the Malay Peninsula. Freight from Medan and other ports on the east coast is fixed at 65 shillings per 50 cubic feet. Commissions for statistical purposes are calculated on a selling value of 24 pence per pound, and would rise or fall with any fluctuation in prices. The custom in Sumatra is to pack the rubber in wooden cases containing II 2 pounds each, and averaging ten boxes to the 50 cubic feet. The charges are-

I. Freight Pence per Lb.

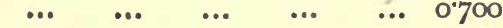

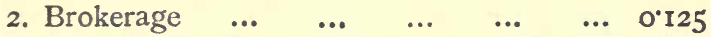

3. Sale charges, insurance, storage, and sun-

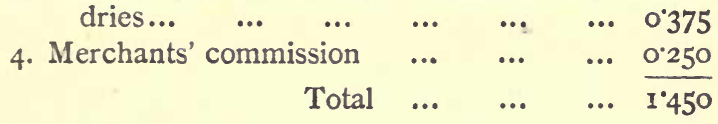

With the average cost f.o.b. Sumatra of II $\frac{1}{2}$ pence per pound of rubber, the total cost up to date of sale in London or Liverpool will be II $\frac{1}{2}$ pence plus $I^{*} 45$ pence, making 12.95 pence per pound for I9I3. As there is every reason to suppose that the future average cost of production f.o.b. Sumatra will not exceed 50 cents, or Io pence, the total cost with rubber at 24 pence would be II*45 pence per pound; or with the selling value at I shilling it would be II'I3 pence per pound, after making due allowance for the decrease in the rate of ad valorem commissions.

In Sumatra at present it is useless to apply normal yields to the total acreage under cultivation in order to ascertain probable immediate production, for until Ig09 nearly all the trees were interplanted with Liberian coffee, their development choked, and their needs 
neglected in every way. It is only in the last four years that proper attention has been given to the rubber, and the coffee cleared away to allow an opportunity for recovery from past ill-treatment. Large numbers of trees that should yield 3 pounds of rubber each at six and seven years of age are giving little more than one-half of that amount. That these trees have survived at all is a matter for surprise, and that they are regaining normal conditions tends to show their amazing vitality. After most careful investigation of past details and existing circumstances, the following results were reached in regard to the future production over the area planted at the end of I9I2:

Actual Production, 1906 to I9I3

\begin{tabular}{|c|c|c|}
\hline Year. & Area under Cultivation. & Rubber exported. \\
\cline { 2 - 3 } & & Tons. \\
1906 & Acres. & 80 \\
1997 & 6,140 & 100 \\
1908 & 20,150 & 150 \\
1909 & 38,800 & 214 \\
1910 & 67,000 & 330 \\
I911 & 100,000 & 678 \\
1912 & 167,000 & 1,923 \\
1913 & 227,000 & 3,440 \\
\hline
\end{tabular}

Estimated Future Production, I9I4 to I9I9

\begin{tabular}{|l|r|r|}
\hline 1914 & 237,000 & 8,000 \\
1915 & 240,000 & 12,000 \\
1916 & 245,000 & 16,000 \\
1917 & 250,000 & 22,000 \\
1918 & 250,000 & 33,000 \\
1919 & 250,000 & 44,000 \\
\hline
\end{tabular}




\section{THE NETHERLANDS EAST INDIES}

No allowance has been made for yield from trees planted after IgI2; there will, however, be a substantial increase from this source from IgI 6 onwards. This additional production will offset any shortage that may occur from unforeseen circumstances in connection with the acreage in cultivation at the beginning of I9I3. 


\section{CHAPTER XVIII}

\section{'THE NETHERLANDS EAST INDIES : JAVA}

Locality of rubber estates-Altitude of plantations above sealevel-Meteorological conditions-Characteristic features of soil - Extension of the rubber plantations-Origin of the Java rubber industry-Trees of the black variety of Hevea Brasiliensis-Land tenure-Revenue and taxation-Capitalization of rubber plantations-Cost of establishing a plantation, including four years' maintenance-Annual expenditure on a rubber plantationRevenue from young plantations-Superintendence of estatesSpacing of trees on plantations-Construction of factories and preparation of latex.

I $\mathrm{N}$ many respects the characteristic features of Java common to both, agricultural industry is the source of wealth in the two islands, and the same products are cultivated under almost identical conditions of climate and soil. Java has the advantages of a very much larger population and a greater area of land suitable for all descriptions of tropical agriculture; Ceylon, on the other hand, is better situated for the sale of produce in the European markets. The two islands have been in friendly competition for nearly a century past in connection with various enterprises, amongst these being the production of coffee, tea, cinchona bark, and, latterly, rubber. So far as coffee was concerned Java showed a greater power of resistance to the ravages of leaf disease than did Ceylon, and the cultivation has survived; in regard to tea plantations Ceylon has more than held 260 


\section{THE NETHERLANDS EAST INDIES 26r}

her own, but in the matter of cinchona bark Java was able to reduce the cost of production to a figure so low that the Ceylon plantations were abandoned as unprofitable. In the direction of the rubber industry the pride of place rests easily with Ceylon, but the estates in Java are developing rapidly, and in a very few years the rivalry between the two countries will be accentuated to a marked degree.

The rubber estates of Java are scattered over the island from east to west; but they are much more numerous in the southern section, for the reason that the rainfall is greater and more regular in the south. The principal districts where plantations have been opened are near Buitenzorg and Krawang, in the province of Batavia; Rangkas-Bitoeng and Menes, in Bantam; Tjandjoer, Bandoeng, and Banjar, in Preanger; Langen, Tjipâri, and Kiliminger, in Banjoemas; Malang and Limburg, in Pasoerean; Djember, Kalisat, and Banjoewani, in Besoeki; and at various points in the provinces of Kediri and Soerabaja. In nearly all districts where coffee plantations previously existed, rubber has been planted whenever conditions of climate and soil permitted. Experiments tried with Pará rubber in the northern sections of the island, between Batavia and Soerabaja, have not proved successful, owing to climatic reasons.

Java differs from the other rubber-producing countries of the Orient in that Pará rubber flourishes at elevations varying from sea-level to 2,000 feet. At the latter height the growth may be somewhat slower, although it is difficult to express a definite opinion on this point, as all the rubber at high elevations has been 
interplanted with other cultivations, and little attention given to it in the earlier stages. As regards yield of latex, there is very small difference from trees of equal ages at high and low elevations; this is in marked contrast to the general characteristic features prevalent in this respect in Ceylon, the only country where the physical conditions in any way resemble those existing in Java. The only plausible explanation is that south of the Equator different climatic influences come into action, and rainfall and temperature are not affected by variations to the same extent as happens in countries lying to the north of the equatorial line.

The following statistics, collected from various rubber estates, afford a general idea of the climatic conditions:

\begin{tabular}{|c|c|c|c|c|}
\hline Estate. & District. & $\begin{array}{c}\text { Elevation } \\
\text { (Feet). }\end{array}$ & $\begin{array}{l}\text { Max. and Min. } \\
\text { Temp. (Fahr.). }\end{array}$ & $\begin{array}{l}\text { Rainfall } \\
\text { (Inches). }\end{array}$ \\
\hline $\begin{array}{l}\text { I. Kiara Pagoeng } \\
\text { 2. Tjirandi } \\
\text { 3. Baud (tea) - } \\
\text { 4. Pasir Oetjing - } \\
\text { 5. Batoe Lawan - } \\
\text { 6. Banjasari - } \\
\text { 7. Tjipâri - - } \\
\text { 8. Kiliminger - } \\
\text { 9. Limburg- } \\
\text { I0. Kalidjeroek - } \\
\text { I1. Mamboel - } \\
\text { I2. Glen More - } \\
\text { I3. Buitenzorg - } \\
\text { I4. Rangkas - Bito- } \\
\text { eng (Tjikadoa) } \\
\text { 15. Menes (Pasir- } \\
\text { Wringin) - }\end{array}$ & $\begin{array}{l}\text { Tjandjoer } \\
\text { Bandoeng } \\
\text { Banjar } \\
\text { Banjoemas } \\
\text { Malang } \\
\text { Djember } \\
\text { Bangoewani } \\
\text { Batavia } \\
\text { Bantam }\end{array}$ & $\begin{array}{r}1,800 \\
950 \\
2,400 \\
900 \\
200 \\
50 \\
500 \\
200 \\
1,050 \\
800 \\
300 \\
200 \\
700 \\
200 \\
\\
260\end{array}$ & $\begin{array}{l}84^{\circ} ; 67^{\circ} \\
86^{\circ} ; 69^{\circ} \\
83^{\circ} ; 64^{\circ} \\
86^{\circ} ; 69^{\circ} \\
91^{\circ} ; 72^{\circ} \\
92^{\circ} ; 71^{\circ} \\
87^{\circ} ; 70^{\circ} \\
85^{\circ} ; 71^{\circ} \\
84^{\circ} ; 68^{\circ} \\
83^{\circ} ; 69^{\circ} \\
84^{\circ} ; 69^{\circ} \\
85^{\circ} ; 70^{\circ} \\
87^{\circ} ; 70^{\circ} \\
87^{\circ} ; 71^{\circ} \\
87^{\circ} ; 71^{\circ}\end{array}$ & $\begin{array}{l}\text { I64 } \\
\text { I } 25 \\
\text { I } 41 \\
\text { I } 36 \\
\text { I } 37 \\
\text { I21 } \\
\text { I3I } \\
\text { I35 } \\
\text { I25 } \\
\text { I } 37 \\
\text { I35 } \\
96 \\
\text { I } 24 \\
\text { I } 17 \\
\text { I9 }\end{array}$ \\
\hline
\end{tabular}

* Exceptional rainfall caused by proximity to mountain ranges. 


\section{THE NETHERLANDS EAST INDIES}

The foregoing observations show a very even temperature and a good average rainfall on the east, west, and south sections of the island, and doubtless explain to some extent the large average yields of latex at comparatively high elevations. The heavy rainfall at Menes is due to its close proximity to a high mountain.

Throughout the highlands of the greater part of Java the soil is red laterite, overlaid with a considerable depth of humus and topsoil on all virgin forest-lands. On low-lying flat country the general characteristics are a dark brown greasy topsoil on stiff blue or yellow clay, these lands requiring extensive draining previous to cultivation to free them from accumulations of excessive moisture. In the eastern provinces of Pasoerean and Besoeki, the soil in the highlands is a rich chocolate, friable loam, not infrequently mixed with black scauria from the great volcanoes in those districts; the soil of the low-lying flat lands in these provinces is a rich brown clayey loam, mixed with sand, alternating at times with a black, sandy soil of volcanic origin. On the laterite soil the growth of the rubber-trees is more satisfactory, and they are less subject to disease than on the low-lying clays; but the latter could be very much improved by adequate draining and occasional forking over, with an application of lime as a top-dressing. Near Rangkas-Bitoeng a curious white soil, very loose on the surface and quite hard a foot or two down, is not uncommon. The rubber planted in this vicinity is healthy in appearance, and yields freely; this class of soil, however, will need heavy manuring in the near future to insure satisfactory returns. 
Official returns for IgIo gave the area planted with Pará rubber as 158,000 acres on 215 estates; in addition, there were under cultivation I,086,126 Ficus, 687,748 Castilloa, and 356,253 Ceará trees. In IgII some 50,000 acres were planted with Pará rubber, and in I9I2 the area was increased by 25,000 acres. This aggregate for IgII and I9I2 is compiled from information supplied by estate agents and planters; it is probably less than the actual amount, and in any case must be considered a very conservative figure. Summed up, the approximate extent now cultivated with Hevea Brasiliensis is-

\begin{tabular}{|c|c|c|}
\hline Year. & Acres. & Increase. \\
\hline I9I0 & I58,000 & - \\
I9II & 208,000 & 50,000 \\
I912 & 233,000 & 25,000 \\
I9I3 & 240,000 & 7,000 \\
\hline
\end{tabular}

The extensions in IgII and IgI2 are directly due to the rubber boom of Igog-Io; they took place principally in the eastern districts of the island in the provinces of Besoeki, Pasoerean, and Kediri.

In 1898 , when the price of coffee dropped so low that no profit remained to planters, efforts were made to find some product as a substitute. The question of converting the coffee estates into rubber plantations was considered in many districts, and application was made to the Government Agricultural Department for advice as to cultivation and the species of rubber-bearing tree most suitable for the conditions prevalent in Java. The 
authorities at Buitenzorg recommended the planting of Ficus, Castilloa, and Ceará and emitted an opinion that Pará rubber (Hevea Brasiliensis) was ill-adapted to the soil and climate of the island. The cultivation of Ficus elastica was strongly advocated on the grounds that it was a natural product of the Java forests. It is due to this advice from the experts of the Agricultural Department that so large an area of Ficus, Castilloa and Ceará trees are found in Java to-day. The cultivation of Pará rubber was only begun seriously about I905, when the experiences of Ceylon and the Malay Peninsula showed clearly its great superiority over all other species. In a few districts a limited number of Hevea trees had been planted before I905, and the satisfactory development of these proved that they could be successfully cultivated, and that the opinion expressed by the authorities at Buitenzorg in 1898 was entirely erroneous. In I906-I908 arrangements were made to obtain seed from the Klang district of Selangor, and in those years a considerable number of coffee estates were interplanted with Pará trees. In Ig09-I9I I the cultivated area was greatly extended in conjunction with the planting of Robusta coffee as a catch crop.

On an estate named Pasir Oetjing, near Bandoeng, there are growing 120 trees planted from seeds collected in the Amazon Valley in 1899 , and sent to Paris to the care of Mr. Godefroy-Lebeuf. After germination the plants were shipped to Java to Mr. A. Bovis, who planted them at the Pasir Oetjing estate. An account of these trees was published in the Journal d'A griculture Tropicale of May 31, I904, and it is claimed that they belong to the black variety of the Hevea Brasiliensis, 
considered in Brazil to be distinctly superior to any other species of the Hevere.

Land is held under long leases, seldom less than seventy-five years, issued by the Dutch Colonial authorities; or in the case of semi-independent Sultanates they are nominally conceded by the Sultans, but must be approved by the resident Commissioner. The annual rental varies from Is. $8 \mathrm{~d}$. to 5s. Iod. per bouw of $I \frac{3}{4}$ acres. A large proportion of the public waste-lands is now reserved for native plantations of rice and other foodstuffs, and grants for establishing new estates for rubber or other cultivations are difficult to obtain. It is, however, easy to buy from the owners of existing leases, the price varying from a few shillings to several pounds sterling per acre, according to the conditions and situation of the property.

In addition to the annual rental paid for leasehold a land-tax of $\frac{3}{4}$ per cent. is levied on a valuation made once in every five years. While this cannot be considered a very heavy contribution, it must be taken into account in all propositions for opening up rubber estates. No export duty is exacted on rubber shipments. The general revenue of the colony is derived from duties of I2 per cent. levied on all important merchandise, a personal income tax of 6 per cent., and various municipal rates charged on house property and other real estate in cities and towns.

At the beginning of I9II-that is to say, three years ago, at the end of the boom period-the amount invested in joint-stock rubber-producing companies in Java was- 


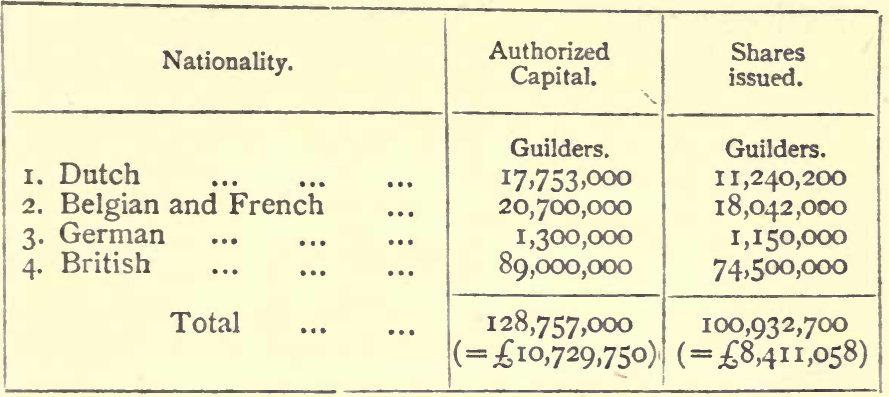

Since those statistics were compiled several additional companies have been formed and the greater part of the unissued shares have been sold, so that to-day the total issued capital of the rubber joint-stock undertakings in Java is not far short of $£ 12,250,000$. The value of any debenture issues or other fixed interest charges in connection with these companies is so small that it need not be taken into consideration. Under the heading of "British Companies" is included the value of various undertakings originating in Hong-Kong and Shanghai.

For general financial purposes the rubber estates in Java must be classified under three headings: (I) Plantations opened on economical lines before the rubber boom of Igog-ro, and not sold during that period of inflated prices; (2) old estates purchased during the boom or new plantations opened at that time ; (3) estates established between IgI2 and I9I3, on a scale of expenditure restricted to conservative limits. Under the three categories the approximate extent and values in I9I2 were- 


\begin{tabular}{|c|c|c|c|}
\hline & Acres. & Value. & $\begin{array}{c}\text { Average per } \\
\text { Acre. }\end{array}$ \\
\hline 1. Old estates with original \\
$\begin{array}{c}\text { capital } \\
\text { 2. Estates recapitalized } \ldots\end{array}$ & 80,000 & $1,600,000$ & $£$ \\
$\begin{array}{c}\text { I909-r9r I ... } \ldots \\
\text { 3. Young estates now in } \\
\text { course of development }\end{array}$ & 128,000 & $9,750,000$ & 76 \\
\hline
\end{tabular}

With regard to the estates under the first heading, the actual expenditure on rubber has been very small, as it was interplanted with coffee still under cultivation. In any considerations of the plantations capitalized during the boom period, allowance must be made for the large area of waste-land acquired by the companies in addition, and out of all proportion to the extent planted with rubber. A nominal sum of $£ 5$ per acre for this may be taken as a fair deduction, thus reducing the cost under the second class to $£ 7$ I per acre. Under the third heading, the price given is the average cost per acre of opening an estate and bringing it into bearing, but does not include any premium paid for the acquisition of the leasehold of the necessary land. It is difficult to estimate the value of this premium, for if a Government grant is obtained, the only payments are the survey fees; on the other hand, if the transfer of a lease from a private individual is arranged, the value of the premium may be anything from Ios., or even less, to $£ 5$ sterling, but as a general rule for rubber lands the average price should seldom exceed $£$ I per acre.

The cost of opening and maintaining $I, 000$ acres under rubber in Java until the estate becomes selfsupporting should be about 288,000 guilders, equal to 
$£ 24$ per acre, exclusive of any premium paid for the acquisition of the land. This cost is distributed as follows :

Guilders.

I. Clearing, felling, and burning $\quad \ldots \quad \ldots \quad$ I5,000

2. Cleaning up after burning... $\quad \ldots \quad \ldots \quad \ldots \quad 20,000$

3. Lining, holing, and filling ... $\quad \ldots \quad \ldots \quad \ldots \quad 2,000$

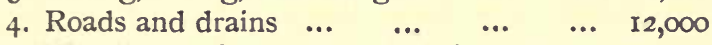

5. Weeding: first nine months, 27,000 guilders; second twelve months, 24,000 guilders; third twelve months, 18,000 guilders; fourth twelve months, 12,000

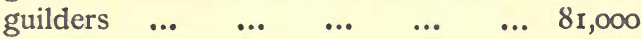

6. Management : manager, 600 guilders per month; two assistants, 200 guilders each per month; two clerks, 100 guilders each per month; contingencies, 2,000 guilders per annum (office expenses) ... 56,000

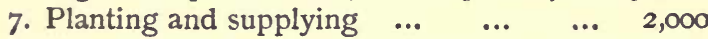

8. Nurseries or purchase of plants ... $\quad \ldots \quad 4,000$

9. Bungalows : one at 3,000 guilders ; one at 2,500 guilders; one at 500 guilders $\begin{array}{lllllll}\text { (clerks) } & \ldots & \ldots & \ldots & \ldots & \ldots & 6,000\end{array}$

10. Factory and-machinery $\quad \ldots \quad \ldots \quad \ldots \quad \ldots, 30,000$

II. Lines for coolies (r25 rooms) $\quad \ldots \quad \ldots \quad 20,000$

I2. Hospital and maintenance (four years) ... 10,000

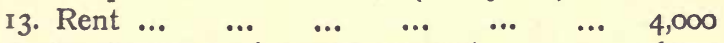

14. Contingencies (general account) ... _.. 26,000

Total $\quad \ldots \quad \ldots \overline{288,000}$

This expenditure is calculated on the actual cost of labour on rubber estates, whether the work is done by contract or by daily payment of wages on the checkroll. In some respects work in Java is cheaper than in Malay or Sumatra. Serviceable bungalows, constructed with wooden frames and interlaced bamboo walls, can be built for 2,500 guilders, equal to similar buildings in 
the Malay Peninsula costing not less than 4,500 dollars, and often exceeding that sum. Then, again, Government regulations are not enforced concerning lines for coolies or for hospitals, although, for the most part, both these important essentials are well looked after by the estate managers. As a rule the Javanese coolies prefer to live in small huts, divided into two or three rooms, and this type of building is found generally on the plantations, in contrast to the barrack-like accommodation provided in Malay, Sumatra, and Ceylon.

As in all rubber-growing countries, the larger proportion of the outgoings is for the payment of labour and cost of management. The rate of wages varies so greatly even in the same district, as explained elsewhere that no hard and fast rule can be laid down for estate expenditure, but an average cost _over a number of plantations in various localities gives an approximate estimate of the necessary expenses. Another factor to be taken into account is that managers and assistants are paid small salaries, with a bonus on profits. The custom in Java is to allow the manager ro per cent. and the assistants $2 \frac{1}{2}$ per cent. on the net profits, in addition to a fixed salary of about $£ 500$ per annum for the former and $£ 25^{\circ}$ for the latter. This rate is paid on important properties, with extensive interests at stake; on small plantations a lower remuneration is given. When an estate has reached the producing stage, this bonus system appeals strongly to the individual manager, but many complaints are heard in connection with newly opened rubber plantations, where four or five years must elapse before the concern becomes dividend-paying; 
certainly much of the enthusiasm in Java for interplanting rubber with coffee and other products arises from the desire to earn profits at an early date. The following is an approximate cost of the annual maintenance of an estate of $\mathrm{I}, 000$ acres of six to seven-yearold trees, planted 20 feet by $I_{5}$ feet (I 49 trees to I acre), or 20 feet by 20 feet ( 108 trees to I acre), and yielding a crop of 280,000 pounds of dry rubber:

I. Rent, I,000 acres at I guilder per acre Guilders.

2. Tapping and collecting (including 50 per cent. depreciation on cups, buckets, implements, etc.) ... $\quad$... $\quad$ I I 7,600

3. Curing and preparation (including 20 per cent. depreciation on factory and machinery) $\quad \ldots \quad$... $\quad .$.

4. Transport, shipping-charges, and commission

5. Management-manager, two assistants,

$\begin{array}{lllllr}\text { two clerks } & \ldots & \ldots & \ldots & \ldots & 11,250 \\ \text { 6. Weeding (6o cents per acre) } & \ldots & \ldots & 6,000 \\ \text { 7. Maintenance of roads and drains } & \ldots & 6,000 \\ \text { 8. Cultivation } & \ldots & \ldots & \ldots & \ldots & 8,500 \\ \text { 9. Manuring } & \ldots & \ldots & \ldots & \ldots & 8,500\end{array}$

Io. Depreciation of buildings other than factory ... $\quad \ldots \quad \quad \ldots \quad \quad \ldots \quad \quad \ldots \quad 6,000$

II. Hospital and medical attendance (optional, but necessary) $\quad \ldots \quad \quad \ldots \quad 5,000$

12. Contingencies (taxes, etc.) $\quad \ldots \quad$... $\quad 5,000$

$$
\begin{array}{llll}
\text { Total } & \ldots & \ldots & \frac{5,000}{\text { I } 91,700} \\
& & (=£ I 5,975)
\end{array}
$$

An allowance of $8 \frac{1}{2}$ guilders per acre has been made for manuring, as with the prevailing system of catch crops of coffee or other products some return to the soil is necessary. 
The cost of tapping and collecting is very much higher in Java than elsewhere in the Orient for reasons explained elsewhere.

The yield of dry rubber from an estate planted I 5 feet by 20 feet with 149 trees to the acre, or 20 feet by 20 feet, with ro8 trees to the acre, should not be less than 280,000 pounds under normal conditions, basing such figures on the actual returns obtained per tree, and after making due allowance for local conditions. The account at the close of the sixth year should be-

Lb.

Dry rubber

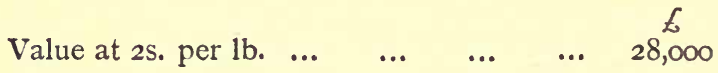

The annual expenditure is $£$ I5,975. Freight and charges from port of shipment to date of sale are I $\frac{1}{2}$ pence per pound, or a sum of $£ I, 750$. The bonus to manager and assistants would be $£ \mathrm{I}, 200$. Directors' fees and secretarial expenses in London or elsewhere, about $£ \mathrm{I}, 500$. Therefore the final return should be-

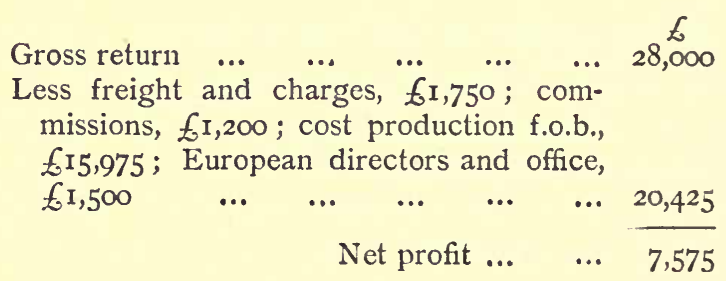

On a capital expenditure of $£ 25,000$ this would enable a dividend of 30 per cent. to be paid. If the price of rubber should drop to I 8 pence per pound, the estate would still be in a prosperous condition. Allowing that 
no reduction be made in the annual estate expenditure, other items would automatically decrease; various charges would fall to $£ \mathrm{I}, 250$ or less, manager's commissions would be reduced to $£ 200$. If the European directors' fees and office charges are unaltered, the total expenditure for the year would be $£ \mathrm{I} 8,925$, leaving a net profit of $£ 2,225$, equivalent to a dividend of 9 per cent. on a capitalization of $£ 25,000$.

The planting industry of Java has been established for so many years that experienced estate managers for tea, coffee, tobacco, sugar, cacao, cocoanuts, coca, and almost all branches of tropical agriculture are found in large numbers in the island. For rubber plantations, however, there is a great scarcity of experienced managers and superintendents. In knowledge of tapping and general conditions in connection with Pará rubber there has been until very recently a marked lack of competent men; even now thoroughly capable men are not easy to find. Of course this is only a passing phase, for with the expansion of the rubber area and the beginning of the production stage of development, serious attention is being paid to the matter, and managers and assistants are sent to the Malay Peninsula in considerable numbers, to learn the methods employed and the general conduct of the business. In Java a few Englishmen and some Frenchmen and Belgians are employed, but the majority of managers and assistants are Dutchmen. The question of language is not an easy one for the newcomer, for to be thoroughly efficient he should understand and talk fluently Dutch, Malay, Sundanese, Javanese, and in some districts Madoerese. In several districts Sundanese and Javanese 
only are spoken by the labouring classes, and Malay is practically unknown. In the planting districts of the extreme East, such as Bangoewani and other parts of Besoeki, the majority of the plantation hands are recruited from the island of Madoera, and only understand their own dialect.

The spacing of trees on estates in Java varies in every district. On some of the older plantations the trees are only 7 feet by 7 feet, 8 feet by 8 feet, and I 2 feet by Io feet. In most cases these are being thinned out, but the process leaves an uneven growth and is unsatisfactory. Other estates have gone to extremes in the opposite direction and planted 24 feet by 24 feet, and 24 feet by 30 feet. Again, instances occur of 12 feet by 36 feet over a considerable area. Probably as an average $I_{5}$ feet by 20 feet, giving I 49 trees to the acre, or 20 feet by 20 feet, with Io 8 trees to the acre, may be taken as average distances for purposes of calculation.

Many estates have recently erected factories devoted solely to the preparation of rubber, but until a year ago the area in bearing was so limited that makeshifts were employed by adapting a portion of the existing coffee stores for preparing the latex.

The system followed in the Malay Peninsula has been adopted generally as the basis for the Java factories; but in many cases water-power, already applied for purposes of coffee machinery, can also be utilized, and this will prove a saving in future years. A disadvantage in Java, however, is the excessive humidity of the climate, necessitating six to eight weeks for drying crape of medium thickness. When the larger estates come into full production, it will be impossible to handle 
the output by the present method of hanging in sheds, and machinery for drying by artificial means will be required. Probably the Passberg Vacuum Dryer will be brought into general use, unless some more effective apparatus can be found. The methods of treating the latex do not differ materially from the description given in connection with Ceylon and the Malayan industry, and therefore no repetition is necessary in regard to Java.

The comparatively small quantity of rubber exported up to the present has gone principally to Rotterdam or London. To the latter port the freight charge is 77 shillings per 50 cubic feet, and to the former 72 shillings. A small quantity is shipped to Singapore and there sold at the regular rubber auctions, and there are indications that such shipments may increase in the future. Prices in Java are governed by London and Liverpool quotations, local sales allowing a deduction equivalent to the value of freight, insurance and commissions. 


\section{CHAPTER XIX}

\section{THE NETHERLANDS EAST INDIES: JAVA- Continued}

The labour-supply-Rate of wages-Working hours-Discipline on plantations-Housing accommodation and food-Sanitary conditions-Opening a rubber plantation-Effects of interplanting with Robusta coffee-Weeding estates-Tapping-Health of rubber-trees-Expansion of the rubber industry-Average yield of trees-Average cost of production at port of shipmentExpenditure analyzed-Costs after shipment up to date of saleAverage cost per pound of rubber sold in I9I3-Past exports and future production-Railways and roads in Java.

THE population of Java is extraordinarily prolific if represent the actual state of affairs. The first attempt at a census of the inhabitants was made in 1815 , under the direction of Sir Stamford Raffles at the time of the British occupation of the island; the figures then returned were 4,390,66I for Java and 224,609 for Madoera, a total of $4,615,270$, of whom $4,499,250$ were natives. In 1878 the total had risen to $19,067,829$, including 200,303 Chinese, 29,998 Europeans, and 9,6 ro Arabs and other Orientals. In 1897 the returns were 26, I25, II 10 divided as to 5I,73I Europeans, 26I, I07 Chinese, 17,075 Arabs, and 3,238 other foreigners. In I9I2, the estimated total number of inhabitants was given as between $34,000,000$ and $35,000,000$, an increase, approximately, of 9,000,000 during the intervening fifteen years. All indications are that the population 
will continue augmenting in the near future. Some 75 per cent. of the natives live by agriculture in one form or another; the Chinese and Arabs are nearly all traders, and of the Europeans 50 per cent. are in civil or military employment. The religion of the Javanese, especially in the eastern districts, is nominally Mahomedanism, but both Buddhism and Brahminism exists; although professing one or other of these faiths, a very large proportion of the inhabitants are still believers in the pagan precepts of their forefathers. In I9I2, the number of native Christians was stated to be between 60,000 and 70,000 , but information on this point is uncertain.

With a population of some $35,000,000$ natives it appears at first sight that no difficulty should be experienced in Java with regard to the requirements of labourers for the sugar-cane, tea, tobacco, coffee, rubber, and cocoa plantations. Such, however, is not the case; with rubber estates particularly the number of coolies available is inadequate in many districts. There is no doubt that this scarcity of labour for plantation purposes is due in great part to the large area under cultivation in the island, the rice-fields extending to $3,000,000$ acres, sugar-cane to some 600,000 , tobacco 200,000 , tea 250,000 , and a similar area is under crop with coffee and rubber combined; native foodstuffs and fruits do not occupy less than I,000,000 acres, coconuts 200,000, and probably not less than 500,000 acres altogether are devoted to other products. This means that a combined demand exists for coolies to cultivate 6,000,000 acres ; in addition, an annual drain takes place to Sumatra of some 50,000 labourers, and to Malay of a further I0,000 
for work on the rubber estates in those countries. It must also be remembered that the native methods of cultivating rice-fields and gardens for fruit and foodstuffs is antiquated and extravagant; labour-saving machinery and modern implements are practically unknown, and the result is waste of energy and time in many directions.

In the eastern districts a large proportion of the coolies employed are recruited from the island of Madoera, close to the province of Soerabaya. This island is poor in agricultural resources; but it has a large population of poverty-stricken inhabitants, of whom a considerable proportion are willing to go to work on the plantations of the mainland. They are weak and sickly on first arrival at the estates, but make useful labourers after a period of regular rations has improved their physique.

No system of contract labour is permitted in Java. The coolies are free to work for any rate of wage they can obtain, and they take full advantage of this condition, leaving an estate at any time they feel inclined to do so without the smallest consideration for the inconvenience occasioned by such action. In order to check this inclination, estate managers endeavour to form resident colonies of plantation hands, and to those who remain permanently a higher wage is granted and many privileges allowed. On old-established estates this resident labouring force is a prominent feature; on rubber plantations, however, it is only a limited factor, owing to the comparatively recent date of the industry, and to its unpopularity compared to other cultivations. Another reason is that the climate and land best suited 
for growing Pará rubber is situated as a rule in unhealthy districts and inaccessible localities, where foodsupplies and other necessaries are expensive and not easy to obtain.

The rate of wages paid to coolies varies in every district, and often even on adjoining estates in the same district. On some tea estates in I9I2, the daily payment was I 7 cents for men and I 5 cents for women, while children of twelve to fourteen years of age earned 8 to Io cents a day. A small present was given at the end of the month if the output of leaf was particularly good, but the average payments to men were only at the rate of 5 guilders per month, and to women and children in like proportion. These coolies were resident on the plantations, and appeared perfectly satisfied with the conditions. At a rubber estate only a few miles distant the men were receiving 40 and the women 30 cents per day, but the labour force was dissatisfied and constantly changing. The average daily wage paid on rubber plantations throughout Java may be taken as 40 cents for men, 30 for women, and 15 cents for children for ordinary work; and 45 cents to men and 35 cents to women daily as tappers. There is not any marked indication of an immediate alteration in these wage conditions, for it happens nearly always that when an estate succeeds in obtaining labour for a lower rate of pay, some neighbouring planter who is short of hands offers an additional money inducement and the coolies go to him. There is no cohesion among planters to check this state of affairs.

The working hours are nominally from 6 a.m. to 4 p.m. with one hour of rest at noon. As a rule, how-. 
ever, all plantation work is divided into tasks which the coolie with a little additional application and energy can finish by 2 p.m. This piecework system is found to be more satisfactory for the estate and the coolies.

In view of the large number of labourers employed in agricultural undertakings in Java, the general standard of discipline is well maintained. Occasional instances of rioting and insubordination occur on plantations; these are sometimes quite unjustified, and as a rule originate in an imaginary grievance not appreciated by the manager or his assistants. Every now and then, however, serious incidents take place and result in the murder of the superintendent, but such occurrences are few and far between.

Where the system of resident colonies of labourers has been established, each family has a house, or part of a house, allotted to them, or land is given to them on which they can build for themselves and remain in possession as long as they continue working on the estate. In many cases plots of land are also allowed to them for the cultivation of fruits and vegetables for their own use. The food is rice, curry-stuffs, fruit, vegetables, and occasionally pork or poultry, but meat is rarely eaten. All provisions are purchased at the neighbouring villages. Health conditions vary greatly in Java. In the highlands there is not a great deal of malaria, but dysentery and smallpox are not infrequent. In the district of Malang an outbreak of bubonic plague occurred in IgII, and occasioned some I0,000 deaths, but no European contracted it. In the low-lying districts malarial fever is prevalent, and at certain seasons of the year the regular practice is to administer daily doses of 5 grains of quinine to every estate coolie. 
The organization of a rubber plantation in Java differs in no essential particulars from the description given of similar work in Malay or Sumatra, except in the matter of the labour question already alluded to. The preliminary work of felling, burning, and cleaning up can be contracted for; but the price shows small difference whether arranged by such contracts or executed by daily labour. The Government impose no restrictions in regard to dwellings for coolies or in regard to hospital accommodation, but it is found by experience that these factors in estate life require careful and serious attention in order to make the place popular for labour. On the rubber plantations in Java it has become an established custom in many districts to grow catch crops of Robusta, Quillou, or Uganda coffee for the first five years after the estate is opened. While catch crops have been condemned in Malay and Sumatra, there is a good deal to be said in favour of planting these varieties of coffee in Java.

Where the catch crops of Robusta, Quillou, or Uganda coffee, are planted at the same time as rubber in Java, the effect is less detrimental than might be expected. The young rubber-trees obtain a fair start before they are shut in by the growth of the coffee bushes, and the estate is kept cleaner from weeds than would be the case if no catch crop was planted. At the end of the second year the coffee-trees are topped at 6 feet from the ground, and by this time the rubber has attained a height of some I2 or I4 feet, so that it is never excluded from light and air. The danger to some extent lies in the third and especially the fourth years, when in order to obtain bigger coffee crops the 
Dutch planters are apt to prune the rubber heavily to reduce the shade for the coffee. If the coffee is eliminated at the end of the fourth year, as has been done on many estates, no great harm is done to the rubber beyond a slightly restricted condition of development. If, however, an attempt is made to obtain a crop of coffee in the fifth year, the rubbertrees undoubtedly suffer, and unevenness in their development becomes most noticeable. Moreover, the thick growth of the coffee-bushes interferes seriously with the supervision of tapping, with the result that the work is badly done and very costly.

One reason given by planters in Java for growing coffee together with rubber is that the former serves to make the estate popular with labourers, for the reason that they earn better wages at picking coffee than at any other cultivation in Java. It is easy work, and a woman with one or two of her children to help her frequently obtains a wage of I guilder (Is. 8d.) a day.

The financial point of view must also be considered. With a small crop in the second year, another of Io to I2 hundredweights per acre in the third, and an even greater yield in the fourth season, with this coffee selling at its present price of about 50 shillings per hundredweight, an actual profit of $£ 30$ sterling per acre can be made by the time the rubber-trees are ready for tapping. In other words, the rubber has cost nothing, and a clear $£ 30$ per acre has been made over the area cultivated. Moreover, catch crops of coffee under existing conditions appeal to the managers of estates, as a percentage of the profits falls to them.

Clean weeding, apart from those estates interplanted with coffee, is not the general rule in Java. Planters 
give as a reason that the trees do not suffer if lalang and other pernicious grasses are kept under; indeed, they go so far as to say that weeds are beneficial to prevent wash in heavy rains, and useful in keeping the ground moist in seasons of drought. In Ceylon and the Malay Peninsula such theories are rejected, and other measures, such as draining and forking, are adopted to remedy the damage caused respectively by superabundant rainfall and the effects of dry weather. As a general rule, the somewhat dirty appearance of the majority of estates in Java is due to careless management or lack of funds to employ sufficient labour.

The standard of tapping in Java is far from satisfactory. It is true that this class of work is only beginning, but with the example of the damage done in the Malay Peninsula by careless work a few years ago, it is inexcusable that the Java planters do not make greater efforts to teach their coolies how to work in a more efficient manner. A reason given for this condition of affairs is that the labour on rubber estates is seldom permanent, and that as soon as a batch of men are efficient, they leave for other estates where they can obtain a higher wage; or the rice harvest of their village begins, and they forsake the plantation and return to their homes. There is a great deal of truth in both these assertions, and for some years to come they will be an obstacle to good tapping. A more serious point, however, is that in view of the difficulties of retaining good tappers an insufficient amount of daily labour is required from them, and, consequently, the cost of the work is far higher than in Malay, Sumatra, or Ceylon. In fact, on several estates the daily task is, approximately, one-half of 
that accomplished in the three countries under similar conditions of age and growth of trees.

The usual diseases of the Pará rubber-tree are present in Java. Evidence of various forms of canker is seen on many plantations ; especially is this the case on lowlying lands near the sea-coast. In the Banjoemas district it is prevalent to a marked degree, and considerable areas have suffered severely on both the Langen and Banjarsari estates, where the soil is of a cold, clay character, and very wet. Decay of the cortex on the tapped surface is also common in these swampy districts, and is similar to cambium rot in Ceylon. Possibly better drainage and the application of lime as a top dressing for the soil may remedy the evil, but it can be eradicated only at comparatively high cost. On the laterite soils of the hilly and undulating lands bark disease is less in evidence; but it exists, and it requires constant watching and treatment. Fomes and "Dieback" are both found, but so far threaten no serious damage when the trees are taken in hand at an early stage of infection. White ants are not very numerous, and do little harm. With the exception of the estates on the very low-lying wet lands, where canker has a strong hold, there is no reason why disease should prove a serious factor in the development of the Java rubber industry.

There is ample room for the extension of the industry as far as suitable land is concerned. The general inclination in Java, however, is not to attempt any fresh undertakings until some tangible results are obtained from the area now under cultivation. A good deal depends upon the course of coffee prices during the next few years; there is no doubt that any great expan- 
sion of the growth of the Robusta, Quillou, and Uganda coffees will be accompanied with a corresponding increase in the area under rubber, for the planting of the latter can be done without cost except for nurseries and putting out the plants in the fields. The Dutch planter likes to have two strings to his bow, and many of them aver that they would always put in coffee and rubber together and decide later on which crop would pay them best to retain under cultivation.

The Java industry is still in its preliminary stages of development, and therefore it is impossible to obtain reliable returns over definite areas on which to base accurate calculations of averages. Many estates have thousands of trees in tapping, but for the most part only begun during the last two years, and too scattered to give representative results per acre. The following yields per tree in various districts only serve as an indication of general conditions :

\begin{tabular}{|c|c|c|c|c|c|}
\hline Altitude. & Estate & District. & $\begin{array}{c}\text { No. of Trees } \\
\text { Tapping. }\end{array}$ & $\begin{array}{l}\text { Average } \\
\text { Yield. }\end{array}$ & Age. \\
\hline $\begin{array}{c}\text { Feet. } \\
600 \text { to I,850 } \\
800 \\
800 \\
200 \\
50 \\
\text { I00 } \\
50 \text { to } 600 \\
1,050 \\
800 \\
800 \\
200 \\
200 \\
200 \\
260 \\
200\end{array}$ & $\begin{array}{l}\text { Kiara, Pagoeng } \\
\text { Tjirandi } \\
\text { Pasir Oetjing } \\
\text { Batoe Lawan } \\
\text { Banjasarie } \\
\text { Langen } \\
\text { Tjipari } \\
\text { Limburg } \\
\text { Kalidjeroek } \\
\text { Mamb̈oel } \\
\text { Glen More } \\
\text { Kaliminger } \\
\text { Pasir Waringen } \\
\text { Tjikadoe }\end{array}$ & $\begin{array}{c}\text { Preanger } \\
\text { ". } \\
\text { Banjar } \\
\text { Banjoemas } \\
\text { Malang } \\
\text { Djember } \\
\text { ". } \\
\text { Banjoewani } \\
\text { Banjoemas } \\
\text { Bantam } \\
\text { ". }\end{array}$ & $\begin{array}{c}31,150 \\
49,000 \\
80,000 * \\
19,437 \\
31,000 \\
148,000 \\
32,000 \\
60,000 \\
6,000 \\
5 \\
15,000 \dagger \\
5,000 \dagger \\
15,000 \\
24,000 \\
20,000\end{array}$ & $\begin{array}{l}\text { Lb. } \\
I \cdot 60 \\
I \cdot 35 \\
I \cdot 80 \\
I \cdot 70 \\
I \cdot 75 \\
I \cdot 53 \\
I \cdot 25 \\
I \cdot I 2 \\
I \cdot 25 \\
7 \cdot 00 \\
O \cdot 35 \\
0 \cdot 40 \\
I \cdot 00 \\
I \cdot 25 \\
I \cdot 50\end{array}$ & $\begin{array}{l}\text { Years. } \\
4 \text { to } 5 \\
4,, 6 \\
4,, 6 \\
4, " 5 \\
4,6 \\
4,, 5 \\
4,, 5 \\
4,, 5 \\
4,, 6 \\
\text { I2 } \\
4 \\
3 \frac{1}{2} \\
4 \frac{1}{2} \\
4 \text { to } 5 \\
4,, 5\end{array}$ \\
\hline
\end{tabular}

I 20 trees eleven years.

+ Tapping only just begun. 
For young trees these results are fairly satisfactory. In several of the records tapping had taken place only for two, three, or four months, and the yield per year is calculated on the monthly returns. These estates were planted with I50 trees to the acre, and on nearly all catch crops of coffee were under cultivation.

Costs of production f.o.b. Batavia, Soerabaja, or other Java ports, are comparatively high; no export duty is payable on rubber, and no Government requirements are enacted in regard to accommodation for coolies or extraordinary expenditure in connection with hospitals or medical attendance. The books of various plantations show what should be the average cost of producing a pound of rubber during the next few years, and this information itemized gives the following figures :

Cents per Lb.

I. Tapping and collecting (including 50 per cent. depreciation on cups and implements) $\quad \ldots \quad 42$

2. Curing and preparation (including 20 per cent. depreciation on factory and machinery) ... 4

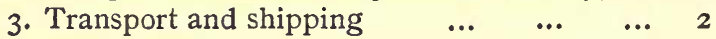

4. Management (exclusive of commissions to

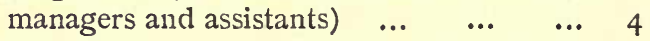

5. Weeding ... $\quad \ldots \quad$... $\quad \ldots \quad$...

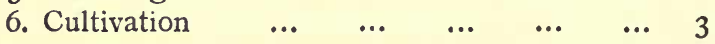

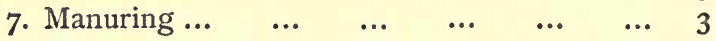

8. Maintenance of roads and drains $\quad \ldots \quad$... 2

9. Depreciation on building other than factory $\begin{array}{lllllll}(20 \text { per cent.) } \ldots & \ldots & \ldots & \ldots & \ldots & 2\end{array}$

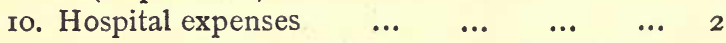

II. Contingencies (including rent and taxes) $\quad \begin{array}{lll}4 & 4\end{array}$

Total $\quad \ldots \quad \ldots . \quad \ldots \quad 70$ 
This sum of 70 cents per pound is equal to Is. $2 \mathrm{~d}$. sterling, and represents the minimum average cost f.o.b. for some years to come. The expenditure for tapping and collecting is unduly high, but for reasons already set out it is difficult to see how any substantial economy is to be effected under this heading in the immediate future. As the trees increase in yield, the cost of tapping and collecting will diminish ; but owing to the labour conditions in Java, the reduction in cost will not be nearly so marked as in the case of Malay and Ceylon, where the system of work is better organized.

The foregoing estimate concerning cost of production shows that 80 per cent. is for expenditure on labour. It is clear that in Java the factor of efficient supervision is of very great importance. Together, management and labour amount to $5^{8}$ cents out of a total expenditure of 70 cents per pound of dry rubber. Therefore it is evident that on the ability of the manager and his assistants to control the labour efficiently and economically depends the failure or success of the plantation.

The charges from port of shipment, Java to London, Rotterdam, or Amsterdam, differ very slightly from those in force for Malay and Sumatra. The present rate of freight to London is 77 shillings per 50 cubic feet. To Dutch ports the cost of freight is 5 shillings less per ton, the higher rate for London being on account of transhipment in Holland. Rubber from Java is packed in boxes containing II 2 pounds, averaging ten to the 50 cubic feet. Commissions in Europe are similar to those from Malay and Sumatra. The total charges are- 
I. Freight

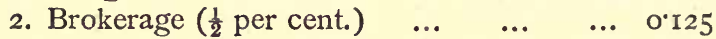

3. Sale charges, insurance, storage, sundries

$\begin{array}{llllll}\left(I \frac{1}{2} \text { per cent.) }\right. & \ldots & \ldots & \ldots & \ldots & 0 \\ 0 & 375\end{array}$

4. Merchants' commission (I per cent.) $\ldots 0^{\circ} 25$

Total $\ldots \quad \ldots \quad \ldots \quad \overline{\mathrm{r} 570}$

These charges are calculated on an average price of 24 pence per pound of rubber.

Adding the cost of production f.o.b. port of shipment in Java, together with the further costs up to date of sale in Europe, the actual total cost is-

I. Cost of production f.o.b. Pence.

$\begin{array}{llllr}\text { 2. Freight, insurance, etc. } & \ldots & \ldots & \ldots & \mathrm{I} 4{ }^{\circ} \mathrm{OO} \\ \end{array}$

$\begin{array}{lllll}\text { Total } & \ldots & \ldots & \ldots & \text { I } 557\end{array}$

As regards past production in Java, the amount shipped is insignificant so far as Pará rubber is concerned. The official returns classify gutta-percha, Rambong, and Pará under the same heading, but with some difficulty the two former have been separated. The return of Pará shipments beginning in I909, were-

Exports AND Production, 1909 to r913

\begin{tabular}{|c|c|c|c|c|c|}
\hline Year. & Tons. & Acres Bearing. & \multicolumn{3}{|c|}{ Remarks. } \\
\hline 1909 & 40 & 600 & \multicolumn{3}{|c|}{ About 20 tons to Singapore } \\
\hline I910 & 70 & 1,000 & 40 & $"$ & $"$ \\
\hline I9I I & 99 & 1,600 & 73 & $"$ & $"$, \\
\hline I9I2 & 530 & 10,000 & $" 100$ & $"$ & $"$ \\
\hline r913 & 1,760 & 40,000 & $"$ I 50 & $"$ & $"$ \\
\hline
\end{tabular}


Estimated Future Production, I9I4 to i921

\begin{tabular}{|c|c|c|}
\hline Year. & Tons. & Acres bearing. \\
\hline I914 & 10,650 & I58,000 \\
I915 & 18,300 & 208,000 \\
I916 & 26,550 & 230,000 \\
I917 & 32,300 & 233,000 \\
I918 & 38,250 & 240,000 \\
I919 & 43,650 & 240,000 \\
I920 & 44,500 & 240,000 \\
I921 & 46,000 & 240,000 \\
\hline
\end{tabular}

The above is calculated on the following basis:

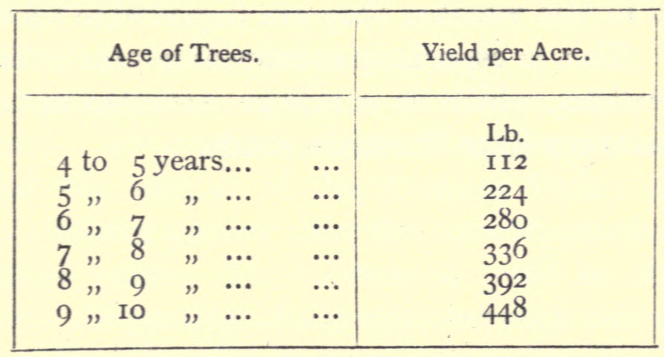

Taking into consideration that a large proportion of the younger rubber suffered in past years by interplanting with Liberian coffee and from careless cultivation, from which it is only now recovering, this basis for calculating future production may be considered a sound one.

The amount of Rambong (Ficus) rubber exported in I9Io was 228 tons; but this dropped off to practically nothing in I9II, for the reason that the high prices of the previous year induced planters to tap the Ficus trees heavily, and they had not recovered sufficiently to 
yield any latex worth collecting. The export of guttapercha in Igro was 300 tons, but in I9II the shipments dropped to 45 tons, the falling off being due to the same cause as occurred with the Ficus.

The railway system is being gradually extended throughout the island, and in the course of a few years will provide access to all the principal districts; but the roads which act as feeders to the various railway lines leave much to be desired. Except in the vicinity of the larger towns, the maintenance of all roads and bridges is neglected. First-class Government roads are metalled; but second-class roads have only an earth surface levelled off, and in wet weather they are impassable for wheeled traffic. This is especially inconvenient for rubber and coffee estates, which as a rule are situated at considerable distances from the main roads. 


\section{CHAPTER XX}

\section{A BRIEF REVIEW OF THE ORIENTAL SI'TUA'TION}

Past and future production in the Orient-Estimated production from 1914 to 1919-Consumption and production-The labour question in the Orient-Effects of diseases and pests on future development-Premium of Amazon Valley rubber over the plantation product-Average total cost of plantation rubber to date of sale-The question of the black and white varieties of Hevea Brasiliensis.

B OTH in the Orient and Brazil the year I9I3 was industry. Production on the Eastern plantations exceeded the output of the Amazon Valley by 25 per cent., and was greater than the total shipments from all Brazilian ports. This increased yield in the Orient signifies the parting of the ways between cultivated and wild rubber, for the Eastern production for I9I4 will surpass by a substantial amount the aggregate wildrubber output in all parts of the world. The dominant factor in the rubber situation from now onwards will be undoubtedly the returns from plantations, and the supplies from wild sources will steadily recede into the background. That production in the Amazon Valley and the Congo territories should cease altogether is by no means a corollary of the conditions now in process of development; the general indications are that Brazilian and African wild rubber will continue to come forward, but the shipments will be smaller in quantity, 
and principally confined to the higher grades. While this reduced output may retain a premium in value for some years to come over the Oriental product, for reasons hereafter explained, its importance as a factor influencing market prices will decline in direct proportion to the progress of the plantation industry, and the occasion for its use in the manufacture of rubber goods will practically become a negligible quantity within the next decade. It will become a luxury instead of a necessity.

The subject of the area under cultivation and the steady increase in production leading up to the existing conditions of to-day has been dealt with in detail in the description of the principal centres of the industry in the East. It is unnecessary, therefore, to recapitulate more than the returns for IgI2 and IgI3, to demonstrate clearly the expansion of the output and the close relation of the increased quantity to the shrinkage in the market value. The Oriental shipments for the past two years are shown in the table on p. 293.

In regard to future production, the yield has been calculated until IgIg upon the acreage planted in IgI2, and leaving out of account any returns from areas planted after that date. Under these conditions, the total acreage on which production is based in I9I9 will comprise trees averaging ten years of age, equal in girth and height to trees of twenty to twenty-five years old in the Amazon Valley. Doubtless with increased development a greater yield will be obtained than at ten years, but for practical purposes the trees may be considered as having reached maturity, and the quality of the latex will show little difference in regard to density after that period is passed. 


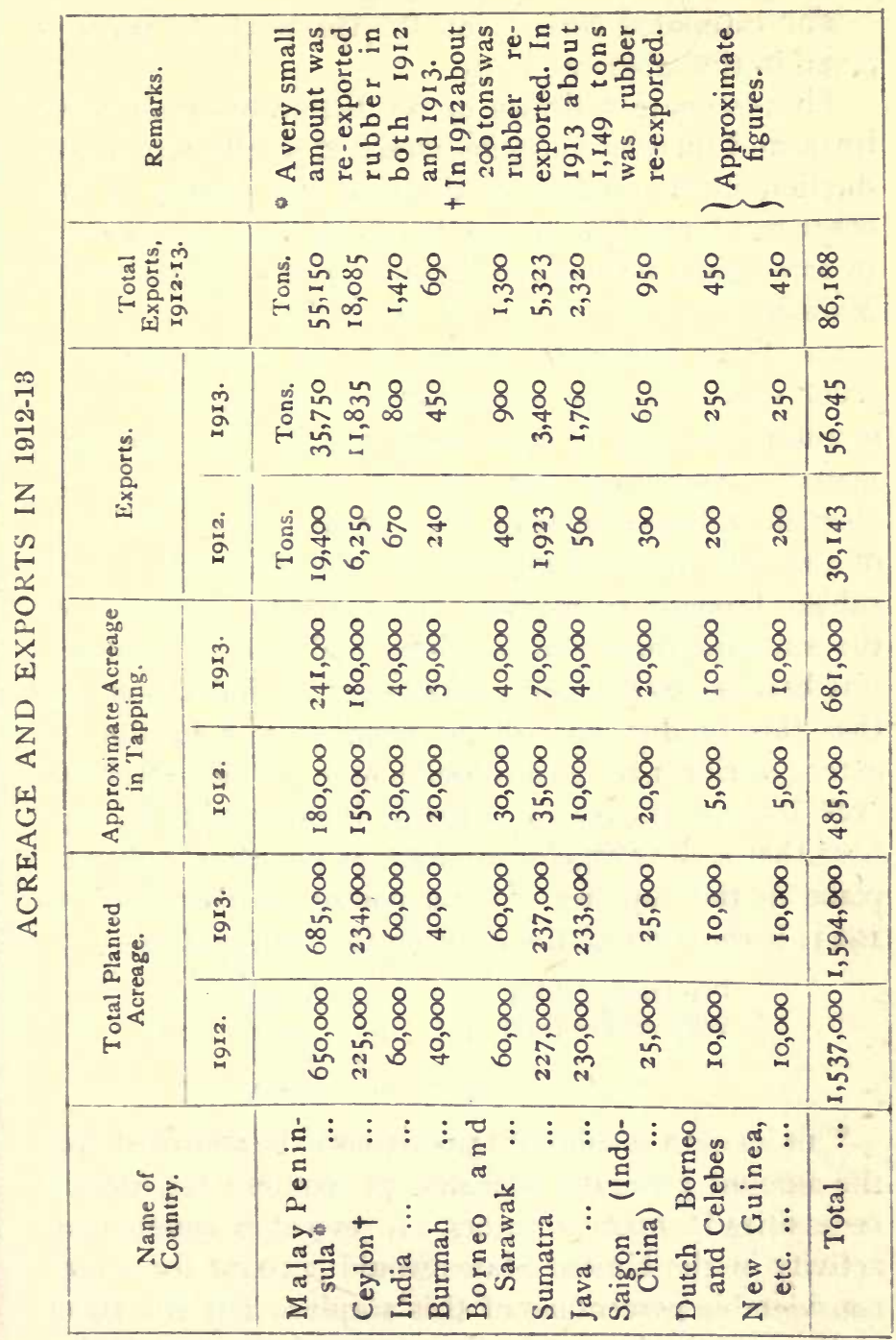


The estimated production for the next six years is given in the table on p. 295.

This estimate is drawn up on distinctly conservative lines, and therefore may be exceeded by the actual production in the course of the next few years; on the other hand, the figures may be above the mark in event of some great unforeseen disaster to the plantations in Malaya.

So far as published returns of the consumption of crude rubber go, they show the amount used by manufacturers in I9I3 to have been IIO,000 tons approximately. Assuming that 120,000 tons are needed to meet the $d$ smand in I9I4, the question of a sufficiency of the raw material depends on the quantity of wild rubber brought to market. In I9I3 the aggregate of the supplies from Brazil, Africa, and Central America, was between 65,000 and 70,000 tons; the indications are that this production will be curtailed to a substantial extent during IgI4 and subsequently. This year, however, in view of present prices, it is reasonable to suppose that a shrinkage of at least 35 per cent. will take place in the supplies of wild rubber as compared to I9I3; if this occurs, the position for I9I4 will be-

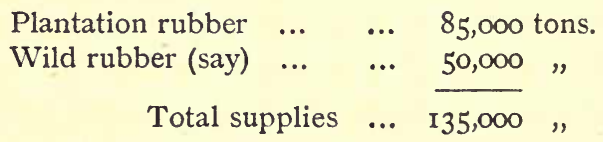

This leaves a surplus of $\mathrm{I} 5,000$ tons to be absorbed over the amount generally accepted as required for normal necessities by manufacturers. A revival of commercial activity in the United States would account for a very considerable percentage of this surplus; but the effect of the over-production in the course of the next twelve 
REVIEW OF THE ORIENTAL SITUATION 295

\begin{tabular}{|c|c|c|c|c|c|c|c|c|c|c|c|c|}
\hline \multicolumn{2}{|c|}{ 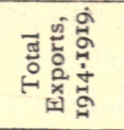 } & & $\begin{array}{l}8 \\
8 \\
8 \\
-1\end{array}$ & $\begin{array}{l}8 \\
\text { \& } \\
\text { भे }\end{array}$ & हీ & $\begin{array}{l}8 \\
3 \\
7\end{array}$ & $\begin{array}{l}8 \\
\text { in } \\
m \\
n\end{array}$ & $\begin{array}{l}8 \\
\text { Na } \\
8 \\
0\end{array}$ & 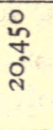 & $\begin{array}{l}8 \\
\text { लू } \\
\text { ले }\end{array}$ & $\begin{array}{l}\text { \& } \\
\text { ली }\end{array}$ & $\begin{array}{l}8 \\
+ \\
8 \\
= \\
=\end{array}$ \\
\hline \multirow{6}{*}{ 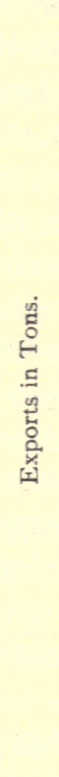 } & ఏ్ర & $\begin{array}{l}8 \\
8 \\
0 \\
0\end{array}$ & $\begin{array}{l}8 \\
8 \\
i \\
+\infty\end{array}$ & $\begin{array}{l}8 \\
\dot{n} \\
-1\end{array}$ & 8 & $\begin{array}{l}8 \\
0 \\
0\end{array}$ & $\begin{array}{l}8 \\
\text { f }\end{array}$ & $\begin{array}{l}\text { 을 } \\
\text { ஸ̂ } \\
\text { y }\end{array}$ & 总 & 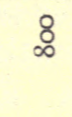 & $\stackrel{\infty}{\circ}$ & $\begin{array}{l}\text { 웅 } \\
\text { o } \\
\text { o }\end{array}$ \\
\hline & 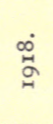 & $\begin{array}{l}\stackrel{\circ}{\Re} \\
\text { ल̂ } \\
=\end{array}$ & 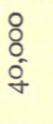 & $\begin{array}{l}8 \\
8 \\
0\end{array}$ & $\begin{array}{l}8 \\
i \\
i n \\
1\end{array}$ & $\begin{array}{l}8 \\
0 \\
0\end{array}$ & $\begin{array}{l}\text { ৪ } \\
\text { ले }\end{array}$ & $\begin{array}{l}\text { 을 } \\
\text { N } \\
\text { of } \\
\text { m }\end{array}$ & $\stackrel{\circ}{\stackrel{\circ}{\mathfrak{f}}}$ & 8 & $\stackrel{8}{\circ}$ & $\begin{array}{l}\text { 을 } \\
\text { on } \\
\text { on } \\
\text { wn }\end{array}$ \\
\hline & 灾 & 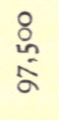 & $\begin{array}{l}8 \\
\text { in } \\
\text { m }\end{array}$ & 8 & $\begin{array}{l}8 \\
0 \\
1\end{array}$ & $\underset{\infty}{8}$ & $\begin{array}{l}8 \\
0 \\
\text { di }\end{array}$ & $\begin{array}{l}8 \\
\text { क̂ } \\
\text { î }\end{array}$ & $\begin{array}{l}8 \\
8 \\
f\end{array}$ & 8 & 8 & \begin{tabular}{l}
8 \\
0 \\
\multirow{2}{4}{}
\end{tabular} \\
\hline & $\begin{array}{l}\dot{0} \\
\text { a }\end{array}$ & $\begin{array}{l}\stackrel{8}{\circ} \\
\circ \\
\infty\end{array}$ & $\begin{array}{l}8 \\
8 \\
0 \\
0\end{array}$ & 8 & 8 & $\begin{array}{l}8 \\
\text { in } \\
\text { nn }\end{array}$ & 8 & 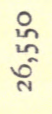 & $\begin{array}{l}8 \\
\text { i }\end{array}$ & $\stackrel{\circ}{\stackrel{\circ}{q}}$ & 옴 & 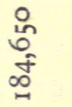 \\
\hline & 岕 & 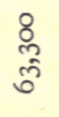 & $\begin{array}{l}8 \\
\text { in } \\
\text { n. }\end{array}$ & 8) & ৪ & $\begin{array}{l}8 \\
i \\
i\end{array}$ & $\begin{array}{l}8 \\
8 \\
\text { I }\end{array}$ & $\begin{array}{c}\text { \& } \\
\text { ó } \\
\text { oీ }\end{array}$ & $\underset{8}{8}$ & 品 & 윾 & $\begin{array}{l}8 \\
\infty \\
-\infty \\
=\end{array}$ \\
\hline & 苟 & 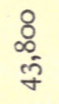 & $\begin{array}{l}8 \\
\text { in } \\
\text { in }\end{array}$ & $\begin{array}{l}8 \\
8 \\
i\end{array}$ & $\underset{-8}{8}$ & 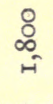 & $\frac{8}{\infty}$ & 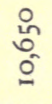 & $\begin{array}{l}\text { ¿্ } \\
-1\end{array}$ & \& & \&్ల & 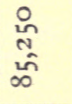 \\
\hline \multicolumn{2}{|c|}{ 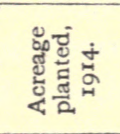 } & $\begin{array}{l}8 \\
0 \\
\text { î } \\
0\end{array}$ & 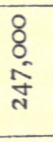 & $\begin{array}{l}8 \\
8 \\
8\end{array}$ & $\begin{array}{l}8 \\
8 \\
0\end{array}$ & $\begin{array}{l}8 \\
8 \\
8\end{array}$ & $\begin{array}{l}4 \\
8 \\
0 \\
0\end{array}$ & $\begin{array}{l}8 \\
8 \\
0 \\
0 \\
4\end{array}$ & $\begin{array}{l}8 \\
\text { ली } \\
\text { ले }\end{array}$ & $\begin{array}{l}8 \\
8 \\
0\end{array}$ & $\begin{array}{l}8 \\
0 \\
0\end{array}$ & 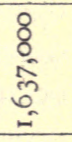 \\
\hline \multicolumn{2}{|c|}{ 这 } & 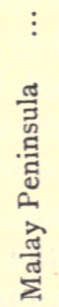 & 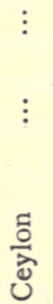 & 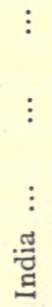 & 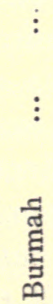 & 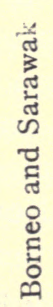 & 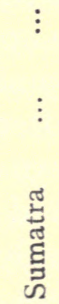 & 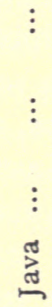 & 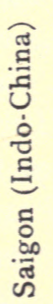 & 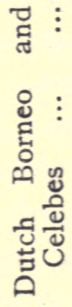 & 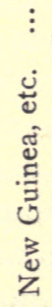 & $\begin{array}{l}\vdots \\
\text { 푱 } \\
0\end{array}$ \\
\hline
\end{tabular}


months will be felt in many directions, and it will probably be reflected in the price of the raw material.

The cry is often raised that a shortage of labour will restrict the production of Eastern plantations. There is nothing in the present situation to justify alarm in this direction. From time to time complaints are heard from planters that more coolies are needed; but such complaints have been made for many years past, and yet the industrial development of the countries now under review has not been checked by any serious labour difficulties. Taking a broad view of the situation, it is impossible to foresee any great set-back from this cause so long as India and China remain open as recruiting-grounds for plantation hands. An adjustment of the wage rate may be necessary as time goes on, and many details in connection with the labour-supply require careful consideration as the situation develops; but the coolies are there in abundance, and must work or starve, therefore it is only a question of adapting conditions to fit the case.

The experience for the last ten years of the damage by diseases and pests to rubber-trees in the Orient, has demonstrated beyond question that no serious loss occurs when adequate vigilance is maintained, and the proper remedies applied to check the spread of the various plagues which appear from time to time on the plantations. This opinion is confirmed by the late Dr. Jacques Huber, after an examination of the principal centres of Eastern production, in a report to the Governor of Pará dated November, I9I2. Dr. Huber states that he was greatly impressed by the magnificent appearance of the trees in all the districts he visited of Ceylon, Malay, Java, and Sumatra. 


\section{REVIEW OF THE ORIENTAL SITUATION}

That fine hard Pará should command a premium of $6 \mathrm{~d}$. (and often more) per pound over the best plantation descriptions would at first sight appear an anomaly. It is more striking when the fact is remembered that the Brazilian rubber often contains 20 per cent. of moisture, as against $\frac{1}{2}$ per cent. in the plantation product. In this connection, the action taken by the Rubber Growers' Association in the autumn of I9I3 was distinctly a step in the right direction. The suggestion to standardize the preparation of latex on the estates is worthy of all consideration, but it would be extremely difficult, if not impossible, to bring any such practice into general use under existing conditions; on the other hand, the proposal to grade all rubber before sale is a practical measure that can be applied with advantage, and should be supported by all Eastern producers. The causes for the lower value of plantation rubber as against fine hard Pará are the following:

Variability. - The practice of treating latex with acetic and other acids tends to bring about unevenness in the rubber, for the reason that each estate applies these coagulants at the discretion of the manager, and therefore without any fixed standard of quantity. The fact that on the more important plantations the percentage of acid is regulated by competent chemists does not affect the general result ; moreover, the majority of producing estates are tapping trees of different ages, and the latex is mixed in a common receptacle on arrival at the factory. It is evident that the product of four-yearold trees requires different treatment from that obtained from trees ten years of age; it would be interesting to know the proportion of plantations making any distinction in regard to the different classes of latex col- 
lected during the day's work, and to compare the final results with the output of estates where no attempt at such distinction has been made. In the Amazon Valley the latex is of much more even quality than in the Orient ; in many extensive districts the variation in density is barely perceptible; the trees in tapping are all of mature age, and the method of coagulating the latex by immersing in the smoke of the Urucury nut is a guarantee that no excessive absorption of carbonic acid can take place. The difference in quality of rubber from Pará is due to the different varieties of the Hevea $B$ rasiliensis common to different sections of territory, and not to any variation in methods of preparation.

Another cause for variability in the plantation product is the rolling and tearing of the rubber sponge after coagulation; in the case of the Brazilian product no manipulation whatever takes place after the latex is coagulated, and the excess of moisture saturated with carbonic acid remains in the rubber and acts as a preservative.

Grading.-No adequate system of grading plantation rubber has yet been attempted. It is not sufficient to separate the rubber into four or five classes, as is done at the present time in the Orient; the finer qualities should be subjected to classification by experts before shipment, or by laboratory tests after arrival in London or Liverpool, as suggested recently by the Rubber Growers' Association. In the Amazon Valley the grading is done by experts at the port of shipment, and the effectiveness of this operation is proved by the willingness of manufacturers to purchase large consignments of Pará rubber on the classification set out in bills of lading. 
Resiliency.-There is no doubt whatever that rubber of greater resiliency and better nerve is obtained from the latex of mature trees than from young plantations. It is a question of opinion as to the age at which trees in the Orient may be said to reach maturity under the existing conditions of cultivation; but on broad lines, based on average density of latex, the period may be placed at from eight to ten years from the date of planting. The advantage enjoyed by the Amazon Valley in this respect, therefore, is only a passing phase which will be rectified automatically in a very few years. After the year IgIg the latex from immature trees in the Orient will be a negligible factor, for it will never exceed 5 per cent. of the total production, and probably fall much below that figure.

Three causes in the last twelve months have contributed to reduce the "all in" costs of rubber. The first was the fall in value of the raw material, leading to the reduction of all ad valorem charges and commissions; the second was the abolition of the $2 \frac{1}{2}$ per cent. and $\frac{1}{2}$ per cent. for draft and allowance to buyers; and the third was the revision of the dock and warehouse charges in London. The combination of these three factors diminish the costs between shipment and sale by approximately 2 pence per pound. Under present conditions the average cost per pound of rubber during the next quinquennial period should not exceed, for the countries specified, the figures given in the table on p. 300. These average costs compare with 28 pence per pound of rubber for the crop season I9I2-I3 in the Amazon Valley.

It is asserted in the Amazon Valley that the superiority of the Brazilian rubber from the upper 
rivers is due to the preponderance in those districts of the variety of Hevea Brasiliensis known locally as the black Hevea, and that the trees in the vicinity of the River Tapajoz, whence Mr. Wickham obtained the seed for the Orient in 1875 , are all of the white variety, producing rubber of an inferior quality. It is true that the product of the lower portion of the Amazon Valley is distinctly inferior to that shipped from the districts of the upper rivers, and does not come under the

Estimated Cost of Production, igr4-igig

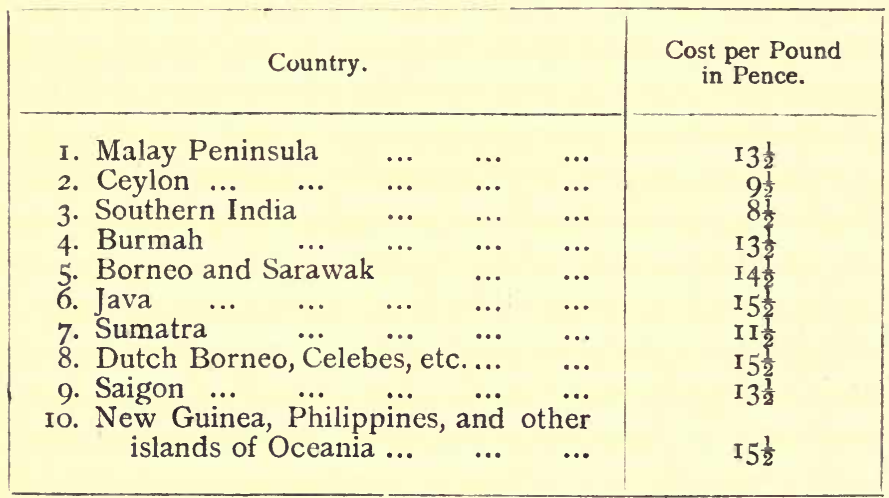

designation of fine hard Pará ; on the other hand, the difference of soil and the effects of cultivation have altered many characteristic features of the tree as regards foliage, development, and production. All indications tend to show that a decided improvement has taken place in the general condition of the tree in its present surroundings, and it is not surprising this should be the case when all the circumstances are given due consideration. In IgI 2 an attempt was made by Dr. Jacques Huber to differentiate between 


\section{REVIEW OF THE ORIENTAL SITUATION 3OI}

the trees growing in the Orient and those found in the vicinity of the River Tapajoz; but in his report to the Governor of Pará on this subject he states his inability to afford any accurate definition of the changes that have occurred without first making a detailed investigation of the district in the Amazon Valley whence the seed for the Eastern industry originated.

In one place only is the black Hevea known to exist in the Orient. On the Pasir Oetjing Estate, near Bandoeng in Java, some I20 trees, now fourteen years of age, are to be seen. They were obtained through the assistance of M. Eugène Poisson in 1889 , and forwarded by him to Paris ; the seeds were there germinated, and the surviving plants were shipped to Java in I89o, and planted at Pasir Oetjing. The following extract from the Journal d'Agriculture Tropicale (published in Paris) on May 3I, I904, in connection with M. Poisson's investigations concerning the black variety of $H$ evea Brasiliensis, is most interesting reading :

“ Nous les avons encadrées de deux passages qui s'y rattachent extraits de l'excellent Rapport de M. Eugène Poisson sur sa mission au Brésil, aux Antilles et au Costa-Rica, publié dans le tome X. (IgO2) des ' Nouvelles Archives des Missions scientifiques.'

“Le premier passage (pp. 7 et 8 du tirage à part) se rapporte au premier voyage, accompli de Février à Juillet 1898 , l'autre (pp. 24, 25) au deuxième voyage accompli de Décembre 1898 à Octobre 1899 . Ce qui y est dit incidemment du Mangabeira, confirme l'appréciation que nous avons donnée de cet arbre dans le chapitre correspondant de notre traduction annotée des Plantes à caoutchouc de Warburg. 


\section{THE RUBBER INDUSTRY}

"Pour ce qui est de l'Hevea, on remarquera que M. Poisson n'ose pas se prononcer sur la question de savoir s'il s'agit de variétés ou d'espèces nettement définies. Le doute ne tardera pas à être levé, la maison Godefroy-Lebeuf ayant pu se procurer des graines des deux Hevea. Grace à son initiative, ils vont prendre place dans les cultures industrielles ainsi que dans les collections scientifiques. D'ici quelques années, on les verra fleurir et fructifier; on pourra semer les graines recueillies, et on sera définitivement fixé sur la constance et la portée taxonomique des caractères. Voici les termes exacts de la description qu'en donne M. Eugène Poisson :

“ 'Dans les forêts avoisinant Pará, où je me suis rendu et où j'ai vécu pendant plusieurs jours et à diverses reprises pour assister à la récolte du caoutchouc, j'ai appris des Indiens qu'ils distinguaient deux sortes d'abres qu'ils appellent l'Hevea blanc et l'Hevea noir, en raison de l'apparence plus foncée de l'écorce et du feuillage de l'un d'eux. Il paraîtrait que le caoutchouc noir donne un latex plus estimé que le blanc et que le mélange des deux formerait un produit supérieur à celui qu'on obtiendrait séparément. Cependant, j'ai la conviction qu'on cherche à éviter la récolte séparée de ces deux latex parce que cela donnerait plus de peine et entraînerait peut-être une moins-value pour la sorte inférieure. S'agit-il ici d'espèces distinctes ou simplement de variétés d'Hevea? C'est un point à élucider, qui a été abordé jusqu'alors sans un réel succès et dont il sera parlé plus loin.

" 'Les tentatives que j'ai faites pour obtenir des rameaux n'ont été que peu fructueuses. Les seringueros sont méfiants et croiraient agir à leur détriment en 


\section{REVIEW OF THE ORIENTAL SITUATION 303}

aidant les Européens à se renseigner sur des pratiques qu'ils se soucient peu de faire connaître; d'autre part, la difficulté d'atteindre le sommet d'arbres éléves est encore un obstacle à vaincre.

" " J'ai dû me contenter de quelques feuilles tombées de ces arbres, dont la floraison est éphémère et capricieuse, et de les conserver en herbier, en attendant une nouvelle occasion de retourner dans ces parages afin de poursuivre ces observations. . . .'

" Et plus loin :

" 'Dans la grande île de Marajó, ainsi que dans les autres îles du delta et de la Basse Amazone, y compris les territoires du Xingu et du Tocantin, les seringueros reconnaissent, dans les Hevea qu'ils exploitent, deux sortes d'arbes dont j'avais déjà parlé dans la première partie de mon rapport de 1898 . Je ne puis assurer que ce sont deux espèces ou deux variétés, n'ayant $\mathrm{pu}$, au moment où je me trouvais au Pará, les voir comparativement en fleur et en fruit, mais les organes de végetation sont certainement distincts. Il est possible que ce soit deux races de l'Hevea brasiliensis; mais, à la simple vue, elles sont différenciées par la couleur de l'écorce, par le port de feuillage et la nuance de celui-ci :

" " I-Le Branco, ou blanc, a les feuilles d'un vert clair, et elles sont tombantes, larges et longues par rapport à la seconde forme, leur sommet est très-acuminé, souvent elles sont tachetées de piqûres d'insectes; les folioles pendent presque verticalement et le pédoncule commun est également infléchi;

" ' 2 - Le Preto, ou noir, pousse plus vite et plus droit; il branche beaucoup plus haut. Sur les jeunes arbres comme sur les adultes, le port du feuillage est différent du Branco. Le pétiole commun est ici plutôt 
relevé qu'infléchi, et il forme même un coude avec les folioles qui sont encore plus relevées que lui.

" 'Je n'ai pas remarqué les taches de piqûres d'insectes fréquentes sur le Branco, et peut-être peut-on attribuer ce fait à une plus grande résistance de l'épiderme.

"J'ai pris des photographies de ces deux formes d'Hevea.

“Les seringueros prétendent que l'Hevea noir a un latex qui coule plus facilement et qu'il est plus riche en caoutchouc que l'Hevea blanc. Il ne m'a pas été possible de contrôler ces assertions, faute de latex suffisant de chacune des deux variétés. Un des avantages de l'Hevea noir serait de prendre plus facilement de bouture que le blanc.

"J'ai vu un essai de plantation de boutures du Preto de I à 2 centimètres de diamètre et de 2 mètres de long, et pas une de ces boutures n'a manqué à la reprise. Cependant, je dois dire qu'il m'a paru que les plante venus de ces boutures n'avaient pas en général la même vigueur que ceux issus de granes.

"J'ai vu, à la localité de Maguary, quelques Hevea blancs, de 8 ans de plantation et ayant un diamètre de 22 centimètres à 25 centimètres sur 9 mètres de haut. Entre Benevides et Benfique, chez un propriétaire italien, M. Frediana, se trouve une plantation d'Hevea et d'arbres fruitiers, et personne dans la contrée ne semble la connaître. J'y ai vu, entre autres, 6 Hevea noirs plantés, il y a onze ans et ayant 95 centimètres à 99 centimètres de circonférence, à I mètre du sol. Ce propriétaire a planté en I896-I898, sur sa concession près de 5,000 Hevea. C'est un domaine qui vaudra dans cinq ou six ans 50 à 60 contos." 


\section{N D E X}

ACETIC acid, use of, for coagulation, 86, I4I, I93, 297

Acheen, Sultan of, 228

Acre, 12, 32, 34, 37, 79, 90, 98, I03, I06, I I 2

Adam's Peak, I32

Aliança (Amazon Valley), tapping tests at, 84,85

Alutgama, I 30

Amazon delta, 27 ; estrada system, 29 ; tapping, 29 ; prospective output, 29 ; labour-supply, 30 ; treatment of trees, 30

islands and lowlands of, 27 ; abundance of trees, 28 ; poor quality of trees, 28 ; inhabitants, 28 ; overhead tapping, 32,67 ; yield, 78

highlands of, 28 ; plantations, 28 ; crops, 28 ; rubber seedlings, difficulties of, 29

Amazon, River, 6, Io, 47, 98

Amazon Steam Navigation Company, 98

Amazonas, 18, 20, 105, 106, II3, I I4

Amsterdam, cost of shipments to (Sumatra), 257

(Java), 287

Anæmia, I3

Andes, 36

Anglo-Malay Company, 220, 222

Ant, white (termes), (Amazon Val-

ley), 40, 49 ; (Ceylon), I 34 ;

(Malay Peninsula), I68;

(Sumatra), 237, 252

red (Ecodoma cephalotes), 40, 49-50, I 24

Antwerp, cost of shipments to (Malay Peninsula), 224

(Sumatra), 257
Anuradhapura, I 32

Aquiry, River, 6

Arabs (Java), 276, 277

Araguaya, River, 6, 23, 102

Asahan, 228, 229, 23I, 233, 234,

235,254

Atmosphere, effect of, on bark excision (Amazon Valley), 80

(Ceylon), $\mathbf{1 4 2}^{2}$

"Avenue planting," 212

Aviadores, 59, 61, 100

Axioma (Amazon Valley), tapping tests at, 84

Ayer Panas Estate, 222

Balls (pelles). See Pelles

Bandoeng, 26I, 262, 265, 301

Bangoewani, 261, 262, 274, 285

Banjar, 26I, 262, 285

Banjasari, 262, 284, 285

Banjoemas, 26I, 262, 284, 285

Bantam, 26I, 262, 285

Barbadoes, I4

Bariguda, 4

Bark disease (Amazon Valley), 40, 4I, 43-8

(Ceylon), I34

(Java), 284

Bark, renewal of, $74,142,160$, $2 \mathrm{I} 4$

Batak Rabit Estate, 222

Batavia, 26I, 262, 286

Bates, "Naturalist on the Amazon," 49

Batoe-Bahra, 229, 234

Batoe Lawan, 262, 285

Batu Caves Company, 220

Batu Gajah, 179, I $\delta 0$

Baud, 262

Beans, 62,63

Belawa, 229 
Belmont Estate, 219

Benevides, 304

Benfique, 304

Beni, River, 6, 7, 12, 23, 34, 35

Bentong, I79, I80

Benzine, solubility of rubber in, 2

Beri-beri, I2

Bernham Estate (Perak), 2 I 9

Besoeki, 26I, 263, 264, 274

Bila, River, 229, 230, 233, 235,

253, 254

Blackstone engines, 192

Black water fever, I2

Blankahan Estate, 254

Bolivia, 5, 6, 7, I2, I4, I8, 27, 34, $35,37,54,6$ I $, 79,98$, I03, I I 2

Bolivians, I3

Booth Steamship Company, 6, 48

Borer (Amazon Valley), 40, 48-9, $66,69,124$

(Ceylon), I 34

Borneo, I 85

Boundaries, definition of (Amazon Valley), I6

Bovis, Mr. A., 265

Brahminism (Java), 277

Brain, Mr. Lewton, I68

Branca (white variety of Hevea Brasiliensis, 3, 28, I 20, 302, 303, 304

Branching, early, I 54-5

Brazil, 20, 24, 29, 37, 49, 62, I I 2

Brazilians, I 3, 54, 60, I 12, I 22

Bridge patent (machines), I 92

British Guiana, 54

British North Borneo, nominal capital of companies exploiting, I 85

Bubonic plague, 280

Buddhism (Java), 277

Buitenzorg, 261, 262, 264, 265

Bukit Kajah Company, I82, I94, $219,220,222$

Bungalows (Ceylon), cost of building, I35

(Malay Peninsula), 2I6; cost of building, 188

(Sumatra), cost of building, 241

(Java), 269

Burgess knife, I24, 214
Burmah, 185

Burrs, formation of, I 68

Cables (Amazon Valley), 23

Cacao, cultivation of (Amazon Valley), 7

(Ceylon), I 33

(Java), 273

Cachoeira, 36

Calcutta, 54

Caledonia Estate, 219,222

Cambium rot (Amazon Valley), 40, $4 \mathrm{I}, 43-4,47-8,65,69,74$, 80,82

(Ceylon), 134, 284

Canker (Amazon Valley), 40, 4 I

(Ceylon), I 34

(Java), 284

Canoes, 22, 24, 29, 31, 99

Canton, I87

"Caoutchouc," 2

Carbolineum Plantarium, use of, for decay, 46

Carey United Company, 220

Castilloa elastica, 3, 5, 34, 35, 7 I-2, 79, I02, I03, I I 2, I 20, I 26, I64, 264,265

Cataracts, 22, 36

Catch crops (Ceylon), I4O

(Malay Peninsula), 212, 213

(Sumatra), 236, 252-254

(Java), 265, 28I-2

Caucho, 3, 5, 27, 34, 35, 72, 79, 80 , IO2, IO3, I I 2, I 20

Ceará, 5, I 4, 32, 35, 52, 53, 54, 76, I2I, $164,264,265$

Cedar, red, 7

Ceylon : growth of trees in, 73 ; no direct taxation in, 108 ; proposed school of tropical agriculture, I 29; separated from Madras Presidency, I29; agricultural industry of, I29; sap disease in coffee plantations of, 129; cultivation of cinchona and tea in, I30; of rice, cacao, and coconuts in, I33 : Government Department of Agriculture, I46 ; Government Medical Officers, I6I; nominal capital of companies exploiting, I 85 
Chaffee and Haskins, 2

Changkat Salak Estate, 219, 222

Children as labourers (Amazon Valley), 57-8, 122

(Ceylon), 138, 141, I6r

(Malay Peninsula), 204

(Java), 282

Chinese (Malay Peninsula), 167, 170, 173, I82, 195, 206, 207 , 208, 209, 212,215

(Sumatra), 231, 249, 250, 25 I (Java), 276, 277

Cicely Company, 182, 219, 220, 222 Cinchona, I30; collection of bark, 7

Clay, use of, as check to borer, 49 Cleaning, cost of, on new plantations (Sumatra), $24 \mathrm{I}$

(Java), 269

Cleanliness: importance of, in preventing tree disease, 48 ; lack of, arrests development, 74 ; not practised by collectors, 75,93 ; attention given to, in East, I 24 ; none in Brazil, 124; dependent on supervision, 210

Climate (Amazon Valley), Io, 92, 99

(Java), 274

Coagulation (Amazon Valley), method of, 91-4, 125

(Orient), method of, I 24

(Ceylon), I4I ; experiments to produce, by smoking process, 143

(Malay Peninsula), process, 192-3

(Sumatra), process, 246

Coast (beri-beri), 179

"Coast advances" (Ceylon), I 36

Coast-town hospital, 179

Coca, 273

Coconuts (Ceylon), I 33

(Malay Peninsula), 173

(Java), 273, 276

Coffee, decadence of industry (Ceylon), 129,130

(Malay Peninsula), 166, 167, 177

Coffee, Liberian (Sumatra), 254, 257
Coffee, Quillou (Java), 281, 285 ।

Robusta (Malay Peninsula), 212

(Sumatra), 229, 236-7, 238,252

(Java), 265, 277, 281, 285

Uganda (Java), 281, 285

Collection (Ceylon): working costs of, I 37 estimated future, 139

(Malay Peninsula), proportionate cost of, to pound of rubber, 126; working costs of, 189,221 ; estimated future, 223

(Sumatra), working costs of, 242 ; estimated future, 256

(Java), working costs of, 271, 272, 286

Collectors (Amazon Valley): poverty of, 28 ; lack of supervision over, 29 ; allotment of estradas to, $3 \mathrm{I}$; rule as to overhead tapping, 32 ; employment of, 38 ; careless use of machadinho by, 48 ; their freedom from restraint, 55 ; temporary partners with owners, 56,75 , 122 ; supervision of their work entrusted to fiscales, 57 ; cheated by regatones, 58 ; accustomed to supply working implements, 65 ; description of their work, 66 ; careless as to cleanliness, 75 : hardships of, 75-76; precarious position of, 88 ; monthly requirements of, analyzed, 89; compared with Oriental tappers, 91 ; hardships of, in coagulating-shed, 92 ; practice as to delivery of rubber, 96 ; cost of clothing, etc., 108

Colombia, 6, 27, 34

Colombians, 13

Colombo, 130, I38, 141; charges per pound from, to London, I39; exports from, in 1913,164 ; esti. mated, for $1914-1919,165$; price of rubber in, compared with London, I9I

Colombo Commercial Company, I 37

Colonization, difficulties of (Amazon Valley), 9 
Congo, 291

Consolidated Malay Company, 220

Consular fees (Amazon Valley), IOI

Cordillera, 8

Costa, da, records of, kept at Santa Maria Estate, 86, 88

Credit. See Truck system

Creping machines, 137, I4I, I92, 194

Crime (Amazon Valley), 58

(Sumatra), 253

(Java), 280

Crossley and Co., I 37

Crossley engines, 192

Culloden Estate (Ceylon), I45

Cultivation (Ceylon), working costs of, I37, estimated future, I 39

(Malay Peninsula), working expenses of, 189, 22 I, estimated future, 223

(Sumatra), working expenses of, 242 , estimated future, 256

(Java), working expenses of, 271,286

Curing (Ceylon), estimated future expenses of, 139; convenience of present process, I43

(Malay Peninsula), working expenses of, 189,221 , estimated future, 223

(Sumatra), working expenses of, 242 , estimated future, 256

(Java), working expenses of, 27I, 286

Currency, Brazilian, 24-5

Damansara Company, 220

Deli, 228, 229, 232, 234, 235

Devon Estate, 208

Diarrhœa, 210

"Die-back," I68, 284

Diesel engines, 192

Dindings, I 74

Discipline (Amazon Valley), 31, 58

(Ceylon), I62

(Sumatra), 253

(Java), 280
Diseases, 40 et seq.

Djember, 261, 262, 285

Dock dues (Amazon Valley), I00

Doranakandy, I36, I46

Drainage (Amazon Valley), as remedy for bark disease, 4I, 43

(Ceylon), cost of, on new plantations, 135

(Malay Peninsula), cost of, on new plantations, 188 ; working costs of, $189,22 \mathrm{I}$, estimated future, 223

(Sumatra), cost of, on new plantations, 24I; working expenses of, 242, estimated future, 256

(Java), 263; cost of, on new plantations, 269; working costs of, 27 I, 286

Dry season (Amazon Valley), 99, I 21

Dryers, mechanical, I94 ; vacuum,

I 37, I 4 I , I94, 275 ; artificial, I94 Dysentery, I 2, 210, 230, 280

Ecuador, 6, 27, 34

Ecuadorians, 13

Education (Amazon Valley), lack of, amongst children, $5^{8}$

(Malay Peninsula), public schools, 217

Entré fina, 3, 5, 101, 102, 103 , I 2

Estraia system, 29

Export duty (Amazon Valley, I8. 19, I0I, 105, 106, I07, I09, I 14, I I 5, I I6, I 28

(Malay Peninsula), 107, 170, 22I ; proportionate cost of to pound of rubber, 126

(Java), none on rubber shipments, 266, 286

Factory (Ceylon), cost of building, 135, 137

(Malay Peninsula), 191, 192 ; cost of building, 188

(Sumatra), 246 ; cost of building, 241

(Java), 269 
Farinha. See Mandioca

Federated Malay Company, 220

Federated Malay States, growth of trees in, 73; cost of planting trees in, 166 ; export duties, 170 , I 76 ; rubber acreage, 172 ; fixed charges for agricultural lands, 175 ; general revenue, 176 ; rainfall in, 178-80; nominal capital of rubber-producing companies, 185

Federated Selangor Company, 182, 220

Felling and lopping (Ceylon), cost of, on new plantations, I35, I 40

(Malay Peninsula), 187 ; cost of, on new plantations, I 88

(Sumatra), cost of, on new plantations, $24 \mathrm{I}$

(Java), 28I ; cost of, on new plantations, 269

Ficus-trees, 231, 264, 265, 289, 290

"Fine hard Pará," 3, 4, 5, 34, IOI, 102, 103, I1 2, 297, 300

Fiscales, 57

Flies, 12

Fluoric acid, use of, for coagulation, 193

Fomes, 168, 237, 284

Forest land (Ceylon), cost of, I 35

(Malay Peninsula), cost of felling and weeding, 187

Formic acid, use of, for coagulation, 193

Fraca, 4, 5, 28, 101, 102, 103, 120

Fraca fina, 4

Freight rates (Amazon Valley), 99, 100, IOI, I09, 127

(Ceylon), I39

(Malay Peninsula), 127, 194

(Sumatra), 243, 257

(Java), 275, 287

Freudweiler, Mr., 246

Fungus (Ceylon), 134

Galle, 130

Galvez, Colonel, 37

Gardens, 30

Gedong Estate, 219, 222
Glen More, 262, 285

Godefroy-Lebeuf, Mr., 265

Golconda Company, 220

Golden Hope Company, 220

Goma, 3

Goodyear, Charles, 2

Gouge, 42, 69, 77, 80-8, 124; bent, $42,65,67,214$

Grading (Amazon Valley), 100, I0I, 102,298

Grand Central Company, 136

Guaporé, River, 6, 23

Guiana Mountains, I I

Guttapercha, 290

Hai Kee Estate, 222

Hamburg, cost of shipments to, 224 Henaratgoda, "No. 2" tree, 73, $146-8,150,154,155,158$; Ceylon Government gardens at, 86, $133,146,147,158$

Herring-bone system of tapping : full, $42,65,67,77,80,82,86$, $87,123,141$; half, 42,82

Heve. See Hevea

Hevea Brasiliensis, 3, 28, 40, I64, $167,235,264,265,298,303$. See also Preta, Branca, and Vermelho

Hevea Guayanensis, 3, 4, 120

Hevea Spruceana, 3, 4

Highlands and Lowlands Company, 220

"Historia Universal de las Indias" of Orviedo y Valle, I

Holing, lining, and filling, cost of, on new plantations (Ceylon), I 35,137

(Malay Peninsula), 188

(Sumatra), 24 I

(Java), 269

Holland-American Company, 23I

Hong-Kong, 182, 184, 267

Hornsby and Co., 137

Hornsby engines, 192

Hospitals (Ceylon), I6 I

(Malay Peninsula), proportionate cost of, to pound of rubber, 126 ; cost of, on new plantations, 188 ; working costs of, I89, 221 ; provision of, 216 ; 
estimated future expenses of, 223

Hospitals (Sumatra), 250; cost of, on new plantations, 242 , working expenses of, 242 , estimated future, 256

(Java), cost of, on new plantations, 269 ; working expenses of, $27 \mathrm{I}$; Government regulations concerning, 270

Huber, Dr. Jacques, I I6, I68, 296, 300

Igarape-Assu, I I

Immigration, Indian, Superintendent of, 195,196

Import duty (Amazon Valley), I920,59, II 4, II $5,116,128$

(Ceylon), I3 I

Inca period, 35

Inch Kenneth Company, 182, 220

India, nominal capital of companies exploiting, 185

Indians (Amazon Valley), I3, I4, $35,39,52,68$

(Ceylon), 16I

(Malay Peninsula), I7I, I95, 207

Indiarubber, origin of name, 2

Inundations, 9, I77

Ipoh, I 80

Iquitos, 6, 8, I2, I 4, 23, 34, 36, 38,103

Italian immigrants (Amazon Valley), 14,54

Itapirá, 4

\section{Jary, River, 7}

Java: treatment of tree diseases in, 46 ; growth of trees in, 73 ; no direct taxation in, 108 ; agricultural industry of, 260 ; cultivation of coffee, tea, and cinchona in, 260 ; leaf disease in coffee plantations, 260; production of tea compared with Ceylon, 260 ; cinchona, $26 \mathrm{I}$; soil of, 263 ; land tenure, 266 ; land $\operatorname{tax}, 266$; general revenue of, 266 ; nominal capital of rubber-producing companies, 267 ; population, 276
Javanese, I95, 201, 207, 2I 5, 2I 7, $249,250,251,270,277$; form of agreement relating to labourers, 202

Javary, River, 7, 79, 90, IO3

Jebong knife, 214

Johore, I69, I70, I 72, I 73, I74, I76, I78, 21 3

Journal d'Agriculture Tropicale of

May 3I, 1904, 265, 30I

Jugra Estate Company, 220

Juruá, River, $6,12,22,27,30,32$, $34,36,53,56,57,66,67,79,90$, 98 , I03

Jutahy, River, 79

Kadjang, I80, 219

Kalidjeroek, 262, 285

Kaliminger, 285

Kalisat, 26I

Kalutara, I30, I3I, I 38, I42, I 45, I60

Kamuning, I90, 219, 220; Com. pany, 220, 222

Kandy, I 30, I 32

Kanganies, 161, 162, 197, 198, I 99, 200, 201

Kedah, I69, I72, I73, I74, I76, I 78

Kediri, 26I, 264

Kelani Valley, I31, I32, I38, I42, I60 ; Planters' Association, 44

Kelantan, I69, I 72, I73, I 74, I76, I 78,206

Kent plantation, I94, 219

Kiara Pagoeng, 262, 285

Kiliminger, $26 \mathrm{I}, 262$

Klang, I 79, I 80, 208, 2 I I , 2 I 9, 265

Knapsack, 92, 93, 95, 96, I02

Krawang, 26I

Kuala Kangsar, I 79, 2 I9

Kuala Kubu, I79, I 80

Kuala Langat, I79

Kuala Lipis, I 80

Kuala Lumpur, I66, I 79, I80 ; Comptany, 218, 2 19, 220, 222

Kuala Pilah, I79

Kuala Selangor, I79, I80

Kuantan, I79

Kumendore Estate, 219, 222

Kurunegala, I 30 
Laboean Bilik, 235

Labour-supply (Amazon Valley), 22, $30,32,33,35,39$; no solution offered by State and Federal Government, 5I ; proposal to introduce Chinese coolies, 5I.2 ; recruitingground for, 52,54 ; how obtained, 53 ; expense of obtaining, 53 ; unsatisfactory conditions of, in Brazil, 54; as opposed to Bolivia, 54; relations between master and man, 54 ; housing accommodation, 55 ; lack of hygiene, 55 ; allotment of work, 56 ; wages, 56-7; truck system, 57; women and children, $57-8$; truck system and its effects, 59-62 ; food-supplies, 62 ; skilful grading by uneducated workmen, IOI ; high rate of wages, II 8 ; comparison of, with Orient, II 8, I22; sources of, I21-2

(Orient), sources of, I2I ; skilled, I2I ; shortage, 296

(Ceylon), payments for, I38; sources of, 161, 162 ; wages, I61; working hours, I62; food-supplies, I62; free primary schools, 162

(Malay Peninsula), 187, 195 et seq.; form of agreement between employers and Javanese labourers, 202; Chinese, 206, 207 ; skilled, 209.10; housing, 216 ; food, 217

(Sumatra), 231-2, 240, 248, 250 ; working hours, 248; wages, 248, 249

(Java), 269, 277, 283 ; wages, 270, 279; bonus system, 270 ; no contract system in, 278 ; working hours, 279

Labu Company, 219, 220, 222

La Condamine, 2 Lalang, I 74, 187, 188, 189, 283 Lanadron Company, 220 Lancewood, 7
Land, tax on sale of (Amazon Valley), 18

Land tenure (Amazon Valley) : criticism of, 15 ; classification of titles, 15 ; survey, 16 ; boundaries, 16 ; value of realty as negotiable security, 16 ; uncertainty of, a drawback, I6; political considerations affecting, 17

(Sumatra), 232

(Java), 266

Langen, 261, 284, 285

Lankat, 229, 233, 234, 235, 254

Lard, 62

Latex (Amazon Valley): not strained, 92 ; crude methods of preparation, 93 ; coagulation in central factories, 93 ; smoking process, advantages of, 94 ; fumigating, 95 ; cylinder system, 95, 96

(Ceylon), curing of, 143 ; proportion of, to dry rubber, 159,160

Latex cups, $65,75,215$

Lauderdale Estate, 219, 222

Leaf disease, Ceylon coffee plantations devastated by, 129

Ledbury Company, 220

Lembrança estate, tapping tests at, 87

Lenggong, 179

Light, effect of, on rubber-trees, 29 , $74,153-4,158,236$

Lima Poeloeh, 234

Limburg, 26r, 262, 285

Lime, use of, in bark disease, $4 \mathrm{I}$

Lines, coolies' (Ceylon): cost of building, I35 ; description of, 162

(Malay Peninsula), 216; cost of building, 188,216

(Sumatra), cost of building, 24I

(Java), cost of building, 269; Government regulations concerning, 270

Linggi, B., 182, 208, 219, 220, 222

Lipis, 179

Liverpool, cost of shipments to, (Malay Peninsula), 224 
Liverpool, cost of shipments to, (Sumatra), 257

(Java), 275

Living, cost of (Amazon Valley), 89,122

(Orient), 122

London, cost of shipments to, (Malay Peninsula), 224

(Sumatra), 257

(Java), 275, 289

London Asiatic Company, 220, 222

Mabira Forest Company, 220

Machadinho, 42, 48, 64 et seq. 77 , $78,80-5$, I24

Machinery, cost of (Malay Peninsula), 188

(Sumatra), 241

(Java), 269

Madeira-Marmoré Railway, I I, I3, $22,32,47,56,67,82,95,99$

Madeira, River, 6, 9, 10, 22, 27, $30,32,36,42,47,56,66,67,73$. 77, $78,80,8 \mathrm{I}, 86,90,98$, IO3. I23, 124

Madoera, 274, 276, 278

Madras, 197, 199, 200

Madre de Dios, Rivér, 6, 34

Madura Company, 199

Maguary, 304

Mahomedanism (Java), 277

Maize, 28, 62, 63

Malacca, I69, I70, I72, I74, I76,

$177,211,219,222$

Malacca Company, 220

Malang district (Java), 70, 26r, 262,285

Malaria (Amazon Valley), I2, 13

(Ceylon), I6o

(Malay Peninsula), 2 ro

(Sumatra), 250

(Java), 280

Malays, I70, 173, 195, 206, 207, $215,217,231,250,25 \mathrm{I}$

Mamboel, 262, 285

Management (Ceylon) : cost of, on new plantations, 135 ; working costs of, 137 , estimated future, 139

(Malay Peninsula), proportionate cost of, to pound of rubber, 126; cost of, on new plantations, 188 ; working costs of, $189,22 \mathrm{I}$, estimated future, 223

Management (Sumatra), cost of, on new plantations, 242 ; working costs of, 242, estimated future, 256

(Java), cost of, on new plantations, 269; working costs of, $27 \mathrm{I}, 286$

Manáos, 5, 9, 10, I1, 12, 14, 16, $22,23,24,27,37,42,47,53$, $54,56,60,93,95,97,98-102$, 104, 106, 108, 112, 120, 125 ; harbour dues, 106, 107

Mandioca, 28, 62, 63

Manihot, 5

Mantin, 179

Manure (Ceylon), 132-3, I42 ; cost of, on new plantations, I 35 ; working costs of, 137, estimated future, 139

Java, working costs of, 27 I, 286 Marajo, 303

Maranhao, 14, 52, 121

Marañon, River, 7

Marmoré, River, 6, 23

Matale district (Ceylon), 44, I30, I $32,134,142$

Matto Grosso, 23, 34, 36, 67, 102, 103, 105, 106, 107, I1 4

McIntosh, Charles, 2

Medan, 229, 234, 235

Menes, 26I, 262, 263

Milreis, value of, 25

Mirary (Amazon Valley), tests of density of latex at, $8 \mathbf{I}$

Moisture, amount of, in rubber

(Amazon Valley), I 25

"Momi " packing-cases, 194

Mosquito-nets, 216

Mosquitoes, I2

Mulattoes (Amazon Valley), 13, 52, 54

Mules, 99

Museo Goeldi, 73, II6

Mycelium, 43

Napo, River, 7

National Coasting Trade Law, 22 
Navigation, impediments to (Amazon Valley), 22

Nederlandsche Handel Maatschappij, 230, 253

Negapatam, 197, 199, 200

Negombo, 130

Negri Sembilan, 169, 1 70, 174, I76, I78, I 79, I80, 219, 222

Negro, River, IO

Negroes (Amazon Valley), 13, 52, 54

Nile, compared with Amazon, I7

North Hummock Company, 220

Northway, System of pricking suggested by, 69-7 I

Nova Scotia Estate, 219, 222

Obidos, 10, I I, 47

Oil engines (Ceylon factories), I 37

Opium, duty on (Malay Peninsula), I 76

Orviedo y Valle, I

Overhead tapping, 32, 67, 68, 124

Pack animals, use of, 31,99

Padang, 229, 234, 235

Pahang, I69, I74, I78, I79, I80

Pará, 5, 9, 10, I1, I2, I 4, 16, 18, $22,23,24,37,48,53,54,56$, $60,73,93,97,98,102,104,105$, 106, 107, 108, 109, II 2, II 3 , I I 4, I I6, I 20, I25; harbour dues, I07

Parahyba, I 4, 52, I 22

Parasites, 40

Paris Academy, expedition sent by, in 1734,2

Parit Buntar, I80

Pary, River, 7

Pasir Oetjing, 262, 265, 285, 30I

Pasir Waringen, 285

Passberg system (vacuum dryers), I 37, I94, 275

Passerean, 26r, 263, 264

Pataling Company, 182, 220

Pauhiny, River, 47

Pegoh Estate, 219, 222

Pekan, 179, 180

Pelles, 92, 93, 95, 96, 102

Penang, I69, I70, I 7 I, I72, I74,
176, 190, 194, 197, 200, 224, 229, 245

Penang Sugar Estates Company, 213

Peradenyia Station (Ceylon), I16, I 29, I 32, I 33, I42, I 58

Perak, 169, 174, 177, 178, 179, I 80,222

Perak Company, 220

Perkins patent (machines), 193

Perlis, I74

Peru, 5, 6, 14, 27, 34, 37

Peruvians, 13

Petch, Mr., Ceylon Government mycologist, 44

Pfleiderer patent (machines), I93

Pineapples, 213

Planters' Labour Association (Malay Peninsula), I 7 I

Planting, cost of, on new plantations (Ceylon), I 35

(Malay Peninsula), I 88

(Sumatra), 24I

(Java), 269

Poisson, M. Eugène, 30I

Population (Amazon Valley), I3

(Malay Peninsula), 207

Port charges (Amazon Valley), IOI

Port office (capatasia), 106, 107

Port Swettenham, 194, 197, 200, 224

Porto Velho, 9, IO, I1, I2, 23, 32, $33,36,47,98$

Portuguese immigrants (Amazon Valley), I4, 52, 54

Postal facilities (Amazon Valley), 24

P. P. K. Company, 220

Preangar district (Java), 44, 26I, 285

Presses, rubber, 194

Preta (black variety of Hevea Bra. siliensis), 3, 120, 265, 300, 301, 302, 303, 304

Pricking, 69; objection to, 69; economical, 70 ; labour-saving, 70 ; possible difficulties, 7 I

Priestly, 2

Province Wellesley, I69, I72, I74, 2I I, 212, 219

Purás, River, 6, 12, 22, 27, 30, 32, 
$34,36,42,47,56,57,66$, $67,77,78,80,81,84,85$, $88,89,90,98$, I03, I 23

Purús (Upper), 53, 79

Putamayo, 34

Quinine (Java), use of, 280

Raffles, Sir Stamford, 276

Rainfall (Amazon Valley), 8, I I, I 2, $30,64,81,121$

(Malay Peninsula), I21, I7880

(Ceylon), 132, 142

(Sumatra), 234

(Java), 262, 263, 283

Rambong. See Ficus

Rangkas-Bitoeng, 261, 262, 263

Rapids, 22, 36

Raub, I 79, I80

Recreio (Amazon Valley), tests of density of latex at, 8I

Regatones (Syrian pedlars), $5^{8}$

Rent (Malay Peninsula): proportionate cost of, to pound of rubber, 126 ; estimate of, on new estates, 188 ; working costs of, I89, 22I, estimated future, 223

(Sumatra), estimate of, on new estates, 24I ; working costs of, 242 , estimated future, 256

(Java), estimate of, on new estates, 269; working costs of, $27 \mathrm{I}$

Resiliency, high standard of, attained by black Hevea, 3, I 20

Rice, cultivation of (Ceylon), I 33

(Sumatra), 236

(Java), 277

Ridley, Mr. H. N., establishes plantations in Malay Peninsula, 167

Rio Branco, River, 7, 22, 23

Rio de Janeiro, 20, 21, 23, 30, 37, 112, I13; botanical gardens at, I 16

Rio Grande del Norte, I4, 52, I2I

Rio Negro, River, 7, 27, 103
River Plate, 62

Rivers (Amazon Valley), gradient of, 8 ; transport by, $2 \mathrm{I}$

Roads (Ceylon) : poll tax for maintenance of, I3I ; cost of, on new plantations, $\mathrm{I} 35$; working costs of, 137

(Malay Peninsula), proportionate cost of, to pound of rubber, 126 ; cost of, on new plantations, I88; working costs of, I89, 221, estimated future, 223

(Sumatra), cost of, on new plantations, 24I; working costs of, 242, estimated future, 256

(Java) cost of, on new plantations, 269; working costs of, 271,286

Root canker. See Fomes

Rotterdam, 275; cost of shipments to (Java), 287

Roxbury Indiarubber Company, 2

Rubana Estate, 219, 222

Rubber boom of 1909, 99, 134-5,

I7I, I82, I83, I9I, 23I, 239, $240,264,266,268$

Rubber (Brazilian), origin of industry, I ; earliest uses of, 2 ; vulcanization, 2; Hevea, 3 (and see title Hevea) ; output from Amazon Valley for year to June, I9I3, 5; Ceará rubber, 5; Brazilian shipments, 6 ; area of producing districts, 6 ; sole important industry of Amazon Valley, 7 ; temperature, Io ; rainfall, II ; land tenure, I5-I 7 ; export duty on, I8 ; transport, $2 \mathrm{I}-3$; characteristic features of Amazon Valley industry, 26; ditto of Orient industry, 26; expeditions for collecting, erroneous impression as to, 26-7 ; classification of producing districts, 27 ;-(Amazon delta district, 28 ; life of collectors in, 28 ; estrada system in, 
Rubber (Brazilian)-continued:

29: Santarem district, 27, 30; wet season in, 30 ; organization of industry in, 30 ; comparison with delta district, 30 ; River Madeira district, 30 ; profitable nature of industry in, 30 ; permanent buildings in, 30 ; height of trees in, 3I ; method of collection in, $3 I$; extent of properties in, 3I ; tapping restrictions in, 32 ; resident population in, 32 ; properties adjoining River Madeira district, 33 ; comparison of trees in, with Ceylon or Malay Peninsula trees, 33 ; percentage of trees reaching maturity in, 34 ; upper rivers district, fine hard Pará exported from, 33 ; caucho, supply of, in, 34 ; annual inundations in, 34 ; black hevea, growth of, in, 34 ; castilloa in, 35 ; collectors in, 35 ; workmen in, 35 ; expense of importing, 35 ; buildings in, 35 ; access to, 36 ; cataracts in, 36 ; cost of transport in, 36 ; expedi. tions from Pacific slopes to, 37 ;)-diseases, 40 et seq. ; remedies for, 44.6 ; trees, girth of forest-grown, in Amazon district, 73 ; age of, 73 ; growth of, planted, 73 ; compared with Orient trees, 73-4 ; yield in Amazon districts, 77.88; exaggeration regarding, 90 ; preparation of, appliances for, $9 \mathrm{I}$; impurities in, 92, 93; advantages of coagulation by smoking process, 94 ; weighing of, 96 ; transport of, 98 ; cost of transport, 98, 99; output of, in Amazon Valley for year to June, 1913, 102 ; classification of output, 102-3; estimated output of, for year
Rubber (Brazilian)-continued: to June, 1914, 102 ; export duties on, 106-7; average cost per pound of, 108; details of average cost, 108-10, 127 ; small profit on total output of, Iro ; need for reorganizing industry, I10- II ; importance of industry to Brazil, III ; production record for eighty-six years, I I I ; weight of cases passing through Pará, I12 ; Federal Government's attitude to, II2; steps taken by Brazilian Congress to relieve situation, I I3; futility of, I I 4 ; suggestions for relief of industry, II4-I6 ; summary of, I16-17, I28; non-cultivation of trees in Brazil, II9; comparison with Orient, II9; area of planted trees in Amazon Valley, 120; suitability of soil for, I2I ; age of producing trees, 122 ; height and girth of ditto, 123; yield of, per tree, 123 ; cost of transport to port of shipment, I25; exportation of, in 1913,126 ; in 1914 (estimated), 126.

(Ceylon), locality of, I30 ; extent, I3O-I; ownership of lands, I3I ; land values, I3I ; reserve price of land, I 31 ; title to land, I3I ; taxation, I3I ; altitude of rubbergrowing districts, I3I ; rainfall, 132 ; soil, 132 ; manuring, I32 ; foundation of industry, I18, 120, 133 ; interplanted with tea, I33. 134; grown by Sinhalese, I 33 ; diseases and pests, I34; wind, 134 ; expenditure necessary for new plantations, 135, 136 ; estimated cost of factory, I37 ; oil-engines, I37; creping and washing machines, 137; working expenses of six-year-old estate 
Rubber (Ceylon)-continued : of 1,000 acres, 137 ; yield of ditto, 138 ; wages, 138 ; cost of dry rubber f.o.b. Colombo, I39; cost of production, I39; Colombo to London charges, 139; cost in Lon. don market, I43; preliminary work on jungle lands, 140 ; spacing of trees, 140; tapping, I4I, I42 ; laboursupply, I4I ; treatment of latex after tapping, I4I, 145; price of plantation rubber compared with Brazil, 143 ; curing of latex, 143； yield, 145-6; old Hevea plantations at Henaratgoda, 146 ; the famous "No. 2 " tree, 146, 147, I 53, I 54, I 58 ; "No. 439," I 54, I 55 ; First Plantation, I47, I 58 ; Second Plantation, 147,158 ; Riverside Plantation, 147, I55, I 58 ; results of tapping on, I 50-2 ; girth of trees, $147-9$; effect of room on, 147-8, I 53 , I 55, I 58 ; early branching trees, I 54 ; proportion of latex to dry rubber, tables, I 59, I60 ; advantage of, I60 ; bark renewal, I60; future production of, anticipations, I63; estimated future cost, f.o.b. Colombo, 164 ; Ceará, I64; Castilloa, I64; devel. opment of industry during past ten years, 164 ; exports from Colombo in I9I $3, \mathrm{I} 64$; estimated exportation for next six years, 165

(Java), comparison with Ceylon rubber, 260; extent of estates, 26I ; their elevation, 26I ; climatic conditions, 262-3 ; soil, 263 ; area of plantations, 264 ; error of Government Agricultural Department as to, $264-5$; origin of industry, 265 ; land tenure, 266; land tax, 266; no
Rubber (Java)-continued:

export duty on, 266, 286 ; capitalization, 267; cost of establishing plantations, 268-9; distribution of, 269 ; wages and salaries, 270 ; cost of maintaining estates, $27 \mathrm{I}$; manuring, $27 \mathrm{I}$; cost of tapping, 272 ; yield of, 272 ; "all in " cost, 272 ; management, 273; language diffculties, 273 ; spacing of trees, 274; factories, 274; humidity of climate, 274 ; preparation of latex, 275 ; labour-supply, 277-8; wages, 279; working hours, 27980 ; discipline, 280 ; labour colonies, 280 ; health conditions, 280 ; organization of plantations, 28I; catch crops, 28r; effect of interplanting with Robusta coffee, 281-2 ; weeding, 282-3 ; tapping, 283 ; labour conditions, 283 ; diseases, 284 ; pests, 284 ; possible extension of industry, $284-5$; yield, 285 ; cost of production f.o.b. Batavian ports, 286 ; analysis of, 286 ; charges from port of shipment, 287-8; past exports, 288 ; estimated future production, 289 ; railways and roads, 290

(Malay Peninsula), origin of industry, $166-7$; healthy conditions of industry, I68; diseases and pests, I68; centres of producing districts, I69; acreage of plantations, 170-2 ; exports of, tabulated, I7I; area under cultivation in 1912,172 ; small holdings, I73; price of lands, I74; fixed charges for land in F.M.S., I75; taxation of, 176 ; export duties on, 176 ; elevation of estates, I76-7 ; characteristic varieties of soil, 177; wind, 177, 178; 
Rubber (Malay Peninsula)-continued:

rainfall, 178, 179; drought, 180 ; temperature, 180 ; capitalization of estates, 181 , 184,185 ; possible developments of industry, $18 \mathrm{I}$; classification of estates, 1823 ; over-capitalization, 182 ; its effects, 183; prospects, 184 ; cost of establishing and maintaining plantations, I 86 I90; quality of, I90; ad. ministration of estates, 191 ; factories for curing and preparation of, I9I ; creped rubber, 193; sheet rubber, 193; water - supply, 193 ; mechanical dryers, I94; packing, 194; labour-supply, I96 et seq. ; wages, 207-9; working hours, 209 ; health conditions, 210; hospitals, 210 ; organization of estates, 211-12; planting trees, 212 ; effect of catch crops on, 212-13 ; tapping, 214 ; cups, 215 ; yield per acre, $218-19$; cost of production, 220.3 ; estimated future ditto, 225 ; " all in" cost, 225 ; freight rates, 224; yield in tons, 1906 - 13, 226 ; estimated output, 1914-19, 226

(Sumatra), principal producing districts, 229 ; statistics, 230 ; expansion of industry for last eight years, $23 \mathrm{I}$; land available for, 231 ; tenure of land, 232 ; no direct taxation on, 233 ; elevation of estates, 233 ; soil, 233 ; rainfall, 234 ; temperature, 235 ; origin of industry, 235; effect of catch crops on, 236; general condition of plantations, 237 ; effect of winds, 237 ; value of plantations, 238; their area, 239 ; capital invested, 239 ; over-capitaliza. tion, 240 ; estimated cost of
Rubber(Sumatra)-continued : opening plantation, 240-2 ; estimated cost of maintaining, 242 ; cost of, per pound f.o.b. Sumatra, 243, 255 ; "all in" cost, 243 ; advantage to, of proximity of Malaya, 244; ditto of Penang and Singapore, 245 ; spacing of trees, 245 ; management of estates, 245 ; factories, 246 ; laboursupply, 248-50; working hours, 248; wages, 249 ; skilled labour, 250; health conditions, 250 ; hospitals, 250 ; organization of estates, $25 \mathrm{I}$; buildings, 25I-3; catch crops, 252 ; tapping, 253 ; discipline, 253 ; crime, 253 ; approximate yield, 254 ; cost of production, difficulty of estimating, 255 ; analysis of, 256 ; costs after shipment, 257 ; estimated "all in" cost, 257; exportation of, since I906, 258 ; estimated output, I914-19, $25^{8}$

Rubber, Oriental : characteristic features of industry, 26 ; damage to, by creping machinery, 94 ; foundation of industry in 1876 , I 8 , I20; systematic cultivation of trees, I19; area of planted trees, 120; cultivation of soil, I20-1 ; age of producing trees, 122 ; height and girth of trees, 123; yield of, per tree, 123: cost of transport to port of shipment, 125 ; exportation of, in 1913, 125, in 1914 (estimate), 126 ; average cost per pound of, 126-7; importance of year 1913 for, 29I ; past production of, tabulated, 293 ; consumption and production of, 294; estimated future production of, tabulated, 295 ; labour question, 296 ; damage to, by diseases and pests, 296 ; premium on fine hard Pará, 297 ; variability, 297; grading, 298; resiliency, 299; reduction 
of " all in" costs, causes of, 299; black Hevea, 301-4

Rubber Growers' Association, 297, 298

\section{Sagga Company, 220}

Saigon, I 85

Salt, 62

San Antonio, 98 ; cataract of, 22

Sandalwood, 7

Santa Catharina (Amazon Valley), tests of density of latex at, 8I

Santa Maria (Amazon Valley), tests of density of latex at, $8 \mathrm{I}, 86,87$

Santarem, 27, 28, 30

São Felipe, 36

Sauba. See Ant, red

Savanas, 7

Scrap (Amazon Valley), 4, 5, 66, 92, I 12,125

(Ceylon), I38, I 50-2

(Malay Peninsula), 193

Seafield Company, 220

Sekong Company, 220

Selangor, I69, I74, I77, I78, I79, I $80,218,219,222,265$

Selangor Company, 182, 220

Senna Madureira, 23

Sennah Estates, 246, 248

Sennah Rubber Company, 254

Serdang, 229, 234, 235, 254

Seremban, 179, 180, 219

Seremban Company, 220

Seringueiros. See Collectors

Sernamby, 4, 5, 75, 88, 102, 103

Servants, domestic (Orient), I 2 I

(Amazon Valley), 122

Sevastopol Estate (Amazon Valley), tapping tests at, 85 ; records of, 88

Shanghai, 182, 184, 187, 267

Shaw patent (machines), 192

Shelford Company, 220

Shipping Convention, 194, 195, 224

Silver, da, Dr. Raymundo Pereira, I 3

Singapore, $169,170,172,174,182$, 190, 194, 205, 206, 213, 224, 245,275

Singapore Pará Company, 220
Singkeh, 206

Sinhalese, 131, 133, 161, 162, 163

Small holdings (Malay Peninsula), I73

Smallpox (Java), 280

Social life (Amazon Valley), 24

Soengei Gerpa, 234, 235, 254

Soengei Poetih, 234, 235, 254

Soengei Roean, 234, 254

Soerabaja, 261, 278, 286

Soil (Amazon Valley), I7, I 2 I

(Ceylon), I3I, I42

(Malay Peninsula), 177

(Sumatra), 233

(Java), 263

Solimoes, River, 47, I03

Spanish immigrants, 14

Steam-launches, 3I, 99

Straits (Bertam) Company, 220

Straits Rubber Company, 222

Straits Settlements : growth of trees

in, $73 ;$ tax on production, 108; assessment tax on trees, I70; rubber acreage, I72; agricultural lands, premium on, I74 ; charges for, 175; methods of taxation, 176 ; general revenue of, 176

Sugar (Amazon Valley), 62

(Java), 273

Sugar-cane, 212, 213, 277

Sulphur, mixture of, with rubber, 2

Sumatra, growth of trees in, 73 ; no direct taxation in, 108; nominal capital of companies exploiting, 185 ; land tenure, 232 ; general revenue of, 233; soil of, 233 ; nominal capital of rubber-producing companies, 239

Sumatra Pará Company, 220

Sungei Kapar Company, 220

Sungei Siput, 219

Sunnycroft Estate (Ceylon), 146

Superintendencia da Defesa de Boracha, II3, II4

Taiping, I79, 180, 219

Tali Ayer Estate, 219, 222

Tamil coolies (Ceylon), 138, I6I

(Malay Peninsula), 195-20r, 208, 209, 21 5, 217 ; Immigration Fund, 196, I98 
Tampin, 169, 170, 179

Tanah Besih, 234, 235

Tandjong Balei, 235

Tangye engines, 192

Tapah, 179, 180

Tapajoz, River, 6,-22, 30, 36, 47, $68,78,102,103,120,300,301$

Tapioca, 212

Tapping (Amazon Valley): full herring-bone system, 42,65 , $67,77,80,82,86,87,123$; half herring-bone system, 42; single V system, 42, 85, 86, 87 ; wounds due to, 45 ; season for, 64 ; tools, $64-5$; description of, 66 ; overhead, $32,67,68,124$; of Castilloa trees, $7 \mathrm{I}-2$; tests demonstrating density of latex, $8 \mathrm{I}$ et seq.; double herring-bone system, 85 ; broad V cuts, 85 ; machadinho, see under title Jebong, 87

(Ceylon), herring-bone system, I4I ; half-spiral system, I4I ; single V system, I4I ; frequency of, experiments in, I4I-2; regularity of, 145 ; three $\mathbf{V}$ system of, I 49

(Malay Peninsula), interfered with by burrs, I68; commencement of, 214 ; single $V_{\text {system, } 214 \text {; half herring- }}$ bone system, 2 I 4

(Java), unsatisfactory standard of, 283 ; cost of, 286,287

See also Gouge

Taxation (Amazon Valley), I 8, 2 I

(Ceylon), 13I, 160

(Sumatra), 233

Taxes, municipal (Amazon Valley), 101, 107 ; bourse, 107

Tea (Ceylon), 130, I 33, I 34

(Java), 273, 277

Telok Anson, 179, 180, 211 , 219

Telok Dalam, 234, 235, 254, 255

Temperature (Amazon Valley), 10, 121

(Malay Peninsula), 121, I80

(Sumatra), 235

(Java), 262, 263
Tin-mining (Malay Peninsula), 170, I 76, 207

Tjandjoer, 26r, 262

Tjikadoe, 285

Tjipâri, 26I, 262, 285

Tjirandi, 262, 285

Tobacco (Amazon Valley), 63

(Sumatra), 232, 236

(Java), 273, 277

Tocantins, River, $6,22,23,36$, 102, 103, 303

Tools, cost of (Ceylon), 135

(Malay Peninsula), I88

(Sumatra), 242

See also Tapping

Transport (Amazon Valley): means of, $21,22,59,99$; cost of, $98,99,108$

(Orient), 125

(Malay Peninsula), proportionate cost of, to pound of rubber, 126 ; working expenses of, 189, 221, estimated future, 223

(Ceylon), working costs of, 137, estimated future, 139 ; facilities, 160

(Sumatra), working expenses of, 242 , estimated future, 256

(Java), working expenses of, 27 I, 286

Trees (Amazon Valley): girth of, 73, 123; approximate number of, I 20 ; their age, 73 ; effect of light on, 29, 74 ; flower in October, 81; approximate number of, in East, 120 ; age of production, 123 ;

(Orient), age of production , 122 ; girth of, 123

(Ceylon), girth of, I48, 149

Cost of planting (Malay Peninsula), 166, 188; (Ceylon), 135 ; (Sumatra), 24 I ; (Java), 269

See also Yields

Trengganu, 169, 172, 173, 174, 176

Trompetas, River, 7

Truck system (Amazon Valley), 57, $59-61$ 
Truck System (Bolivia), 61-2

(Peru), 62

Tumuc Humac, II

Ucayale, River, 7,36

Ulu Langat, 179

United Serdang Company, 220

Urucury nuts, use of, 3, 92, 125, 298

Vallambrosa Company, 182, 219, 220, 222, 235

Vegetation (Amazon Valley), 7, 33

"Venesta" packing-cases, I94

Vermelho (red variety of Hevea Brasiliensis), 3, 4, 120

"Vulcanization," 2

Wages (Amazon Valley), 33, 46, 52, $59,82,98$, I09, I 22

(Orient), I22

(Ceylon), I38, 161, 163

(Malay Peninsula), 203, 206, 207-208

(Sumatra), 249

(Java), 279

Wardiebrun plantation, 194, 218

Washing-machines, I37, I4 I, I92, I94

Waterproof coats, 2

Water-supply (Malay Peninsula), bad, 193, I94

Weeding (Ceylon): cost of, on new plantations, 135, 140 ; working costs of, 137, estimated future, I 39

(Malay Peninsula), 187 ; proportionate cost of, to pound of rubber, 126; expense of, diminishes as trees grow, I27 : cost of, on new plantations, I88; working costs of, I88, 221 , estimated future, 223

(Sumatra), cost of, on new plantations, 24I ; working costs of, 242, estimated future, 256
Weeding (Java), 282-3; cost of, on new plantations, 269 ; working costs of, 27I, 286

Weighing (Amazon Valley), 96, Ioo

Werner patent (machines), 193

West Country Estate, 222

Wickham, Mr., "Father of the rubber industry," I I 8, I 20, I 33, I43, I 47, I 54, I67, 300

Wild rubber, 26, 38, 41, I19, I26, 291

Willis, Dr., I 16

Wind, growth of rubber-trees affected by, 134, I77, 237

Wireless (Amazon Valley), 23-4

Women as labourers (Amazon Valley), 57-8, I22

(Ceylon), 138, I4 I, I6r

(Malay Peninsula), 201-3, 208

(Sumatra), 248, 249

(Java), 279, 282

Xarque (dried meat), 62, 63

Xingu, River, $6,22,36,47,78$, 102, 103, 303

Yam Seng Company, 220

Yapurá, River, 7

Yellow fever, I2

Yields : on the Madeira, 77,78 , 84 ; on the Purús, $77,78,84$; on the Tapajoz, $78 ;$ on the Xingu, 78 ; in Bolivia, 79 ; on the Upper Purús, 79 ; on the Juruá, 79 ; on the Jutahy, 79 ; on the Javary, 79 ; vary according to season, 8I ; exaggerated reports of, 90 ; for the year to June, I9I3 (Amazon Valley), IO2 ; (Ceylon), I 38, I45-7, I 50-2 ; estimated future, 163; (Malay Peninsula), 190, 214, 218, 226; estimated future, 226; (Sumatra), 254,258 ; estimated future, $25^{8}$; (Java), 264, 285, 288; estimated future, 272,289 


\section{A SELECTION OF BOOKS}

PUBLISHED BY METHUEN AND CO. LTD., LONDON 36 ESSEX STREET W.C.

\section{CONTENTS}

\begin{tabular}{|c|c|c|c|c|c|}
\hline eneral Literature & $\cdot$ & - & 2 & Little Quarto Shakespeare & 20 \\
\hline Ancient Cities & $\therefore$ & $\cdot$ & 13 & Miniature Library . & .20 \\
\hline Antiquary's Books . & $\because 31$ & . & 13 & New Library of Medicine & 21 \\
\hline Arden Shakespaaro. & $\cdot$ & - & $x_{4}$ & New Library of Music . & 21 \\
\hline Classics of Art & 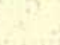 & $\cdot$ & 14 & Oxford Biographies & (-) 21 \\
\hline 'Complete' Series . & & . & $\geq 5$ & Four Plays. & 21 \\
\hline Connoisseur's Library & & - & 15 & States of Ita!y & 21 \\
\hline $\begin{array}{l}\text { Handbooks of English } \\
\text { History }\end{array}$ & $\begin{array}{l}\text { Chur } \\
\text {. }\end{array}$ & & 16 & Nestminster Commentaries & 22 \\
\hline Handbooks of Theology & 7 . & - & 36 & Young' Series. & $\cdot$ \\
\hline 'Home Life' Series. & - & - & 16 & Shilling Library & - 22 \\
\hline $\begin{array}{l}\text { Illustrated Pocket Lib } \\
\text { Plain and Coloured }\end{array}$ & rary & of & 16 & Books for Travellers & 23 \\
\hline Leaders of Religion & & . & 17 & olss on & \\
\hline Library of Devotion & - & - & 17 & Some Books on Italy & 24 \\
\hline Little Books on Art & & - & 18 & Fiction . & 25 \\
\hline Little Galleries & & - & 18 & Rooks for Boys and Girls & 30 \\
\hline Little Guldos : & & . & 18 & Shilling Novels. . & 30 \\
\hline Little Library . & - & • & 19 & Sevenpenny Noveis & 32 \\
\hline
\end{tabular}




\section{A SELECTION OF}

\section{MESSRS. METHUEN'S PUBLICATIONS}

In this Catalogue the order is according to authors. An asterisk denotes that the book is in the press.

Colonial Editions are published of all Messrs. Merhuen's Novels issued at a price above $2 s$. $6 c$. , and similar editions are published of some works of General Literature. Colonial Editions are only for circulation in the Pritish Colonies and India.

All books marked net are not subject to discount, and cannot be bought at less than the published price. Books not marked net are subject to the discount which the bookseller allows.

Messrs. MethuEN's books are kept in stock by all good booksellers. If there is any difficulty in seeing copies, Messrs. Methuen will be very glad to have early information, and specimen copies of any books will be sent on receipt of the published price plus postage for net books, and of the published price for ordinary books.

This Catalogue contains only a selection of the more important books published by Messrs. Methuen. A complete and illustrated catalogue of their publications may be obtained on application.

Abraham (G. D.). MOTOR WAYS IN L A K E I, A N D. Illustrated. Second Edition. Demy 8vo. 7s. 6d. net.

Adcock (A. St. John). THE POOKLOVER'S LONDON. Illustrated. $\mathrm{Cr}$. 8vo. 6s. net.

Ady (Cecilla M.). PIUS II.: The Humanist Pope. Illustrated. Demy $8 v 0$. ros. 6 d. net.

Andrewes (Lancelot). PRECES PRI. VATAE. Translated and edited, with Notes, by F. E. Brightman. Cr. 8vo. $6 s$.

Aristotle. THE ETHICS. Edited, with an Introduction and Notes, by JоHN BURNet. Demy 800 . ros. $6 d$. net.

Atkinson (C. T.). A HISTORY OF GER. MANY, 1715-1815. Demy 8vo. r2s. 6d.net.

Atkinson (T. D.). ENGLISH ARCHITECTURE. Illustrated. Third Edition. Fcap. 8vo. 3s. 6d. net.

A GLOSSARY OF TERMS USED IN ENGLISH ARCHITECTURE. IHustrated. Second Edition. Fcap. 8vo. 3s. 6d. net.

ENGIISH AND WELSH CATHE. DRALS. Illustrated. Demy 800 . ros. 6d. net.

Bain (E. W.). A DIGIT OF THE MOON: A Hindoo Love Story. Tenth Edition. Fcap. 8vo. 3s. 6d. net.
THE DESCENT OF THE SUN : A CyCLE OF BirTH. Sixth Edition. Ficap. 8vo. 3s. 6 d. net.

A HEIFER OF THE DAWN. Seventh Edition. Fcap. 800 . 2s. 6d. net.

IN THE GREAT GOD'S HAIR. Fifth Edition. Fcap. 8vo. 2s. 6d. net.

A DRAUGHT OF THE BLUE. Fifth Edition Fcap. 8vo. 2s. 6d. net.

AN ESSENCE OF THE DUSK. Third Edition. Fcap. 8vo. 2s. 6 d. net.

AN INCARNATION OF THE SNOW. Third Edition. Fcap. 8vo. 3s. 6d. net.

A MINE OF FAULTS. Third Edition. Ficap. 800 . 3s. 6 d. net.

THE ASHES OF A GOD. Second Edition. Fcap. 8vo. 3s. 6d. net.

BUBBLES OF THE FOAM. Second Edition. Fcap. 4to. 5s. net. Also licap. 800. $3 s .6 d$. net.

Balfour (Graham). THE LIFE OF ROBERT LOUIS STEVENSON. IlluStrated. Eleventh Edition. In one Volume. Cr. 800. Buckram, 6s.

Also Fcap. 800. 1s. net.

Baring (Hon. Maurice). LANDMARKS IN RUSSIAN LITERATURE. Second Edition. Cr. 8vo. 6s. net.

RUSSIAN ESSAYS AND STORIES. Second Edition. Cr. 8vo. 5s. net.

THE RUSSIAN PEOPLE. Demy 800. ${ }^{5} 5$ s. net. 
Baring-Gould (8.). THE LIFE OF NAPOLEON BONAPARTE. Illustrated. Sccond Edition. Royal 8vo. ros. 6d. net. THE TRAGEDY OF THE CAESARS: A Study of the Characters of the Chsars of the Julian and Claudian Houses. Illustrated. Seocnth Edition. Royal 8vo. ros. 6d. net.

THE VICAR OF MORWENSTOW. With a Portrait. Third Edition. Cr.800. 3s.6d. Also Ficnp. 800. 1s. net.

OLD COUNTRY LIFE. Illustrated. Fifth Edition. Large Cr. 8no. 6s. Also Fcap. 800. is. net.

A BOOK OF CORNWALL. Illustrated. Third Edition. Cr. 800 . 6 .

A BOOK OF DARTMOOK. Illustrated. Second Edition. Cr. 8vo. 6s.

A BOOK OF DEVON. Illustrated. Third Edition. Cr. 800. 6s.

Barlng-Gould (8.) and Sheppard (H. Fleotwood). A GARLAND OF COUNTRY SONG. English Folk Songs with their Traditional Melodies. Demy 4 to. 6 s.

SONGS OF THE WEST. Folk Songs of Devon and Cornwall. Collected from the Mouths of the People. New and Revised Edition, under the musical editorship of Cecil J. Sharp. Large Imperial $8 v 0$. 55. thet.

Barker (E.), THE POLITICAL THOUGHT OF PLATO AND ARISTOTLE. Demy 8vo. ras. 6.d net.

Bastable (C. F.) THE COMMERCE OF NATIONS. Sixth Edition Cr. 800. 25. 64 .

Beckford (Peter), THOUGHTS ON HUNTING. Edited by J. OThо PAGrT. Illustrated. ThirdEdition. Demy 800. 6s.

Belloc (H.). PARIS. Illustrated Third Edition. Cr. 8vo. 6s.

HILLS AND THE SEA. Fourth Edition. Fcap. 8vo. 5 s. Also Fcap. 800. is. net.

ON NOTHING AND KINDRED SUB. JECTS. Fourth Edition. Fcap. 8v0. 55 . ON EVERYTHING. Third Edition. Fcap. 800. 5s.

ON SOMETHING. Second Edition. Fcap. 800. 55.

FIRST AND LAST. Second Edition. Fcap. 8v0. 5 s.

THIS AND THAT AND THE OTHER. Second Edition. Fcap. 800.55.

MARIE ANTOINETTE. Illustrated. Third Edition. Demy 800. 15s. net.

THE PYRENEES. Illustrated. Second Edition. Demy 8vo. 7s. 6d. net.

Bennett (ARnold). THE TRUTH ABOUT AN AUTHOR. Crown 800. 6s.

Bennett (W. H.) A PRIMER OF THE BIBI.E Fift Edition Cr. 8vo. as. 6d.
Bennett (W. H.) and Adeney (W. F.). A BIBLICAL INTRODUCTION. With a concise Bibliography. Sixth Edition. Cr. 800. 75. 6d. Also in Two Volumes. Cr. 800. Each 3s. 6d. net.

Benson (Irchbishop). GOD'S BOARD. Communion Addresses. Second Edition. Fcap. 800. 3s. 6d. nct.

Berriman (AIgernon E.). AVIATION. Illustrated. Second Edition. Cr. 800 . ros. 6d. ret.

Blcknell (Ethel E.). PARIS AND HER TREASURES. Illustrated. Fcap. $8 v 0$. Round corners. 5s. net.

Blake (WIlliam), ILIUUSTRATIONS OF THE BOOK OF JOB. With a General Introduction by LAURENCE Binyon. Illus. trated. Quarto. 2xs. net.

Bloemfontein (BIshop of). ARA CELI : AN Essay in Mystical Theology. Fifth Edition. Cr. 800 . 3s. 6d. net.

FAITH AND EXPERIENCE. Second Edition. Cr. 8vo. 35.6d. net.

Boulenger (G. A.). THE SNAKES OF EUROPE. Illustrated. $C r .8 v 0.6 s$.

Bowden (E. M.). THE IMITATION OF BUDDHA. Quotations from Buddhist Literature for each Day in the Year. Sirth Edition. Cr. $16 m$. 2s. $6 d$.

Brabant (F. G.). RAMBLES IN SUSSEX. Illustrated. Cr. 800. 6s.

Bradley (A. G.). THE ROMANCE OF NORTHUMBERLAND. Illustrated. Third Edition. Demy 800. 7s. 6d. net.

Brald (James). ADVANCED GOLF. Illustrated. Seventh Edition. Demy 800 . ros. 6d. net.

Bridger (ㅍ. E.), MINDS IN DISTRESS. A Psychological Study of the Masculine and Feminine Minds in Health and in Dis. order. Second Edition. Cr. 800. 2s. 6d. net.

Brodrick (Mary) and Morton (A. Anderson). A CONCISE DICTIONARY OF EGYPTIAN ARCH EOLOGY. A Hand. book for Students and Travellers. Illustrated. Cr. 8vo. 3s. $6 d$.

Browning (Robert). PARACELSUS. Edited with an Introduction, Notes, and Bibliography by MARGARET L. LEE and Katharine B. Locock. Fcap. 8vo. 3s.6d. net.

Buckton (I. M.). EAGER HEART: A Christmas Mystery-Play. Twelfth Edi. tion. Cr. 800. Is, net.

Bull (Paul), GOD AND OUR SOLDIERS. Second Edition. Cr. 8vo. 6s.

Barns (Robert). THE POEMS AND SONGS. Edited by ANDREW LANG and W. A. Craigie. With Portrait. Third Edition. Wide Demy 800. 6s. 
Calman (W. T.) THE LIFE OF CRUSTACEA. Illustrated. $\mathrm{Cr}$. 8vo. $6 s$.

Carlylo (Thomas), THE FRENCH REVOLUTION. Edited by C. R. L. Fletcher. Three Volumes. Cr. 8vo. $18 s$. THE LETTERS AND SPEECHES OF OLIVER CROMWELL. With an In. troduction by C. H. FIRTH, and Notes and Appendices by S. C. Lomas. Three Volumes. Demy 880 . 18s. net.

Chambers (Mrs. Lambert). LAW N TENNIS FOR LADIES. Illustrated. Second Edition. Cr. 8vo. 2s. 6d. net.

Chesser (Ellzabeth Sloan). PERFECT HEALTH FOR WOMEN AND CHIL. DREN. Cr. 8vo. 3s. 6 d. net.

Chesterfleld (Lord). THE LETTERS OF THE EARL OF CHESTERFIELD TO HIS SON. Edited, with an Introduction by C. Strachey, and Notes by A. Calthrop. Two Volumes. Cr. 8vo. I2s.

Chesterton (G. K.). CHARLES DICKENS. With two Portraits in Photogravure. Eighth Edition. Cr. 8vo. 6s. Also Fcap. 8vo. is. net.

THE BALLAD OF THE WHITE HORSE. Fifth Edition. Fcap. 8vo. 5 s.

ALL THINGS CONSIDERED. Serenth Edition. Fcap. 8vo. 5 s.

TREMENDOUS TRIFLES. Fifth Edi. tion. Ficap. 8vo. 5 s.

ALARMS AND DISCURSIONS. Second Edition. Fip. 8vo. 5 s.

A MISCELLANY OF MEN. Second Edition. Ficap. 8vo. 5 s.

Clausen (George). ROYAL ACADEMY LECTURES ON PAINTING. Illustrated. Cr. 8vo. 5s. net.

Conrad (Joseph). THE MIRROR OF THE SEA: Memories and Impressions. Fourth Edition. Ficap. 8vo. 5 s.

Coolidge (W. A. B.). THE ALPS: IN NATURE AND HISTORY. Illustrated. Demy 800. 7s. 6d. net.

Correyon (H.). ALPINE FLORA. Translated and enlarged by E. W. CLAYforth. Illustrated. Square Demy 8vo. I6s. net.

Coulton (G. G.). CHAUCER AND HIS ENGLAND. Illustrated. Second Edition. Demy 8vo. ros. $6 d$. net.

Cowper (William). POEMS. Edited, with an Introduction and Notes, by J. C. BAILEY. Illustrated. Demy 8vo. ros. $6 d$. net.
CoX (J. C.). RAMLLES IN SURREY. Illustrated. Second Eidition. Cr. 8vo. 6s. RAMBLES IN KENT. Illustrated. $C r$. 8vo. 6s.

Crawley (A. E.). THE BOOK OF THE BALL: AN Account OF What it Does AND Why. lllustrated. $\mathrm{Cr}$. 8vo. 3s. $6 d$. net.

Crowley (H. Ralph). THE HYGIENE OF SCHOOL LIFE. Illustrated. $C r$. 8vo. 3s. 6d. net.

Davis (H. W. O.). ENGLAND UNDER THE NORMANS AND ANGEVINS: 1066-1272. Third Edition. Demy 8vo. Ios. $6 d$. net.

Dawbarn (Charles). FRANCE AND THE FRENCH. Illustrated. Demy $8 v 0$. ros. 6 d. net.

Dearmer (Mabel). A CHILD'S LIFE OF CHRIST. Illustrated. Large Cr. 8vo. $6 s$.

Deffand (Madame du). LETTRES DE LA MARQUISE DU DEFFAND $A$ HORACE WALPOLE. Edited, with Introduction, Notes, and Index, bv Mrs. Paget TOynber. Three Volumes. Demy 800. $£_{3} 3$ s. net.

Dlckinson (G. L.). THE GREEK VIEW OF LIFE. Eighth Edition. Cr. $8 v 0$. 2s. 6d. net.

Ditehfleld (P. H.). THE OLD.TIME PARSON. Illustrated. Second Edition. Denty 8vo. 7s. 6d. net.

THE OLD ENGLISH COUNTRY SQUIRE. Illustrated. Demy 8vo. ros. $6 d$. net.

Dowden (J.). FURTHER STUDIES IN THE PRAYER BOOK. Cr. 8vo. $6 s$.

Driver (\$. R.). SERMONS ON SUBJECTS CONNECTED WITH THE OLD TESTAMENT. Cr. 8vo. $6 s$.

Dumas (Alexandre). THE. CRIMES OF THE BORGIAS AND OTHERS. With an Introduction by R. S. GARNETT. Illustrated. Second Edition. Cr. 8\%o. 6 s.

THE CRIMES OF URBAIN GRAN. DIER AND OTHERS. Illustrated. $C r$. 8vo. 6 s.

THE CRIMES OF THE MARQUISE DE BRINVILLIERS AND OTHERS. Illustrated. Cr. 800 . 6s.

THE CRIMES OF ALI PACHA AND OTHERS. Illustrated. Cr. 8vo. $6 s$.

MY PETS. Newly translated by A. R. Aluinson. Illustrated. Cr. 8vo. $6 s$.

Dunn-Pattisen (R. P.). NAPOLEON'S MARSHALS. Illustrated. Second Edition. Derny 8vo. 12s. 6\%. net. 
THE BLACK PRINCE. Illustrated. Second Fidition. Demy 8v0. 7s. 6d. net.

Durham (Tbe Earl on, THE REPORT ON CANADA. With an Introductory Note. Demy 800. 4s. 6 . net.

Egerton (H. E.) A SHORT HISTORY OF BRITISH COLONIAL POLICY. Fourth Edition. Demy 800. 75. 6d. net.

Eyans (Herber: A.). CASTLES OF ENGLAND AND WALES. Ilustrated. Demy 800. I2s. 6d. net.

Exeter (BIshop of). REGNUM DEI. (The Bampton Lectures of rgoz.) $A$ Cheaper Edition. Demy 8vo. 7s. 6d. net.

Emald (Carl) MY LITTLE BOY. Translated by ALEXANDER TEIXeIRA DE Matros. Illustrated. Fcap. 800. 55.

Falrbrother (W. H.). THE PHILOSOPHY OF T. H. GREEN. Second Edition. Cr. svo. 3s. 6d.

ffoulkes (Charles), THE ARMOURER AND HIS CRAFT. Illustrated. Royal 4to. $\ell_{2}$ 2s. net.

DECORATIVE IRONWORK From the xith to the xvrith Century. IJlustrated. Royal 4 to. $\ell_{2} 2$ s. net.

Flrth (C. H.) CROMWELL'S ARMY. A History of the English Soldier during the Civil Wars, the Commonwealth, and the Protectorate. Illustrated. Second Edition. Cr. 8vo. 6s.

Hsher (H. A. L.) THE REPUBLICAN TRADITION IN EUROPE. $C r .800$. 6s. net.

FitzGerald (Edward), THE RUBA'IYAT OF OMAR KHAYYAM. Printed from the Fifth and last Edition. With a Commentary by H. M. BATsON, and a Biographical Introduction by E. D. Ross. Cr. 800 . 6.

Also Illustrated by E. J. Sur.tvan. Cr. 4to. I5s. net.

Flux (A. W.), ECONOMIC PRINCIPLES. Demy 8v0. 75. 6d. net.

Eraser (E.). THE SOLDIERS WHOM WELLINGTON LED. Deeds of Daring, Chivalry, and Renown. Illustrated. $C r$. 850. 5s. net.

THE SAILORS WHOM NELSON LED. Their Doings Described by Themselves. Illustrated. $\mathrm{Cr} .820$. 5s. net.

Erazer (J. F.). ROUND THE WORLD ON A WHEEI. Illustrated. Fiflh Édition. Cr. 800. 6s.
Galton (Str Francls). MEMORIES OF MY LIFE. Illustrated. Third Edition. Demy 8vo. ros. 6d. net.

Glbblns (H. de B.) INDUSTRY IN ENGLAND: H ISTORICAL OUT. LINES. With Maps and Plans. Eighth Edition. Demy 800. ros. 6d.

THE INDUSTRIAL HISTORY OF ENGLAND. With 5 Maps and a Plan. Nireternth Edition. Cr. 800 . 35.

E NGLISH SOCIAL RE FORMERS. Third Edition. Cr. 8vo. 2s. $6 d$.

Gibbon (Edward). THE MEMOIRS OF THE LIFE OF EDWARD GIBBON. Edited by G. Btrkbeck Hillo Cr. 800. $6 s$. THE DECLINE AND FALL OF THE ROMAN EMPIRE. Edited, with Notes, Appendices, and Maps, by J. B. BURY, Illustrated. Seven Volumes. Demy $8 v 0$. Illustrated. Each ros. 6d. net. Also in Seoer Volumes. Cr. 800. 6s. each.

Glover (T. R.). THE CONFIICT OF RELIGIONS IN THE EARLY ROMAN EMPIRE. Fourth Edition. Dimy 800 . 75. 6d. net.

VIRGIL. Second Edition. Demy 800. 7s. 6d. net.

THE CHRISTIAN TRADITION AND ITS VERIFICATION. (The Angus Lecture for 1912.) Second Edition. Cr. 8vo. 3s. 6 d. net.

Godley (A. D.). LYRA FRIVOLA. Fifth Edition. Fcap. 800. 2s. 6d.

VERSES TO ORDER. Second Edition. Fcas. 800. 2s. 6d.

SECOND STRINGS. Fcap. 800. 25. $6 d$.

Gostling (Frances M.). AUVERGNE; AND ITS PEOPLE. Illustrated. Deniy 8v0. Ios. $6 d$. net.

Gray (Arthar). CAMBRIDGE. Illustrated. Demy 800. ros. $6 d$. net.

Grahsme (Renneth), THE WIND IN THE WILLOWS. Seventh Edition. Cr. 8vo. $6 s$.

Also Illustrated. Cr. 4to. 7s, 6d. net.

Grangor (Frank). HISTORIC $\triangle$ L SOCI. OLOGY: A TEXT-Book or PoLrTícs. Cr. 800. 35. 6 . net.

Gretton (10. 5turge) A CORNER OF THE COTSWOLDS. Illustrated. Demy 800. 7s. 6d. net.

Grep (Edrin Bharpe). THE GROWTH OF A PLANET. Illustrated. $C r .800$. 6 s.

Grimn (W. Hall) and Minchin (T. C.) THE LIFE OF ROBERT BROWNING. Illustrated. Second Edition. Demy 800 . 12s. $6 d$ net. 
Malg (K. O.). HEALTH THROUGH DIET. Second Edition. Cr. 820. 3s. $6 d$. net.

Hale (J. R.). FAMOUS SEA FIGHTS : From Salamis to Tsu-shima. Illustrated. Second Edition. Cr. 8vo. 6s. net.

HaIl (H. R.). THE ANCIENT IIISTORY OF THE NEAR EAST FROM THE EARLIEST TIMES TO THE BATTLE OF SALAMIS. Illustrated. Second Edition. Demy 800. 15.5. net.

Rannay (D.). A SHORT HISTORY OF THE ROYAL NAVY. Vol. 1., $1217-1688$. Second Edition. Vol. II., 1689-1815. Domy 8vo. Each 7s. 6d.

Hare (B.). THE GOLFING SWING SIMPLIFIED AND ITS MECHANISM CORRECTLY EXPLAINED. Third Bdition. Fcap. 8vo. Is. net.

Harper (Charles G.). THE AUTOCAR ROAD-BOOK. With Maps. Four Volumes. Cr. 8ro. Each 7s. 6d. net.

Vol. I.-SOUTH OF THE Thames.

Vol. II.-NORTH AND SOUTH Wares aNd West Midlands.

Vol. III.-EAst Anglia and EAst MidLANDS.

Vol. IV.-THE NORTH OF ENGLAND AND South of ScotLand.

Harris (Frank). THE WOMEN OF SHAKESPEARE. Demy 8vo. 7s. 6d. net.

Hassall (Arthur). THE LIFE OF NAPOLEON. Illustrated. Demy 800 . 7s. 6d. net.

Headley (F. W.). DARWINISM AND MODERN SOCIALISM. Second Edition. Cr. 8v0. 5s. net.

Henderson (M. Sturfe). GEORGE MERFDITH : NOVELIST, POET, REFORMER. With a Portrait. Second Edition. Cr. 800. 6s.

Henley (W. E.). ENGLISH LYRICS: CHAUCER TO POE. Second Edition. Cr. 8vo. 2s. 6 d. net.

Hill (Georgo Francis). ONE HUNDRED MASTERPIECES OF SCULPTURE. lllustrated. Demy $8 v 0$. ras. $6 d$. net.

Find (C. Lewis). DAYS IN CORNWALL. Illustrated. Third Edition. Cr. 800. 6s.

Hobhouse (L. T.). THE THEORY OF KNOWLEDGE. Demy 8zo. ros. 6d. net.

Robson (J. A.). INTERNATIONAL TRADE: AN APplication OF ECONOMIC THRORY. Cr. 8 vo. 2s. 6 d. net.
PROBLEMS OF POVERTY : AN INQUIR INTO THE INDUSTRIAL CONDITION OF THE POoR. Eighth Edition. Cr. 8v0. 2s. $6 d$.

THE PROBLEM OF THE UN. EMPLOYED: AN INQUIRY AND AN Economc Policy. Fifth Edition. Cr.8vo. 2s. $6 d$.

GOLD, PRICES AND WAGES: WITH AN EXaMination of THF, QUANTITy THEORY. Second Edition. Cr. $800 . \quad 3^{s .6}$. net.

Hodgson (Mrs. W.). HOW TO IDENTIFY OLD CHINESE PORCELAIN. Illustrated. Third Edition. Post 8vo. 6s.

Holdich (Sir T. H.). THE INDIAN BORDERLAND, r880-rgoo. Illustrated. Second Edition. Demy 800. ros. 6d. net.

Holdsworth (W. 8.). A HISTORY OF ENGLISH LAW. Four Volumes. Vols. I., II., III. Demy 8vo. Each ros. 6d. net.

Holland (Clive), TYROL AND ITS PEOPLE. Illustrated. Demy 800. Ias. $6 d$. net.

Morgburg'h (B. L. 8.). WATERLOO: A NarRative ANd a CRIticism. With Plans. Second Edition. Cr. 800 . 5s.

THE LIFE OF SAVONAROI.A. Illustrated. Cr. 8vo. 5s. net.

Hosio (Alexander). MANCHURIA. Illustrated. Second Edition. Demy 8vo. 7s. 6d. net.

Howell (A. G. Ferrers), ST. BERNARD. INO OF SIENA. Illustrated. Demy $8 v 0$. Ios. 6d. net.

Hudson (W. H.). A SHEPHERD'S LIFE: IMPRESSIONS OF THE SOUTH WILT. sHire Downs. Illustrated. Third Edition. Demy 800. 7s. 6d. net.

Humphreys (John H.). PROPORTIONAL REPRESENTATION. Cr. 8vo. 5s. net.

Hutton (Rdward). THE CITIES OF SPAIN. Illustrated. Fourth Edition. Cr. 8vo. 6s.

THE CITIES OF UMBRIA. Illustrated. Fifth Edition. Cr. 800. 6s.

THE CITIES OF LOMBARDY. Illus. trated. Cr. 8vo. 6s.

THE CITIES OF ROMAGNA AND THE MARCHES. Illustrated. Cr. 8\%o. 6s.

FLORENCE AND NORTHERN TUSCANY WITH GENOA. Illustrated. Third Edition. Cr. 8vo. 6s.

SIENA AND SOUTHERN TUSCANY. Illustrated. Second Edition, Cr, 8vo. 6 s. 
VENICE AND VENETIA. Illustrated. Cr. 8vo. 6s.

ROME. Illustrated. Third Edition. Cr. 8vo. 6s.

COUNTRY WALKS ABOUT FLORENCE. Illustrated. Second Edition. Fcap. 800. 5s. nct.

A BOOK OF THE WYE. Illustrated. Demy 800. 75. 6d. net.

Ibsen (Henrik)。 BRAND. A Dramatic Poem, translated by William Wilson. Fourth Edition. Cr. 800. 3s. 6d.

Inge(W. R.). CHRISTIAN MYSTICISM. (The Bampton Lectures of 1899.) Thind Edition. Cr. 8200 . 5s. net.

Innes (A. D.) A HISTORY OF THE BRITISH IN INDIA. With Maps and Plans. Cr. 8vo. 6 s.

ENGLAND UNDER THE TUDORS. With Maps. Fonrth Edition. Demy 800. 10s. 6 d. net.

Innes (远ary). SCHOOLS OF PAINT. ING. Illustrated. Second Edition. $\mathrm{Cr}$. 800. 5s. net.

Jenks (E.). AN OUTLINE OF ENGLISH LOCAL GOVERNMENT. Third Edition. Revised by R. C. K. Ensor Cr. 8vo. 2s. 6 d. net.

A SHORT HISTORY OF ENGLISH LAW: FroM THE EARLIEST TIMES TO tIIE END OF the Year 1911. Demy 800. 1os. $6 d$. net.

Jerningham (Charles Edward), THE MAXIMS OF MARMADUKE. Second Edition. Ficap. 800. 55.

JeYons (F. B.). PERSONALITY. Cr. 800. 2s. 6 d. net.

Johnston (Sir H. H.) BRITISH CEN. TRAL AFRICA. Illustrated. Third Edition. Cr. 4 to. 18s. net.

THE NEGRO IN THE NEW WORLD. lllustrated. Demy 800. 21s. net.

Julian (Lady) of Norwich. REVELA. TIONS OF DIVINE LOVE. Edited by GRACB WARRACK. Fiflh Edition. Cr. 8vo. 3s. 6d.

Keats (John). POEMS. Edited, with Introducrion and Notes, by E. de SÉlincourt. With a Frontispiece in Photogravure. 7hird Edition. Demy 800. 75. 6d. net.

Reble (John). THE CHRISTIAN YEAR. With an Introduction and Notes by W. LOCK. Illustrated. Third Edition. Fcap. Soc. 3s. $6 d$.
Kempis (Thomas a). THE IMITATION OF CHRIST. From the Latin, with an Introduction by DeAN FARRAR. Illustrated Fourth Edition. Fcap. 8vo. 35. 6d.

*THOMAE HEMERKEN A KEMPIS DE IMITATIONE CHRISTI. Edited by Adrian Fortescur. Cr. 4 to. Ei is. net.

Kipling (Rudyard). BARRACK.ROOM BALIADS. 127th Thowsand. Thirtyeighth Edition. Cr. 800. Buckram, 6s. Also Fcap. 8vo. Cloth, 4s. 6d. net; leather, 5s. net.

THE SEVEN SEAS. rorst Thousand. Twenty-third Edition. Cr. 8vo. Buckram, 6s. Also Fcap. 800. Cloth, 4s. 6d. net; leather, 5s. net.

THE FIVE NATIONS. 82nd.Thousand, Thirteenth Edition. Cr. 8vo. Buckram, 6s. Also Fcap. 800. Cloth, 4s.6d. net; leather. 5s. net.

DEPARTMENTAL DITTIES. Twenty. Fifth Edition Cr. 800. Buckram, 6s. Also Fcap. 8vo. Cloth, 45. 6d. net; leather, 5s. net.

Lamb (Charles and Mary). THE COM. PLETE WORKS. Edited, with an Introduction and Notes, by E. V. Lucas. $A$ New and Revised Edition in Six Volumes. With Frontispiece. Fcap. 800 . 5s. each. The volumes are :-

I. Miscellaneous Prose. II. Elia axd THz LAST ESSAYS OF Elia. III. BOOKS for Children. iv. Plavs and Poems. v. and VI. LeTters.

Lane-Poole (8tanley). A HISTORY OF EGYPT IN THE MIDDLE AGES. Illustrated. Cr. 8vo. 6s.

Lankester (Sir Ray). SCIENCE FROM AN EASY CHAIR. Illustrated. Seventh Edition. Cr.800. 6s.

Lee (Gerald Stanley). INSPIRED MIL LIONAIRES. Cr. 8vo. 35. 6d. net.

CROWDS: A STUDY OF THE GENIUS of DEMOCRACY, AND OF THE FEARS, DESIRES, AND Expectations of THE PEOPLE. Second Edition. Cr. 800 . $6 s$.

Lock (Walter). ST. PAUL, THE MASTER BUILDER. Third Edition. Cr. 800. 35. $6 \%$.

THE BIBLE AND CHRISTIAN LIFE. Cr. 800. 6s.

Lodge (8ir Oliver). THE SUBSTANCE OF FAITH, ALLIED WITH SCIENCE: A CATEChism fOR PARENTS AND TEAChERS Eleoenth Edition. Cr. 800. 2s. net.

MAN AND THE UNIVERSE: A STUDY OF THE INFLUENCE OF THE ADVANCE IN SCIENTIPIC KNOWLEDGE UTON OUR UNDERstanding of Christianity. Ninth Edition Demy 8vo. 5s. net.

Also Fcap. 800. 1s. net. 
THE SURVIVAL OF MAN : A STUDY IN UNRECOCNISEd Human Faculty. Fifth Edition. Wide Cr. 8vo. 5s. net.

REASON AND BELIEF. Fifth Edition. Cr. 8vo. 3s. 6 . set.

MODERN PROBLEMS. Cr. 8vo, 5s. net.

Lorebum (Karl). CAPTURE A'T SEA. Cr. 8vo. 2s. 6d. net.

Iorimer (Georfe Horace). LETTERS FROM A SELF.MADE MERCHANT TO HIS SON. Illustrated. Twenty. fourth Edition. Cr. $8 v 0$. 3s. $6 d$. Also Fcap. 8vo. is. net.

OLD GORGON GRAHAM. Illustrated. Second Edition. Cr. 8vo. 6s. Also Cr. 8vo. 2s. net.

Lucas (E. Y.). THE LIFE OF CHARLES LAMB. Illustrated. Sixth Edition. Demy 8v0. 7s. 6d. net.

A WANDERER IN HOLLAND. Illustrated. Fifteenth Edition. Cr. 8vo. 6 s.

A WANDERER IN LONDON. Illustrated. Sixteenth Edition. Cr. 8vo. 6s.

A WANDERER IN PARIS. Illustrated. Eleventh Edition. Cr. 8vo. 6s. Also Fcap. 8vo. 5s.

A WANDERER IN FLORENCE. Illus. trated. Fourth Edition. Cr. 8vo. $6 s$.

THE OPEN ROAD: A LITTLE BOOK FOR W A Y A RERS. Twenty-second Edition. Fcap. 8vo. 5s. India Paper, 7s. 6d. Also Illustrated. Cr. $4^{\text {to. }}$ iss. net.

THE FRIENDIY TOWN : A LiTTLE Book FOR THE URBANE. Eighth Edition. Fcap. 8700. 5 s.

FIRESIDE AND SUNSHINE. Seventh Edition. Fcap 8vo. 5 s.

CHARACTER AND COMEDY. Seventh Edition. Fcap. 8va. 5s.

THE GENTLES'T ART: A CHOICE OP LETTERS BY ENTERTAINING HANDS. Eighth Edition. Fcap. 800. 5 s.

THE SECOND POST. Third Edition. Fcap. 8vo. 5 s.

HER INFINITE VARIETY : A FEMININE, Portrait Gallery. Sixth Edition. Fcap. 8vo. 5 s.

GOOD COMPANY: A Rally of MEN. Second Edition. Fcap. 8vo. 5s.

ONE DAY AND ANOTHER. Fifth Edition. Fcap. \&vo. 5s.

OLD LAMPS FOR NEW. Fifth Edition. Fcap. 800. 5s.

LOITERER'S HARVEST. Second Edition. ficap. 8vo. 5 s.

LISTENER'S LURE: AN OBLIQUE NARRA. TION. Tenth Edition. Ficap. 8vo. 5s.

OVER BEMERTON'S: AN EASY-GOING Chronicle. Eleventh Edition. Frap. 8vo. 5s.
MR. INGLESIDE. Tenth Edition. Fcap 8v0. 55.

LONDON LAVENDER. Fcap. 8vo. 5s.

THE BRITISH SCHOOL : AN ANECDOTAL Guide to the British Painters and Paintings in the National Gallery. Fcap. 800. 2s. 6d. net.

HARVEST HOME. Fcap. 8vo. rs. net.

A LITTLE OF EVERYTHING. Third Edition. Fcap. 8vo. is. net.

See also Lamb (Charles).

Lydakker (R.). THE OX AND ITS KINDRED. Illustrated. $C r .8 v 0.6 s$.

Lydekker (R.) and others. REPTILES, AMPHIBIA, FISHES, AND LOWER CHORDATA. Edited by J. C. CunNINGHAM. Illustrated. Demy 8vo. ros. $6 d$. net.

Macaulay (Lord). CRITICAI, AND HISTORICAL ESSAYS. Edited by $\mathrm{F}$. C. Montague. Three Volumes. Cr. 800 . I8s.

McCabe (Joseph). THE EMPRESSIES OF ROME. Illustrated. Demy 8vo. 12s. 6ct. net.

THE EMPRESSES OF CONSTANTINOPLE. Illustrated. Dcmy 8vo. ros. 6i. net.

MacCarthy (Desmond) and Russell (Agatha). LADY JOHN RUSSELL: A Memolr. Illustrated. Fourth Edition. Demy 8zo. ros. 6d. net.

McDongall (William). AN INTRODUC. TION TO SOCIAL PSYCHOLOGY. Seventh Edition. Cr. 8vo. 5s. net.

BODY AND MIND: A HISTORY AND A DEFENCE or ANIMISM. Second Edition. Demy 8vo. ros. $6 d$. net.

Haeterlinck (Manrice). THE BLUE BIRD: A FaIKy Play IN Six ACTS. Translated by Alexander TEIXEIRA DE Mattos. Fcap. 8zo. Deckle Edges. 3s. 6d. net. Also Fcap. 8vo. Is. net. An Edition, illustrated in colour by F. CAYLEY RoBINson, is also published. Cr. 4 to. 21s. net. Of the above book Thirty-three Editions in all have been issued.

MARY MAGDALENE: A Play in Three Acts. Translated by Alexander Teixeira DE MATtos. Third Edition. Ficap. 8vo. Deckle Edges. 3 s. 6 d. net. Also Fcap. $8 v 0$. is. net.

OUR ETERNITY. Translated by ALExander Teixeira de Mattos. Ficap. 80 . 5s. net.

Maeterlinck (IIme. M.) (Gsorgette Lebianc). THE CHILDREN'S BLUEBIRD. Translated by ALEXANDER TeIXeIra de MAtros. Illustrated. Faca. 8vo. 5s. net. 
Mahaffy (J. P.)。 A HISTORY OF EGYPT UNDER THE PTOLEMAIC DYNASTY. Illustrated. Second Edition. Cr. 8ro. 6s.

Maitiand (F. W.), ROMAN CANON LAW IN THE CHURCH OF ENGLAND. Royal 8vo. 7s. $6 d$.

Marett (R. R.). THE THRESHOLD OF RELIGION. Third Edition. Cr. 800 . 5s. net.

Marriott (Charles), A SPANISH HOLIDAY. Illustrated. Demy 8vo. 75.6d. net. THE ROMANCE OF THE RHINE. Illustrated. Demy 8vo. ros. $6 d$. net.

Harriott (J. A. R.). ENGLAND SINCE WATERLOO. With Maps. Demy $8 v 0$. ros. $6 d$. ret.

Masefield (John), SEA LIFE IN NELSON'S TIME. Illustrated. Cr. 820 . 3s. 6 d. net.

A SAILOR'S GARLAND. Selected and Edited. Second Edition. Cr. 8vo. 3s. 6 d. net.

Masterman (C. F. G.) TENNYSON AS A RELIGIOUS TEACHER. Second Edition. Cr. 8vo. 6s.

THE CONDITION OF ENGLAND. Fourth Edition. Cr. 800. 6s. Also Fcap. 8vo. Is net.

Also Fcap. 8vo. Is. net.

Mayne (Ethel Colburn), BYRON. Illus. trated. Two Volumes. Demy 8vo. 21s. net.

Medley (D. J.). ORIGINAL ILLUSTRA. TIONS OF ENGLISH CONSTITU. TIONAL HISTORY. Cr. 800. 7s.6d. net.

Methuen (A.M. \$.). ENGLAND'S RUIN : Discussed in Fourteen LetTers to A Protrctionist. Ninth Edition. Cr. $8 v 0$. 3d. net.

Miles (Eustace). LIFE AFTER LIFE; or, The Theory of Reincarnation. Cr. 8vo. 2s. 6d. net.

THE POWER OF CONCENTRATION : How to ACQUiRe IT. Fourth Edition. Cr. 800. 3s. 6d. net.

MIllais (J. G.). THE LIFE AND LET. TERS OF SIR JOHN EVERET'T MILLAIS. Illustrated. New Edition. Demy 800. 7s. 6d. net.

Mline (J. G.). A HISTORY OF EGYPT UNDER ROMAN RULE. Illustrated. Second Edition. Cr. 8vo. 6s.

Mitchell (P.Chalmers). THOMAS HENRY HUXLEY. Fcap. 820. is. net.

Moffat (Mary M.)。 QUEEN LOUISA OF PRUSSIA. Illustrated. Fourth Edition. Cr. 8vo. 6s.

MARIA THERESA. Illustrated. Demy 8vo. Ios. $6 d$. net.
Money (L. G. Chlozza). RICHES AND POVERTY, rgro. Eleventh Edition. Demy 8vo. 5s. net.

MONEY'S FISCAL DICTIONARY, Igra Second Edition. Demy 800. 5s. net.

THINGS THAT MATTER: PAPERS ON SUBJECTS WHICH ARE, OR OUGHT TO BE, under Discussion. Demy 800 . 5s. net.

Montague (C. E.). DRAMATIC VALUES. Second Edition. Fcap. 800. 5s.

Moorhouse (E. Hallam). NELSON'S LADY HAMILTON. Illustrated. Third Edition. Demy 800. 75.6d. net.

Morgan (C. Hoyd). INSTINCT AND EXPERIENCE. Second Edition. Cr. 800. 5s. net.

Nevill (Lady Dorothy). MY OWN TIMES. Edited by her Son. Second Edition. Demy 8vo. 15s, net.

O'Donnell (Elliot). WERWOLVES. $C r$. 800. 5s. net.

Oman (C. W. C.). A HISTORY OF THE ART OF WAR IN THE MIDDLE AGES. Illustrated. Demy 800. zos. $6 d$. net.

ENGLAND BEFORE THE NORMAN CONQUEST. With Maps. Third Edition, Revised. Demy 8vo. 1os. 6d. net.

Oxford (M. N.). A HANDBOOK OF NURSING. Sixth Edition, Revised. Cr. 800 . 35. 6d. net.

Pakes (IV. C. C.). THE SCIENCE OF HYGIENE. Illustrated. Second and Cheaper Edition Revised by A. T. Nankivello Cr.800. 5s. net.

Parker (Eric). A BOOK OF THE ZOO. Illustrated. Second Edition Cr. 8vo. 6s.

Pears (Sir Edyin). TURKEY AND ITS PEOPLE. Second Edition. Demy 800. 12s. $6 d$. net.

Petrie (W. M. Flinders.) A HISTORY OF EGYPT. Illustrated. Six Volwmes. Cr. 8vo. 6s. each.

Vol. I. FROM THE Ist TO THE XVITH Dynasty. Seventh Edition.

VOL. II. THE XVIITH AND XVIIITH Dynasties. Fifih Edition.

Vol. III. XIXth to XXXth Dynasties. VOL. IV. EGYPT UNDER THE PTOLEMAIC Dynasty. J.P. MahafFy. Second Edition.

Vol, V. Egypt under Roman Rule. J. G. MILNE. Second Edition.

Vol. VI. Egypt in THE MidDLe AGtes. Stanley Lane-Poole. Second Edition. 
RELIGION AND CONSCIENCE IN ANCIENT EGYPT. Illustrated. Cr.8vo. 2s. $6 d$.

SYRIA AND EGYPT, FROM THE TELL EL AMARNA LETTERS. Cr. $8 v o$. 2s. $6 d$.

EGYPTIAN TALES. Translated from the Papyri. First Series, Ivth to xith Dynasty. Illustrated. Second Edition. Cr. $8 v 0$. 3s. $6 d$.

EGYPTIAN TALES. Translated from the Papyri. Second Series, xvilith to xixth Dynasty. Illustrated. Second Edition. Cr. 8vo. 3s. $6 d$.

EGYPTIAN DECORATIVE ART. Illus• trated. Cr. $8 z^{\prime 0}$ 3s. $6 d$.

Pollard (Alfred W.). SHAKESPEARE FOLIOS AND QUARTOS. A Study in the Bibliography of Shakespeare's Plays, 1594-1685. Illustrated. Folio. EI Is. net.

Porter (G. R.). THE PROGRESS OF THE NATION. A New Edition. Edited by F. W. Hirst. Demy $8 v 0$. EI is. net.

Power (J. O'Connor). THE MAKING OF AN ORATOR. Cr. 8vo. 6s.

Price (L. Lo), A SHORT HISTORY OF POLITICAL ECONOMY IN ENGLAND FROM ADAM SMITH TO ARNOLD TOYNBEE. Seventh Edition. Cr. 8vo. 2s. $6 d$.

Pycraft (W.P.). A HISTORY OF BIRDS. Illustrated. Demy $8 v 0$. Ios. 6 d. net.

Rawlings (Gertrude B.). COINS AND HOW TO KNOW THEM. Illustrated. Third Edition. Cr. 8vo. 6s.

Regan (C. Tait). THE FRESHWATER FISHES OF THE BRITISH ISLES. Illustrated. $\mathrm{Cr} .8 v 0$. $6 s$.

Reid (Arrchdall). THE LAWS OF HEREDITY. Second Edition. Demy 800. EI Is. net.

Robertson (C. Grant). SELECT STAT. UTES, CASES, AND DOCUMENTS, 1660-1832. Second, Revised and Enlarged Edition. Demy 8vo. ros. 6d. net.

ENGLAND UNDER THE HANOVERIANS. Illustrated. Second Edition. Demy 8vo. Ios. $6 d$. net.

Roe (Fred), OLD OAK FURNITURE. Illustrated. Second Edition. Demy 8vo.
*Rolle (Richard). THE FIRE OF LOVE and THE MENDING OF LIFE. Edited by Frances M. Comper. Cr. $8 v 0$. 3s. $6 d$. net.

Ryan (P. F. W.). STUART LIFE AND MANNERS: A Soc1al History. Illustrated. Demy 8vo. ros. 6d. net.

Ryley (A. Beresford). Illustrated. Royal 8vo. £2 2s. net.

'Saki' (H. H. Munro). REGINALD. Third Edition. Fcap. 8vo. 2s. 6d. net.

REGINALD IN RUSSIA. Fcap. $8 v 0$. 2s. 6d. net.

Bandeman (G. A. C.). METTERNICH. Illustrated. Demy 8vo. ros. 6d. net.

Schidrowitz (Philip). RUBBER. Illustrated. Demy 8vo. Ios. 6 . net.

Schloesser (H. H.). TRADE UNIONISM, Cr. 8vo. 2s. $6 d$.

Selous (Edmund). TOMMY SMITH'S ANIMALS. Illustrated. Thirtecnth Edition. Fcap. 8vo. 2s. 6d.

TOMMY SMITH'S OTHER ANIMALS. Illustrated. Sixth Edition. Fcap. 8vo. 2s. $6 d$.

JACK'S INSECTS. Illustrated. Cr.8vo. $6 s$.

Shakespeare (William).

THE FOUR FOLIOS, $1623 ; 1632 ; 1664$; x685. Each $£_{4} 4$ s. net, or a complete set, tI2 12s. net.

THE POEMS OF WILLIAM SHAKESPEARE. With an Introduction and Notes by George Wyndham. Demy 8vo. Buckram, ios. $6 d$.

Shaw (Stanley), WILLIAM OF GERMANY. Demy 8vo. 7s. 6d. net.

Shelley (Percy Bysshe). POEMS. With an Introduction by A. CLUTTON-BROCK and notes by C. D. Locock. Two Volumes. Deny 8vo. EI is. net.

Smith (Adam). THE WEALTH OF NATIONS. Edited by EDwin CANNAN. Two Volumes. Demy 8vo. EI is. net.

Smith (G. F. Herbert). GEM-STONES AND THEIR DISTINCTIVE CHARACTERS. Illustrated. Second Edition. Cr. 8vo. 6s. net. 
8nell (F. J.). A BOOK OF EXMOOR. Illustrated. $\mathrm{Cr} .820 .65$.

THE CUSTOMS OF OLD ENGLAND. Illustrated. Cr. 8vo. 6 s.

'Stancliffo.' GOLF DO'S AND DONT'S. Fifth Edition. Fcap. 8v0. 1s. net.

Stexenson (R. L.). THE LETTERS OF ROBERT LOUIS STEVENSON. Edited by Sir Sidney Colvin. A New and En. langed Edition in four volumes. Fourth Edition. Fcap. 8vo. Each 5s. Leather, each 5s. net.

Storr (Yernon F.) DEVELOPMENT AND DIVINE PURPOSE. Cr. 800.55. net.

Streatfelld (R. A.) MODERN MUSIC AND MUSICIANS. Illustrated. Second Edition. Demy 8vo. 7s. 6d. net.

Surtees (R. 8.). HANDLEY CROSS. Illustrated. Fifth Edition. Fiap. 8rn. Gilt top. 3s. 6d. net.

MR. SPONGE'S SPORTING TOUR. Illustrated. Second Edition. Ficap. 8vo. Gilt top. 3s. 6d. net.

ASK MAMMA; OR, THE RICHEST COMMONER IN ENGLAND. Illustrated. Fcap. 8vo. Gilt top. 35. 6d. not.

JORROCKS'S JAUNTS AND JOLLITIES. Illustrated. Fourth Edition. Fcap. 800. Gilt top. 3s. 6 d. net.

MR. FACEY ROMFORD'S HOUNDS. Illustrated. Fcap. 8vo. Gilt top. $3^{s}$. 6d. net.

HAWBUCK GRANGE; OR, THE SPORTING ADVENTURES OF THOMAS SCOTT, EsQ. Illustrated. Fcap. 800. Gilt top. 3s. 6 d. net.

Suso (Henry). THE LIFE OF THE BLESSED HENRY SUSO. BY HIMASELF. Translated by T. F. Knox. With an Introduction by DeAn INGE. Second Edition. Cr. 800. 3s. 6d. net.

Bwanton (E. W.). FUNGI AND HOW TO KNOW THEM. Illustrated. $C r$. 800 . 6s. net.

BRITISH PLANT.GALIS. Cr. 800. 75. 6d. net.

8ymes (J. E.). THE FRENCH REVO. LUTION. Second Edition. Cr:800. 2s.6d.

Tabor (Margaret E.). THE SAINTS IN ART. With their Attributes and Symbols Alphabetically Arranged. Illustrated. Third Edition. Fcap.8vo. 35.6d.net.

Taylor (A. E.). ELEMENTS OF META. PHYSICS. Second Edition. Demy $8 v 0$. ros. $6 d$. net.
Taylor (Mra. Basil) (Harriet Osgood) JAPANESE GARDENS. Illustrated. Cr. 4 to. EI is. net.

Thibaudeau (A. C.) BONAPARTE AND THE CONSULATE. Translated and Edited by G. K. Fortzscue Illustrated. Dency 8vo. ros. $6 d$. net.

Thomas (Edward). MAURICE MAETERLINCK. Illustrated. Second Edition. Cr. 8v0. 5s. net.

Thompson (Francis). SELECTED POEMS OF FRANCIS THOMPSON. With a Biographical Note by WILFRID Mernell. With a Portrait in Photogravure. Twentieth Thousand. Ficap. 8vo. 55. net.

Tileston (Mary W.). DAILY STRENGTH FOR DAILY NEEDS. Truenty-first Edition. Medium x6mo. 2s. 6d. net. Also an edition in superior binding, 6 .

THE STRONGHOLD OF HOPE. Medium r6me. 2s. 6d. net.

Toynbee (Paget). DANTE ALIGHIERI. His LifE AND WORKS. With $x 6$ Illustra. tions. Fourth and Enlarged Edition. Cr. 8vo. 5s. net.

Trexelyan (Q. M.). ENGLAND UNDER THE STUARTS. With Maps and Plans. Sixth Edition. Demy 8vo. ros. 6d. net.

Triggs (H. Inlgo). TOWN PLANNING : PAST, PRESENT, and Possiblet lilustra: ted. Second Edition. Wide Royal 800 . 15. net.

Turner (SIr Alfred E.). SIXTY YEARS OF A SOLDIER'S LIFE. Demy svo. 12s. $6 d$. net.

Underhill (Evelyn)。 MYSTICISM A Study in the Nature and Development of Man's Spiritual Consciousness. Fifth Edition. Demy 8vo. 15s. net.

Urwick (E. J.). A PHILOSOPHY OF SOCIAL PROGRESS. Cr. $800.6 s$.

Yardon (Harry). HOW TO PLAY GOLF. Illustrated. Seventh Edition. Cr. $8 v 0$. 2s. $6 d$. net.

Yernon (Hon. W. Warren), READINGS ON THE. IN FERNO OF DANTE. With an Introduction by the Rev. Dr. MOORE. Two Volumes. Second Edition. Cr. 8vo. 35. net.

READINGS ON THE PURGATORIO OF DANTE. With an Introduction by the late Dran CHurch. Two Volumes. Third Edition. Cr. 800 . 15s. net. 
READINGS ON THE PARADISO OF DANTE. With an Introduction by the Bishop of Ripon. Two Volumes. Second Edition. Cr. 8vo. 15s. net.

Yickers (Kenneth H.). ENGLAND IN THE LA'TER MIDDLE AGES. With Maps. Denty 8vo. Ios. $6 d$. net.

Waddell (L. A.). LHASA AND ITS MYSTERIES. With a Record of the Expedition of 1903-1904. Illustrated. Third and Cheaper Edition. Mediwm 8vo. 7s.6d. net.

Wade (G. W. and J. H.). RAMBLES IN SOMERSET. Illustrated. $C r$. 8vo. $6 s$.

Wagner (Richard), RICHARD WAGNER'S MUSIC DRAMAS. Interpretations, embodying Wagner's own explanations. By Al.ICE Leighton Cleather and BasiL CRUMP. Fcap. 8vo. 2s. 6d.each. The Ring of the Nibelung. Sixth Edition.

LOHENGRIN AND PARSIFAl. Third Edition.

TRISTAN AND ISOLDE. Second Edition.

Tannhāuser and the Mastersingers OF NUREMBURG.

Waterhouse (Elizabeth). WITH THE SIMPLE-HEARTED. Little Homilies to Women in Country Places. Third Edition. Small Pott 8vo. 2s. net.

THE HOUSE BY THE CHERRY TREE. A Second Series of Little Homilies to Women in Country Places. Small Pott 8vo. 2s. net.

COMPANIONS OF THE WAY. Being Selections for Morning and Evening Reading. Chosen and arranged by ELIZABETH WATERHOUSE. Large Cr. 8vo. 5s. net.

THOUGH'TS OF A TERTIARY. Small Pott 8vo. is. net.

VERSES. A New Edition. Fcap. 8vo. 2s. net.

Waters (W. G.). ITALIAN SCULPTORS. Illustrated. $C r .8 v o$. $7 s$. $6 d$. net.

Watt (Francis). EDINBURGH AND THE LOTHIANS. Illustrated. Second Edition. Cr. $8 v 0$. tos. 6 d. net.

R. L. \$. Second Edition. Cr. 8vo. 6s.

Wedmore (Sir Frederick). MEMORIES. Second Edition. Demy 8vo. 7s. 6d. net.

Weigall (Arthur E. P.). A GUIDE TO THE ANTIQUITIES OF UPPER EGYPT : FROM ABYDOS TO THE SÚDAN Frontier. Illustrated. Second Edition. Cr. 8vo. 7s. 6d. net.
Wells (J.). OXFORD AND OXFORD LIFE. Third Edition. Cr. 800. 3s. $6 d$.

A SHORT HISTORY OF ROME. Thir. teenth Edition. With 3 Maps. Cr. 8vo. 3s. $6 d$.

Whitten (Wilfred). A LONDONER'S LONDON. Illustrated. Second Edition. Cr. 8vo. 6s.

Wilde(Oscar). THE WORKS OF OSCAR WILDE. Twelve Volumes. Ficap. 8vo. 5s. net each volume.

I. Lord Arthur Savile's Crime and the Portrait of Mr. W. H. II. The Duchess of Padua. III. Poems. IV. LADY WINDERMERE'S FAN. v. A WOMAN of No Importance. VI. AN IDEAL HUSBAND. VII. THE IMPORTANCE OF BEING EARnest. vili. A HOUSE OF POMEgranates. IX. Intentions. X. De ProFUNDIS AND PRISON LetTers. XI. EsSays. Xil. Salome, A Florentine Tragedy, and La Sainte Courtisane.

Williams (H. Noel). A ROSE OF SAVOY : Marie Adélaide of Savov, Duchesse de Bourgogne, Mother of Louis xv. Illustrated. Second Edition. Demy 8vo. ${ }_{5} 5$. net.

THE FASCINATING DUC DE RICHELIEU: LOUIS FRANÇOIS ARMAND DU Plessis (1696-1788). Illustrated. Demy 8vo. I5s. net.

A PRINCESS OF ADVENTURE: MARIE Caroline, Duchesse de BerRy (I7981870). Illustrated. Demy 8vo. I5s. net.

THE LOVE AFFAIRS OF THE CONDÊS (1 530-r740). Illustrated. Demy 8vo. 15s. net.

Wilson (Ernest H.). A NATURALIST IN WESTERN CHINA. Illustrated. Second Edition. Demy 8vo. ŁI ros. net.

Wood (Sir Eyelyn), FROM MIDSHIP. MAN TO FIELD-MARSHAL. Illustrated. Fifth Edition. Demy 8vo. 7s. 6d. net.

Also Fcap. 8vo. is. net.

THE REVOLT IN HINDUSTAN (185759). Illustrated. Second Edition. Cr.8vo. $6 s$.

Wood (W. Birkbeck) and Edmonds (Col. J. E.). A HISTORY OF THE CIVIL WAR IN THE UNITED STATES $(1861-65)$. With an Introduction by SPENSER Wilkinson. With 24 Maps and Plans. Third Edition. Demy 800. 12s. 6d. net.

Wordsworth (W.). POEMS. With an Introduction and Notes by Nowel $C$. Smith. Three Volumes. "Demy 8zo. 15. net.

Yeats (W. B.). A BOOK OF IRISH VERSE. Third Edition. Cr. 8vo. 3s. 6 d. 


\section{Part II.-A Selection of Series}

\section{Ancient Cities}

General Editor, Sir B. C. A. WINDLE

Cr. 8vo. 4s. 6d. net each volume

With Illustrations by E. H. New, and other Artists

BRISTOL Alfred Harvey.

Canterbury. J. C. Cox.

Chester. Sir B. C. A. Windle.

Dublin. S. A. O. Fitzpatrick.
EDINBURGH. M. G. Williamson.

Lincoln. E. Mansel Sympson.

Shrewsbury. T. Auden.

Wells and Glastonbury. T. S. Holmes.

\section{The Antiquary's Books}

\section{General Editor, J. CHARLES COX}

\section{Demy 8vo. 75. 6d. net each volume}

With Numerous Illustrations

Ancient Painted Glass in England. Philip Nelson.

\section{Arch fology and False Antiquities.} R. Munro.

Bells of England, The. Canon J. J. Raven. Second Edition.

Brasses of England, The. Herbert W. Macklin. Third Edition.

Celtic Art in Pagan and Christian Trmes. J. Romilly Allen. Second Edition.

Castles and Walled Towns of England, THE. A. Harvey.

ChuRChWARDEN'S ACCOUNTS FROM THE Fourteenth Century to the Close of the Seventeenth Century.

DOMESday Inquest, The. Adolphus Ballard.

English Church Furniture. J. C. Cox and A. Harvey. Second Edition.
English Costume. From Prehistoric Times to the End of the Eighteenth Century. George Clinch.

English Monastic Life. Abbot Gasquet. Fourth Edition.

English Seals. J. Harvey Bloom.

Felk-Lore as an Historical Science. Sir G. L. Gomme.

Gilds and Companies of London, The. George Unwin.

*Hermits and Anchorites of England, The. Rotha Mary Clay.

Manor and Manorial Records, The. Nathaniel J. Hone. Second Edition.

Medieval Hospitals of England, The. Rotha Mary Clay.

Old English Instruments of Music. F. W. Galpin. Second Edition. 


\section{The Antiquary's Books-continued}

Old English Libraries. James Hutt.

Old Service Books of the ENglish Church. Christopher Wordsworth, and Henry Littlehales. Second Edition.

Parish Life in Medifeval England. Abbot Gasquet. Third Edition.

Parish Registers of England, The. J. C. Cox.
Remains of the Prehistoric Age in ENGLAND. Sir B. C. A. Windle. Second Edition.

ROMAN ERA in Britain, The. J. Ward. Romano-British Buildings and Earth wORKS. J. Ward.

Roval Forests of England, The. J. C. Cox.

Shrines of British Saints. J. C. Wall.

\section{The Arden Shakespeare.}

\section{Demy 8vo. 2s. $6 d$. net each volume}

An edition of Shakespeare in Single Plays; each edited with a full Introduction, Textual Notes, and a Commentary at the foot of the page

All's Well That Ends Well.

Antony and Cleopatra. Second Edition. As You Like IT.

Cymbeline.

Comedy of Errors, The

HaMlet. Third Edition.

Julius Caesar.

*King Henry iv. PT. I.

KING HENRY v.

King HenRy vi. PT. I.

King Henry vi. Pt. Il.

King Henry vi. Pr. III.

King Lear.

KING RICHARD II.

KING RICHARD 111.

Life and Death of King John, The.

Love's Labour's Lost. Second Edition.
Macbeth.

Measure for Measure.

Merchant of Venice, The. Second Edition. MERRY Wives OF WiNDSOR, The.

Midsummer Night's Dream, A.

OTHELLO.

Pericles.

Romeo and Juliet.

TAMING OF THE SHREW, THE.

Tempest, The.

TimON OF ATHENS.

Titus ANDRONicus.

Troilus AND Cressida.

Two Gentlemen of Verona, The.

TWELFTH Night.

Venus and Adonis.

Winter's TAle, THE

\section{Classics of Art}

Edited by Dr. J. H. W. LAING

\section{With numerous Illustrations. Wide Royal 8vo}

Art of the Greeks, The. H. B. Walters. i2s. 6 d. net.

Art of the Romans, The. H. B. Walters. 15s. net.

Chardin. H. E. A. Furst. 12s. 6 d. net.
Donatello. Maud Cruttwell. I5s. net.

Florentine Sculptors of ThE RENAISSANCE. Wilhelm Bode. Translated by Jessie Haynes. 12s. 6 d. net.

George Romney. Arthur B. Chamberlain. 12s. 6d. net. 


\section{Classics of Art-continued}

Ghirlandaio. Gerald S. Davies. Second Edition. ros. 6 d. net.

Lawrence. Sir Walter Armstrong. EI rs. net. Michelangelo. Gerald S. Davies. 12s. $6 d$. net.

Raphael. A. P. Oppe. 12s. 6d. net.

REMBRANDT'S ETCHINGS. A. M. Hind. Two Volumes, 21s, net.
RUBENS. Edward Dillon. 25s. net.

Tintoretro. Evelyn March Phillipps. 15 s. net.

Titian. Charles Ricketts. 15s. net.

TURner's Sketches and Drawings. A. J. Finberg. Second Edition. 12s. 6d. net.

Velazquez. A. de Beruete. ros. 6 d. net.

\section{The 'Complete' Series.}

\section{Fully Illustrated. Demy $8 v 0$}

The Complete Association Footballer. B. S. Evers and C. E. Hughes-Davies. 5s. net.

The Complete Athletic Trainer. S. A. Mussabini. 5s. net.

The Complete Billiard Player. Charles Roberts. xos. $6 d$. net.

The Complete Boxer. J. G. Bohun Lynch. ss. net.

The Complete Cook. Lilian Whitling. 7s. 6d. net.

The Complete Cricketer. Albert E. KNIGHT. 75. 6d. net. Second Edition.

The Complete Foxhunter. Charles Richardson. 12s. 6d. net. Second Edition.

Thr CoMplete Golfer. Harry Vardon. I0s. 6d. net. Thirteenth Edition.

The Complete Hockey-Player. Eustace E. White. ss. net. Second Edition.

The Complete Horseman. W. Scarth Dixon. Second Edition. xos. $6 d$. net.
The Complete Lawn Tennis Player. A. Wallis Myers. jos. 6d. net. Fourth Edition.

The Complete Motorist. Filson Young. 12s. 6d. net. New Edition (Siventh).

The Complete Mountaineer. G. D. Abraham. 15s, net. Second Edition.

The Complete Oarsman. R. C. Lehmann. 105. $6 d$. net.

The Complete Photographer. R. Child Bayley. ros. 6d. net. Fifith Edition, Revised.

The Complete Rugey Footballer, on the New Zealand System. D. Gallaher and W. J. Stead. ros. $E d$. net. Second Edition.

The Complete Shot. G. T. TeasdaleBuckell. 12s. 6 d. net. Third Edition.

The Complete Swimmer. F. Sachs. 7s. $6 d$. net.

The Complete Yachtsman. B. HeckstallSmith and E. du Boulay. Second Edition, Reoised. r5s. net.

\section{The Connoissear's Library}

\section{With numerous Illustrations. Wide Royal 8vo. 25s. net each volume}

ENGLiSh Furniture. F. S. Robinson.

English Coloured Books. Martin Hardie. Etchings. Sir F. Wedmore Second Edition. European Enamels. Henty H. Cunyng. hame.

Grass, Edward Dillon.

GoldsMiths' AND Silversmiths' Work. Nelson Dawson. Second Edition.

illuminated Manuscripts. J. A. Herbert. Second Edition.
Ivories. Alfred Maskell.

Jrwellery. H. Clifford Smith. Second Edition.

Mezzotints. Cyril Davenport.

Miniatures. Dudley Heath.

Porcelain. Edward Dillon.

Fine Books. A. W. Pollard.

Seals. Walter de Gray Birch.

Wood Sculpture. Alfred Maskell. Second Edition. 


\section{Handbooks of English Church History}

Edited by J. H. BURN. Crozen 8vo. 2s. 6d. net each volume

The Foundations of the English Church. J. H. Maude.

The Saxon Church and the Norman Conquest. C. T. Cruttwell.

The Medieval Church and the Papacy. A. C. Jennings,

\section{Handbooks of Theology}

The Doctrine of THE Incarnation. R. L. Ottley. Fifth Edition, Revised. Demy 8vo. I2s. 6d.

A History of Early Christian Doctrine. J. F. Bethune-Baker. Demy 8vo. Ios. $6 d$.

AN INTRODUCTION TO THE HISTORY OF Religion. F. B. Jevons. Sixth Edition. Deiny 8vo. ros. $6 d$. Ios. $6 d$.
The Reformation Period. Henry Gee.

The Struggle with Puritanism. Bruce Blaxland.

The Church of England in The Eigh. teenth Century. Alfred Plummer.

AN IntRoduction to THE History OF the Creeds. A. E. Burn. Demy 8vo. 10s. $6 d$.

The Philosophy of Religion in England AND America. Alfred Caldecott. Demy $8 v 0$.

The XXXIX Articles of the Church of ENGLAND. Edited by E. C. S. Gibson. Seventh Edition. Demy 8vo. r2s. 6 d.

\section{The 'Home Life' Series}

\section{Illustrated. Demy 8vo. 6s. to ros. 6d. net}

Home Life in America. Katherine G. Home Life in Italy. Lina Duff Gordon. Busbey. Second Edition.

Home Life in France. Miss Betham. Edwards. Sixth Edition.

Home Life in Germany. Mrs. A. Sidgwick. Second Edition.

Home Life in Holland. D. S. Meldrum. Second Edition. Second Edition.

Home Life in Norway. H. K. Daniels. Second Edition.

Home Life in Russia. A. S. Rappoport.

Home Life in Spain. S. L. Bensusan. Second Edition.

\section{The Illustrated Pocket Library of Plain and Coloured Books} Fcap. 8vo. 3s. 6d. net each volume

\section{WITH COLOURED ILLUSTRATIONS}

The Life and Death of John Mytton, EsQ. Nimrod. Fifth Edition.

The Life of a Sportsman. Nimrod.

Handley Cross. R. S. Surtees. Fourth Edition.

Mr. Sponge's Sporting Tour. R. S. Surtees. Second Edition.

JoRROCKS'S JAUNTS AND JOLlities. R. S. Surtees. Third Edition.

Ask Mamma. R. S. Surtees.
The Analysis of the Hunting Field. R. S. Surtees.

The Tour of Dr. Syntax in Search of the Picturesque. William Combe.

The Tour of Dr. Syntax in Search of Consolation. William Combe.

The Third Tour of Dr. Syntax in Searcil of A Wife. William Combe.

Life in London. Pierce Egan.

\section{WITH PLAIN ILLUSTRATIONS}

The Grave: A Poem. Robert Blair.

ILI.USTRATIONS OF THE BOOK OF JOB. Invented and Engraved by William Blake, 


\section{Leaders of Religion}

\section{Edited by H. C. BEECHING. With Portraits}

\section{Crown 8vo. 2s. net each volume}

Cardinal Newman. R. H. Hutton.

JOHN WESLEY. J. H. Overton.

BISHOP WILBERFORCE. G. W. Daniell.

Cardinal Manning. A. W. Hutton.

Charles Simeon. H. C. G. Moule.

Jонn Knox. F. MacCunn. Second Edition. John Howe. R. F. Horton.

Thomas Ken. F. A. Clarke.

George Fox, the QuAKer. T. Hodgkin. Third Edition.

JoHN KeBLE. Walter Lock.
Thomas Chalmers. Mrs. Oliphant. Second Edition.

LANCELot ANDrewes. R. L. Ottley. Second Edition.

Augustine of Canterbury. E. L. Cutts.

William LaUd. W. H. Hutton. Fourth Edition.

John Donne. Augustus Jessop.

Thomas Cranmer. A. J. Mason.

Latrmer. R. M. and A. J. Carlyle.

Bishop ButLER, W. A. Spooner.

\section{The Library of Deyotion}

With Introductions and (where necessary) Notes

Sinalt Pott 8vo, cloth, 2s.; leather, 2s. 6d. net each volume

The Confessions of St. Augustine. Eighth Edition.

The Imitation of Christ. Sixth Edition. The Christian Year. Fifth Edition.

Lyra In NOCENTIUM. Third Edition.

The Temple. Second Edition.

A Book of Devotions. Second Edition.

a Serious Call to a Devout and Holy LifE. Fifth Edition.

A Guide to Eternity.

THE INNER WAy. Second Edition.

ON THE LOVE OF God.

Thb Psalms of David.

Lyra Apostolica.

The SONg of SONGS.

The Thoughts of Pascal. Second Edition.

A Manual of Consotation from the Saints and Fathers.

DEVOTIONS From the APOCRYPHA.

The Spiritual Combat.
The Devotions of St. Anselm.

Bishor Wilson's Sacra Privata.

Grace Abounding to the Chief of Sin. NERS.

LyRA SACRA. A Book of Sacred Verse. Second Edition.

A Day Book from the Saints and Fathers.

A Little Book of Heavenly Wisdom. A Selection from the English Mystics.

LiGHT, LIFE, and Love. A Selection from the German Mystics.

AN Introduction to the Devout Life.

The Little Flowers of the Glorious Messer St. Francis and of his Friars.

DEATH AND IMMORTALITY.

The SpIritual Guide. Third Edition.

Devotions for EVERY DAY IN THE WEEk AND The. Great Festivals.

Preces Privatae.

Horae Mysticar. A Day Book from the Writings of Mystics of Many Nations. 


\section{Little Books on Art}

With many Illustrations. Demy 16mo. 2s. 6 d. net each volume

Each volume consists of about 200 pages, and contains from 30 to 40 Illustrations, including a Frontispiece in Photogravure

Albrecht DÜRER. L. J. Allen.

Arts of JAPAN, ThE. E. Dillon. Third Edition.

Bookplates. E. Almack.

Bot ticell. Mary L. Bonnor.

Burne-Jones. F. de Lisle.

Cellini. R. H. H. Cust.

Christian Symbolism. Mrs. H. Jenner.

Christ in Art. Mrs. H. Jenner.

Claude. E. Dillon.

Constable H. W. Tompkins. Second Edition.

Corot. A. Pollard and E. Birnstingl.

EArly English Water-Colour. C. E. Hughes.

Enamels. Mrs. N. Dawson. Second Edition.

Frederic Leighton. A. Corkran.

George Romney. G. Paston.

Greek ARt. H. B. Walters. Fifth Edition.

Greuze AND Boucher. E. F. Pollard.

Holbein. Mrs. G. Fortescue.

Illuminated Manuscripts. J. W. Bradley.

Jewellery. C. Davenport. Second Edition.

JOHN HOPPNER. H. P. K. Skipton.

Sir Joshua Reynolds. J. Sime. Second Edition.

Millet. N. Peacock. Second Edition.

Miniatures. C. Davenport, V.D., F.S.A. Second Edition.

OUR LAdy in ARt. Mrs. H. Jenner.

Raphael. A. R. Dryhurst.

Rodın. Muriel Ciolkowska.

TURNer. F. Tyrrell-Gill.

VANDYCK. M. G. Smallwood.

VELAzQuez. W. Wilberforce and A. R. Gilbert.

Watrs. R. E. D. Sketchley. Second Edition.

\section{The Little Galleries}

\section{Demy I6mo. 2s. 6d. net each volume}

Each volume contains 20 plates in Photogravure, together with a short outline the life and work of the master to whom the book is devoted

A Little Gallery of Reynolds.

A Little Gallery of Rominey.
I A little Gallery of Hoppner.

A Little Gallekry of Mullais.

\section{The Little Guides}

With many Illustrations by E. H. New and other artists, and from photographs Small Pott 8vo. Cloth, 2s. 6d. net; leather, 3s. 6d. net each volume

The main features of these Guides are ( 1 ) a handy and charming form ; (2) illustrations from photographs and by well-known artists; (3) good plans and maps; (4) an adequate but compact presentation of everything that is interesting in the natural features, history, archæology, and architecture of the town or district treated.

CAMBRIDGE AND ITS Colleges. A. H.
Thompson. Third Edition, Revised.

Channel Islands, The. E. E. Bicknell.

ENGLiSH LaKes, THE, F, G. Brabant.
Isle of Wight, The. G. Clinch.

LONDON. G. Clinch.

Malvern Country, The. Sir B.C.A. Windle. NORTh WALES. A. T. Story. 


\section{The Little Guides-continued}

OXFORD AND itS COLleges. J. Wells. Tenth Edition.

St. Paul's Cathedral. G. Clinch.

Shakespeare's Country. Sir B. C. A. Windle. Fifth Edition.

South Wal.es. G. W. and J. H. Wade.

Westminster AbBey. G. E. Troutbeck. Second Edition.

Berkshire. F. G. Brabant.

Bickinghamsitire. E. S. Roscoe. Second Edition.

Cheshrre. W. M. Gallichan.

Cornwallo A. L. Salmon. Second Edition. Derbyshire. J. C. Cox.

Devon. S. Baring-Gould. Third Edition.

DORSET. F. R. Heath. Third Edition.

DURнам. J. E. Hodgkin.

Essex. J C. Cox.

HAMPShIRE. J. C. Cox. Second Edition.

HertFordshire. H. W. Tompkins.

KENT. G. Clinch.

Kerry. C. P. Crane. Second Edition.

Leicestershire and Rutland. A. Harvey and V. B. Crowther-Beynon.

Middlesex. J. B. Firth.

MoNmouthshire. G. W. and J. H. Wade.
NoRfOLK. W. A. Dutt. Third Edition, Revised.

Northamptonshire. W. Dry. New and Revised Edition,

Northumberland. J. E. Morris.

Nottinghamshire. Luilford.

Oxfordshire. F. G. Brabant.

Shropshire. J. E. Auden.

Somerset. G. W. and J. H. Wade Second Edition.

Staffordshire. C. Masefield.

Sufrolk. W. A. Dutt.

SURREY. J. C. Cox.

Sussex. F. G. Brabant. Fourth Edition.

WILtshire. F. R. Heath. Second Edition.

YoRkshire, The EAst Riding J. E. Morris.

YORKSHIRE, THE NORTH RIDING. J. E. Morris.

Yorkshire, The West Riding. J. E. Morris. Cloth, 3s. 6d. net; leather, 4s. $6 d$. net.

Brittany. S. Baring-Gould. Second Editipn. Normandy. C. Scudamore.

Rome. C. G. Ellaby.

Sicily. F. H. Jackson.

\section{The Little Library}

With Introduction, Notes, and Photogravure Frontispieces

Small Pott 8vo. Each Voluine, cloth, Is. 6d. net

Anon. A LITTLE BOOK OF TNGLISH LYRICS. Second Edition.

Austen (Jane). PRIDE AND PREJU. DICE. Two Volumes.

NORTHANGER ABBEY.

Bacon (Francis), THE ESSAYS OF LORD BACON.

Barham (R. H.). THE INGOLDSBY LEGENDS. Two Volumes.

Barnott (Innie). A LITTLE BOOK OF ENGLISH PROSE.

Beckford (William)。 THE HISTORY OF THE CALIPH VATHEK.
Blake (William), SELECTIONS FROM THE WORKS OF WILLIAM BLAKE.

Borrow (George). LAVENGRO. Two Volumes.

THE ROMANY RYE.

Browning(Robert). SELECTIONS FROM THE EARLY POEMS OF ROBERT BROWNING.

Canning (Georgo). SELECTIONS FROM THE ANTI-JACOBIN : With some later Poems by George Canning.

Cowley (Abraham), THE ESSAYS OF ABRAHAM COWLEY. 


\section{The Little Library-continued}

Crabbe (George). SELECTIONS FROM THE POEMS OF GEORGE CRABBE.

Cralk (Mrs.). JOHN HALIFAX, GENTLEMAN. Two Volumes.

Crashay (Richard). THE ENGLISH POEMS OF RICHARD CRASHAW.

Dante Alighieri. THE INFERNO OF DANTE. Translated by H. F. CARY.

THE PURGATORIO OF DANTE. Translated by H. F. CARY.

THE PARADISO OF DANTE. Trans. lated by H. F. CARY.

Darley (George). SELECTIONS FROM THE POEMS OF GEORGE DARLEY.

Dickens(Charles). CHRISTMAS BOOKS. Two Volumes.

Ferrier (Susan). MARRIAGE. Two Volumes.

THE INHERITANCE. Two Volumes.

Gaskell (Mrs.). CRANFORD. Second Edition.

Haw thorne (Nathaniel). THE SCARI.ET LETTER.

Henderson (T. F.). A LITTLE BOOK OF SCOTTISH VERSE.

Kinglake (A. W.). EOTHEN. Second Edition.

Locker (F.). LONDON LYRICS.
Maryell (Andrew). THE POEMS OF ANDREW MARVELL.

Milton (John). THE MINOR POEMS OF JOHN MILTON.

Molr (D. M.). MANSIE WAUCH.

Nichols (Boxyer). A LITTLE BOOK OF ENGLISH SONNETS.

Smith (Horace and James). REJECTED ADDRESSES.

Sterne (Laurence). A SENTIMENTAL JOURNEY.

Tennyson (Alfred, Lord). THE EARLY POEMS OF ALFRED, LORD TENNY. SON.

IN MEMORIAM.

THE PRINCESS.

MAUD.

Thackeray (W. M.). VANITY FAIR. Three Volumes.

PENDENNIS. Three Volumes.

CHRISTMAS BOOKS.

Yaughan (Henry). THE POEMS OF HENRY VAUGHAN.

Waterhouse (Elizabeth), A LITTLE BOOK OF LIFE AND DEATH. Fourteenth Edition.

Wordsworth (W.). SELECTIONS FROM THE POEMS OF WILLIAM WORDS. WORTH.

Wordsworth (W.) and Coleridge (S. T.). LYRICAL BALLADS. Third Edition.

\section{The Little Quarto Shakespeare}

Edited by W. J. CRAIG. With Introductions and Notes Pott I6mo. 40 Volumes. Leather, price Is. net each volume Mahogany Revolving Book Case. ros. net

\section{Miniature Library}

Demy 32mo. Leather, Is. net each volume

Euphranor: A Dialogue on Youth. Edward FitzGerald.

The Life of Edward, Lord Herbert of Cherbury. Written by himself,
Polonius; or, Wise Saws and Modern Instances. Edward FitzGerald.

The Rubátyát of OMar KhaYvám. Edward FitzGerald. Fifth Edition. 


\section{The New Library of Medicine}

\section{Edited by C. W. SALEEBY. Demy $8 v 0$}
Care of the Body, The. F. Cavanagh. Second Edition. 7 s. 6 d. net.
Hygiene of Mind, The. T. S. Clouston. Sixth Edition. 7s. 6d. net.
Children of the Nation, The. The Right Hon. Sir Jobn Gorst. Second Edition. 7s. 6d. net.
Diseases of Occupation. Sir Thos. Oliver. ros. 6d, net. Second Edition.
Drugs and the Drug Habit. H. Sains- bury.
Infant MoRtality. Sir George Newman. 7s. 6d. net.
Prevention of Tuberculosis (Consump- TION), The. Arthur Newsholme. ros. $6 d$. net. Second Edition.
Functional Nerve Diseases. A. T. Sclo- field. 7s. 6d. net.
Air and Health. Ronald C. Macfie. 7s. $6 d$. net. Second Edition.

\section{The New Library of Music}

Edited by ERNEST NEWMAN. Illustrated. Demy 8vo. 7s. 6d. net Brahms. J. A. Fuller-Maitland. Second HANDEL R. A. Streatfeild Second Edition. Edition. Hugo Wolf. Ernest Newman.

\section{Oxford Biographies}

1llustrated. Fcap. 8vo. Each volume, cloth, 2s. 6d. net; leather, 3s. 6d. net Dante Alighieri. Paget Toynbee. Third Erasmus. E. F. H. Capey. Edition.

Girolamo Savonarola. E. L.S. Horsburgh. Sixth Edition.

John Howard. E. C. S. Gibson.

Alfred Tennyson. A. C. Benson. Second Edition.

Robert Burns. T. F. Henderson.

Chatham. A. S. McDowall.

Canning. W. Alison Phillips.

Beaconsfield. Walter Sichel.

Johann Wolfgang Goethe. H. G. Atkins. Sir Walter Raleigh. 1. A. Taylor.

Françols de Fénelon. Viscount St. Cyres.

\section{Four Plays \\ Fcap. 8vo. 2s. net}

The Honeymoon. A Comedy in Three Acts. Arnold Bennett. Third Edition.

The Great Adventure. A Play of Fancy in Four Acts. Arnold Bennett. Fourth Edition.

Milestones. Arnold Bennett and Edward Knoblauch. Seventh Edition.
Kismer. Edward Knoblauch. Third Edi. tion.

Trphoon. A Play in Four Acts. Melchior Lengyel. English Version by Laurence Irving. Second Edition.

\section{The States of Italy}

\section{Edited by E. ARMSTRONG and R. LANGTON DOUGLAS}

\section{Illustrated. Demy 8vo}
A History of Milan under the Sforza. Cecilia M. Ady. ros. $6 d$. net.
A History of PERUgia.
A History OF VERONA. I2s. 6d. net.
A. M. Allen W. Heywood.
12s. 6 d. net. 


\title{
The Westminster Commentaries
}

\author{
General Editor, WALTER LOCK \\ Demy 8vo
}

The Acts of the Apostles. Edited by R. B. Rackham. Sixth Edition. ros. 6 d.

The First Epistle of Paul the Apostle to THE Corinthians. Edited by $\mathrm{H}$. L. Goudge. Third Edition. 6s.

THE BoOK of Exodus. Edited by A. H. M'Neile. With a Map and 3 Plans, ros. $6 d$.

The Book of Ezekiel. Edited by H. A. Redpath. ros. $6 d$.

THE BOOK OF GENESIS. Edited, with Introduction and Notes, by S. R. Driver. Ninth Edition. ros. 6 \%.
ADDITIONS AND CORRECTIONS IN THE SEvENTH AND Eighth EDItions of THE Book of Genesis. S. R. Driver. Is.

The Book OF the Prophet Isaiah. Edited by G. W. Wade. ros. $6 d$.

The Boок OF Job. Edited by E. C. S. Gibson. Second Edition. $6 s$.

The Epistle of St. James. Edited, with Introduction and Notes, by R. J. Knowling. Second Edition. 6 s.

\section{The 'Young' Series}

\section{Illustrated. Crown $8 v 0$}

The Young Botanist. W. P. Westell and C. S. Cooper. 3 s. $6 d$. net.

The Young Carpenter. Cyril Hall. $5 s$.

The Young Electrician. Hammond Hall. 5 s.
The Young Engineer. Hammond Hall. Third Edition. 5 s.

Tue Young Naturalist. W. P. Westell. Second Edition. 6s.

The Young ORnithologist. W. P. Westell. 5 s.

\section{Methuen's Shilling Library}

\section{Fiap. 8vo. Is. net}

Blue Bird, The. Maurice Maeterlinck.

Charles Dickens. G. K. Chesterton.

Charmides, and other Poems. Oscat Wilde.

ChitrAl: The Story of a Minor Siege. Sir G. S. Robertson.

Condition of England, The. G. F. G. Masterman.

De Profundis. Oscar Wilde.

From Midshipman to Field-Marshal. Sir Evelyn Wood, F.M., V.C.

Harvest Home. E. V. Lucas.

Hills and the Sea. Hilaire Belloc.

Huxley, Thomas Henry. P. ChalmersMitchell.

Ideal Husband, An. Oscar Wilde.

INTENTIONS. Oscar Wilde.

Jimmy Glover, his Book. James M. Glover.

John Boyes, King of the Wa-KikUYu. John Boyes.

LAdY Windermere's Fan. Oscar Wilde.

Letters From a Self-made Merchant TO HIS Son. George Horace Lorimer.
LifE of John RUskin, ThE. W. G. Colling. wood.

Life of Robert Louis Stevenson, The. Graham Balfour.

Life of Tennyson, The. A. C. Benson.

Little of Everything, A. E. V. Lucas.

LoRd Arthur Savile's Crime. Oscar Wilde.

LORE OF THE HONEY-BEE, THE. Tickner Edwardes.

MAN AND The Universe. Sir Oliver Lodge. Mary Magdalene. Maurice Maeterlinck.

Old Country Life. S. Baring-Gould.

Oscar WILde: A Critical Study. Arthur Ransome.

Parish Clerk, The. P. H. Ditchfield.

Selected Poems. Oscar Wilde.

SEVAstopol, AND OTHER Stories. Leo Tolstoy.

Two Admirals. Admiral John Moresby.

Under Five Reigns. Lady Dorothy Nevill.

Vallima LetTers. Robert Louis Stevenson.

Vicar of Morwenstow, The. S. BaringGould. 


\section{Books for Travellers}

\section{Crown 8vo. 6s. each}

Each volume contains a number of Illustrations in Colour

Avon and Shakespeare's Country, Thz. A. G. Bradley.

BLACK FOREST, A BOOK OF THE. C. E. Hughes.

Bretons at Home, The. F. M. Gostling.

Citizs of Lombardy, The. Edward Hutton.

Cities of Romagna and the Marches, THE. Edward Hutton.

Cities of Spain, The. Edward Hutton. Cities of Umbria, The. Edward Hutton. Days in Cornwall. C. Lewis Hind.

FLORENCE AND NORTHERN TUSCANY, with GENOA. Edward Hutton.

LaNd of Pardons, The (Brittany). Anatole Le Braz.

Naples. Arthur H. Norway.

NAPLES RIVIERA, THE. H. M. Vaughan.

NEW FOREST, THE. Horace G. Hutchinson.
Norfolk Bronds, The. W. A. Dutt.

NORWAY AND ITS FJords. M. A. Wyllie.

RHINE, A BOOK OF THE. S. Baring-Gould.

RoMe. Edward Hutton.

ROUND ABOUT WILTSHIRE. A. G. Bradley.

SCOTLAND OF TO-DAY. T. F. Henderson and Francis Watt.

StENa AND SOUThern Tuscany. Edward Hutton.

Skirts of the Great City, The. Mrs. A. G. Bell.

Through East angua in a Motor Caro J. E. Vincent.

Venice and Venetia. Edward Hutton. Wanderer in Florence, A. E. V. Lucas. WANDgrer in Paris, A. E. V. Lucas. WANDERER IN HolLAND, A. E. V. Lucas. WANDERER IN LONDON, A. E. V. Lucas.

\section{Some Books on Art}

Armourer and his CRaft, The. Charles foulkes. Illustrated. Royal 4to. $£_{2} 2 s$. net.

ART AND Life. T. Sturge Moore. Illustrated. Cr. 8vo. 5s. net.

British School, The. An Anecdotal Guide to the British Painters and Paintings in the National Gallery. E. V. Lucas. Illus. trated. Ficap. 800. 25. 6d. net.

Decorative IroN Work. From the xith to the Xvilith Century. Charles foulkes. Royal 4 to. $\zeta_{2} 25$. net.

Francesco Guardi, 1712-i793. G. A. Simonson. Illustrated. Imperial 4 to. t2 2s. ret.

Illustrations of THE BOOK of JOB. William Blake. Qwarto. EI Is, net.

Johy Locas, Portrait Painter, 1828-1874. Arthur Lucas. Illustrated. Imperial 4 to. $£_{3} 35$ net.

Old PAste. A. Beresford Ryley. Illustrated. Royal 4to. ¿2 2s. net.

One Hundred Masterpieces of Painting. With an Introduction by R. C. Witt. Illus: trated. Second Edition. Demy 8vo. ror. $6 d$. net.
One Hundred Masterpieces of Sculpture, With an Introduction by G. F. Hill. Illus. trated. Demy 800. ros. 6 d. net.

Rommey Folio, A. With an Essay by A. B. Chamberlain. Imperial Folio. EI5 155. net.

Royal Academy Lectures on Painting. George Clausen. lllustrated. Crouen 820. 55. net.

SAINTS in ART, THE. Margaret E. Tabor. Illustrated. Third Edition. Ficap. 820 . 3s. 6d. net.

Schools of Painting. Mary Innes Illustrated. Cr. 820 . 55. net.

Celtic Art in Pagan and Christian Times. J. R. Allen. Illustrated. Second Edition. Demy 8v0. 7s. 6d. net.

'Classics of ARt.' See page 14.

'The Connolsseur's Library.' See page 15.

'Little Books on Art.' See page 18.

'The Little Galleries.' See page 18. 


\section{Some Books on Italy}

Etruria and Modern Tuscany, Old. Mary L. Cameron. Illustrated. Second Edition. Cr. 8vo. 6s. net.

FloRence: Her History and Art to the Fall of the Republic. F. A. Hyett. Demy $8 v 0$. 7s. 6d. net.

Florence, A Wanderer in. E. V. Lucas. Illustrated. Sixth Edition. Cr. 8vo. 6 s.

Florence and her Treasures. H. M. Vaughan. Illustrated. Fcap. 8vo. 5s. net.

Florence, Country Walks about. Edward Hutton. Illustrated. Second Edition. Fcap. 800. 5s. net.

Florence and the Cities of Northern Tuscany, with Genoa. Edward Hutton. Illustrated. Third Edition. Cr. 8vo. $6 s$.

Lombardy, The Cities or. Edward Hutton. Illustrated. Cr. 8vo. $6 s$.

Milan under the Sforza, A History of. Cecilia M. Ady. Illustrated. Demy $8 v 0$. Ios. $6 d$. net.

Naples: Past and Present. A. H. Norway. Illustrated. Third Edition. Cr. 8vo. 6s.

Naples Riviera, The. H. M. Vaughan. Illustrated. Second Edition. Cr. 8voo. 6 s.

Perugia, A Histony of. William Heywood. Illustrated. Demiy 8vo. ras. 6d. net.

Rone. Edward Hutton. Illustrated. Third Edition. Cr. 8vo. 6 s.

Romagna and the Marches, The Cities of. Edward Hutton. Cr. 8vo. $6 s$.

Roman Pilgrimage, A. R. E. Roberts. lllustrated. Demy 8vo. 10s. 6 d. net.

Rome of the Pilgrims and Martyrs. Ethel Ross Barker. Demy 8vo. 12s. $6 d$. net.

Rome. C. G. Ellaby. Illustrated. Small Pott 8vo. Cloth, 2s. 6d. net; leather, 3s. 6d. net.

Sicıly. F. H. Jackson. Illustrated. Small Pott 8vo. Cloth, 2s. 6d. net; leather, 35.6 d. net.

Sicily: The New Winter Resort. Douglas Sladen. Illustrated. Second Edition. Cr. 8vo. 5s. net.

Siena AND Southern Tuscany. Edward Hutton. Illustrated. Second Edition. Cr. 8vo. 6s.
Umbria, The Cities of. Edward Hutton. Illustrated. Fifth Edition. Cr.8vo. $6 s$.

Venice and Venetia. Edward Hutton. Illustrated. $\mathrm{Cr} .800$. $6 \mathrm{~s}$.

Venice on Foot. H. A. Douglas. Illustrated. Second Edition. Fiap.8vo. 5s, net.

VENICE AND her TrEasures. H. $A$. Douglas. Illustrated. Fcap. 8vo. 5s. nct.

Verona, A History of. A. M. Allen. Illustrated. Demy $8 v 0$. 12s. $6 d$. net.

Dante and his Italy. Lonsdale Ragg. Illustrated. Demy 8vo. 12s. $6 d$. net.

DANTe Alighieri : His Life and Works. Paget Toynbee. Illustrated. $C r .8 v 0 .{ }_{5}$. net.

Home Life in ITALy. Lina Duff Gordon. Illustrated. Third Edition. Demy 8vo. Ios. 6 d. net.

LAKES OF NORTHERN ITALY, THE. Richard Bagot. Illustrated. Second Edition. Fcap. 8vo. 5s. net.

Lorenzo the Magnificent. E. L. S. Horsburgh. Illustrated. Second Edition. Demy 820. 15s. net.

Medici Popes, The. H. M. Vaughan. Illustrated. Demy 8vo. 15s. net.

St. Catherine of Siena and her Times. By the Author of 'Mdlle. Mori.' Illustrated. Second Edition. Demy 8vo. 7s.6d. net.

S. Francis of Assisi, The Lives of. Brother Thomas of Celano. Cr. 8vo. ${ }^{s}$. net.

Savonarola, Girolamo. E. L. S. Horsburgh. Illustrated. $\mathrm{Cr}$.8zo. 5s. net.

Shelley and his Friends in Italy. Helen R. Angeli. Illustrated. Demy $8 v 0$. rcs. $6 d$. net.

Skies Italian : A Little Breviary for Travellers in Italy. Ruth S. Phelps. Fcap. 8vo. 5s. net.

United Italy. F. M. Underwood. Demy 8vo. xos. $6 d$. net.

Woman in Italy. W. Boulting. Illustrated. Demy 820 . 1os. 6d. net. 


\section{PART III. - A SELECTION OF WORKS OF Fiction}

Albaresl (E. Naria). SUSANNAH AND ONE OTHER. Fourth Edition. Cr. 800 . $6 s$.

THE BROWN EYES OF MARY. Third Edition. Cr. 8vo. Gs.

I KNOW A MAIDEN. Third Edition. Cr. 8oo. 6s.

THE INVINCIBLE AMELIA; OR, THE Polite AUVenturess. Third Edition. Cr. 800. 3s. 6d.

THE GLAD HEART. Fifth Edition. Cr. 800. 6s.

OLIVIA MARY. Fourth Edition. Cr. 800. 6s.

THE BELOVED ENEMY. Second Edition. Cr. 8vo. Gs.

Bagot (Richard). A ROMAN MYSTERY. Third Edition Cr. 800. 6s.

THE PASSPORT. Fourth Edition. Cr. 800. 6s.

ANTHONY CUTHBERT. Fourth Edition. Cr. 800. 6s.

LOVE'S PROXY. Cr. 800. 6s.

DONNA DIANA. Second Edition. $C r$. 800. 65.

THE HOUSE OF SERRAVALLE. Third Edition. Cr. 8ro. 6s.

DARNELEY PLACE. Second Edition. Cr. 800. Gr.

Balley (H. C.). STORM AND TREASURE. Thind Edition. Cr. 8vo. 6s.

THE LONELY QUEEN. Third Edition. Cr. 800 . 6s.

THE SEA CAPTAIN. Third Edition. Cr. 800 . 6s.

Baring-Gould (S.). IN THE ROAR OF THE SEA. Eighth Edition. Cr. 8vo. 6s. MARGERY OF QUETHER. Second Edition. Cr. 800 . 6s.

THE QUEEN OF LOVE. Fifth Edition. Cr. 800. 6s.

JACQUETTA. Third Edition. Cr. 800. 6s. KITTY ALONE. Fifth Edition. Cr. 800. 6 s. NOÉMI. Illustrated. Fourth Edition. Cr. 8vo. $6 s$.

THE BROOM-SQUIRE. Illustrated. Fifth Edition. Cr. 800. 6s.
PLADYS OF THE STEWPONEY. Illustrated. Second Edition. Cr. 800 . 6s. PABO THE PRIEST. Cr. 800. $6 s$.

WINEFRED. Illustrated. Second Edition. Cr. 8vo. 6s.

IN DEWISLAND. Second Edition. $\mathrm{Cr}$ : 8vo. 6s.

MRS. CURGENVEN OF CURGENVEN. Fifth Edition. Cr. 8 vo. $6 s$.

Bart (Robsrt). IN THE MIDST OF ALARMS. Third Edition. Cr. 8v0. 6s.

THE COUNTESS TEKLA. Fifth Edition. Cr. 8vo. 6s.

THE MUTABLE MANY. Third Edition. Cr. 800 . 6s.

Begble (Harold)。THE CURIOUS AND DIVERTING ADVENTURES OF SIR JOHN SPARROW, BART.; OR, THE PROGRESS OF AN OPEN MIND. Second Edition. Cr. 800. 6r.

Belloc (8.). EMMANUEL BURDEN, MERCHANT. Illustrated. Second Edition. Cr. 800. 6s.

A CHANGE IN THE CAliNET. Third Edition. Cr. 8vo. 6s.

Bennett (Xrmold), CLAYHANGER. Elecenth Edition. Cr. 8vo. 6s.

THE CARD. Sixth Edition, Cr. 800. 6s. HILDA LESSWAYS. Eighth Edition. Cr. 8vo. 6s.

BURIED ALIVE. Third Edition $\mathrm{Cr}$ 820. 6s.

A MAN FROM THE NORTH. Third Edition. Cr. 800 . 6 s.

THE MATADOR OF THE FIVE TOWNS. Second Edition. Cr. 8vo. Gs.

THE REGENT: A Five TOWNS STORY OF ADVENTURE IN LoNDON. Third Edition. Cr. 800 . 6s.

ANNA OF THE FIVE TOWNS. Fipap. 800. is. net.

TERESA OF WATLING STREET. Fcap. 8vo. Is. net.

Benson (E. F.). DODO : A DETAIL OF THE DAy. Sixteenth Edition. Cr. 300 . 6s. 
Birmingham (Georgo A.). S P A N I S H GOLD. Seventeenth Edition. Cr 8vo. 6s. Also Fcap. 8vo. is. net.

THE SEARCH PARTY. Tenth Edition. Cr. 8vo. 6s.

Also Fcap. 8no. Is. net.

LALAGE'S LOVERS. Third Edition. Cr. 8vo. 6s.

THE ADVENTURES OF DR. WHITTY. Fourth Edition. Cr. 8vo. 6s.

Bowen (Marjorie). I WILL MAINTAIN Ninth Edition. Cr. 8vo. 6 s.

DEFENDER OF THE FAITH. Seoenth Edition. Cr. 8vo. 6 s.

A KNIGHT OF SPAIN. Third Edition. Cr. 8vo. 6s.

THE QUEST OF GLORY. Third Edition. Cr. 8vo. 6s.

GOD AND THE KING. Fifth Edition. Cr. 8vo. 6s.

THE GOVERNOR OF ENGLAND. Third Edition. Cr. 8vo. 6 s.

Castle (Agnes and Egerton). THE GOLDEN BARRIER. Second Edition. Cr. 8vo. 6s.

Chesterton (G. K.). THE FLYING INN. Third Edition. Cr. 8vo. 6s.

Clifford (Mrs. W. K.). THE GETTING WELL OF DOROTHY. Illustrated. Third Edition. Cr. 8vo. 3s.6d.

Conrad (Joseph). THE SECRET AGENT: A Simple TALE. Fourth Edition Cr. 800 . 6s.

A SET OF SIX. Fourth Edition. Cr. 8vo. 6s.

UNDER WESTERN EYES. Second $\mathcal{B} d i$. tion. Cr. 8 ro. $6 s$.

CHANCE. Fifth Edition. Cr.8vo. 6s.

Conyers (Dorothea), SALLY. Fourth Edition. Cr. 8vo. 6s.

SANDY MARRIED. Fifth Edition. $C r$. 8vo. 6s.

Corelli (Marle). A ROMANCE OF TWO WORLDS. Thirty-Second Edition. Cr. 8vo. $6 s$.

VENDETTA; OR, THE STORY OF ONE FORGOTTEN. Thirty-first Edition. Cr. 8vo. $6 s$.

THELMA: A Norwegian Princess, Forty-fourth Edition. Cr. 8vo. 6s.

ARDATH: THE STORY OF a DEAD SElF. Twenty-first Edition. Cr. $8 v o$. $6 s$.

THE SOUL OF LILITH. Eighteenth Edition. Cr. 8vo. 6s.

WORMWOOD: A DRAMA OF PARIS. Nineteenth Edition. Cr. 8vo. 6s.

BARABBAS: A DREAM OF THE WORLD'S TRAGRDY. Forty-seventh Edition. Cr. 8 oo. $6 s$.

THE SORROWS OF SATAN. Fifty. cighth Edition. Cr. 8vo. $6 s$.

THE MASTER-CHRISTIAN. Fourteenth Edition. 179th Thousand. Cr. 8vo. 6s.

TEMPORAL POWER: A STUDY IN SUPREMACY. Second Edition. 150th Thousand. Cr. 800. 6s.
GOD'S GOOD MAN: A Simple LOvB STORy. Sixteenth Edition. 154th Thousand. Cr. 8vo. 6s.

HOLY ORDERS: THE TRAGEDY OF A QUIET LiFE. Second Edition. 120th Thousand. Cr. 8vo. 6s.

THE MIGHTY ATOM. Twenty-ninth Edition. Cr. 8vo. 6s.

Also Fcap. 8vo. is. net.

BOY : A SkETCH. Thirteenth Edition. Cr. 8vo. $6 s$.

Also Fcap. 8vo. 1s. net.

CAMEOS. Fourteenth Edition. Cr. $8 v 0$. 6s.

THE LIFE EVERLASTING. Sixth Edition. Cr. 8vo. 6s.

JANE : A SOcial Incident. Fcap. $8 v 0$. Is. net.

Crockett (S. R.). LOCHINVAR. Illustrated. Fourth Edition. Cr. 8vo. 6s.

THE STANDARD BEARER. Second Edition. Cr. 8vo. 6s.

Croker (B. M.). THE OLD CANTON. MENT. Second Edition. Cr. 8vo. 6s.

JOHANNA. Second Edition. Cr.8vo. 6s. THE HAPPY VALLEY. Fourth Edition. Cr. 800. 6s.

A NINE DAYS' WONDER. Fifth Edition. Cr. 8vo. 6s.

ANGEL. Fifth Edition. Cr. 8vo. $6 s$.

KATHERINE THE ARROGANT. Sevcnth Edition. Cr. 8vo. 6 s.

BABES IN THE WOOD. Fourth Edition. Cr. 8vo. 6s.

Danby(Frank). JOSEPH IN JEOPARDY. Fcap. 8vo. Is. net.

Doyle (Sir A. Conan). ROUND THE RED LAMP. Twelfth Edition. Cr. 800. 6s. Also Fcap. 8vo. is. net.

Drake (Maurice). $\mathrm{WO}_{2}$. Sixth Edition. Cr. 800. 6s.

Findlater (J. H.). THE GREEN GRAVES OF BALGOWRIE. Fifth Edition. Cr. 8vo. 6s.

THE LADDER TO THE STARS. Second Edition. $C r$. 8vo. $6 s$.

Findlater (Mary). A NARROW WAY. Fourth Edition. Cr. 8vo. 6s.

THE ROSE OF JOY. Third Edition. Cr. 8zo. 6s.

A BLIND BIRD'S NEST. Illustrated. Second Edition. Cr. 8vo. $6 s$.

Fry (B. and C. B.). A MOTHER'S SON. Fifth Edition. Cr. 8vo. $6 \mathrm{~s}$.

Harraden (Beatrice). IN VARYING MOODS. Fourteenth Edition. Cr. 8vo. 6s. HILDA STRAFFORD and THE REMIT. TANCE MAN. Trmelfth Edition. Cr. $8 v 0$. $6 s$.

INTERPLAY. Fifth Edition. Cr.8vo. 6s. 
Hauptmann (Gerhart). TIIE FOOL IN CHRIST: EMmanUel, QUINT. Translated by Thomas Seltzer. Cr. 800 . $6 s$.

Hlchens (Robert). THE PROPHET OF BERKEIEY SQUARE. Second Edition. Cr. 800. 6s.

TONGUES OF CONSCIENCE. Third Edition. Cr. 8ro. 6s.

FELIX: THRER YEARS IN A LTrE Tenth Edition. Cr. 8200. 6s.

THE WOMAN WITH THE PAN. Eighth Edition. Cr. 800 . Gs.

Also Feap 800. is. net.

BYEWAYS. Cr. 800. 6s.

THE GARDEN OF ALLAH. Twenty. third Edition. Cr. 8vo. 6s.

THE BLACK SPANIEL Cr. 800. 6s.

THE CALL OF THE BLOOD. Winth Edition. Cr. 800. Gs.

BARBARY SHEEP. Second Edition $C r$. 800. 35. 6d.

Also Frcap. 8co. rs. net.

THE DWELLER ON THE THRESHOLD. Second Bdition. Cr. 800 . 6 s.

THE WAY OF AMBITION. Fifth Edition. Cr. 800. 6s.

Hope (Inthony). A CHANGE OF AIR. Sixth Edition Cr. 800. 6s.

A MAN OF MARK. Seacnth Edition. $C r$. 800 . 6s.

THE CHRONICLES OF COUNT AN. TONIO. Sixth Edition. Cr. 8vo. 6s.

PHROSO. Illustrated. Ninth Edition. Cr. 8vo. $6 s$.

SIMON DALE. Illustrated. Ninth Edition. Cr. 800. 6 s.

THE KING'S MIRROR. Fifth Edition. Cr. 800. 6s.

QUISANTE. Fourth Edition. Cr. 800. 6s. THE DOLLY DIALOGUES. Cr. 800. 6 s. TALES OF TWO PEOPLE. Third Edition. Cr. 800. 6s.

A SERVANT OF THE PUBLIC Illus. trated. Sixth Edition Cr. 8vo. 6s.

THE GREAT MISS DRIVER. Fourth Edition. Cr. 8 ov. 6s.

MRS. MAXON PROTESTS. Third Edition. Cr. 800. Gs.

Hutten (Baroness zon), THE HALO. Fifth Edition Cr. 800 . 6s.

A lso Fcap. 800 . 1s. net.

'The Inner 8hrine' (Author of)。 THE WILD OLIVE Third Edition. Cr. 800. 6s.

THE STREET CALLED STRAIGHT. Fifth Edition. Cr. 800. 6s.

THE WAY HOME. Second Edition. Cr. 800. 6s.
Jacobs (W. W.). MANY CARGOES Thirty-third Edition. Cr. 8vo. 3s. $6 d$. Also lllustrated in colour. Demy 800 . 75. 6 d. net.

SEA URCHINS. Swenteenth Edition. $\mathrm{Cr}$. 800. 35. 6 .

A MASTER OF CRAFT. Illustrated. Tenth Edition. Cr. 8vo. 3s. 6d.

LIGHT FREIGHTS. Illustrated. Eleoenth Edition. Cr. 800 . 3s. $6 d$. Also Fcap. 800 . 1s. net.

THE SKIPPER'S WOOING. Eleoenth Edition Cr. 800 . 35. 6d.

AT SUNWICH PORT. Illustrated. Eleventh Edition. Cr. 800. 35. 6 d,

DIALSTONE LANE. Illustrated. Eighth Edition. Cr. $800.35 .6 d$.

ODD CRAFT. Illustrated. Fifth Edition. Cr. 820. 3s. $6 d$.

THE LADY OF THE BARGE. Illustrated. Ninth Edition. Cr. 8vo. 35. 6 d.

SALTHAVEN. Illustrated. Third Edition. Cr. 800 . 3s. $6 d$.

SAILORS' KNOTS. Illustrated. Fifth Edition Cr. 8v0. 3s. 6 d.

SHORT CRUISES. Third Edition $C r$. 800. $35.6 d$.

James (Henry) THE GOLDEN BOWL. Thind Edition. Cr. 8vo. 6s.

Le Queax (William), THE HUNCHBACK OF WESTMINSTER. Third Edition. Cr. 800. 6s.

THE CLOSED BOOK. Third Edition Cr. 800. 6s.

THE VALLEY OF THE SHADOW. Illustrated. Third Edition Cr. 820 . 6 s.

BEHIND THE THRONE. Third Edition Cr. 800 . 6s.

London (Jack), WHITE FANG. Ninth Edition. Cr. 800. $6 s$.

Lowndes (Mrs. Belloc), THE CHINK IN THE ARMOUR. Fourth Edition. Cr. 800. 6s. net.

MARY PECHELL. Second Edition Cr. 800 . 6 s.

STUDIES IN LOVE AND IN TERROR. Second Edition. Cr. 8vo. 6s.

THE LODGER. Fourth Edition. Crown 800. Gs.

Lucas (E. Y.) LISTENER'S LURE: AN Oblique Narration. Tenth Edition. Fcap. 800 . ss.

OVER BEMERTON'S: AN EASY-GOING Chronicue. Eleventh Edition. Ficap. 800. 5 s.

MR. INGLESIDE Tenth Edition Fcap. 800. 5 .

LONDON LAVENDER. Eighth Edition. F cap. 800 . 59. 
Lyall (Edna). DERRICK VAUGHAN, NOVELIST. 44th Thousand. Cr. 800 . $3 s .6$.

Macnaughtan (ฆ.). THE FORTUNE OF CHRISTINA M'NAB. Sixt/ Edition. Cr. 8vo. 2s. net.

PETER AND JANE. Fourth Edition. Cr. 8vo. 6s.

Maist (Lucas), A COUNSEL OF PER. FECTION. Second Edition. Cr. 8vo. 6s. COLONEL ENDERBY'S WIFE. Sixth Edition. Cr. 8vo. $6 s$.

THE HISTORY OF SIR RICHARD CALMADY: A Romance. Seventh Edi. tion. Cr. 8vo. 6s.

THE WAGES OF SIN. Sixteenth Edition. Cr. 8vo. 6s.

THE CARISSIMA. Fifth Edition. Cr. 820. $6 s$.

THE GATELESS BARRIER. Fifth Edition. Cr. 8vo. 6s.

Mason (A. E. W.). CLEMENTINA. Illustrated. Eighth Edition. Cr. 8vo. 6s.

Maxwell (W. B.). THE RAGGED MESSENGER. Third Edition. Cr. 8vo. 6s.

VIVIEN. Truelfth Edition. Cr. 8vo. $6 s$.

THE GUARDED FLAME. Secenth Edition. Cr. 8vo. 6s.

Also Fcap. 8vo. is. net."

ODD LENGTHS. Second Edition. Cr. 800 . $6 s$.

HILL RISE. Fourth Edition. Cr. 8vo. 6s. Also Ficap. 8vo. is. net.

THE COUNTESS OF MAYBURY: BETWEEN YOU AND I. Fourth Edition. Cr. 800 . $6 s$.

THE REST CURE. Fourth Edition. Cr. 8vo. 6s.

Milne (A. A.). THE DAY'S PLAY. Fifth Edition. Cr. 8vo. 6s.

THE HOIIDAY ROUND. Second Edition. Cr. 8vo. 6s.

Montague (C. E.). A HIND LET LOOSE. Third Eatition. Cr. 8vo. $6 s$.

THE MORNING'S WAR. Second Edition. Cr. 8vo. 6s.

Morrison (Arthur). TALES OF MEAN STREETS. Seventh Edition. Cr.8vo. $6 s$. Also Fcap. 8vo. Is. net.

A CHILD OF THE JAGO. Sixth Edition. Cr. 8vo. 6s.

THE HOLE IN THE WALL. Fourth Edition. Cr. 8vo. 6s.

DIVERS VANITIES. Cr. 8vo. 6 s.

ollivant (Mlfred). OWD BOB, THE GREY DOG OF KENMUIR. 'With a Frontispiece. Truelfth Edition. Cr. 800. 6 s.
THE TAMING OF JOHN BLUNT Second Edition. Cr. 8vo. $6 s$.

THE ROYAL ROAD Second Edition. Cr. 8 vo. 6s.

Onions (OliYer). GOOD BOY SELDOM: A Romance or AdVertisement. Second Edition. Cr. 800 . 6 s.

THE TWO KISSES. Third Edition. Cr. 800. 6s.

Oppenheim (E. Phillips). MASTER OF MEN. Fifth Edition. Cr. 8vo. 6 s.

THE MISSING DELORA. Illustrated. Fourth Edition. Cr. 8vo. 6s.

Also Fcap. 8vo. is. net.

Orezy (Baroness). FIRE IN STUBRLE. Fifth Edition. Cr. 8vo. 6 s.

Also Fcap. 8vo. is. net.

Orenham (John). A WEAVER OF WEBS. Illustrated. Fifth Edition. $\mathrm{Cr}$. 8vo. 6s.

THE GATE OF THE DESERT. Eighth Edition. Cr. 8vo. 6s.

*Also Fcap. \&vo. is. ret.

PROFIT AND LOSS. Sixth Edition. Cr. 8vo. 6s.

THE LONG ROAD. Fourth Edition. Cr. 2vo. 6s.

Also Fcap. 8vo. is. net.

THE SONG OF HYACINTH, AND OTHER STORIEs. Second Edition. Cr. 8zo. 6s.

MY LADY OF SHADOWS. Fourth Edition. Cr. 8vo. $6 s$.

LAURISTONS. Fourth Edition. Cr. 8vo. $6 s$.

THE COIL OF CARNE. Sixth Edition. Cr. 8vo. 6s.

THE QUEST OF THE GOLDEN ROSE. Fourth Edition. Cr. 8vo. 6s.

MARY ALL-ALONE. Thirl Edition. Cr. 8vo. 6s.

Farker (Gllbert). PIERRE AND HIS PEOPLE. Seventh Edition. Cr: 8vo. $6 s$. MRS. FALCHION. Fifih Edition. Cr: 8vo. 6s.

THE TRANSLATION OF A SAVAGE. Fourth Edition. Cr. 8vo. 6s.

THE TRAIL OF THE SWORD. Illustrated. Tenth Edition. Cr. 8vo. 6 s.

WHEN VALMOND CAME TO PONTIAC: The Story of a Lost NApoleon. Seventh Edition. Cr. 8vo. 6 s.

AN ADVENTURER OF THE NORTH: The LAST ADVENTURES OF 'PRETTY PierRe.' Fifth Edition. Cr. 8vo. 6s.

THE SEATS OF THE MIGHTY. Illustrated. Nineteenth Edition. Cr. 8vo, $6 s$.

THE BATTLE OF THE STRONG: $\Lambda$ RoMANCE of Two KingDoms. Illustrated. Seoenth Edition. Cr. 8vo. 6r. 
THE POMP OF THE LAVILETTES. Third Edition Cr. $800.35 .6 d$.

NORTHERN LIGHTS. Fourth Edition. Cr. 800. 6s.

THE JUDGMENT HOUSE.

Third Edition. Cr. 8vo. 6 s.

Pasturo (Mrs. Henry de Ia), THE TYRANT. Fourth Edition. Cr. 820. 6 s. Also Fcap. 8vo. Is. net.

Pemberton (Max), THE FOOTSTEPS OF A THRONE. Illustrated. Fourth Edition. Cr. 800. 6s.

I CROWN THEE KING. Illustrated. Cr. 800. 6s.

LOVE THE HARVESTER: A STORY OF THI SHIRnS. Illustrated. Third Edition. Cr. 8v0. 3s. $6 \%$.

THE MYSTERY OF THE GREEN HEART. Fifth Edition. Cr. 800 . 2s. net

Perrin (Allce), THE CHARM. Fifth Edition. Cr. 8vo. 6s.

Also Fcap. 800 . is. net.

THE ANGLO-INDIANS. Sixth Edition. Cr. 8vo. 6s.

Phillpotts (Bden). LYING PROPHETS. Third Edition. Cr. 800 . 6 s.

CHILDREN OF THE MIST. Sixth Edition. Cr. 8vo. 6s.

THE HUMAN BOY. With a Frontispiece. Seventh Edition. Cr.8vo. 6s.

SONS OF THE MORNING. Second Edition. Cr. 800. 6s.

THE RIVER. Fourth Edition. Cr. 8vo. 6s. THE AMERICAN PRISONER. Fourth Edition. Cr. 8vo. Gs.

KNOCK AT A VENTURE. Third Edition Cr. 800. 6s.

THE PORTREEVE. Fourth Edition. $C r$. 8vo. Gs.

THE POACHER'S WIFE. Second Edition. Cr. 8vo. 6s.

THE STRIKING HOURS. Second Edition. Cr. 800. 6s.

DEMETER'S DAUGHTER. Third Edition. Cr. 8ro. 6 s.

THE SECRET WOMAN. Fcap. 800. Is. net.

Pickthall (Marmadeke). SAÏD, THE FISHERMAN. Tenth Edition. Cr. $8 v 0$. 6s.

Also Fcap. 800 . is, net.

' $Q$ ' (A. T. Qulller-Couch). THE MAYOR OF TROY. Fourth Edition. Cr. 800. Gs. MERRY-GARDEN AND OTHER STORIES. Cr. 8vo. 6s.

MAJOR VIGOUREUX. Third Edition. Cr. 800 . 6s.
Ridge (W. Pett), ERB. Second Edition. Cr. 8vo. 6s.

A SON OF THE STATE. Third Edition. Cr. 8vo. 3s. 6d.

A BREAKER OF LAWS. A New Edition Cr. 8vo. 3s. 6d.

MRS. GALER'S BUSINESS. Illustrated. Second Edition. Cr. 800. 6 s.

THE WICKHAMSES. Fourt/ Edition. Cr. 8vo. 6s.

SPLENDID BROTHER. Fourth Edition. Cr. 8vo. 6s.

Also ficap. $8 v o$. Is. net.

NINE TO SIX-THIRTY. Third Edition. Cr. 8v0. 6s.

THANKS TO SANDERSON. Second Edition. Cr. 800.6 . 6 .

DEVOTED SPARKES. Second Edition. Cr. 8zo. 6s.

THE REMINGTON SENTENCE. Third Edition. Cr. 800 . 6s.

Russell (W. Clark), MASTER ROCKAFELLAR'S VOYAGE. Illustrated Fift/ Edition. Cr. 800 . 3s. 6 d.

Bidgwick (Hrs. Llfred). THE KINS MAN. Illustrated. Third Edition. Cr. 8vo. 6s.

THE LANTERN-BEARERS. Third Edition. Cr. 8vo. 6s.

THE SEVERINS. Sixth Edition. Cr. 800 6s.

Also Fcap. 8vo. is. net.

ANTHEA'S GUEST. Fourth Edition. Cr. 800. 6s.

LAMORNA. Third Edition. Cr. 800. 6s.

BELOW STAIRS. Second Edition. Cr. 800 . 65.

Snaith (J. C.). THE PRINCIPAL GIRL Second Edition. Cr. 8vo. 6s.

AN AFFAIR OF STATE. Second Edition Cr. 800. Cs.

Somerville (E. E.) and Ross (Martin). DAN RUSSEL THE FOX. Iliustratec. Secucnth Edition. Cr. 800. 6s. Also Fcrp. 8vo. 1s. net.

Thurston (E. Temple). MIRAGE. Fowrth Edition. Cr. 800 . 6s.

Also Ficap. 8ro. is. net.

Watson (H. B. Marriott), ALISE OF ASTRA Third Edition. Cr. 8vo. Es.

THE BIG FISH. Third Edition. Cr. 800. 6s.

Webling (Peggy). THE STORY OF VIRGINIA PERFECT. Third Edition. Cr. 8vo. 6s.

Also Fcrp. 8so. rs. net. 
THE SPIRIT OF MIRTH. Sixth Edition. Cr. 8vo. 6s.

FELIX CHRISTIE Third Edition Cr. 8vo. 6s.

THE PEARL STRINGER, Third Edi. tion. Cr. 8vo. 6s.

Westrup (Margaret) (Mrs. W. Sydney Stroey). TIDE MARKS. Third Edition. Cr. 8vo. 6s.

Weyman (Stanley). UNDER THE RED ROBE. Illustrated. Twenty-third Edi. tion. Cr. 8zo. 6 .

Also Fcap. 8vo. is. net.

Whitby (Beatrlce). ROSAMUND. Second Edition. Cr. 8vo. 6s.

Williamson (C. $\boldsymbol{N}$. and A. M.), THE LIGHTNING CONDUCTOR : The Strange Adventures of a Motor Car. Illustrated. Twenty-first Edition $C r .8 v 0$. $6 s$. Also Cr. 8vo. is. net.

THE PRINCESS PASSES: A ROMANCE OF A Motor. Illustrated. Ninth Edition. Cr. 8vo. 6s.

I.ADY BETTY ACROSS THE WATER. Eleventh Edition. Cr. 8vo. 6s.

Also Ficap. 8vo. is. net.
THE BOTOR CHAPERON. Illustrated. Tenth Edition. Cr. 8vo. 6s.

*Also Ficap. 8vo. is. net.

THE CAR OF DESTINY. IHustrated. Seventh Edition. Cr. 8vo. 6s.

MY FRIEND THE CHAUFFEUR. Illustrated. Thirtecnth Edition. Cr. 8vo. 6s.

SCARLET RUNNER. Illustrated. Third Edition. Cr. 8vo. 6s.

SET IN SILVER. Illustrated. Fifth Edition. Cr. 800. 6s.

LORD LOVELAND DISCOVERS AMERICA. Second Edition. Cr. 8vo. 6s. THE GOLDEN SILENCE. Sixth Edition. Cr. 8vo. 6s.

THE GUESTS OF HERCULES. Fourth Edition. Cr. 8vo. 6s.

THE HEATHER MOON. Fifth Edition. Cr. 8vo. 6s.

THE LOVE PIRATE. Illustrated. Second Edition. Cr. 8vo. 6s.

THE DEMON. Fcap. Bro. is. net.

Wyllarde (Dolf). THE PATHWAY OF THE PIONEER (Nous Autres). Sixth Edition. Cr. 8vo. 6s.

\section{Books for Boys and Girls}

\section{Illustrated. Crown 8vo. 3s. 6d.}

Getting Well of Dorothy, The. Mrs.
W. K. Clifford.

Girl of the People, A. L. T. Meade.

Honourable Miss, Thz. L. T. Meade.

Master Rockafellar's Voyage. W. Clark Russell.

ReD Grange, ThE. Mrs. Molesworth.

Syd Belton: The Boy who would not go to Sea. G. Manville Fenn.

There was once a Prince. Mrs. M. E. Mann.

\section{Methuen's Shilling Novels}

\section{Fcap. 8vo. Is, net}

Anwa of the Five Towns. Arnold Bennett. Barbary Shrep. Robert Hichens.

Botor Chaperon, The. C. N. \& A. M. Williamson.

Bov. Marie Corelli.

Charm, The. Alice Perrin.

Dan Russel the Fox. E. C. Somerville and Martin Ross.
Demon, The. C. N. and A. M. Williamson.

Fire in Stubble. Baroness Orczy.

Gate of Desert, The. John Oxenham.

Guarded Flame, The. W. B. Maxwell.

Halo, The. Baroness von Hutten.

Hill Rise. W. B. Maxwell.

JANR. Marie Corelli. 


\section{Fiction}

\section{Heלhuen's Shilling Novels-continued.}

Joserh. Frank Danby.

Lady Betty Across the Water. C. N. and A. M. Williamson.

Light FrEIGHTS. W. W. Jacobs.

LoNG RoAD, THE. John Oxenham.

Mighty Aтом, The. Marie Corelli.

Mirage. E. Temple Thurston.

Missing Delora, The. E. Phillips Oppenbeim.

Round the Red Lamp. Sir A. Conan Doyle. SaĨd, The Fisherman. Marmaduke Pickthall.
Search Party, Thr. G. A. Birmingham. Secret Womar, The. Eden Phillpotts. Severins, The. Mrs. Alfred Sidgwick. SPANish Gold. G. A. Birmingham Splendid Brother. W. Pett Ridge. Tales of Mean Streets. Arthur Morrison. Teresa of Watling Street. Arnold Bennett.

Tyrant, The. Mrs. Henry de la Pasture. UNDER the RED Robe. Stanley J. Weyman. Virginia Perfect. Peggy Webling.

Woman with the FAN, The. Robert Hichens.

\section{Methuen's Sexenpenny Novels}

\section{Fcap. 8vo. $7 d$. net}

ANGel. B. M. Croker.

Broom Squire, The. S. Baring-Gould By Stroke of Sword. Andrew Balfour. House of Whispers, The. William Le Queux.

Human Boy, The. Eden Phillpotts.

I Crown Then King. Max Pemberton.

LAte in Life. Alice Perrin.

Lone Pine. R. B. Townshend.

Master of Men. E. Phillips Oppenheim. Mixed Marriage, A. Mir. F. E. Penny.
Peter, a Parastre. E. Maria Albanesi.

Pomp of the Lavilettes, The. Sir Gilbert Parker.

Prince Rupert the Buccaneer. C. J. Cutcliffe Hyne.

Princess Virginia, The. C. N. \& A. M. Williamson.

Profit and Loss. John Oxenham.

Red House, The. E. Nesbit.

Sign of the Spider, The. Bertram Mitford.

Son of the State, A. W. Pett Ridge. 


$$
\text { r.7. }
$$

Whas aroner tro

$$
18^{0.60}
$$







\section{RETURN CIRCULATION DEPARTMENT}

TO

202 Main Librar,

LOAN PERIOD I

2

HOME USE

4

ALL BOOKS MAY BE RECALLED AFTER 7 DAYS

1-month loans may be renewed by calling 642-3405

6- month loans may be recharged by bringing books to Circulation Des

Renewals and recharges may be made 4 days prior to due date

\section{DUE AS STAMPED BELOW}

MAY 261977 AUTo OIS JUL 161987

June $2 / 261$
0126

Rec'd UCB ANTH

MAR 121990

REC CIR.AUG 10 '77

INTERLIBRARY LOAN

UNIV. OE CAFIF, BERK.

APR 301992

JUN 251937

AUTO DISG MAR 1290

FORM NO. DD 6,

UNIVERSITY OF CALIFORNIA, BERKELE BERKELEY, CA 94720 
YB 64175

U.C. BERKELEY LIBRARIES ||||||||||||||||||||||||||||||||||||||||||| B001023745

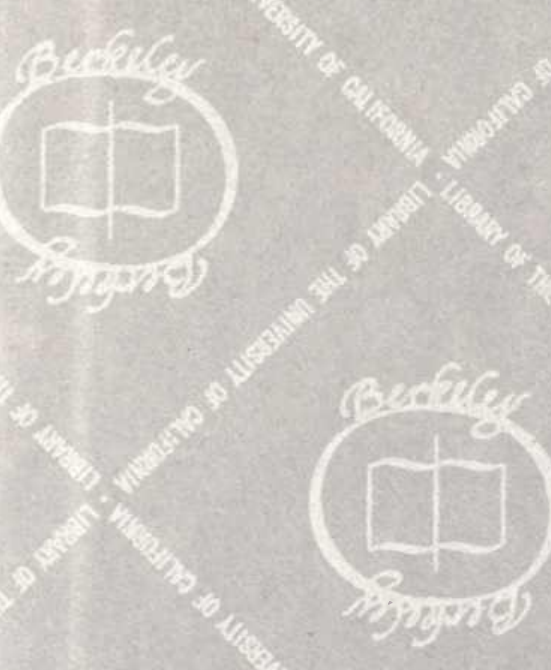


